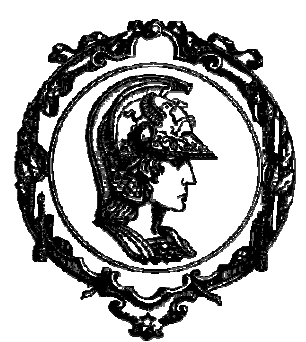

Escola Politécnica da UniVersidade de SÃo PaUlo

\title{
APLICAÇÕES DE MODELAGEM MOLECULAR EM ENGENHARIA QUÍMICA: INVESTIGAÇÃO DO MECANISMO DE DEGRADAÇÃO DO FENOL EM PROCESSOS OXIDATIVOS AVANÇADOS
}

\author{
BRUNO RAMOS
}

São Paulo 
BRUNO RAMOS

\section{APLICAÇÕES DE MODELAGEM MOLECULAR EM ENGENHARIA QUÍMICA: INVESTIGAÇÃO DO MECANISMO DE DEGRADAÇÃO DO FENOL EM PROCESSOS OXIDATIVOS AVANÇADOS}

Dissertação apresentada à Escola

Politécnica da Universidade de São Paulo

para obtenção do título de Mestre em Engenharia. 


\title{
APLICAÇÕES DE MODELAGEM MOLECULAR EM ENGENHARIA QUÍMICA: INVESTIGAÇÃO DO MECANISMO DE DEGRADAÇÃO DO FENOL EM PROCESSOS OXIDATIVOS AVANÇADOS
}

\author{
Dissertação apresentada à Escola \\ Politécnica da Universidade de São Paulo \\ para obtenção do título de Mestre em \\ Engenharia. \\ Área de concentração: Engenharia \\ Química \\ Orientador: Prof. Dr. Antonio Carlos \\ Silva Costa Teixeira
}


FICHA CATALOGRÁFICA

Ramos, Bruno

Aplicações de modelagem molecular em engenharia química:

investigação do mecanismo de degradação do fenol em processos oxidativos avançados / B. Ramos. -- São Paulo, 2009.

$171 \mathrm{p}$.

Dissertação (Mestrado) - Escola Politécnica da Universidade de São Paulo. Departamento de Engenharia Química.

1. Modelagem molecular (Aplicações) 2. Cinética (Simulação) 3. Oxidação (Processos) I.Universidade de São Paulo. Escola Politécnica. Departamento de Engenharia Química II.t. 
A meu orbital $\pi$. 


\section{Agradecimentos}

Agradeço a todos que tornaram este trabalho possível, particularmente ao Prof. Dr. Antonio Carlos S. C. Teixeira e ao Prof. Dr. João Pedro S. Farah pelas discussões, pelas dicas e pela paciência. Agradeço também ao Prof. Dr. Roberto Guardani pelos apontamentos feitos ao longo dos seminários e do Exame de Qualificação, que contribuiram para enriquecer este trabalho, e à Silvia Baeder, pelas ajudas fundamentais na configuração e instalação do terminal Linux.

Aos colegas de laboratório e do departamento, pelas conversas e discussões engenheirísticas e químicas;

Aos meus amigos e familiares que, muitas vezes sem saber, proveram a energia necessária para "manter o sistema funcionando" - em particular aos meus avós e meu irmão pela paciência e preocupação, e à Suélen por todos momentos de atenção, força, carinho, amor e sorrisos;

À CAPES e ao CNPq pelo suporte financeiro;

Ao Laboratório de Computação Cientifica Avançada pelas máquinas disponibilizadas para os cálculos. 
"The more progress physical sciences make, the more they tend to enter the domain of mathematics, which is a kind of centre to which they all converge. We may even judge the degree of perfection to which a science has arrived by the facility with which it may be submitted to calculation" (A. Quetelet) 


\section{RESUMO}

O trabalho tem por objetivo a aplicação de técnicas de modelagem molecular como ferramenta de pesquisa em Engenharia Química, em particular no estudo das reações químicas envolvidas na degradação do fenol em processos oxidativos avançados. Os resultados obtidos para reações em fase gasosa mostram que o uso dessa ferramenta, no nível de teoria selecionado (B3LYP/6-31++G(d,p)), é adequado para descrever a maioria das reações do mecanismo proposto. As constantes cinéticas calculadas (através da Teoria do Estado de Transição), quando comparadas com os dados experimentais disponíveis, encontram-se dentro da mesma ordem de grandeza para a rota mais viável. A simulação de um par de reações paralelas mostra o mesmo perfil de queda do fenol encontrado para as constantes cinéticas experimentais. A comparação com resultados teóricos prévios mostra que a adição de efeitos de polarização das nuvens eletrônicas ao conjunto de base resulta em um aperfeiçoamento nos valores das constantes cinéticas.

Os estudos do meio solvatado mostram que o modelo de solvatação implícita SM5.42R é adequado para descrever o sistema, por reproduzir bem o valor experimental da energia de solvatação do fenol. Entretanto, não é possível fazer comparações quanto aos radicais devido à ausência de dados experimentais. Dentre os modelos de solvatação explícita construídos, o modelo que conta com uma esfera de solvatação de 4 moléculas de água se mostrou melhor para o fenol. Já para o intermediário radicalar O1, o modelo mais adequado foi o que conta com 6 moléculas de água formando um ciclo sobre as hidroxilas ligadas ao anel.

Com os resultados obtidos e suas comparações com valores experimentais discute-se a aplicabilidade de técnicas de Modelagem Molecular em estudos aplicados em Engenharia Química, reforçando a visão desta ferramenta como um instrumento importante no projeto de novos produtos e na otimização de processos de interesse tecnológico. 


\begin{abstract}
This work has the main objetive of applying molecular modeling techniques as a research tool in Chemical Engineering - particularly on the study of the chemical reactions involved in the degradation of phenol by Advanced Oxidation Processes. The obtained results for gas phase reactions show that the use of this tool, in the selected level of theory (B3LYP/6$31++G(d, p))$ is adequate to describe most of the reactions within the proposed mechanism. The calculated kinetic constants (through Transition State Theory), when compared with the available experimental data, were found to be within the same order for the most likely pathway. The simulation of a parallel reactions pair shows the same declining profile found for experimental kinetic constants. The comparison with previous theoretical results suggest that the addition of polarization effects on the basis set results in a higher accuracy of the kinetic constant values.

The studies of the continuum show that the implicit solvation model SM5.42R is adequate to describe the system, since it reproduces well the experimental value of solvation energy for phenol. However, it is not possible to do comparisons for the radicals due to the absence of experimental data. Among the explicit solvation models constructed, the one which represents a solvation sphere of four water molecules has shown better accuracy to phenol. For the radical intermediate O1, the most suitable model found was the one with six water molecules joined in a cycle on the hydroxyls bonded to the ring.

With the obtained results and their comparisons with experimental data, the applicability of Molecular Modeling techniques in Chemical Engineering studies is discussed, reinforcing the perspective of this tool as an important instrument for the design of new products and the optimization of technologically relevant processes.
\end{abstract}




\section{LISTA DE ILUSTRAÇõES}

Página

Título I - Introdução e Justificativa do tema

\begin{tabular}{lll}
\hline Figura I.1 & Abordagem hierárquica combinando diferentes métodos de modelagem... & $\mathbf{2 8}$ \\
Figura I.2 & Reações do ozônio em meio aquoso na presença de um soluto orgânico... & $\mathbf{3 3}$ \\
Figura I.3 & Esquema do processo de formação de radicais hidroxila e peroxila... & $\mathbf{3 4}$ \\
Figura I.4 & Sistema de reações para o processo UV/ $\mathrm{H}_{2} \mathrm{O}_{2}$. & $\mathbf{3 5}$ \\
Figura I.5 & Esquema das principais reações (...) do processo foto-Fenton. & $\mathbf{3 6}$ \\
Figura I.6 & Esquema das reações envolvidas (...) no processo fotocatalítico. & $\mathbf{3 7}$ \\
Figura I.7 & Esquema das reações envolvidas no processo $\mathrm{O}_{3} / \mathrm{UV}$. & $\mathbf{3 8}$ \\
\hline
\end{tabular}

Titulo II - Fundamentação Teórica

Figura II.1 Domínios das equações dinâmicas. $\quad 47$

Figura II.2 Diagrama de fluxo citando os métodos de Modelagem Molecular. 49

Figura II.3 Gráfico ilustrando a intensidade da emissão do corpo negro ...

Figura II.4 Diagrama de blocos ilustrando o procedimento (...) HF SCF.

Figura II.5 Dependência de $E_{X C}$ em relação a $\lambda . \quad 84$

Figura II.6 Estruturas de Lewis das principais espécies de oxigênio envolvidas nas ... $\quad 94$

Figura II.7 Reatividade dos radicais hidroxila na ausência de espécies sequestradoras. $\quad \mathbf{9 5}$

Figura II.8 Reatividade dos radicais hidroperoxila e superóxido na ausência de ...

Figura II.9 Resumo dos principais métodos físicos para geração das espécies ...

Figura II.10 Reações sofridas pelas espécies precursoras geradas pelos métodos ... $\quad 98$

Figura II.11 Ciclo termodinâmico representando ... energias de solvatação...

Figura II.12 Efeito da solvatação aquosa na reação de cloreto com clorometano $\quad 101$

Figura II.13 Cluster Fenol- $\left(\mathrm{H}_{2} \mathrm{O}\right)_{4}$ (representação genérica 2D) 105

Figura II.14 Isômeros dos dímeros fenol + água $\quad 106$

Título III - Apresentação e Discussão da Metodologia

Figura III.1 $\quad$ Mecanismo de oxidação do fenol proposto por Devlin e Harris (1984). 110

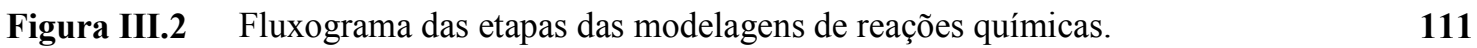

Figura III.3 Principais pontos de uma superfície de energia potencial. 112

$\begin{array}{lll}\text { Figura III.4 Diagrama ilustrando o processo de otimização pelo algoritmo SD. } & 113\end{array}$

$\begin{array}{lll}\text { Figura III.5 } & \text { Fluxograma de um processo de otimização de estruturas. } & 114\end{array}$

Figura III.6 Superficie de energia potencial de uma molécula diatômica AB. $\quad \mathbf{1 1 5}$

Figura III.7 Ilustração dos métodos QST e LST, comparados com a IRC. 118

Figura III.8 $\quad$ Ilustração do algoritmo utilizado para o cálculo de frequencias. 119

$\begin{array}{lll}\text { Figura III.9 Ilustração do algoritmo utilizado para o cálculo das propriedades termo... } & \mathbf{1 2 1}\end{array}$

Título IV - Resultados e Discussão

Figura IV.1 Energias totais em fase gasosa e aquosa e entalpias calculadas... 
Figura IV.2 Comportamento da constante cinética para a reação de adição do radical... $\quad 129$

$\begin{array}{lll}\text { Figura IV.3 Curva de Eyring para os dados experimentais levantados por ... } & \mathbf{1 3 0}\end{array}$

Figura IV.4 Avaliação da energia livre por três métodos de cálculo distintos. 131

Figura IV.5 Posições possíveis para a adição do oxigênio molecular ao radical... 132

Figura IV.6 Energias das três estruturas possíveis após adição do $\mathrm{O}_{2}$. 132

Figura IV.7 Variação da energia livre durante a adição do $\mathrm{O}_{2}$ nas posições ipso e meta. 133

Figura IV.8 Mecanismo proposto para a etapa final da conversao fenol -> catecol. $\quad \mathbf{1 3 4}$

Figura IV.9 Variação de energia livre para a reação proposta na Fig. IV.8. 134

Figura IV.10 Perfil energético da primeira etapa do mecanismo de degradação do fenol. $\quad 135$

Figura IV.11 Perfil energético para a etapa de adição para ao anel aromático.

$\begin{array}{lll}\text { Figura IV.12 Variação de energia livre ao longo da Reação R3 } & 137\end{array}$

Figura IV.13 Caminho energético da Reação R5. 138

Figura IV.14 Simulação para a reação de degradação do fenol em fase gasosa. $\quad \mathbf{1 4 0}$

Figura IV.15 Dados experimentais obtidos para a degradação do fenol ...

Figura IV.16 Perfis de concentração do fenol, $o$ - e $p$-DCHR simulados. 14

Figura IV.17 Coordenada da reação, usando o modelo de solvatação SM5.42R $\mathbf{1 4 6}$

Figura IV.18 Principais propriedades calculadas para os diferentes modelos do fenol $\quad \mathbf{1 5 1}$

Figura IV.19 Principais propriedades calculadas para os diferentes modelos de O1 153

$\begin{array}{llr}\text { Figura IV.20 } & \text { Estrutura otimizada para O1-3W } & \mathbf{1 5 3}\end{array}$

$\begin{array}{lll}\text { Figura IV.21 } & \text { Estrutura otimizada para O1-3W2 } & 154\end{array}$ 


\section{Lista DE TABELAS}

Página

Título I - Introdução e Justificativa do tema

Tabela I.1 Características da Engenharia Química em 1988 e a previsão para 2008. 24

Titulo II - Fundamentação Teórica

$\begin{array}{lll}\text { Tabela II.1 } & \text { Operadores quânticos e suas operações. } & \mathbf{6 1}\end{array}$

$\begin{array}{lll}\text { Tabela II.2 } & \text { Valores absolutos de erro (...) em relação a energias de atomização... } & \mathbf{8 5}\end{array}$

Tabela II.3 Erros absolutos (...) nas entalpias de ativação e de reação direta...

Tabela II.4 Erros absolutos médios nos comprimentos de ligação...

Título III - Apresentação e Discussão da Metodologia

Tabela III.1 Equipamentos e softwares utilizados na execução do projeto. $\quad \mathbf{1 0 8}$

$\begin{array}{lll}\text { Tabela III.2 Discriminação do uso dos softwares disponíveis por etapa de modelagem. } & 109\end{array}$

Tabela III.3 Matriz interna para otimização da geometria do fenol. 112

\section{Título IV - Resultados e Discussão}

\begin{tabular}{lll}
\hline Tabela IV.1 & Resultados energéticos obtidos para a primeira reação da primeira etapa... & $\mathbf{1 2 8}$
\end{tabular}

Tabela IV.2 Resultados energéticos obtidos por Kiliç et al. (2007)...

$\begin{array}{lll}\text { Tabela IV.3 } & \text { Parâmetros termodinâmicos estimados a partir de dados experimentais... } & \mathbf{1 3 1}\end{array}$

Tabela IV.4 Energias livres de ativação calculadas (...) da Reação R1.

Tabela IV.5 Energias livres de ativação para os processos moleculares da Reação R4. $\quad 137$

Tabela IV.6 Constantes cinéticas calculadas e valores experimentais. 139

Tabela IV.7 Modelo cinético para a oxidação do fenol por processo foto-Fenton. $\quad \mathbf{1 4 1}$

Tabela IV.8 Dados de projeto de um reator PFR para degradação...

Tabela IV.9 Principais resultados energéticos obtidos pelo modelo SM5.42R...

Tabela IV.10 Energias livres de ativação e reação em fase gasosa para a reação...

$\begin{array}{lll}\text { Tabela IV.11 } & \text { Resultados obtidos pelo modelo PCM } & 147\end{array}$

Tabela IV.12 $\quad$ Propriedades de solvatação em função dos oxigênios e hidrogênios... $\quad 148$

Tabela IV.13 Resultados energéticos para os três pontos de interação da molécula... $\quad 149$

$\begin{array}{lll}\text { Tabela IV.14 Energias livres de solvatação para as diferentes supramoléculas... } & \mathbf{1 5 1}\end{array}$ 


\section{CONTEÚDO}

Página

Título I: Introdução e justificativa do tema

Capítulo I-1. Modelagem molecular como ferramenta de pesquisa em Engenharia Química $\quad 18$

I-1.1 A Engenharia Química .................................................................................. 18

I-1.2 Os paradigmas da Engenharia Química................................................................ 20

I-1.3 A Modelagem Molecular na Engenharia Química................................................... 25

Capítulo I-2. Os Processos Oxidativos Avançados (POAs)....................................................... 29

I-2.1 Fotólise UV ....................................................................................... 30

I-2.2 Oxidantes químicos.................................................................................... 31

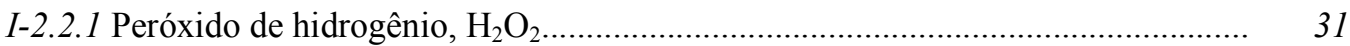

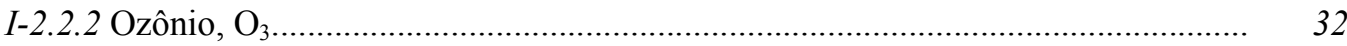

I-2.2.3 Reação de Fenton (Dark Fenton) ........................................................................

I-2.3 Métodos irradiados........................................................................................

I-2.3.1 Combinações com UV ................................................................................

I-2.4 Projeto de POAs.................................................................................................... 39

Capítulo I-3. Objetivos e justificativa.............................................................................. 41

\section{Título II: Fundamentação Teórica}

Parte A: Modelagem Molecular

Capítulo II-A1. Introdução à Modelagem Molecular.............................................................. 43

II-A1.1 Métodos de Modelagem Molecular ...................................................................... 44

II-A1.2 Simulação molecular.......................................................................................... 48

Capítulo II-A2. Fundamentos de Mecânica Quântica............................................................... 50

II-A2.1 Uma breve introdução: a alvorada da Teoria Quântica...................................... 50

II-A2.2 A Catástrofe do Ultravioleta e o nascimento do quantum.................................... 52

II-A2.3 O quantum e o modelo atômico....................................................................... 54

II-A2.4 A dualidade da Matéria............................................................................... 55

II-A2.5 A "Nova Teoria Quântica"...................................................................... 55

II-A2.6 A Equação de Schrödinger.............................................................................. 56

II-A2.7 Postulados e princípios gerais da Mecânica Quântica......................................... 59

II-A2.8 A aproximação de Born-Oppenheimer.............................................................. 64

II-A2.9 A construção das funções de onda: abordagem CLOA (LCAO)........................... 64

II-A2.10 Avaliando a energia da função de onda.......................................................... 65

II-A2.11 Sistemas multieletrônicos e a aproximação de Hartree-Fock............................... 68

II-A2.12 A correlação eletrônica e a evolução da teoria HF............................................ 69

Capítulo II-A3. Teoria do Funcional da Densidade............................................................... 71 


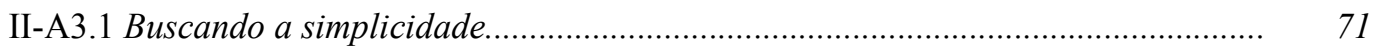

II-A3.2 Teoremas de Hohenberg-Kohn.....................................................................

II-A3.3 Abordagem de Kohn-Sham ..............................................................................

II-A3.4 Funcionais de troca e correlação...................................................................... 76

II-A3.4.1 Aproximação da densidade local (LDA)........................................................ $\quad 78$

II-A3.4.2 Aproximação do gradiente generalizado (GGA)............................................. 79

II-A3.5 A Conexão Adiabática e o funcional B3LYP...................................................... 81

II-A3.6 Performance do modelo...................................................................................... 84

Parte B: Mecanismo estudado

Capítulo II-B1. Os radicais de oxigênio............................................................................. 91

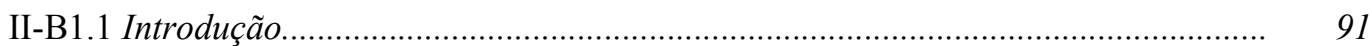

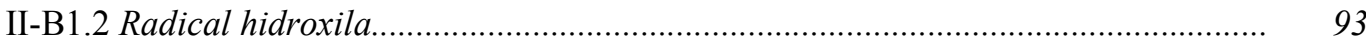

II-B1.3 Radical peroxila......................................................................................... 95

II-B1.4 Ânion-radical superóxido ............................................................ 96

Parte C: A modelagem dos efeitos da solvatacão

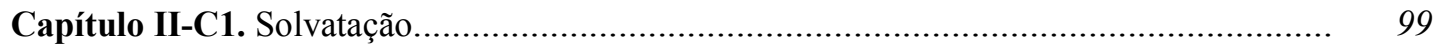

Capítulo II-C2. Modelos implícitos de solvatação.................................................................. 102

Capítulo II-C3. Modelos de solvatação explícita...................................................................... 104

\section{Título III: Apresentação e Discussão da Metodologia}

Capítulo III-1. Equipamentos e softwares................................................................ 107

Capítulo III-2. Etapas das modelagens.................................................................... 109

III-2.1 Construção das matrizes internas.................................................................. 111

III-2.2 Otimização e pré-otimização.................................................................... 112

III-2.2.1 Eigenvector Following................................................................ 114

III-2.2.2 Otimização do Estado de Transição (ET) ............................................. 116

III-2.3 Cálculos de frequência.............................................................................. 117

III-2.4 Cálculos termodinâmicos.................................................................... 118

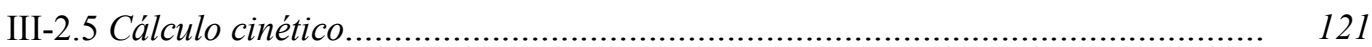

III-2.6 Cálculos de solvatação............................................................................. 122

\section{Título IV: Resultados e discussão}

Capítulo IV-1. Estudo de intermediários...................................................................... $\quad 126$

IV-1.1 Adição orto ao anel aromático..................................................................... 126

VI-1.2 Adição para ao anel aromático..................................................................... 134

VI-1.3 Oxidação do catecol a o-benzoquinona........................................................ 135

VI-1.4 Oxidação da o-benzoquinona: abertura do anel............................................ 137

Capítulo IV-2. Estudo cinético.................................................................................... 138

Capítulo IV-3. Estudo da solvatação 144 
Referências Bibliográficas... 
Título I

INTRODUÇÃO E JUSTIFICATIVA DO TEMA 
A qualidade do meio ambiente tem sido foco das notícias nos últimos tempos. Emissões descontroladas de poluentes em rios, solos e na atmosfera são apontadas como causa de mudanças que vêm afetando os elementos climáticos do planeta. A preocupação com a manutenção de nossos recursos naturais e a compreensão de que a Natureza não é capaz de tratar tudo que nela se dispõe levou a ciência a desenvolver novas ferramentas para o tratamento adequado de resíduos de suas atividades de modo a minimizar ou neutralizar o impacto sobre o meio ambiente. Algumas dessas técnicas, desenvolvidas com objetivos de remover completamente poluentes orgânicos persistentes e garantir a mineralização completa dos resíduos, são os Processos Oxidativos Avançados, baseados na oxidação dos poluentes promovida por espécies reativas de oxigênio - principalmente o radical hidroxila, $\bullet \mathrm{OH}-$ conforme discutido ao longo do Capítulo I-2..

O presente trabalho tem por objetivo realizar o estudo do mecanismo da degradação envolvido na mineralização do fenol por espécies oxidativas geradas nos Processos Oxidativos Avançados, conforme proposto por Devlin e Harris (1984) entre outros, e discutido ao longo da Parte II-B. O estudo propõe-se a identificar os intermediários e calcular as constantes cinéticas, quando possível, através do uso de técnicas de Modelagem Molecular.

A Modelagem Molecular é uma ferramenta interessante que permite a estimativa de propriedades físico-químicas de substâncias de interesse científico e tecnológiao, a partir da resolução de equações de métodos de Química Teórica, como as Teorias do Orbital Molecular e a Teoria do Funcional da Densidade. Nesta ferramenta, as propriedades são calculadas em computadores e dispensam a execução de experimentos. A qualidade do método pode ser avaliada se comparada com resultados obtidos por métodos experimentais. A Modelagem Molecular é discutida em detalhes na Parte II-A. Os modelos de solvatação são apresentados e discutidos ao longo da Parte II-C. Os principais aspectos operacionais são apresentados e discutidos ao longo do Título III, e os resultados obtidos são discutidos no Título IV. 


\title{
Capítulo I-1
}

\section{A Modelagem Molecular como Ferramenta de Pesquisa em Engenharia Química: Uma Perspectiva Histórica}

\author{
"Chemical Engineering is the profession in which \\ a knowledge of mathematics, chemistry, and other natural sciences \\ gained by study, experience, and practice \\ is applied with judgment to develop economic ways \\ of using materials and energy for the benefit of mankind." \\ (AIChE Constitution - Artigo III: Definição da Profissão)
}

\section{I-1.1 A ENGENHARIA QUíMICA}

Ao longo dos últimos 100 anos, a definição fundamental de Engenharia Química manteve-se a mesma: "Engenheiros químicos levam a química do laboratório para a indústria e o mundo ao nosso redor", de acordo com o Instituto Americano dos Engenheiros Químicos $^{1}$ (RITTER, 2001). Mas as coisas não são mais bem assim.

A principal tarefa do engenheiro químico na indústria tem sido e sempre será a de projetar e implementar sistemas completos (WINTERMANTEL, 1999). Por "sistemas completos" compreende-se tanto processos individuais como plantas para produzir produtos com propriedades específicas bem definidas, e também a integração dos processos individuais em um sítio de produção global, em termos de materiais, energia e logística. Para uma descrição e controle precisos dos processos, suas complexidades devem ser drasticamente reduzidas, e sub-sistemas devem ser descritos em termos de modelos. Nesta abordagem, como ressalta Wintermantel, a engenharia química não diverge muito de outras disciplinas acadêmicas, como física e química.

De acordo com o artigo $4^{\circ}$ da RN 36 do CFQ (CONSELHO FEDERAL DE QUÍMICA, 1974), a Engenharia Química compreende “conhecimentos de química em caráter profissional, de Tecnologia, abrangendo processos e operações, e de planejamento e projeto de equipamentos e instalações da indústria química e correlatas," e unicamente ao Engenheiro Químico competem as atribuições de planejamento, projeto, especificações, execução, fiscalização de montagem e instalação de equipamentos e instalações industriais. $\mathrm{O}$ Conselho Federal de Engenharia e Arquitetura, CONFEA, determina ao engenheiro químico atribuições similares, mas com enfoque maior em projetos e operações de processos

\footnotetext{
* AIChE, 2003

${ }^{1}$ American Institute of Chemical Engineers (AIChE)
} 
(CONSELHO FEDERAL DE ENGENHARIA E ARQUITETURA, 1947). No Brasil, a profissão é regulamentada pelos dois órgãos profissionais, o que causa alguns desentendimentos com frequência.

Para o exercício das atribuições declaradas por lei, o CFQ estabelece o cumprimento de um currículo mínimo compreendendo um total de 48 créditos divididos igualmente entre quatro áreas da Química (Geral e Inorgânica, Analítica, Orgânica e Físico-Química), 32 créditos em disciplinas técnicas (Processos Industriais, Operações Unitárias e Projetos) e outros 6 créditos complementares, totalizando 86 créditos (CONSELHO FEDERAL DE QUÍMICA, 1975). O curso de graduação em Engenharia Química da Escola Politécnica possui um total de 193 créditos, distribuídos entre disciplinas, estágios e atividades complementares (DEPARTAMENTO DE ENGENHARIA QUÍMICA, 2007), promovendo uma formação sólida e abrangente nas diversas áreas de atuação do profissional de Engenharia Química, ao longo de cinco anos de curso ideal. Ao fim do curso, outorga-se ao aluno o grau de Engenheiro Químico (BRASIL, 2001).

É fato reconhecido que a evolução da Engenharia Química está intimamente relacionada à evolução da indústria química, tanto no Brasil quanto no resto do mundo (CREMASCO, 2004; MORAES, 2000; LAUDARES e RIBEIRO, 2000; COBB et al., 2007; RITTER, 2001). Como comentado por Hougen (1977), embora formalmente a Engenharia Química tenha se iniciado no fim do século XIX, muitos dos processos associados à disciplina foram desenvolvidos na antiguidade: operações de filtração, por exemplo, eram conduzidas há mais de 5000 anos durante a terceira dinastia egípcia. Outro exemplo é o processo de recuperação de sal pela água oceânica, descrito em 1556 por Georgius Agrícola em "De Re Metallica" (AGRICOLA, 1556), e ainda em uso. Novos processos de produção, particularmente para a decomposição de minérios em compostos minerais (ácidos, bases, sais, óxidos), surgiram no final do século XIII. Outro marco seguiu-se, quase um século depois, com a evolução da síntese orgânica, levando a compostos de carbono covalentemente ligados; obtidos inicialmente de carvão (carboquímica) e posteriormente do petróleo (petroquímica). Esse período coincidiu com a emergência da química industrial e com o crescimento exponencial das indústrias de processos químicos. Atualmente, mais de $10^{7}$ compostos são conhecidos e cerca de $10^{5}$ encontram-se disponíveis no mercado (FAVRE et al., 2002). G. A. Silva faz um paralelo entre a evolução da profissão do engenheiro químico e a evolução do mercado industrial brasileiro (MORAES, 2005), destacando a cooperação Universidade-Escola para a formação de um profissional de qualidade e capaz de atender à demanda das empresas. 
Obviamente, com a nítida evolução da indústria, as instituições de ensino não poderiam manter-se estagnadas, e a revisão do currículo do engenheiro químico sofreu várias alterações ao longo dos anos em resposta às exigências do mercado. Mas como são estruturadas essas alterações?

"It would be a great mistake to think of the content of chemical engineering science as permanently fixed. It is likely to alter greatly over the years, in response to the changing requirements of industry and to new scientific discoveries and ideas for their application."

(P.V. Danckwerts $)^{2}$

\section{I-1.2 OS PARADIGMAS DA ENGENHARIA QUÍMICA}

O filósofo moderno Thomas Kuhn (KUHN, 1996) argumenta que a ciência é construída através de conjuntos de conquistas científicas: conquistas que uma comunidade científica em particular reconhece por um tempo como suporte dos fundamentos de suas práticas. Segundo Kuhn, essas "conquistas", às quais ele dá o nome de 'paradigmas', devem compartilhar de duas importantes características:

- Serem suficientemente sem precedentes, a ponto de atraírem um grupo de seguidores, afastando-os de um modo de atividade científica competitivo;

- Serem suficientemente abertas, permitindo a existência de vários tipos de problemas para que o novo grupo de praticantes resolva.

Pela adoção do termo, Kuhn sugere que alguns exemplos aceitos da prática científica atual (incluindo leis, teorias, aplicações e instrumentação) provêm modelos a partir dos quais constróem-se tradições coerentes de pesquisa científica.

O estudo dos paradigmas é o que prepara o estudante para atuar no mundo científico, após sua formação. Visto que o estudante, após sua formação, será integrado em um grupo de homens que foram apresentados ao mundo científico pelos mesmos modelos concretos, dificilmente haverá discordâncias sobre questões fundamentais. Todos os que seguem um mesmo paradigma em sua pesquisa, mesmo que de maneira isolada uns dos outros, são

\footnotetext{
${ }^{2}$ Danckwerts, 1966
} 
guiados pelas mesmas regras e padrões. Essa semelhança é necessária para haver a ciência normal, ou seja, "a gênese e a continuação de uma tradição de pesquisa determinada".

Como comentado por Mesquita (MESQUITA, 2007), a partir do momento em que o cientista pode contar com um paradigma que guia todas as pesquisas de seu campo, ele pode concentrar-se nos fenômenos e características que ainda não foram explicados pelo paradigma, tornando sua pesquisa mais meticulosa.

Uma vez estabelecido o paradigma, os cientistas passam a exercer o que é chamado de 'ciência normal': uma pesquisa orientada pelo paradigma. Kuhn argumenta que os paradigmas adquirem tal status por serem mais bem sucedidos na resolução de determinados problemas do que seus competidores; o que não significa necessariamente a solução de todos os problemas da área. De fato, o estabelecimento de um paradigma significa a abertura de um leque de possíveis experimentos para problemas que, algumas vezes, sequer existiam antes do mesmo. Essa é a função da ciência normal: atualizar a promessa do paradigma de resolver problemas e explicar fenômenos que o próprio indica como particularmente relevantes para o progresso científico.

A Engenharia Química, assim como as demais disciplinas científicas, tem seu paradigma. Desde seu nascimento nos finais do século XIX, seu modelo intelectual fundamental sofreu uma série de mudanças, como apontado pelo professor James Wei (WEI, 2002), que separa essas fases sobre o prisma de Kuhn em um "pré-paradigma", dois paradigmas estabelecidos e um proposto.

O que Wei chama de "pré-paradigma" é representado pela situação encontrada no início do estabelecimento da disciplina, quando o MIT (Massachusetts Institute of Technology) ofereceu um programa em Engenharia Química como uma opção dentro do Departamento de Química, em 1888: a falta de um paradigma. O currículo era composto basicamente pela descrição de operações industriais, organizadas por produtos específicos (AMUNDSON, 1988).

\section{3: O primeiro paradigma}

O primeiro paradigma para a disciplina baseou-se no conceito unificador de "operações unitárias”, proposto por William H. Walker e Arthur D. Little, em 1915. Walker e colegas compuseram em 1923 o livro texto "Principles of Chemical Engineering”, quantificando as operações unitárias e fornecendo, então, ferramentas para que os engenheiros analisassem os processos químicos (DEPARTMENT OF CHEMICAL ENGINEERING, 2007). 
Segundo esse conceito, qualquer processo de manufatura químico poderia ser resolvido em uma série coordenada de operações, como pulverização, secagem, cristalização, filtração, evaporação, destilação, e assim por diante (AMUNDSON, 1988). Até então, embora houvesse um conhecimento de operações individuais, não havia um estudo estruturado a respeito de cada operação, mas sim de processos específicos, como notado em um dos primeiros livrostexto sobre Engenharia Química, publicado pelo então coordenador do programa em Engenharia Química do MIT, Frank H. Thorpe (THORPE \& LEWIN, 1916). A habilidade dos engenheiros químicos de caracterizar quantitativamente operações unitárias, como a destilação, permitiu o projeto racional das primeiras refinarias de óleo modernas, e ao primeiro boom de contratação de engenheiros químicos.

\section{0: O segundo paradigma}

Não satisfeitos com as descrições empíricas do desempenho de equipamentos e processos, os engenheiros químicos passaram a reexaminar as operações unitárias de um ponto de vista mais fundamental. Os fenômenos que ocorrem nas operações unitárias foram resolvidos em conjuntos de eventos moleculares. Os modelos mecanísticos quantitativos para esses eventos foram desenvolvidos e usados para analisar os equipamentos existentes, assim como projetar novos equipamentos e processos (AMUNDSON, 1988). Esse paradigma foi identificado sob a alcunha dos "Fenômenos de Transporte", e sua evolução marcada pela publicação da obra Transport Phenomena, de Bird, Stewart e Lightfoot, em 1960 e atualmente em sua segunda edição revisada (primeira impressão em agosto, 2007) após sessenta e duas impressões da primeira edição e oito da segunda (BIRD, 2007).

$\mathrm{O}$ assunto fenômenos de transporte é um ramo bem desenvolvido da física e eminentemente útil que permeia muitas áreas da ciência aplicada, e inclui três tópicos intimamente relacionados: dinâmica dos fluidos, transferência de calor e transferência de massa. A dinâmica dos fluidos envolve o transporte de momento, a transferência de calor lida com o transporte de energia e a transferência de massa diz respeito ao transporte das espécies químicas (BIRD, 2002).

Porém, há vinte anos já se falava na emergência de um novo paradigma. O comitê da FCE listou, em 1988, algumas das características que deveriam ser alteradas no "engenheiro químico do futuro" (AMUNDSON, 1988): 
Tabela I.1 - Características da Engenharia Química em 1988 e a então previsão para 2008.

\begin{tabular}{|c|c|}
\hline Características de então (1988) & Características previstas \\
\hline $\begin{array}{l}\text { Servir a indústrias cujos produtos permanecem sem } \\
\text { alterações no mercado por longos períodos. }\end{array}$ & $\begin{array}{l}\text { Servir indústrias cujos produtos são rapidamente } \\
\text { ultrapassados no mercado por concorrentes. }\end{array}$ \\
\hline $\begin{array}{l}\text { Servir a indústrias que competem principalmente na } \\
\text { base de preço/disponibilidade. }\end{array}$ & $\begin{array}{l}\text { Servir a indústrias que competem na base da qualidade } \\
\text { e performance. }\end{array}$ \\
\hline $\begin{array}{l}\text { Especialista na manufatura de materiais homogêneos a } \\
\text { partir de pequenas moléculas. }\end{array}$ & $\begin{array}{l}\text { Especialista na manufatura de compósitos e materiais } \\
\text { estruturados a partir de moléculas grandes. }\end{array}$ \\
\hline Especialista no projeto de processo. & $\begin{array}{l}\text { Especialista em projetar produtos com características } \\
\text { de performance especiais. }\end{array}$ \\
\hline Especialista em projetar processos de $\xi$ & Especialista em projetar processos em pequena escala. \\
\hline Especialista em projetar processos contínuos. & Especialista em projetar processos em batelada. \\
\hline $\begin{array}{l}\text { Especialista em projetar plantas industriais dedicadas a } \\
\text { um só produto ou processo. }\end{array}$ & $\begin{array}{l}\text { Especialista em projetar plantas de manufatura } \\
\text { flexíveis. }\end{array}$ \\
\hline $\begin{array}{l}\text { Os praticantes usam modelos simples e aproximações } \\
\text { para a resolução de modelos. }\end{array}$ & $\begin{array}{l}\text { Os praticantes usam modelos mais completos, } \\
\text { melhores aproximações, e computadores mais } \\
\text { sofisticados para resolver os problemas mais } \\
\text { rigorosamente. }\end{array}$ \\
\hline $\begin{array}{l}\text { cantes têm acesso a apenas alguns poucos } \\
\text { entos analíticos simples. }\end{array}$ & $\begin{array}{l}\text { Os praticantes têm acesso a vários instrumentos } \\
\text { analíticos sofisticados. }\end{array}$ \\
\hline $\begin{array}{l}\text { Os praticantes constroem suas carreiras acerca de uma } \\
\text { única linha de produto ou processo. }\end{array}$ & Os praticantes têm múltiplas mudanças de carreira. \\
\hline $\begin{array}{l}\text { A pesquisa acadêmica é conduzida principalmente por } \\
\text { alguns investigadores principais dentro de } \\
\text { departamentos de engenharia química. }\end{array}$ & $\begin{array}{l}\text { A pesquisa acadêmica é conduzida também por grupos } \\
\text { multidisciplinares de investigadores principais, as } \\
\text { vezes em centros ou outros ambientes organizacionais. }\end{array}$ \\
\hline $\begin{array}{l}\text { A pesquisa e a educação focam-se na meso-escala } \\
\text { (nível de equipamentos). }\end{array}$ & $\begin{array}{l}\text { A pesquisa e a educação também incluem a micro- } \\
\text { escala (nível molecular) e a macro-escala (nível de } \\
\text { sistemas). }\end{array}$ \\
\hline
\end{tabular}

Como pode ser observado pela tabela acima, as características mais marcantes esperadas da engenharia química do século XXI incluem sua dinâmica e a ampliação de sua área de abrangência para enfoques em micro- e macro-escalas. Essa visão de então é sustentada por muitos pesquisadores ao redor do mundo, promovendo a evolução de um novo paradigma. Parece haver um consenso na literatura acerca de algumas das implicações deste novo paradigma que se desenvolve (WEI, 2002; FAVRE et al., 2002; WINTERMANTEL, 1999; CHARPENTIER, 2007; COSTA et al., 2006; CHARPENTIER, 2002), embora não haja uma denominação específica, como no caso das operações unitárias ou dos fenômenos de transporte. Entretanto, há uma corrente bastante volumosa que o denomina "Engenharia de Produto".

\section{A Engenharia de Produto e o futuro da Engenharia Química}

Uma busca simples pelo termo Engenharia de Produto (Product Engineering) no portal da Web of Science $^{3}$ retorna mais de 100 publicações a respeito. Costa et al. (2006) vão ainda

\footnotetext{
3 http://portal.isiknowledge.com/
} 
além e comentam a ocorrência de mais de 300 referências a respeito. Os autores ressaltam que a ciência da Engenharia Química deve evoluir tanto na perspectiva educacional quanto na pesquisa, uma vez que muitos dos produtos químicos da atualidade (e do futuro, por consequência) não apresentam muito em comum com aqueles de vinte anos atrás, demandando a mudança no portfolio de habilidades e conhecimentos técnicos adquiridos pelos engenheiros químicos.

Jean-Claude Charpentier (CHARPENTIER, 2002; 2007) utiliza uma terminologia particular para descrever o que ele acredita ser a base do futuro da Engenharia Química: a engenharia do tripé "processos moleculares-produto-processo". Como o nome já indica, o autor acredita que o progresso necessário na engenharia química será alcançado através de uma multidisciplinaridade e uma abordagem multiescalar em tempo e espaço. Ainda segundo Charpentier, isso se dará através de constantes inovações em modelagem molecular, instrumentação científica e processamento de sinais, e poderosas ferramentas computacionais.

Wintermantel (1999), numa visão também defendida por Charpentier (2007), reforça a importância que o estudo em ciências básicas deve ter em um currículo de Engenharia Química ao comentar sobre duas tarefas que, a seu ver, devem ser objetivadas ao se desenvolver a Engenharia Química enquanto disciplina:

modelar subsistemas usando os conhecimentos científicos metodológicos e teóricos;

desenvolver métodos e procedimentos que permitam o projeto e a construção de sistemas reais, em toda sua complexidade, mesmo com a ausência de uma modelagem precisa de todos seus subsistemas devido à falta de um conhecimento extensivo da física e da química ali envolvidas.

Para atender a esses requisitos, faz-se necessário o investimento em pesquisa fundamental, tida como fonte da maioria das inovações do mercado, como comentado por Marcinowski. (1998).

Seguindo a mesma linha de perspectiva de Charpentier, Wintermantel, Wei e outros, Dixon e Feller (1999) reforçam a importância da modelagem e da simulação no desenvolvimento da engenharia química. Segundo eles, a modelagem e a simulação são tecnologias críticas para atingir os objetivos da indústria atual ${ }^{4}$, à medida em que reduzem

\footnotetext{
4 definidos como sendo o desejo de aperfeiçoar os processos produtivos e a necessidade de projetar racionalmente novos materiais; aliados ao desenvolvimento dos chamados "processos verdes" - que minimizam a utilização de energia e a produção de correntes contaminadas.
} 
custo e tempo de ciclo, e destacam ainda a modelagem molecular como uma ferramenta de forte impacto na engenharia química.

\section{I-1.3 A Modelagem Molecular na Engenharia Química}

As aplicações de modelagem molecular (MM) em engenharia química são consideravelmente recentes e diversas. A Academic Press lançou em 2001, como parte de sua série de livros Advances in Chemical Engineering um tomo especialmente dedicado à modelagem molecular, intitulado "Molecular Modeling and Theory in Chemical Engineering”, com trabalhos de renomados pesquisadores ao redor do mundo, reunidos pelo professor Chakraborty, da University of California at Berkeley, colocando a Modelagem Molecular como uma ferramenta de destaque no panorama da pesquisa em Engenharia Química.

Chakraborty comenta sobre a necessidade crescente de compreensão dos processos em níveis espaciais de diferentes ordens de magnitude, opinião partilhada de outros pesquisadores contemporâneos em engenharia química, como mencionado anteriormente. Segundo ele, o conhecimento acerca de como a constituição molecular e as características mesoscópicas de um sistema de componentes interagentes influenciam no comportamento de um sistema só pode ser abordado por uma pesquisa sinérgica experimental e teórica, cujos métodos devem ser capazes de interrogar os sistemas em uma larga extensão nas escalas temporais e espaciais (CHAKRABORTY, 2001).

A abordagem teórica de um problema que, como ressaltado por Dixon e Feller (DIXON \& FELLER, 1999), pode muito bem ser um sistema de interesse real à indústria química, é cada vez mais permissível com a evolução constante na tecnologia da informação. Com a disponibilidade de novos computadores de alto desempenho, novos algoritmos e novos métodos teóricos têm sido desenvolvidos com objetivo de tomar vantagem do poder computacional oferecido por esses sistemas. O desenvolvimento de terminais de trabalho de alto desempenho e custo moderado tem facilitado a execução de cálculos razoavelmente complexos em um desktop. Graças aos constantes aperfeiçoamentos da indústria da informação e as subsequentes melhorias nos algoritmos e softwares, a química computacional 
mostra-se como uma parceira em potencial aos experimentos no objetivo de desenvolver novos materiais e processos químicos.

A modelagem molecular tem sido empregada de maneiras diversas na indústria química. O mais simples desses cálculos envolve uma molécula isolada. Eles permitem a obtenção de informações como a geometria molecular de equílibrio, a energia eletrônica e as frequências vibracionais. A partir dessas informações, obtem-se a energia de dissociação a $0 \mathrm{~K}$, e através do uso de mecânica estatística, a entropia e outras propriedades termodinâmicas podem ser calculadas. Esses cálculos permitem a obtenção de calores de formação de diferentes compostos e, associados à Teoria do Estado de Transição, fornecem informações acerca de caminhos de reação e da seletividade de reagentes (SANDLER et al., 2001), o que constitui um atalho no projeto de processos químicos e no desenvolvimento de produtos com estruturas específicas.

Uma potencialidade interessante da modelagem molecular é seu uso na obtenção de inferências a respeito do comportamento de sistemas químicos. Maroudas (2001), por exemplo, estudou a aplicação de técnicas de MM ao estudo das interações radical-superfície na deposição de filmes finos de silicone através do método da deposição de vapores químicos com auxílio de plasma (PECVD - Plasma-enhanced chemical vapor deposition). A PECVD é uma tecnologia útil para a manufatura de dispositivos elétricos, optoelétricos e fotovoltaicos que faz uso de plasmas altamente reativos, requerindo assim temperaturas menores do que os processos usuais (CVD - chemical vapor deposition) para obtenção destes filmes. Apesar de ser um processo já bastante utilizado, sua otimização e projeto baseiam-se em procedimentos completamente empíricos que não são transferíveis para outros tipos de reatores ou sistemas químicos. Para que isso mude, é necessário um avanço na compreensão da tecnologia do processamento de plasma. O autor comenta que as interações plasma-superfície são os aspectos menos compreendidos. Essas interações dependem de três fatores: fluxos e energias das espécies que passam do plasma à superfície, estrutura e composição da superfície de deposição e o conhecimento das reações elementares que produzem as espécies da superfície a partir das espécies do plasma. Os dois primeiros são acessíveis a partir da experimentação, mas o último só pode ser obtido a partir de estudos teóricos. Para o estudo, o autor utilizou uma combinação de métodos de mecânica quântica (QM) - a DFT - e métodos clássicos de simulação molecular (MD, MS e KMC - dinâmica molecular, estática molecular e MonteCarlo cinético) usando uma abordagem conhecida como "abordagem hierárquica", como mostrado na Figura I.1: 


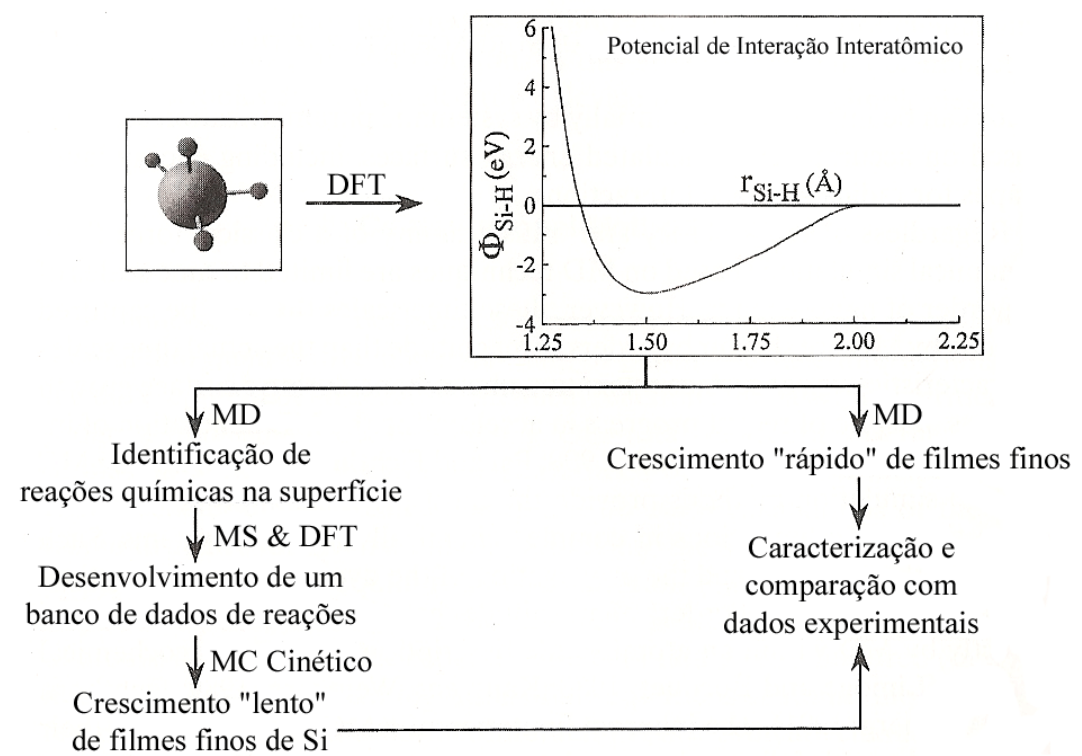

Figura I.1 - Abordagem hierárquica combinando diferentes métodos de modelagem molecular ao estudo de processos de deposição de filmes de silício através de técnicas de deposição por vapor químico com auxílio de plasma.

Com auxílio dessa abordagem, pode-se combinar as principais características dos métodos quânticos e clássicos e obter resultados com precisão quantitativa apreciável mas, particularmente, diversas informações qualitativas sobre o sistema. $\mathrm{O}$ autor comenta que, apesar de as taxas de reação obtidas através de MD serem várias ordens de magnitude mais rápidas que as taxas experimentais, os filmes MD e suas superfícies podem ser caracterizados e comparados com medidas experimentais, gerando resultados bastante satisfatórios.

A combinação de métodos de QM com $\mathrm{MD}, \mathrm{MC}, \mathrm{KMC}$ e $\mathrm{MS}$ é uma técninca comumente empregada em estudos de Engenharia Química, em particular em estudos termodinâmicos. De fato, Sandler et al. (2001) comentam sobre as diversas aplicações dessas técnicas em termodinâmica, como a obtenção de coeficientes de atividade de diluições infinitas e cálculos $a b$ initio para a predição de equilíbrios de fase.

É fato reconhecido que a modelagem molecular atingiu um nível de sofisticação e exatidão, tornando-se uma ferramenta essencial e altamente útil para os engenheiros químicos (CHAKRABORTY, 2001), ainda que seus métodos, capacidades e limitações não estejam bem difundidos e conhecidos pela comunidade de engenharia química. $\mathrm{O}$ uso da modelagem em escala molecular está tornando-se cada vez mais importante na indústria conforme os pesquisadores e desenvolvedores de produtos procuram maneiras de reduzir os custos e o 
tempo associado ao desenvolvimento de novos produtos, constituindo uma necessidade no currículo do pesquisador em engenharia química. 


\section{Capítulo I-2 \\ Os Processos Oxidativos AvanÇados}

"To purify, irradiate!"*

Em meio a acalorados debates e alarmantes publicações (GORE, 2006a; 2006b; IPCC, 2007), a comunidade tem voltado a atenção - como nunca antes - ao impacto que as atividades humanas exercem sobre o planeta. Segundo uma pesquisa realizada em 2006 pela revista norte-americana TIME em parceria com a Universidade de Stanford (TIME Magazine, 2006), mais da metade da população entrevistada acredita que o homem tem pelo menos parte da responsabilidade pelo fenômeno das mudanças climáticas. Uma outra pesquisa, em escala global, realizada pela GlobeScan International em parceria com o Programa de Atitudes de Regulação Internacionais (PIPA) da Universidade de Maryland sob encomenda da BBC (BBC News, 2007) demonstrou que 79\% dos entrevistados acreditam que a culpa das mudanças no clima é do homem, e que $90 \%$ exibem uma preocupação com a urgência de medidas. Grande parte dos entrevistados sugere que a culpa recai principalmente sobre a disposição extensiva de resíduos na Natureza, em particular as emissões de poluentes na atmosfera e o descarte de rejeitos industriais no sistema hídrico. Isso demonstra que grande parte da população vê a atividade industrial como a grande culpada pelas mudanças climáticas.

Independentemente de estarem ou não corretos, o fato é que a Química e a Engenharia Química ainda não conseguiram desvincular por completo o termo "químico" à idéia de poluição, e "indústria" ainda remete à imagem de uma chaminé despejando litros e litros de fumaça negra na atmosfera e líquidos de coloração forte e mau cheiro nos leitos d'água. Neste sentido, uma das missões dos profissionais da Química é desenvolver novas tecnologias que $i$ ) diminuam a geração de resíduos, ii) permitam um aproveitamento eficaz dos resíduos gerados, e/ou iii) gerem resíduos que sejam facilmente tratáveis ou ambientalmente seguros de serem dispensados no meio ambiente. Além disso, compete também a esses profissionais o desenvolvimento de técnicas para remediar leitos d'água, solos ou atmosfera que porventura sejam contaminados por poluentes dispostos de maneira inadequada, e para tratar efluentes industriais com via de torná-los seguramente dispensáveis na Natureza.

* Oppenländer, 2003, p. 3 
As principais técnicas em uso corrente de tratamento e remediação baseiam-se ou na tecnologia de transferência de fase, na qual os poluentes da fase de interesse (aquela que se deseja despoluir) são transferidos para uma outra fase, mediante um processo físico, como adsorção, absorção ou dessorção; ou em processos de separação simples, como decantação ou filtração. Entretanto, é fácil perceber que estes métodos físicos não eliminam o poluente, apenas transferem o problema de uma fase a outra. Alternativas comuns aos métodos físicos incluem o uso de espécies químicas oxidativas que promovam a oxidação do poluente em substâncias mais brandas ao meio ambiente, ou o uso de métodos biológicos. Neste sentido, têm-se desenvolvido novas tecnologias que sejam capazes de realizar a completa eliminação dos poluentes; em particular visando a melhor relação custo/benefício, ao buscar aliar técnicas que façam uso de reagentes mais baratos e menos agressivos ao meio ambiente, mas que ao mesmo tempo sejam eficazes na degradação dos substratos orgânicos. Dessa constante busca surgiram as chamadas Tecnologias Oxidativas Avançadas (TOAs), ou Processos Oxidativos Avançados (POAs), tópico deste capítulo.

\section{I-2.1 OXIDAÇÃO POR FOTÓLISE UV (FOTOOXIDAÇÃo)}

Os poluentes orgânicos podem ser degradados sem uso de reagentes químicos auxiliares, através da aplicação de radiação UV. A radiação interage com o substrato promovendo uma excitação eletrônica. A oxidação pode ocorrer por duas formas, $i$ ) transferência de elétron, do substrado orgânico excitado ao oxigênio molecular fundamental (Reação I-2.1a) com subsequente recombinação dos íons-radicais formados ou hidrólise do cátion-radical orgânico; ou ii) homólise do substrato (Reação I-2.1b) com posterior ataque dos radicais ao oxigênio molecular (Reação I-2.1c) (LEGRINI et al., 1993; MUKHERJEE, 1986).

$$
\begin{gathered}
\mathrm{R}_{1}-\mathrm{C}^{*}-\mathrm{R}_{2}+\mathrm{O}_{2} \longrightarrow \mathrm{R}_{1}-\mathrm{C}^{\bullet+}-\mathrm{R}_{2}+\mathrm{O}_{2}^{\bullet-} \\
\mathrm{R}-\mathrm{X} \stackrel{\mathrm{h} v}{\longrightarrow} \mathrm{R}^{\bullet}+\mathrm{X}^{\bullet} \\
\mathrm{R}^{\bullet}+\mathrm{O}_{2} \longrightarrow \mathrm{RO}_{2}
\end{gathered}
$$


A fotólise UV tem sido usada para eliminar aromáticos clorados e nitrados, fenóis, halogênios alifáticos, co-produtos de metalúrgicas, e de processadoras de aço e óleos, além de outros poluentes perigosos presentes em correntes aquosas (LEGRINI et al., 1993).

\section{I-2.2 OXIDANTES AUXILIARES}

Em alguns casos, a radiação por si só é incapaz de degradar o poluente com eficiência adequada e, nestes casos, faz-se uso de algum composto que auxilie o processo oxidativo. Esses compostos são denominados oxidantes auxiliares, pois usualmente são os precursores das espécies que protagonizam a oxidação.

A combinação dos oxidantes com radiação ultravioleta implica, na maioria dos casos, na geração (e subsequente consumo) de radicais hidroxila (LEGRINI et al., 1993), como exemplificado nas Reações I-2.2a para o peróxido de hidrogênio e I-2.2b para o ozônio:

$$
\begin{aligned}
& \mathrm{H}_{2} \mathrm{O}_{2} \stackrel{\mathrm{h} v}{\longrightarrow} 2 \mathrm{HO} \bullet \\
& 3 \mathrm{O}_{3} \stackrel{\mathrm{h} v}{\longrightarrow} 2 \mathrm{HO} \bullet
\end{aligned}
$$

O radical hidroxila é um agente oxidante de vida curta e extremamente reativo, capaz de oxidar compostos orgânicos por diversos mecanismos, como será exposto na Parte II-B deste texto. De fato, o potencial de redução do radical hidroxila $(2,80 \mathrm{~V})$ é próximo ao do flúor $(3,03$ V) (HAGER, 1990), colocando-o em lugar de destaque em meio aos oxidantes comumente empregados.

\section{I-2.2.1 Peróxido de Hidrogênio $\left(\mathrm{H}_{2} \mathrm{O}_{2}\right)$}

O peróxido de hidrogênio é um forte agente oxidante $\left(E^{0}=1,78 \mathrm{~V}\right)$, já aplicado no tratamento de águas no passado. Sua eficiência na degradação de componentes ou no tratamento de rejeitos industriais que demandam condições oxidativas mais sutis é conhecida (AYLING \& CASTRANTAS, 1981), mas sua aplicação em sistemas reais mais complexos é 
ainda alvo de pesquisas. Processos com peróxido de hidrogênio têm sido empregados no tratamento de efluentes industriais para detoxificação de cianetos, nitritos e hipocloritos; destruição de aromáticos fenólicos e formaldeído; e remoção de sulfitos, tiosulfatos e sulfetos (Gogate \& Pandit, 2004). Entretanto, sua eficiência na remoção de poluentes orgânicos depende de uma associação intermediária para gerar $\mathrm{OH}^{-}$e radicais $\mathrm{HO}_{2} \cdot$. Devido às lentas taxas de reação com orgânicos e a lenta taxa de auto-decomposição, o $\mathrm{H}_{2} \mathrm{O}_{2}$ por si só não é suficientemente eficaz para degradar compostos recalcitrantes (Kurniawan et al., 2006).

\section{I-2.2.2 Ozônio $\left(\mathrm{O}_{3}\right)$}

O ozônio é também um poderoso agente oxidante; mais poderoso, de fato, que o peróxido de hidrogênio, como pode ser observado pelo valor de seu potencial de redução, $E_{O}$ $=2,07 \mathrm{~V}$. O ozônio é capaz de reagir com a maioria das espécies contendo insaturações $(\mathrm{C}=$ $\mathrm{C}, \mathrm{C}=\mathrm{N}, \mathrm{N}=\mathrm{N}$, etc.), e com íons simples oxidáveis como o sulfeto, $\mathrm{S}^{2-}$, formando oxiânions, como $\mathrm{SO}_{3}{ }^{2-} \mathrm{e} \mathrm{SO}_{4}{ }^{2-}$ (Gogate \& Pandit, 2004). Contudo, vários compostos químicos, como alcanos clorados, reagem a taxas muito pequenas com o ozônio molecular, devido principalmente à ausência de um mecanismo adequado (Masten \& Davies, 1994; Gogate \& Pandit, 2004). Na Figura I-2, resumem-se as reações sofridas pelo ozônio em meio aquoso na presença de solutos $M$, que reagem diretamente com ozônio, ou interagem com os radicais hidroxila gerados a partir dele.

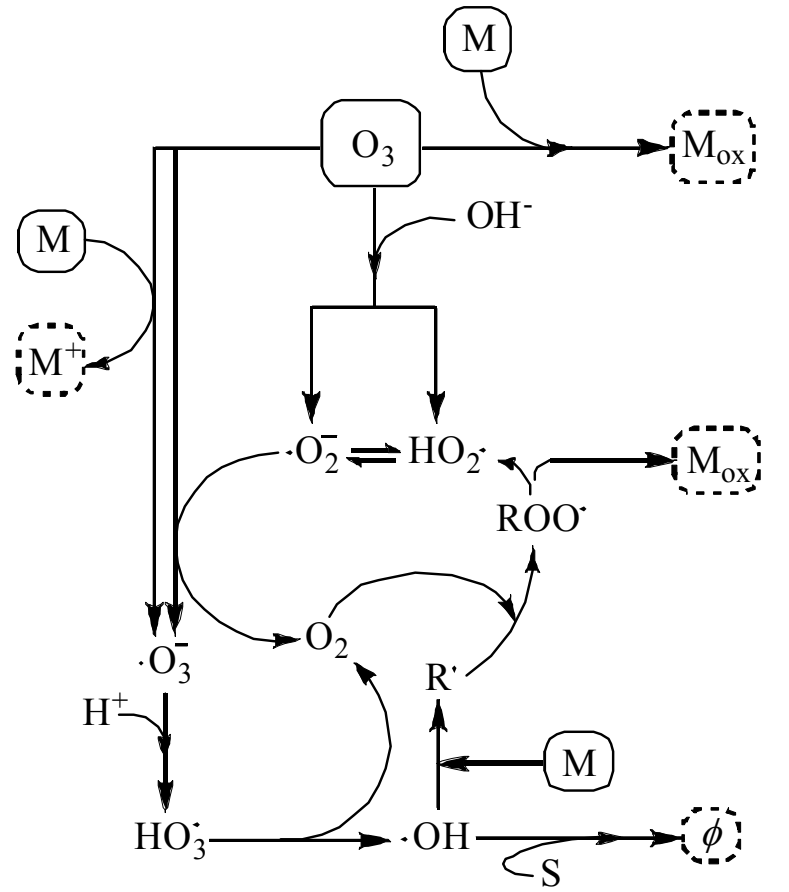

Figura I.2 - Reações do ozônio, $\mathrm{O}_{3}$, em meio aquoso na presença de um soluto orgânico reagente M. $S$ representa as espécies sequestradoras de radical, com as quais o radical hidroxila reage, gerando produtos indesejados $\phi$ (baseado em Peyton (1990), p. 329). 


\section{I-2.2.3 Reagente de Fenton}

O uso do reagente de Fenton é um dos meios mais eficazes para a geração de radicais hidroxila (ZAZO et al., 2007). O reagente de Fenton é uma combinação entre sais ferrosos e peróxido de hidrogênio. Na reação de Fenton, o peróxido é decomposto cataliticamente pelo íon ferroso $\left(\mathrm{Fe}^{2+}\right)$ em $\mathrm{pH}$ ácido, dando origem a radicais hidroxila. $\mathrm{O}$ íon férrico formado $\left(\mathrm{Fe}^{3+}\right)$ pode reagir com o peróxido em uma reação similar à reação de Fenton em pH ácido, regenerando o catalisador $\left(\mathrm{Fe}^{2+}\right)$ e mantendo assim o processo (ZAZO et al., 2005), esquematizado na Figura I.3:

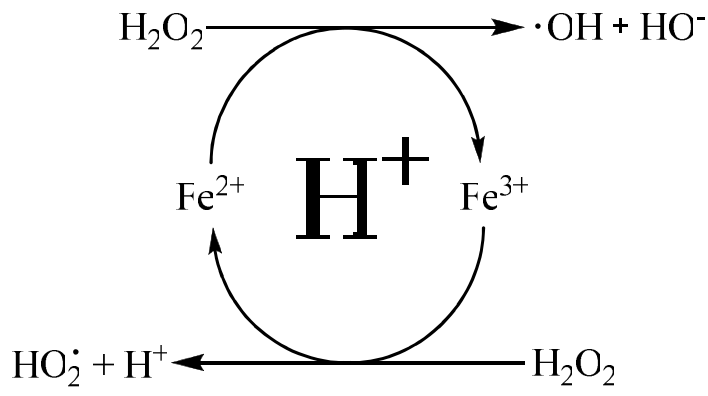

Figura I.3 - Esquema do processo de formação de radicais hidroxila e peroxila catalisado por íons de ferro (reações de Fenton).

Os radicais hidroxila produzidos pela reação de Fenton são a principal espécie que promove a oxidação do substrato orgânico, mas os íons de ferro também podem participar de reações redox com alguns intermediários, possibilitando novas vias de regeneração do íon ferroso a partir do férrico além da ilustrada na Figura I.3. De fato, segundo pesquisa realizada por Chen e Pignatello (1997), a reação de Fenton apresenta constante cinética de $76 \mathrm{M}^{-1} \mathrm{~s}^{-1}$, ao passo que para a reação do íon férrico com o peróxido de hidrogênio a constante é de $0,01 \mathrm{M}^{-1}$ $\mathrm{s}^{-1}$. Contudo a reação do mesmo íon com o ânion radical intermediário superóxido $\left(\cdot \mathrm{O}_{2}{ }^{-}\right)$, gerando oxigênio molecular e $\mathrm{Fe}^{2+}$, apresenta constante cinética de $1,5 \times 10^{8} \mathrm{M}^{-1} \mathrm{~s}^{-1}$.

A taxa de geração de radicais hidroxila é incrementada na presença de radiação ultravioleta, que promove algumas das reações sofridas pelos oxidantes auxiliares, a exemplo das Reações I-2.2a) e b). Devido a esse efeito, é senso comum usar a radiação UV em combinação com os oxidantes auxiliares para o tratamento de efluentes por Processos Oxidativos Avançados. 


\section{I-2.3 MÉTOdOS IRRADIADOS}

A radiação ultravioleta usada como promotora das reações pode ser oriunda tanto de irradiação natural (solar) quanto artificial (por lâmpadas), e a eficiência do processo irradiado relaciona-se intimamente às características da fonte e do reator utilizados, como distribuição espectral das fontes radiantes, geometria e material de construção do reator, disposição geométrica das fontes radiantes, volume de solução irradiado, entre outros; e, por isso, a correta seleção da fonte radiante e do reator fotoquímico são elementos essenciais para o sucesso do POA empregado.

\section{I-2.3.1 Combinações com UV}

$\mathrm{UV} / \mathrm{H}_{2} \mathrm{O}_{2}$

$\mathrm{O}$ processo $\mathrm{UV} / \mathrm{H}_{2} \mathrm{O}_{2}$ é baseado na geração de radicais hidroxila por meio da Reação I2.2a) e na subsequente oxidação do poluente promovida pelos radicais hidroxila gerados. A eficiência, em comparação com o processo sem assistência de radiação UV, é incrementada não apenas pela produção de radicais hidroxila como também pela interação direta do poluente com a radiação (KURNIAWAN et al., 2006). A Figura I.4 ilustra um esquema do processo $\mathrm{UV} / \mathrm{H}_{2} \mathrm{O}_{2}$.

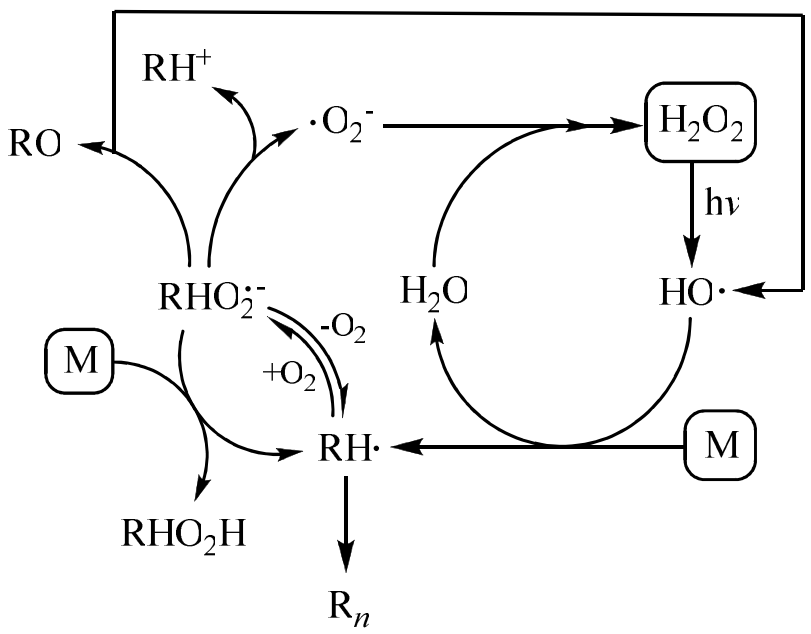

Figura I.4 - Sistema de reações para o processo $\mathrm{UV} / \mathrm{H}_{2} \mathrm{O}_{2}$. (baseado em Legrini et al. (1993), p. 675) 
Para a ocorrência da Reação I-2.2a), a solução é normalmente irradiada com radiação de $253,7 \mathrm{~nm}$, apresentando rendimento quântico em meio aquoso de $\Phi(+\bullet O H)=0,98$; i.e. geram-se 0,98 mol de radicais hidroxila para cada mol de fótons absorvidos nesse comprimento de onda (LEGRINI et al., 1993).

$\mathrm{UV} / \mathrm{Fe}^{2+} / \mathrm{H}_{2} \mathrm{O}_{2}$ (foto-Fenton)

O grande ponto do processo Fenton é sua capacidade em gerar radicais hidroxila através da decomposição catalítica do peróxido de hidrogênio promovida pelos íons ferrosos, como comentado anteriormente. E se essa geração de radicais pudesse ser incrementada? Combinando a decomposição catalítica do peróxido usando $\mathrm{Fe}^{2+}$ com a fotolítica promovida pela radiação UV, desenvolveu-se o processo chamado de foto-Fenton. Este processo oferece três grandes vantagens sobre o Fenton não-assistido (usualmente conhecido como dark Fenton): $i$ ) maior geração de radicais $\bullet \mathrm{OH}$ por decomposição fotolítica do $\mathrm{H}_{2} \mathrm{O}_{2}$; ii) maior capacidade de regeneração do $\mathrm{Fe}^{2+}$ através da introdução de oxalatos; e iii) maior capacidade de mineralização do substrato (o processo dark Fenton usualmente limita-se à formação dos ácidos orgânicos de cadeia curta, não atingindo a mineralização completa da carga orgânica) (PIGNATELLO et al., 2006; KURNIAWAN et al., 2007; KAVITHA \& PALANIVELU, 2005; ESPLUGAS et al., 2002). A Figura I.5 resume as principais reações envolvidas no processo foto-Fenton.

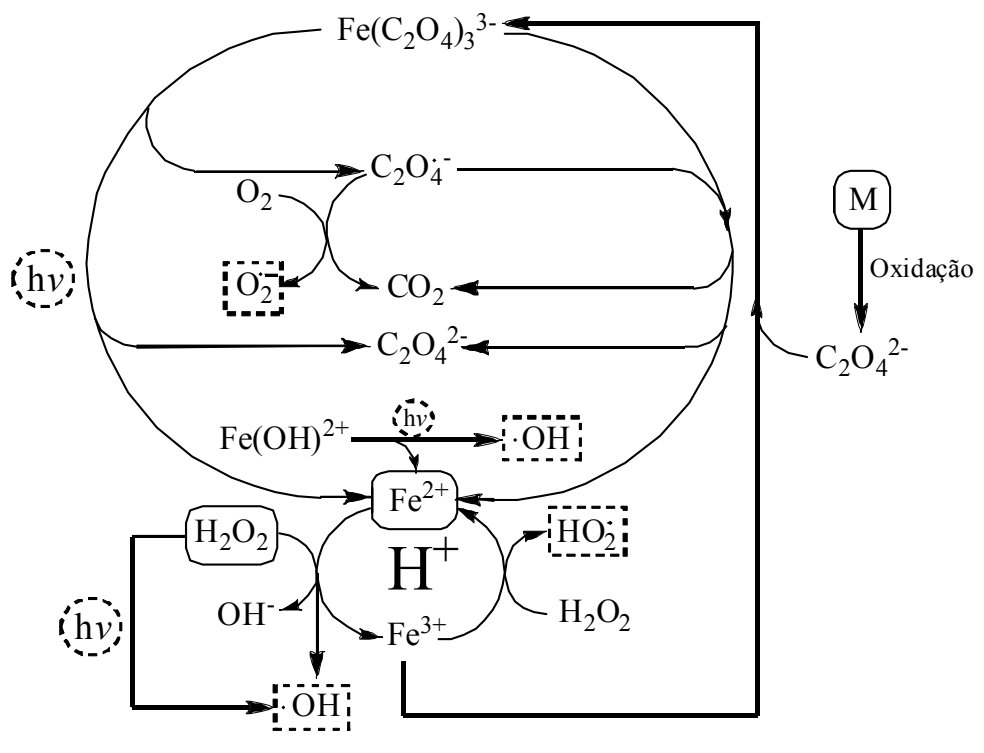

Figura I.5 - Esquema das principais reações envolvidas na geração dos radicais envolvidos na degradação dos substratos orgânicos pelo processo fotoFenton, a partir de $\mathrm{Fe}^{2+}, \mathrm{H}_{2} \mathrm{O}_{2}$, radiação UV e um substrato orgânico M (baseado na discussão de Kurniawan et al. (2007)). 
Como pode ser observado na Figura I.5, o processo foto-Fenton gera radicais hidroxila, peroxila e o ânion radical superóxido; espécies reativas de oxigênio que protagonizam a degradação oxidativa dos poluentes orgânicos. A degradação de poluentes orgânicos produz radicais oxalato no meio de reação (DEVLIN \& HARRIS, 1984); estes, por sua vez, podem combinar-se com íon férrico $\left(\mathrm{Fe}^{3+}\right)$, gerando o ânion ferrioxalato que, através dos mecanismos mostrados na Figura I-2.4, regenera o íon ferroso. O íon ferroso também é regenerado pela reação direta do $\mathrm{Fe}^{3+}$ com peróxido de hidrogênio, e pela decomposição fotolítica do íon $\mathrm{Fe}(\mathrm{OH})^{2+}$.

\section{Fotocatalítico Heterogêneo}

O POA conhecido como fotocatalítico heterogêneo emprega semicondutores em combinação com radiação UV para iniciar a geração de radicais · OH (KURNIAWAN et al., 2007). Os semicondutores são absorvedores primários de luz. São utilizados em fotocatálise por oferecerem uma combinação favorável entre estrutura eletrônica, propriedades de absorção, características de transporte de cargas e duração dos estados excitados. Quando uma superfície fotocatalítica é irradiada por radiação com energia igual ou superior à energia de band gap do material semicondutor, ela tem seus elétrons excitados da banda de valência à banda de condução, resultando na formação de um buraco positivo $\left(\mathrm{h}^{+}\right)$com energia na banda de valência e de um elétron na banda de condução (e`) (OPPENLÄNDER, 2003), como mostrado para o $\mathrm{TiO}_{2}$ (cuja energia de band gap é 3,03 eV) na Reação I-2.3:

$$
\mathrm{TiO}_{2} \stackrel{h v}{\longrightarrow} e^{-}+h^{+}
$$

Na superfície da partícula de $\mathrm{TiO}_{2}$, essas espécies podem reagir com espécies adsorvidas, como ilustrado na Figura I.6.

Entre os diversos semicondutores, há um consenso geral entre os pesquisadores de que o $\mathrm{TiO}_{2}$ é superior, devido a sua atividade, elevada estabilidade à irradiação, baixo custo e atoxicidade (OPPENLÄNDER, 2003). Okomoto et al. (apud Oppenländer (2003)) observaram maior atividade fotocatalítica do $\mathrm{TiO}_{2}$ em comparação ao $\mathrm{CdS}$ para a decomposição do fenol, e Sakthivel et al. (apud Oppenländer, (2003)) mostraram que, sob condições similares, o $\mathrm{TiO}_{2}$ apresentou melhor eficiência fotocatalítica do que $\alpha-\mathrm{Fe}_{2} \mathrm{O}_{3}, \mathrm{ZrO}_{2}$, $\mathrm{CdS}, \mathrm{WO}_{3}$ e $\mathrm{SnO}_{2}$. O $\mathrm{ZnO}$ apresentou melhor desempenho, mas apesar disso - conforme 
ressaltado por Augugliaro et al. (apud Oppenländer (2003)) -, o $\mathrm{TiO}_{2}$ apresenta maior estabilidade fotoquímica em meio aquoso.

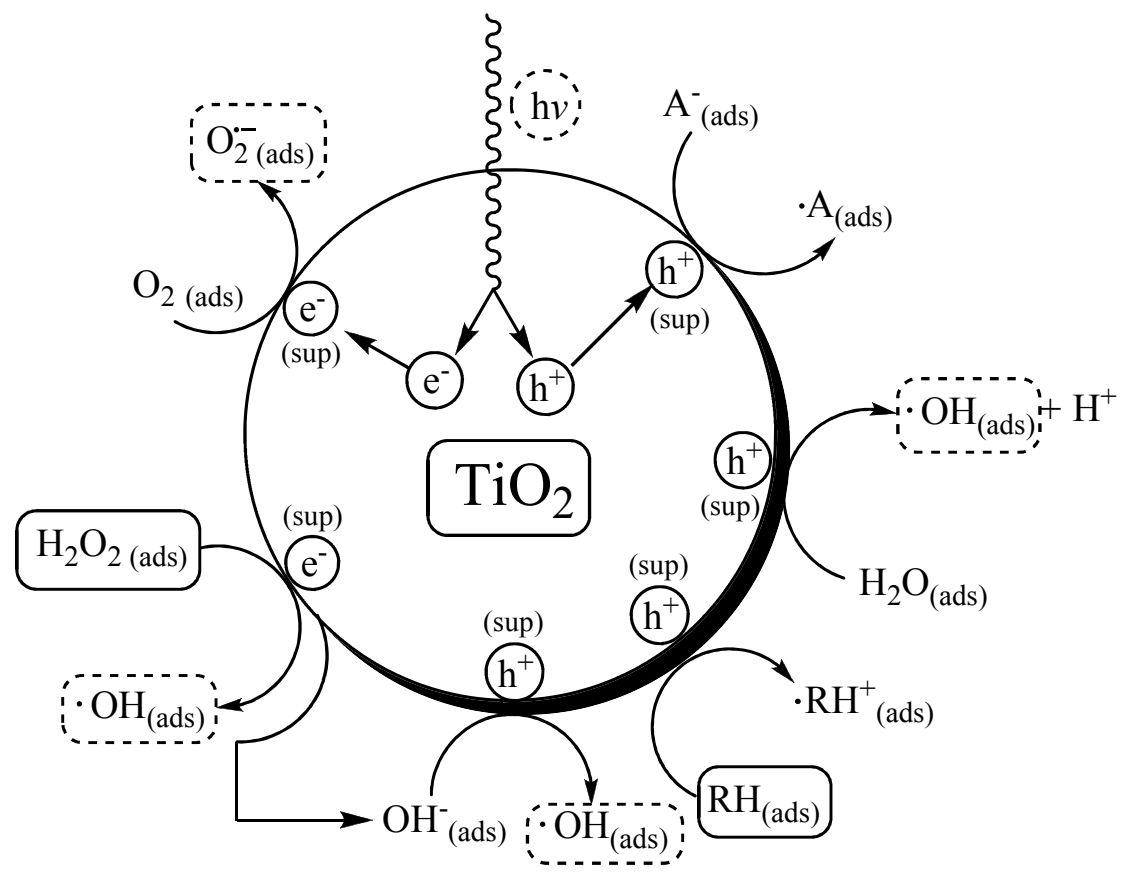

Figura I.6 - Esquema das reações envolvidas na formação de espécies reativas e na oxidação direta do substrato orgânico pelo processo fotocatalítico com semicondutor (baseado nas discussões de Legrini et al. (1993), Kurniawan et al. (2006) e Matthews (1986))

O cátion-radical orgânico formado pela reação direta do poluente RH adsorvido com um buraco $\mathrm{h}^{+}$pode prosseguir reagindo com a água em redor, oxigênio e as demais espécies reativas de oxigênio e ser degradada. Os radicais gerados, entretanto, correspondem à maior contribuição para a degradação do poluente (LEGRINI et al., 1993).

\section{$\mathrm{O}_{3} / \mathrm{UV}$ (ozonação fotolítica)}

A ozonação por si só não é capaz de transformar compostos recalcitrantes em $\mathrm{CO}_{2} \mathrm{e}$ $\mathrm{H}_{2} \mathrm{O}$, e alguns dos compostos intermediários restantes podem inclusive ser mais tóxicos do que os iniciais (KURNIAWAN et al., 2006). Para complementar a oxidação pelo ozônio, pode-se fazer uso de radiação UV. Neste processo combinado, a irradiação UV não apenas ativa as moléculas de ozônio pela absorção de radiação em $254 \mathrm{~nm}$, mas também torna outras moléculas orgânicas susceptíveis à oxidação. 


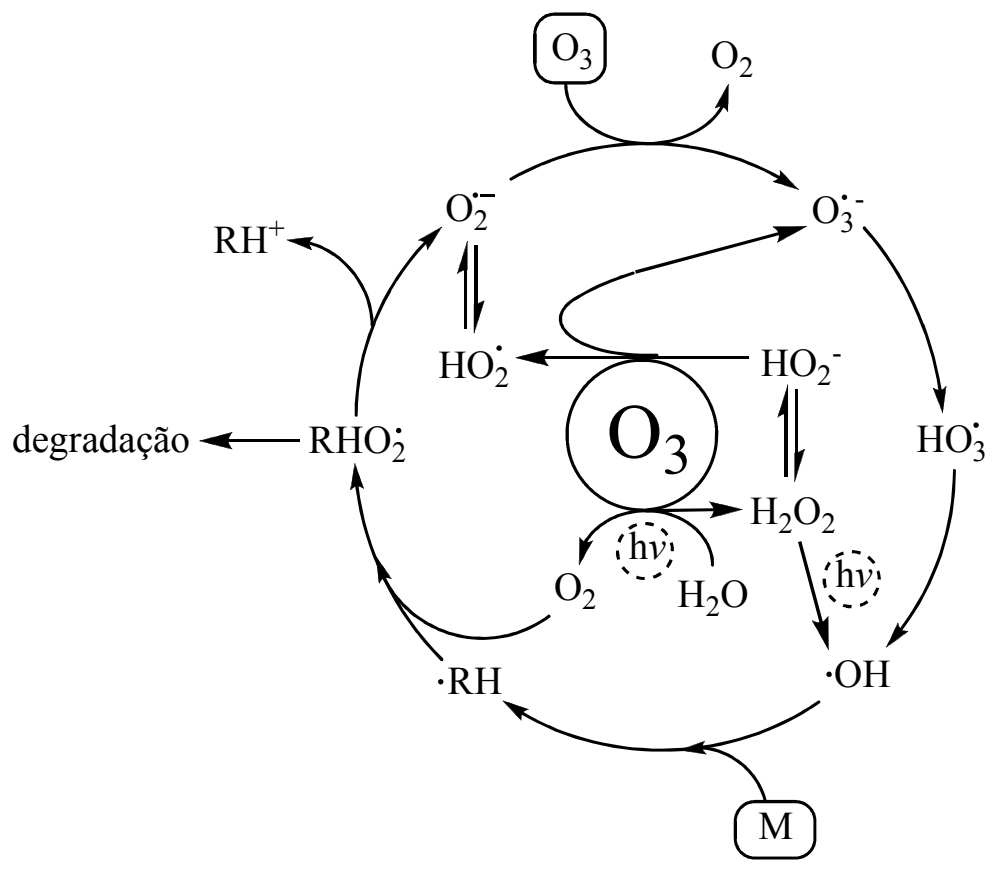

Figura I.7 - Esquema das reações envolvidas no processo $\mathrm{O}_{3} / \mathrm{UV}$ (baseado em Legrini et al. (1993) e Peyton (1990)).

Além dos processos apresentados, é comum a combinação $\mathrm{UV} / \mathrm{H}_{2} \mathrm{O}_{2} / \mathrm{O}_{3}$ (INCE, 1998), $\mathrm{TiO}_{2} / \mathrm{O}_{3}$ (GILBERT, 2002), visando sempre a maximização da geração de radicais hidroxila e o consequente aperfeiçoamento do processo, aumentando-se a velocidade de degradação, o teor de mineralização e/ou a remoção total do poluente recalcitrante.

Uma das principais características dos POAs, como esperou-se ressaltar nesta breve revisão, é a geração de espécies reativas de oxigênio (radicais hidroxila, peroxila, ânionradical superóxido, entre outros) que, por sua vez, estão envolvidos diretamente na degradação dos poluentes orgânicos. A tecnologia dos POAs é consideravelmente recente e permite um grando avanço no tratamento de correntes aquosas e gasosas, na medida em que permite a destruição de compostos recalcitrantes, e promove a mineralização completa dos poluentes, algo dificilmente conseguido por outros métodos de tratamento usuais. 


\section{I-2.4 Principais CRitérios de Projeto de Processos Oxidativos AvanÇados}

A eficiência de um POA é bastante influenciada pela qualidade do meio, por parâmetros de engenharia diversos e, indiretamente, pela estratégia analítica empregada (definição dos objetivos e metodologias analíticas de acompanhamento). O projeto de um POA fotoquímico é um desafio ainda maior. Oppenländer (2003) cita algumas exigências que devem ser cumpridas:

- A excitação específica do oxidante auxiliar ou fotocatalisador deve ser obtida;

- Deve-se garantir a absorbância total de radiação eletromagnética, para evitar perda desnecessária de energia radiante, por exemplo por absorção pelas paredes do reator;

- Perdas de radiação por reflexão e espalhamento devem ser minimizadas;

- Deve-se considerar as heterogeneidades das reações fotoquímicas no volume do reator. A reflexão de radiação UV pelas paredes do reator pode ser vantajosa, já que permite taxa de incidência de fótons mais uniforme, e diminui a susceptibilidade do reator à ineficiência na mistura;

- A condição saturada de oxigênio na fase aquosa é necessária na maioria dos casos;

- Deve existir convergência entre a lâmpada e a geometria do reator, e a separação espacial entre a lâmpada e a mistura reagente constitui um parâmetro importante;

- É necessária uma descrição precisa da distribuição da radiação no volume do reator (perfis de fluxo fotônico e taxa de incidência de fótons), considerando a heterogeneidade do processo fotoquímico.

Para um projeto adequado de um processo químico, é necessário que se conheça também a cinética do processo. De fato, Edalatmanesh (2008) comenta que a modelagem cinética de um POA é uma ferramenta útil para o estudo das variáveis de processo e, portanto, da otimização do sistema e determinação dos melhores parâmetros para o projeto do processo. A modelagem cinética de um processo químico depende de um conjunto de dados acerca do mecanismo, normalmente tomados da literatura, oriundos de ensaios experimentais. Há que se notar, entretanto, que a maioria das expressões empíricas obtidas para a cinética dos processos são interpolação de dados, muitas vezes desconsiderando a complexidade das reações químicas e fotoquímicas por trás do processo. Ademais, as constantes de velocidades obtidas 
por esses métodos são específicas àquela condição experimental em particular (EDALATMANESH, 2008), daí a necessidade de uma descrição mais precisa dos sistemas estudados, levando em consideração os aspectos químicos e fotoquímicos envolvidos. 


\section{Capítulo I-3 \\ OBJETIVOS E JUSTIFICATIVA}

Os objetivos deste trabalho podem ser resumidos em:

- Ilustrar a aplicação de técnicas de Modelagem Molecular a problemas de Engenharia Química;

- Estudar os intermediários propostos para a degradação oxidativa do fenol através de primeiros princípios;

- Avaliar, através de primeiros princípios, as cinéticas das reações intermediárias de degradação oxidativa do fenol em fase gasosa e em fase aquosa;

- Discutir a validade de modelos obtidos a partir da comparação com dados experimentais.

Seguindo essa tendência, o Centro de Engenharia de Sistemas Químicos do Departamento de Engenharia Química da Escola Politécnica da Universidade de São Paulo (CESQ/DEQ-EPUSP) vem incluindo estudos teóricos em seus trabalhos, como observado, por exemplo, no trabalho de pós-doutorado do Prof. Dr. Antonio Carlos Teixeira (TEIXEIRA, 2005), em trabalhos de iniciação científica (PINTO et al., 2007; MENDES et al., 2003), na dissertação de mestrado de Henrique Queiroga (QUEIROGA, 2004), na tese de doutoramento de Jeanne Giroto (GIROTO, 2007), e no trabalho de estágio do aluno Laurent Draperi (DRAPERI, 2007).

Ademais, o grupo vem realizando um intenso trabalho experimental utilizando o fenol como poluente modelo. Dessa forma, dispõe-se de uma importante coleção de dados experimentais disponíveis para comparação com resultados teóricos, que têm também o objetivo de prover o grupo com mais informações para auxiliar nas inferências químicas sugeridas pelas observações experimentais. 


\section{Título II}

FUNDAMENTAÇÃo TEÓRICA

Parte A: Modelagem Molecular 


\section{Capítulo II-A1}

\section{INTRODUÇão À MODElaGem MoleCUlar}

"Agora não há nada novo por ser descoberto em física. Tudo o que resta são medidas cada vez mais precisas (...) e duas pequenas nuvens no horizonte. ",

(Lorde Kelvin, 1900)

Desde os primórdios da humanidade o homem vem tentando entender o que se passa ao seu redor, observando o meio e a partir de suas observações fazendo inferências futuras, tanto qualitativas como quantitativas. Mas somente a partir do século XVII os fenômenos da natureza começaram a ser entendidos com maior rigor, a partir dos trabalhos de Galileu Galilei (que sistematizou as análises dos fenômenos naturais através da experimentação) e de Isaac Newton, que construiu as bases da mecânica clássica e todo um aparato matemático para a análise desta. A partir de então, as ciências exatas - em especial a Física - atingiram um desenvolvimento assustador nunca antes visto pela humanidade, com contribuições posteriores como as de Joseph Lagrange, Simon Laplace, Lord Kelvin, James Maxwell entre outros.

A Modelagem Molecular (ou Química Computacional) tem suas origens na curiosidade humana em compreender a constituição última da matéria que nos cerca, força-motriz dos estudos realizados em física atômica e físico-química. A química computacional pode ser entendida como a aplicação desses estudos através do uso de computadores (JENSEN, 2007). Apenas com o advento da tecnologia da informação e a capacidade de processamento de um grande número de informações e execução de trabalhosos cálculos é que foi possível o uso e o aperfeiçoamento das teorias então estabelecidas a respeito do comportamento da matéria a nível molecular.

Tradicionalmente, as moléculas são pensadas como sendo "compostas" por átomos ou, de modo mais geral, como uma coleção de partículas carregadas: núcleos positivos e elétrons negativos. A única força importante para os fenômenos químicos é a interação Coulômbica entre essas partículas carregadas (CRAMER, 2004). As moléculas diferem entre si por conterem núcleos e números de elétrons diferentes, ou os centros nucleares podem estar em

\footnotetext{
5 Estas "nuvens" seriam os resultados negativos dos experimentos de Michelson-Morley e a não explicação das propriedades radiantes do "corpo negro". Ele nem imaginaria que estes dois problemas, chamados por ele de pequenas nuvens em um céu azul, viriam a modificar radicalmente as bases da ciências naturais, como uma tempestade avassaladora: o primeiro problema iria levar a Teoria da Relatividade proposta por Albert Einstein em 1905 e concluída em 1915, e o segundo ao desenvolvimento da Mecânica Quântica, cujas principais bases encontram-se nos trabalhos de Erwin Schrödinger e de Max Born, da década de 1920. (PIZA, 2005)
} 
diferentes posições geométricas. Dado um conjunto de núcleos e elétrons, a modelagem molecular intenciona calcular parâmetros como (JENSEN, 2007):

- Os arranjos geométricos dos núcleos que correspondem a estruturas estáveis;

- Suas energias relativas;

- Suas propriedades (momento de dipolo, polarizabilidade etc.);

- A taxa à qual uma molécula estável pode se transformar em outra;

- A dependência temporal das estruturas e propriedades moleculares.

A Modelagem Molecular tem seu foco na obtenção de resultados relevantes aos problemas químicos sem a necessidade da realização de experimentação (i.e. com base unicamente nas teorias vigentes) e no desenvolvimento de novos métodos teóricos, capazes de representar os sistemas químicos com apreciável exatidão e com custo computacional compatível com os recursos atualmente disponíveis no mercado da tecnologia da informação. Os métodos teóricos, por sua vez, podem ser dividos em três grandes grupos: métodos de mecânica molecular, métodos eletrônicos ou de mecânica quântica ou ab-initio (de primeiros princípios), e os métodos da Teoria do Funcional da Densidade (DFT); cada qual com suas vantagens e desvantagens, adequando-se melhor a uma ou outra situação em particular. Nos capítulos a seguir, serão expostos alguns dos fundamentos sobre os quais constróem-se os principais métodos teóricos, com particular ênfase na DFT, abordagem empregada neste trabalho.

\section{II-A1.1 Métodos de Modelagem MoleculaR}

De acordo com os objetivos com se aplica a modelagem molecular, faz-se a seleção de um dentre os diversos métodos de cálculo existentes. Esta seleção depende do sistema escolhido para trabalhar. Para a descrição completa de um sistema, necessitam-se quatro características fundamentais (YOUNG, 2001):

- A descrição do sistema - Quais são as unidades fundamentais ou "partículas" e quantas são?

- As condições iniciais - Onde estão as partículas e quais suas velocidades?

- As interações - Qual a forma matemática das forças que agem entre as partículas? 
- Equação dinâmica - Qual a forma matemática para a evolução do sistema de acordo com o tempo?

A consideração dessas características em conjunto com o objetivo em mente é o que determina a escolha do método. Por exemplo, se forem escolhidos os núcleos atômicos e os elétrons como as unidades fundamentais, podem-se descrever átomos e moléculas - mas não a estrutura interna do núcleo atômico. Escolhendo-se os átomos como as unidades fundamentais, podem-se descrever as estruturas moleculares, mas não os detalhes da distribuição eletrônica. Escolhendo-se amino-ácidos como unidades fundamentais, pode-se descrever a estrutura global de uma proteína, mas não os detalhes dos movimentos atômicos, e assim por diante. A escolha das unidades fundamentais, ou partículas, limita o que se deseja descrever, mas facilita a descrição do sistema. Se o pesquisador estivesse interessado, por exemplo, na estrutura da proteína, não haveria razão em escolher os átomos como unidades fundamentais: seria um desperdício de recursos computacionais.

A escolha das condições iniciais determina aquilo que se tenta descrever. O espaço fásico (phase space) - i.e. todos os valores possíveis de posição e velocidades para todas as partículas - é enorme, e só é possível descrever uma pequena parte. A escolha das condições iniciais determina qual parte do espaço fásico é amostrada. Por exemplo, qual isômero de uma determinada estrutura deseja-se descrever.

A interação entre as unidades fundamentais, em combinação com a equação dinâmica, determina como o sistema evolui com o tempo. No nível atômico, a única força importante é a interação eletromagnética. Dependendo da escolha das unidades fundamentais contudo, podese ter diferentes forças efetivas agindo sobre o sistema. Nos métodos dos campos de força (force fields), as interações são parametrizadas como interações de distorção, de dobra, torsionais, de van der Waals etc.

A equação dinâmica descreve a evolução temporal do sistema. É dada como uma equação diferencial envolvendo derivadas tanto em relação ao tempo quanto ao espaço, e sua forma exata depende das massas e velocidades das partículas. Resolvendo-se a equação dinâmica, pode-se prever a posição e a velocidade das partículas em momentos posteriores (ou anteriores) às condições iniciais; ou seja, prevê-se como o sistema evolui no espaço fásico. A equação dinâmica, segundo Jensen (2007), pode ser dividida em quatro regimes, como mostrado na Figura II.1: 


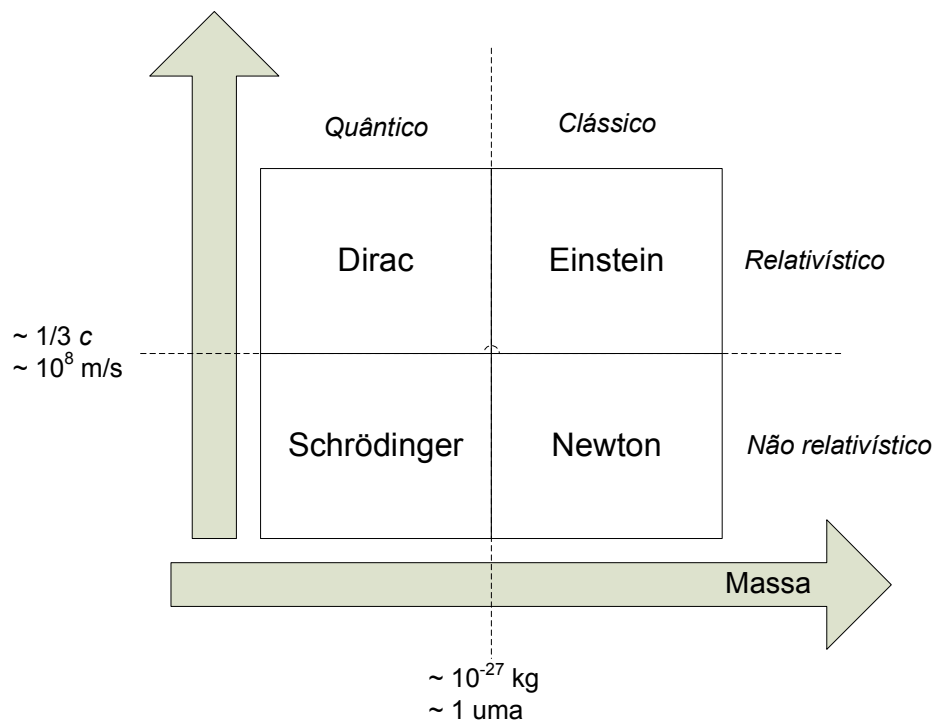

Figura II.1 - Domínios das equações dinâmicas.

A mecânica Newtoniana, exemplificada pela Segunda Lei de Newton $(\mathbf{F}=m \mathbf{a})$, aplica-se a partículas "pesadas" e "lentas". Os efeitos relativísticos tornam-se importantes quando a velocidade é comparável à velocidade da luz, causando um aumento na massa $m$ da partícula, em relação à sua massa de repouso. Partículas leves apresentam características tanto de ondas quanto de partículas, e devem ser descritas pela mecânica quântica, sendo a fronteira definida como aproximadamente a massa do próton. Os elétrons são muito mais leves e só podem ser descritos pela mecânica quântica, enquanto átomos e moléculas (com algumas exceções) comportam-se essencialmente como partículas clássicas.

Neste ponto pode-se traçar uma primeira divisão entre os métodos de modelagem molecular. Os que levam em consideração os efeitos eletrônicos (e, portanto, fazem uso da mecânica quântica), conhecidos como métodos de estrutura eletrônica, e os métodos que ignoram os movimentos eletrônicos, fazendo uso da mecânica clássica de Newton: os métodos de mecânica molecular ou métodos de campo de força.

Os métodos de estrutura eletrônica se baseiam fundamentalmente na resolução (ou na sua tentativa) da Equação de Schrödinger (discutida mais adiante no Capítulo II-A2.6). De acordo com a teoria utilizada para chegar a uma resolução, podem-se agrupar os métodos de estrutura eletrônica em duas classes: os métodos da teoria do orbital molecular, aqueles que baseiamse na mecânica ondulatória e nos métodos iniciais desenvolvidos para abordar o problema da resolução da Equação de Schrödinger, propostos por Hartree em 1927; e os métodos da teoria 
do funcional da densidade (DFT), que utilizam a densidade eletrônica em vez da complexa função de onda da mecânica ondulatória e que têm raízes também em 1927 com os trabalhos dos físicos Thomas e Fermi. Os princípios da mecânica quântica e a teoria do funcional da densidade serão apresentadas e discutidas em maiores detalhes nos Capítulos II-A2 e II-A3 respectivamente.

Dentro dos métodos baseados na teoria do orbital molecular, podem-se agrupar duas classes de métodos: os métodos que envolvem modelos de partículas independentes, i.e. em que as interações entre as partículas não são modeladas explicitamente, apenas aproximadas; e os chamados métodos de correlação eletrônica, que consideram explicitamente as interações intereletrônicas.

No conjunto dos métodos que envolvem modelos de partículas independentes, se podem distinguir duas classes de métodos: os ab initio, ou de primeiros princípios (classificação que se aplica a todos os métodos que não têm parâmetros experimentais envolvidos em sua formulação), e os métodos que fazem uso de aproximações oriundas de dados experimentais, os chamados métodos semi-empíricos. As diferenças entre os diversos métodos semiempíricos é devida à natureza da aproximação feita ao modelo de Hartree-Fock (HF) (i.e. quais tipos de integrais são descartadas e/ou como elas são tratadas, ou que tipo de dados experimentais são utilizados para a parametrização, como detalhado posteriormente).

Os métodos de correlação eletrônica, também conhecidos como métodos ab-initio pósHF, são divididos em diferentes classes de acordo com o método como abordam a correlação eletrônica: interação de configurações (CI) (configuration interaction), campo autoconsistente multi-configuracional (MCSCF) (multi-configuration self-consistent field), interação de configurações multi-referencial (MRCI) (multi-reference configuration interaction), cluster acoplado (CC) (coupled cluster), teoria da perturbação de vários corpos (MPn) (multi-body perturbation theory, ou Møller-Plesset perturbation theory), Monte Carlo quântico (QMC) (Quantum Monte Carlo).

A Figura II-2 ilustra a árvore de ramificações dos métodos de modelagem molecular. 


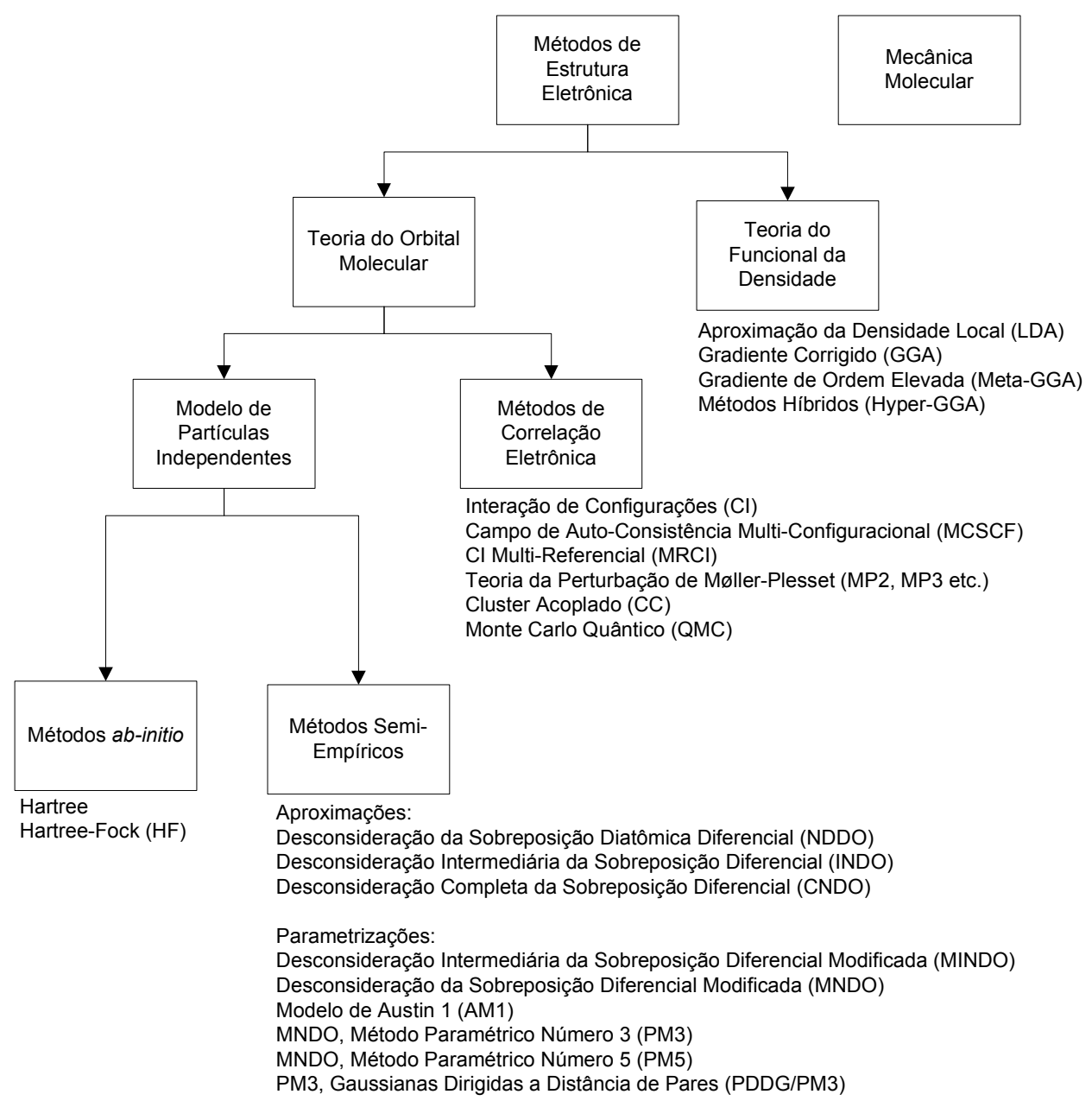

Figura II.2 - Fluxograma citando os métodos de Modelagem Molecular.

\section{II-A1.2 SimulaÇÃo MolecUlaR}

Normalmente, um cálculo de modelagem molecular começa com a determinação da estrutura mais estável para uma molécula em particular; ou seja, uma matriz de posições nucleares fixas para as quais a estrutura apresente uma menor energia. Esse arranjo de núcleos representa um ponto mínimo local no espaço de fase. Corresponde a modelar o sistema à temperatura de $0 \mathrm{~K}$, em que todas as moléculas estão em seus estados eletrônicos, vibracionais e rotacionais fundamentais. Os efeitos de uma outra temperatura finita qualquer podem ser incorporados aos resultados através da Mecânica Estatística. A Mecânica Estatística provê, em teoria, um meio para determinar propriedades físicas não de uma molécula apenas, mas de uma amostra macroscópica, o bulk. Isso é possível conhecendo-se as 
propriedades de várias moléculas em várias conformações, estados energéticos etc. $\mathrm{Na}$ prática, é muito complicado conseguir reunir todas essas informações. A Dinâmica Molecular e as Simulações de Monte Carlo são dois métodos existentes para obter essas informações. Nesse contexto, simulação refere-se a métodos que objetivam gerar uma amostragem representativa de um sistema a uma temperatura finita. 


\section{Capítulo II-A2 \\ Fundamentos da Mecânica QuÂnTICA}

\section{II-A2.1 UMA BREVE INTRODUÇão: A ALVORADA DA TEORIA QUÂNTICA}

"How does it feel to be the only other person to know the true nature of starlight? $", 6$

Ao fim do século XIX, muitos cientistas acreditavam que todas as descobertas fundamentais na ciência já haviam sido feitas e pouco restava, senão esclarecer alguns pequenos problemas e aperfeiçoar os métodos experimentais para medir resultados físicos com um maior número de casas decimais. Tal atitude era justificável pelo grande número de avanços feitos até então. Os químicos haviam finalmente solucionado o aparentemente insuperável problema de designar um conjunto auto-consistente de massas atômicas aos elementos. O conceito de Stanislao Cannizzaro de molécula (inicialmente controverso) passou então a ser amplamente aceito. O grande trabalho do químico russo Dmitri Mendeleev resultou em uma tabela periódica dos elementos, apesar de ainda não se conhecer bem as razões de tais periodicidades ocorrerem na Natureza. Friedrich Kekulé havia resolvido a grande controvérsia a respeito da estrutura do benzeno. Os fundamentos das reações químicas haviam sido elucidados por Svante Arrhenius, e o trabalho restante parecia consistir, basicamente, em catalogar os vários tipos de reações químicas.

No campo da Física, a mecânica Newtoniana havia sido extendida pelo Conde Joseph Lagrange e por Sir William Hamilton. A teoria resultande era aplicada ao movimento planetário e podia também explicar outros fenômenos naturais complicados, como a elasticidade e a hidrodinâmica. O Conde Rumford e o físico inglês James Joule demostraram a equivalência entre trabalho e calor, e as investigações do engenheiro francês Sadi Carnot resultaram na formulação do que hoje é a Entropia e da Segunda Lei da Termodinâmica. Esse trabalho foi seguido pelo completo desenvolvimento de Josiah Gibbs do campo da Termodinâmica. Rapidamente, os cientistas viriam a descobrir que as leis da Física também eram relevantes à compreensão dos sistemas químicos. Os campos da Óptica e do Eletromagnetismo sofriam maturação similar. O século XIX tertemunhou uma contínua

\footnotetext{
${ }^{6}$ James Clark Maxwell. Maxwell descobrira, no começo do século XX, a natureza da radiação luminosa. Descobrira que a luz é uma radiação eletromagnética. Diz a História que, no dia de sua célebre conclusão, enquanto cortejava a moça que viria a ser sua esposa, caminhando à tardezinha por um jardim e observando as estrelas, teria contado a ela sobre sua descoberta e indagado a questão citada. (COBB \& GOLDWHITE, 1995)
} 
controvérsia sobre se a luz seria ondulatória ou corpuscular. Várias observações diversas e importantes foram unificada pelo físico escocês James Clark Maxwell em uma série de equações aparentemente simples que levam seu nome. As predições de Maxwell acerca do comportamento eletromagnético da luz não apenas serviram para unificar os campos da Óptica, Eletricidade e Magnetismo, mas sua subsequente demonstração experimental por Heinrich Hertz in 1887 viria a demonstrar que a luz apresenta natureza ondulatória.

O corpo dessas conquistas na Física é considerado o desenvolvimento do que hoje é conhecido como Física Clássica. Os cientistas pouco imaginavam que, em face dessa era de sucessos, os pilares fundamentais do funcionamento do mundo físico seriam reconstruídos em breve. Descobertas fantásticas viriam revolucionar não apenas a Física, a Química, a Biologia e a Engenharia; mas também teriam efeitos significativos na tecnologia e na política. $O$ começo do século XX viu o nascimento da Teoria da Relatividade e da Mecânica Quântica. A primeira, devida unicamente aos trabalhos de Albert Einstein, alterou completamente a visão de tempo e espaço dos cientistas, e era uma extensão das ideias clássicas, incluindo altas velocidades e distâncias astronômicas. A Mecânica Quântica, extensão das ideias clássicas ao comportamento de espécies subatômicas, atômicas e moleculares, por sua vez, resultou dos esforços de muitos cientistas criativos ao longo de décadas. Até então, o efeito da Relatividade em sistemas químicos tinha sido limitado. Apesar de ser importante na compreensão das propriedades eletrônicas dos átomos pesados, não desempenha um papel muito importante na estrutura molecular e na reatividade. A Mecânica Quântica, entretanto, forma a fundação sobre a qual toda a Química é construída. Toda a compreensão atual da estrutura atômica e das ligações moleculares é descrita em termos dos princípios fundamentais da Mecânica Quântica, e não é possível um entendimento dos sistemas químicos sem o conhecimento dos princípios básicos dessa teoria da matéria. Por isso, ao longo deste capítulo, que possivelmente será o mais longo dos capítulos teóricos, serão abordados alguns conceitos e apresentadas algumas equações fundamentais para a compreensão da constituição das moléculas e dos sistemas químicos modelados e estudados neste trabalho. 


\section{II-A2.2 A CATÁSTROFE DO ULTRAVIOLETA E O NASCIMENTO DO QUANTUM}

Um dos problemas que despontavam na Física, como uma nuvem num céu de brigadeiro (analogia, aliás, utilizada por Lorde Kelvin em uma conferência em 1900), era a aparente falha do modelo clássico ao explicar a emissão de energia pelo corpo ideal conhecido como 'corpo negro'. O corpo negro é um objeto ideal, que absorve e emite energia em todas as frequências. A radiação emitada por um corpo negro é denomidada 'radiação do corpo negro'.

De acordo com as leis físicas do século XIX, a densidade de energia radiante entre um intervalo de frequências $v+\mathrm{d} v$ é dada por:

$$
\rho_{v}(\mathrm{~T}) \mathrm{d} v=\left(\frac{8 \pi \mathrm{k}_{\mathrm{B}}}{\mathrm{c}^{3}}\right) \mathrm{T} v^{2} \mathrm{~d} v
$$

em que $\rho_{v}(\mathrm{~T}) \mathrm{d} v$ é a densidade de energia radiante entre as frequências $v+\mathrm{d} v$ e tem unidades de $\mathrm{J} \cdot \mathrm{m}^{-3}$; T é a temperatura absoluta $(\mathrm{K})$, e c é a velocidade da luz. $\mathrm{k}_{\mathrm{B}}$ é a constante de Boltzmann, em unidades $\mathrm{J} \cdot \mathrm{K}^{-1} \cdot$ partícula $^{-1}$. A equação II.1 originou-se dos trabalhos de Lord Rayleigh e J. H. Jeans, e é conhecida como Lei de Rayleigh-Jeans. Entretanto, como pode ser observado pela Figura II.3, o modelo é completamente inexato ao explicar o fenômeno a que se propõe:

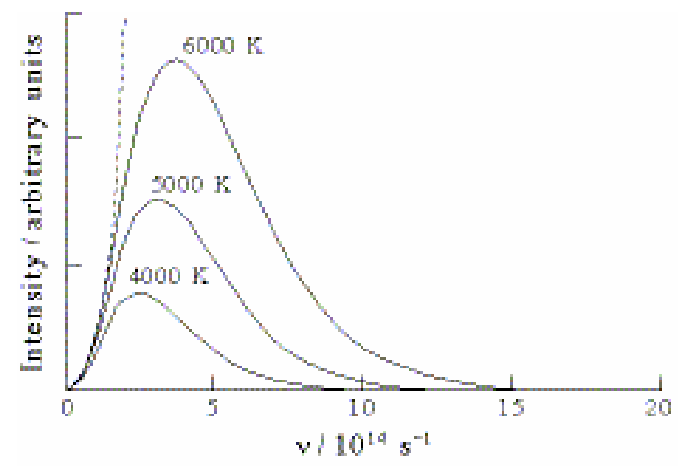

Figura II.3 - Gráfico ilustrando a intensidade da emissão do corpo negro por frequência em diferentes temperaturas. A linha pontilhada refere-se à predição de acordo com a Mecânica Clássica (Equação II-A2.1).

A equação é válida para explicar o comportamento da emissão em baixas frequências, mas prevê que a densidade de energia radiante diverge. Essa divergência é conhecida como 
Catástrofe do Ultravioleta. Não foi um erro de Rayleigh e Jeans. Eles não aplicaram erroneamente nenhum conceito físico da época, uma vez que diversos pesquisadores reproduziram a mesma equação, demonstrando que ela era correta de acordo com a Física existente. Alguma coisa deveria estar errada com a Física então.

O físico alemão Max Planck tinha uma crença firme de que todos os fenômenos físicos deveriam sucumbir a um pensamento analítico, e decidiu trabalhar no problema do corpo negro. Ele abordou o problema do ponto de vista da Termodinâmica, por ser familiarizado com a área. Planck sabia que se o calor era adicionado à cavidade de um corpo negro, então deveria haver uma mudança de entropia. Então ele tentou calcular uma expressão para a entropia que explicasse as observações experimentais. Mas seus esforços foram em vão, e resultaram em falhas sucessivas, até que ele fez o que chamou de "ato de desespero" (Segrè, 1980). Ele assumiu que a energia da luz não fosse contínua, mas que ocorresse em pacotes discretos, chamados quanta, e que o tamanho desses pacotes seria maior quanto menor o comprimento de onda. Assim como Rayleigh e Jeans antes dele, Planck assumiu que a radiação emitida pelo corpo negro era causada pelas oscilações dos elétrons nas partículas constituintes do corpo negro. Implícita na derivação de Rayleigh-Jeans estava a hipótese de que as energias dos osciladores eletrônicos poderiam assumir qualquer valor. Essa suposição é uma das hipóteses básicas da Física Clássica, segundo a qual as variáveis que representam observáveis (como posição, momento e energia) podem assumir valores contínuos. Fazendo a revolucionária consideração de que as energias dos osciladores seriam discretas, e que teriam de ser proporcionais à frequência ou, sob a forma de uma equação, que $E=n h v$, em que $E$ é a energia de um oscilador, $n$ é um número inteiro, $h$ é uma constante de proporcionalidade e $v$ é a frequência da oscilação. Usando essa quantização da energia e idéias da termodinâmica estatística, Planck chegou à equação:

$$
\rho_{v}(T) d v=\frac{8 \pi h}{c^{3}} \frac{v^{3} d v}{e^{h v / k_{B} T}-1}
$$

Todos os símbolos, com exceção da constante $h$ têm os mesmos significados da Equação II-A2.1. Planck demonstrou que essa equação concorda excelentemente com os dados experimentais para todas as frequências e temperaturas se $h$ tem $\mathrm{o}$ valor de $6,626 \times 10^{-34}$ Joules segundo $(\mathrm{J} \cdot \mathrm{s})$. Essa constante é uma das mais famosas e fundamentais constantes da Física, e é conhecida como Constante de Planck. Posteriormente, Einstein usou 
a teoria dos quanta de Planck para explicar o efeito fotoelétrico, fenômeno em que elétrons são ejetados de placas metálicas após a incidência de radiação ultravioleta. Einstein propôs que não apenas a radiação luminosa, mas a radiação em si existiria como pequenos pacotes de energia, que ele chamou de fótons.

\section{II-A2.3 O QUANTUM E O MODELO ATÔMICO}

Einstein não foi o único a achar o conceito de quantum de Planck útil. No laboratório de J. J. Thomson, o pós-doutorando Niels Bohr entrava em conflito com seu orientador sobre o modelo mais adequado para um átomo. Thomson aderia a seu modelo do "pudim de passas", enquanto Bohr preferia o modelo do físico neo-zelandês e ex-orientado de Thomson, Ernest Rutherford.

Bohr instintivamente sentiu que as energias quantizadas de Planck relacionavam-se às linhas discretas dos espectros elementais e ao modelo planetário do átomo, embora não conseguisse encontrar a conexão. No estudo do espectro discreto do hidrogênio, o físico e matemático suiço Johan Jakob Balmet chegou a uma relação entre as frequências e o recíproco quadrado de números inteiros $n$. Essa característica chamou a atenção de Bohr, que acabou por postular - seguindo o modelo atômico de Rutherford - que só podem existir órbitas discretas para o elétron ao redor de um núcleo (chamadas de estados estacionários), e que para ir de um estado a outro, um átomo deve absorver ou emitir um pacote com a quantidade exata de energia - um quantum. A partir daí, o modelo atômico foi desenvolvido, adicionando-se aos níveis de energia subníveis, orbitais e momentos angulares de posição e de spin.

Havia contudo sérios problemas com o modelo de Bohr; o mais importante deles sendo o fato de o modelo ser exato apenas para o átomo de hidrogênio. O hélio, com dois elétrons, já era suficientemente complicado para o modelo abordar com exatidão. 


\section{II-A2.4 A DUALIDADE DA MATÉRIA}

Em 1924, o francês Louis Victor Pierre Raymond de Broglie submeteu uma tese de doutorado à Sorbonne na qual propunha uma idéia radical: Se a luz se comportava como uma onda ou uma partícula, por que não poderia uma partícula, como o elétron, se comportar como uma onda?

de Broglie colocou sua idéia em um esquema quantitativo. Einstein mostrou, em sua Teoria da Relatividade, que o comprimento de onda, $\lambda$, e o momentum, $p$, de um fóton podem ser relacionados por:

$$
\lambda=\frac{h}{p}
$$

Ele argumentou que tanto luz quanto matéria obedeceriam a essa equação. Como momentum é definido como o produto entre massa e velocidade, essa equação prediz que uma partícula de massa $m$ movendo-se a uma velocidade $v$ terá um comprimento de onda dado por $\lambda=h / m v$.

Langevin encaminhou o trabalho de de Broglie a Einstein e a um outro físico alemão, na Universidade de Zurique: Erwin Schrödinger.

A propriedade ondulatória dos elétrons é utilizada na microscopia eletrônica. Os comprimentos de onda dos elétrons podem ser controlados através da aplicação de uma voltagem. Os menores comprimento de onda alcançados permitem obter um sensor mais preciso do que a microscopia óptica convencional.

\section{II-A2.5 A "NOVA TEORIA QUÂNTICA"}

Em 1925, Erwin Schrödinger e Werner Heisenberg formularam uma teoria quântica geral, independentemente. A primeira vista, os dois métodos parecem diferentes: O método de 
Heisenberg é formulado em termos de matrizes, enquanto o de Schrödinger é tratado em termos de equações diferenciais.

Um resultado interessante que adveio dos trabalhos de Heisenberg é que suas matrizes não permitiam a computação da posição e do momento do elétron em um mesmo instante no tempo. Esse resultado, conhecido como Princípio da Incerteza de Heisenberg, tem uma interpretação física: As propriedades atômicas são mensuradas pela interação da radiação eletromagnética com a matéria. Heisenberg mostrou que, se $\Delta x$ é a região na qual deseja-se localizar um elétron em particular e $\Delta p$ é a incerteza de seu momento, então:

$$
\Delta x \Delta p \geq h
$$

O Princípio da Incerteza de Heisenberg é um dos princípios fundamentais da Natureza, e declara que ao se desejar localizar qualquer partícula dentro de uma distância $\Delta x$, então automaticamente será introduzida uma incerteza a respeito de seu momento.

\section{II-A2.6 A EQUAÇÃO DE SCHRÖdINGER}

A equação de Schrödinger é a equação fundamental da Mecânica Quântica. As soluções da equação de Schrödinger são chamadas de funções de onda. Uma função de onda fornece a descrição completa de um dado sistema.

Como não pode ser derivada de outras leis fundamentais, a equação de Schrödinger é considerada um postulado fundamental, ou axioma, da mecânica quântica, assim como as leis de Newton são postulados fundamentais da Mecânica Clássica.

Uma vez que a Matéria apresenta propriedades ondulatórias, ela deve ser descrita por uma equação de onda. Escrevendo uma equação de onda clássica unidimensional:

$$
\frac{\partial^{2} u}{\partial x^{2}}=\frac{1}{v^{2}} \frac{\partial^{2} u}{\partial t^{2}}
$$


Essa equação pode ser resolvida pelo método de separação de variáveis, escrevendo $u(x, t)$ - a amplitude - como o produto de uma função de $\mathrm{x}$ e uma função harmônica ou senoidal do tempo. Expressando a parte temporal como uma função $\cos (\omega t)$ :

$$
u(x, t)=\psi(x) \cos \omega t
$$

Substituindo a Equação II-A2.6 na II-A2.5, obtém-se uma expressão para a amplitude espacial $\psi(x)$ da onda:

$$
\frac{d^{2} \psi}{d x^{2}}+\frac{\omega^{2}}{v^{2}} \psi(x)=0
$$

Usando o fato que $\omega=2 \pi v$ e que $v \lambda=v$, a Equação II-A2.7 torna-se:

$$
\frac{d^{2} \psi}{d x^{2}}+\frac{4 \pi^{2}}{\lambda^{2}} \psi(x)=0
$$

A energia total de uma partícula é a soma de sua energia cinética e sua energia potencial. Introduzindo o conceito de onda de matéria de Broglie:

$$
E=\frac{p^{2}}{2 m}+V(x)
$$

em que $\mathrm{p}=\mathrm{mv}$ é o momento da partícula e $\mathrm{V}(\mathrm{x})$ é sua energia potencial. Resolvendo a Equação II-A2.9 para o momento $p$, chega-se que:

$$
p=\sqrt{2 m[E-V(x)]}
$$

De acordo com de Broglie:

$$
\lambda=\frac{h}{p}=\frac{h}{\sqrt{2 m[E-V(x)]}}
$$


Substituindo na Equação II-A2.8:

$$
\frac{d^{2} \psi}{d x^{2}}+\frac{2 m}{\hbar^{2}}[E-V(x)] \psi(x)=0
$$

em que $\hbar=h / 2 \pi$. Rearranjando a equação acima, chega-se à Equação II-A2.13:

$$
-\frac{\hbar^{2}}{2 m} \frac{d^{2} \psi}{d x^{2}}+V(x) \psi(x)=E \psi(x)
$$

A Equação II-A2.13 é a famosa Equação de Schrödinger; uma equação diferencial cuja solução, $\psi(x)$, descreve uma partícula de massa $m$ movendo-se em um campo de energia potencial $\mathrm{V}(\mathrm{x})$. A natureza exata de $\psi(x)$ é ainda vaga mas, em analogia à função de onda clássica, é a medida da amplitude da onda de matéria e é chamada de função de onda da partícula. A Equação II-A2.13 não contém a variável tempo, e é chamada de Equação de Schrödinger independente do tempo. As funções de onda obtidas a partir dessa equação são chamadas de funções de onda do estado estacionário.

A Equação de Schrödinger poder ser formulada como um problema de autovalores:

$$
\hat{H} \psi(x)=E \psi(x)
$$

$\hat{H}$ é chamado de operador Hamiltoniano. A função de onda $\psi(x)$ é denominada autofunção do operador Hamiltoniano que, ao ser aplicado sobre $\psi(x)$ retorna o autovalor da energia total. Comparando a Equação II-A2.13 com a II-A2.14, o Hamiltoniano pode ser escrito como:

$$
\hat{H}=-\frac{\hbar^{2}}{2 m} \frac{d^{2}}{d x^{2}}+V(x)
$$

Estendendo o conceito para o espaço N-dimensional: 


$$
H=-\frac{\hbar^{2}}{2 m} \nabla^{2}+V\left(\vec{e}_{1}, \vec{e}_{2}, \vec{e}_{3}, \ldots, \vec{e}_{n}\right)
$$

em que $\nabla^{2}$ representa o operador Laplaciano, cuja regra aplica a derivada segunda do argumento em relação às posições espaciais (qualquer sistema de coordenadas).

A energia total, como mostrado na Equação II-A2.9, é dada pela soma das energias cinética e potencial. Se V corresponde à última, então a energia cinética é dada por:

$$
\hat{T}=-\frac{\hbar^{2}}{2 m} \nabla^{2}
$$

\section{II-A2.7 Postulados E PRINCÍPIOS GERAIS da MECÂNICA QUÂNTICA}

\section{Postulado I}

O estado de um sistema mecânico-quântico é completamente especificado por uma função $\psi(x)$ que depende da coordenada da partícula. Toda informação possivel sobre o sistema pode ser derivada a partir de $\psi(x)$. Esta função, chamada a função de onda ou a função de estado, tem a importante propriedade de $\psi^{*}(x) \psi(x) d x$ representar a probabilidade de que a partícula se localize no intervalo $d x$, localizada à posição $x$.

Novamente, por simplicidade de notação, admite-se que apenas uma coordenada seja necessária para especificar a posição de uma partícula. Em três dimensões, ter-se-ia que $\psi^{*}(x, y, z) \psi(x, y, z) d x d y d z$ representa a probabilidade de que uma partícula descrita por $\psi(x, y, z)$ localize-se no elemento de volume $d x d y d z$, localizado no ponto $(x, y, z)$. Se houver mais de uma partícula, duas por exemplo, então $\psi^{*}\left(x_{1}, x_{2}\right) \psi\left(x_{1}, x_{2}\right) d x_{1} d x_{2}$ é a probabilidade de que a partícula 1 encontre-se no intervalo $d x_{1}$ localizado em $x_{1}$, e a partícula 2 no intervalo $d x_{2}$, localizada em $x_{2}$. O postulado 1 diz que o estado de um sistema mecânico-quântico é completamente especificado por esta função, e que nada mais é necessário.

Como o quadrado da função de onda tem uma interpretação probabilística, ela deve satisfazer certos requerimentos físicos. A probabilidade total de encontrar uma partícula em algum lugar deve ser a unidade. Portanto: 


$$
\int_{\forall S} \psi^{*}(x) \psi(x) d x=1
$$

Para um sistema em três coordenadas:

$$
\iiint_{\forall V} \psi^{*}(x, y, z) \psi(x, y, z) d x d y d z=1
$$

As funções de onda que satisfazem a Equação II-A2.19 são ditas normalizadas. Apenas funções normalizáveis são aceitáveis como funções de estado. Além disso, para que $\psi(x)$ seja uma função de onda fisicamente aceitável, ela e sua primeira derivada devem ter um único valor, serem contínuas e finitas. Esses requisitos estão implícitos ao se dizer que $\psi(x)$ deve ser bem comportada.

\section{Postulado II}

A cada observável na Mecânica Clássica corresponde um operador na Mecânica Quântica.

Este postulado afirma que a Mecânica Quântica permite obter, a partir da função de onda e da aplicação de um operador adequado nesta, cada observável da Mecânica Clássica. A Tabela II.1 resume os principais operadores da Mecânica Quântica e a operação realizada para avaliação do observável.

Tabela II.1 - Operadores quânticos e suas operações.

\begin{tabular}{lccc}
\hline \multicolumn{2}{c}{ Observável } & & Operador \\
Nome & Símbolo & Símbolo & Operação \\
\hline Posição & $x$ & $\hat{X}$ & Multiplicar por $x$ \\
Momento & $\vec{r}$ & $\vec{R}$ & Multiplicar por $\vec{r}$ \\
Energia & $\vec{p}$ & $\hat{\vec{P}}$ & $-i \hbar\left(\vec{i} \frac{\partial}{\partial x}+\vec{j} \frac{\partial}{\partial y}+\vec{k} \frac{\partial}{\partial z}\right)$ \\
cinética & $T$ & $\hat{T}$ & $-\frac{\hbar^{2}}{2 m}\left(\frac{\partial^{2}}{\partial x^{2}}+\frac{\partial^{2}}{\partial y^{2}}+\frac{\partial^{2}}{\partial z^{2}}\right)=-\frac{\hbar^{2}}{2 m} \nabla^{2}$ \\
$\begin{array}{l}\text { Energia } \\
\text { potencial } \\
\text { Energia total }\end{array}$ & $E(x, y, z)$ & $\hat{V}(\hat{x}, \hat{y}, \hat{z})$ & Multiplicar por $V(x, y, z)$ \\
& $E$ & $\hat{H}$ & $-\frac{\hbar^{2}}{2 m} \nabla^{2}+V(x, y, z)$
\end{tabular}




$$
\begin{array}{llll}
\begin{array}{l}
\text { Momento } \\
\text { angular }
\end{array} & L_{x}=y p_{z}-z p_{y} & \hat{L}_{x} & -i \hbar\left(y \frac{\partial}{\partial z}-z \frac{\partial}{\partial y}\right) \\
L_{y}=z p_{x}-x p_{z} & \hat{L}_{y} & -i \hbar\left(z \frac{\partial}{\partial x}-x \frac{\partial}{\partial z}\right) \\
L_{z}=x p_{y}-y p_{z} & \hat{L}_{z} & -i \hbar\left(x \frac{\partial}{\partial y}-y \frac{\partial}{\partial x}\right)
\end{array}
$$

\section{Postulado III}

Em qualquer medição do observável associado ao operador $\hat{A}$, os únicos valores que serão observados são os autovalores $a_{n}$ que satisfazem a equação de autovalores

$$
\hat{A} \psi_{n}=a_{n} \psi_{n}
$$

Então, em qualquer experimento planejado para medir o observável correspondente a Â, os únicos valores que serão encontrados são $a_{1}, a_{2}, \ldots$ correspondentes aos estados $\psi_{1}, \psi_{2}, \ldots$ Nenhum outro valor será observado.

\section{Postulado IV}

Se um sistema em um estado descrito por uma função de onda normalizada $\psi$, então o valor médio do observável correspondente a Ấ dado por:

$$
\langle a\rangle=\int_{\forall S} \psi^{*} \hat{A} \psi d x
$$

Como, de acordo com o Postulado 1, as funções de onda têm interpretação probabilística, elas podem ser usadas para calcular valores médios de quantidades físicas.

\section{Postulado V}

A função de onda, ou função de estado, de um sistema evolui temporalmente de acordo com a equação de Schrödinger dependente do tempo:

$$
\hat{H} \Psi(x, t)=i \hbar \frac{\partial \Psi(x, t)}{\partial t}
$$


Para a maioria dos sistemas, $\hat{H}$ não contém a variável tempo explicitamente, e nesses casos pode-se aplicar o método de separação de variáveis à Equação II-A2.22 e escrever:

$$
\Psi(x, t)=\psi(x) f(t)
$$

Substituindo na Equação II-A2.22 e dividindo ambos lados por $\psi(x) f(t)$, obtém-se:

$$
\frac{1}{\psi(x)} \hat{H} \psi(x)=\frac{i \hbar}{f(t)} \frac{d f(t)}{d t}
$$

O lado esquerdo da Equação II-A2.24 independe do tempo, e o lado direito depende apenas do tempo, de forma que ambos os lados devem ser iguais à uma constante. Então, denotando a constante por $E$, chega-se à Equação de Schrödinger (Equação II-A2.14):

$$
\hat{H} \psi(x)=E \psi(x)
$$

$\mathrm{e}$

$$
\frac{d f(t)}{d t}=-\frac{i}{\hbar} E f(t)
$$

A primeira equação, como já discutido, é conhecida como Equação de Schrödinger independente do tempo. A Equação II-A2.25 pode ser integrada, resultando:

$$
f(t)=e^{-i E t / \hbar}
$$

e $\Psi(x, t)$ tem a forma:

$$
\Psi(x, t)=\psi(x) e^{-i E t / \hbar}
$$

Usando a quantização de Planck, $E=h v=\hbar \omega$ :

$$
\Psi(x, t)=\psi(x) e^{-i \omega t}
$$




\section{Postulado VI}

As autofunções de qualquer operador mecânico-quântico correspondente a uma variável observável constituem um conjunto completo.

Uma série de funções $\{\phi\}$ possuindo certas restrições é dita completa se uma função $f$ que apresente as mesmas restrições puder ser expressa em termos da série:

$$
f=\sum_{i} c_{i} \phi_{i}
$$

\section{Postulado VII}

O princípio variacional declara que para qualquer função normalizada aceitável $\phi$,

$$
H_{\text {med }}=\int \phi^{*} \hat{H} \phi d \tau \geq E_{0}
$$

em que $E_{0}$ é o menor autovalor de $\hat{H}$.

A maioria dos cálculos de Química Quântica baseia-se no princípio da variação que, em resumo, diz que o valor médio de $\hat{H}$ atuando sobre $\phi$ é um limite superior do menor autovalor de $\hat{H}$.

\section{Postulado VIII}

$O$ princípio da exclusão de Pauli declara que $\psi$ deve ser anti-simétrica para a troca de férmions (partículas de spin semi-inteiro) idênticos:

$$
\psi\left(x_{1}, x_{2}\right)=-\psi\left(x_{2}, x_{1}\right)
$$

Estes postulados impõem certas restrições sobre o que constitui uma função de onda aceitável. A partir dessa apresentação um tanto quanto formal, a natureza de $\psi$ não pode 
assumir outro adjetivo senão "misteriosa". De fato, talvez a melhor descrição de $\psi$ nesse ponto é um oráculo: quando perguntada por um operador, ela fornece as respostas.

\section{II-A2.8 A APROXIMAÇÃO DE BORN-OPPENHEIMER}

Funções de onda precisas para sistema multiparticulados são extremamente dificeis de serem calculadas, em grande parte devido aos movimentos correlacionados das partículas. Para simplificar um pouco o problema, faz-se uso da aproximação de Born-Oppenheimer.

Sob condições físicas típicas, os núcleos dos sistemas moleculares estão em um movimento bem mais lento do que o dos elétrons. É razoável considerar que a relaxação eletrônica com relação ao movimento nuclear é instantânea. Assim sendo, é conveniente desacoplar esses dois movimentos, e computar as energia eletrônicas para posições nucleares fixas. Ou seja, o termo da energia cinética nuclear é tratado independentemente do dos elétrons. Assim, a Equação de Schrödinger eletrônica fica:

$$
\left(-\sum_{i} \frac{\hbar}{2 m_{e}} \nabla_{i}^{2}-\sum_{k} \frac{\hbar}{2 m_{k}} \nabla_{k}^{2}+\sum_{i<j} \frac{e^{2}}{r_{i j}}+V_{k}\right) \psi_{\text {elec }}=E_{\text {elec }} \psi_{\text {elec }},
$$

em que o índice $i$ refere-se aos elétrons e $k$ aos núcleos. $V_{k}$, o potencial de repulsão núcleonúcleo, é uma constante para um dado conjunto de coordenadas nucleares fixas.

\section{II-A2.9 A CONSTRUÇÃO DAS FUNÇÕES DE ONDA: ABORDAGEM LCAO E CONJUNTOS DE BASE}

As funções de onda podem ser construídas da forma que se julgar adequada, desde que obedeçam aos postulados enunciados nos tópicos anteriores, e suas energias avaliadas pelo autovalor computado. Aquela com menor energia será a mais precisa e supostamente a melhor para se utilizar no cálculo de outras propriedades através da aplicação de outros operadores. 
Pode-se construir uma função de onda inicial $\phi$ como uma combinação linear de funções de onda atômicas $\varphi$, isto é:

$$
\phi=\sum_{i=1}^{N} a_{i} \varphi_{i}
$$

em que o conjunto de $N$ funções $\varphi_{i}$ é chamado de conjunto de base, e cada função está associada a um coeficiente $a_{i}$. Essa abordagem é conhecida como combinação linear de orbitais atômicos (LCAO), e a teoria que faz usufruto dela é denominada Teoria do Orbital Molecular, teoria sobre a qual se baseiam os chamados métodos ab-initio, ou de estrutura eletrônica.

Em sua essência, a função de onda eletrônica pode ser compreendida como um "mapa" que dá uma indicação das regiões do espaço onde podem encontrar-se elétrons. Portanto, é desejável que as funções de base promovam a flexibilidade necessária para permitir que os elétrons "desloquem-se" às regiões onde sua presença em altas densidades promova um abaixamento na energia. Por exemplo, para descrever uma ligação de um átomo de hidrogênio a um de carbono é desejável usar uma função $p$ para o hidrogênio, orientada ao longo do eixo da ligação, de modo a permitir que a densidade eletrônica se localize na região da ligação mais eficientemente do que seria possível usando apenas uma função $s$ esfericamente simétrica.

Há de se notar o limite superior $N$ na somatória da Equação II-A2.33: não é possível trabalhar como uma base infinita de maneira conveniente. Contudo, quanto mais orbitais atômicos forem permitidos no conjunto de base, mais similar a base utilizada estará da "abrangência" da verdadeira região contemplada pelo orbital molecular.

\section{II-A2.10 O OBJETIVO: CALCULAR A ENERGIA}

O princípio variacional, enunciado no Postulado VII (subitem II-A2.7), pode ser expresso como: 


$$
\frac{\int \phi \hat{H} \phi d \vec{r}}{\int \phi^{2} d \vec{r}} \geq E_{0}
$$

Quando a função é normalizada, premissa tomada no enunciado do postulado mencionado, o denominador no membro esquerdo da equação é igual a 1.

Com as Equações II-A2.33 e II-A2.34, pode-se avaliar a energia de uma função de onda:

$$
\begin{aligned}
E & =\frac{\int\left(\sum_{i} a_{i} \varphi_{i}\right) \hat{H}\left(\sum_{j} a_{j} \varphi_{j}\right) d \vec{r}}{\int\left(\sum_{i} a_{i} \varphi_{i}\right)\left(\sum_{j} a_{j} \varphi_{j}\right) d \vec{r}} \\
= & \frac{\sum_{i j} a_{i} a_{j} \int \varphi_{i} \hat{H} \varphi_{j}}{\sum_{i j} a_{i} a_{j} \int \varphi_{i} \varphi_{j}} \\
= & \frac{\sum_{i j} a_{i} a_{j} H_{i j}}{\sum_{i j} a_{i} a_{j} S_{i j}}
\end{aligned}
$$

Os elementos matriciais $H_{i j}$ e $S_{i j}$ são chamados, respectivamente, de integral de ressonância e integral de sobreposição.

O princípio variacional instrui que se busque a menor energia possível. Portanto, uma vez que se selecione um conjunto de base, devem-se escolher os coeficientes $a_{i}$ de forma a minimizar a energia para todas as possíveis combinações lineares das funções de base. Isso pode ser feito tomando-se:

$$
\frac{\partial E}{\partial a_{k}}=0 \quad \forall k
$$

A diferenciação parcial para cada uma das $N$ variáveis $a_{k}$ leva a $N$ equações que devem satisfeitas para que a Equação II-A2.36 seja verdadeira, ou seja:

$$
\sum_{i=1}^{N} a_{i}\left(H_{k i}-E S_{k i}\right)=0 \quad \forall k
$$


Esse conjunto de $N$ equações (sobre $k$ ) envolve $N$ incógnitas (cada $a_{i}$ ). Da Álgebra Linear, sabe-se que um conjunto de $N$ equações em $N$ incógnitas tem uma solução não-trivial se, e apenas se, o determinante formado pelos coeficientes das incógnitas (nesse caso, os coeficientes são as várias quantidades $\left.H_{k i}-E S_{k i}\right)$ é zero:

$$
\left|\begin{array}{cccc}
H_{11}-E S_{11} & H_{12}-E S_{12} & \cdots & H_{1 N}-E S_{1 N} \\
H_{21}-E S_{21} & H_{22}-E S_{22} & \cdots & H_{2 N}-E S_{2 N} \\
\vdots & \vdots & \ddots & \vdots \\
H_{N 1}-E S_{N 1} & H_{N 2}-E S_{N 2} & \cdots & H_{N N}-E S_{N N}
\end{array}\right|=0
$$

A Equação II-A2.38 é uma equação secular. De maneira geral, existem $N$ raízes $E$ que permitem que essa equação seja satisfeita. Ou seja, existem $N$ energias $E_{j}$, e cada valor de $E_{j}$ dará origem a um diferente conjunto de coeficientes $a_{i j}$ que podem ser encontrados resolvendo-se o conjunto de Equações lineares II-A2.37 usando $E_{j}$, e esses coeficientes definem uma função de onda ótima $\phi_{j}$ dentro do conjunto de base dado, i.e.,

$$
\phi_{j}=\sum_{i=1}^{N} a_{i j} \varphi_{i}
$$

Resumidamente, para se encontrar a função de onda monoeletrônica ótima para um sistema molecular, deve-se (Young, 2001):

1. Selecionar um conjunto de $N$ funções de base;

2. Para aquele conjunto de funções de base, determinar todos os $N^{2}$ valores de ambos $H_{i j}$ e $S_{i j}$;

3. Formar o determinante secular e determinar as $N$ raízes $E_{j}$ da equação secular;

4. Para cada um dos $N$ valores de $E_{j}$, resolver o conjunto de Equações lineares II-A2.37 para determinar os coeficientes $a_{i j}$ do conjunto de base para aquele orbital molecular. 


\section{II-A2.11 Sistemas MULTIELETRÔNICOS E A APROXIMAÇÃo de HARTREE-FOCK}

Resolver a Equação II-A2.34 procurando por todas as funções de onda $N$-eletrônicas aceitáveis é uma tarefa virtualmente impossível. É necessário definir um subconjunto adequado, que ofereça uma aproximação fisicamente razoável à função de onda exata e que seja manuseável na prática. No esquema de Hartree-Fock a aproximação mais simples, e ainda fisicamente razoável, é utilizada. Consiste em aproximar a função de onda $N$-eletrônica por um produto antissimétrico de $N$ funções de onda monoeletrônicas $\chi_{i}\left(\vec{x}_{i}\right)$. Esse produto é denominado determinante de Slater, $\Phi_{S D}$ :

$$
\Psi \approx \Phi_{S D}=\frac{1}{\sqrt{N !}}\left|\begin{array}{cccc}
\chi_{1}\left(\vec{x}_{1}\right) & \chi_{1}\left(\vec{x}_{1}\right) & \ldots & \chi_{1}\left(\vec{x}_{1}\right) \\
\chi_{1}\left(\vec{x}_{1}\right) & \chi_{1}\left(\vec{x}_{1}\right) & \ldots & \chi_{1}\left(\vec{x}_{1}\right) \\
\vdots & \vdots & \ddots & \vdots \\
\chi_{1}\left(\vec{x}_{1}\right) & \chi_{1}\left(\vec{x}_{1}\right) & \chi_{1}\left(\vec{x}_{1}\right) & \chi_{1}\left(\vec{x}_{1}\right)
\end{array}\right|
$$

As funções monoeletrônicas $\chi_{i}\left(\vec{x}_{i}\right)$ são chamadas de orbitais de spin, e são compostas de um orbital espacial $\phi_{i}(\vec{r})$ e uma das duas funções de spin, $\alpha(s)$ ou $\beta(s)$ :

$$
\chi(\vec{x})=\phi(\vec{r}) \sigma(s), \quad \sigma=\alpha, \beta
$$

Uma vez definida a forma da função de onda, a resolução segue como comentado no subitem anterior. O procedimento iterativo realizado pelo método do Campo Autoconsistente (SCF, Self-consistent Field) é ilustrado no diagrama de blocos, Figura II.4. 


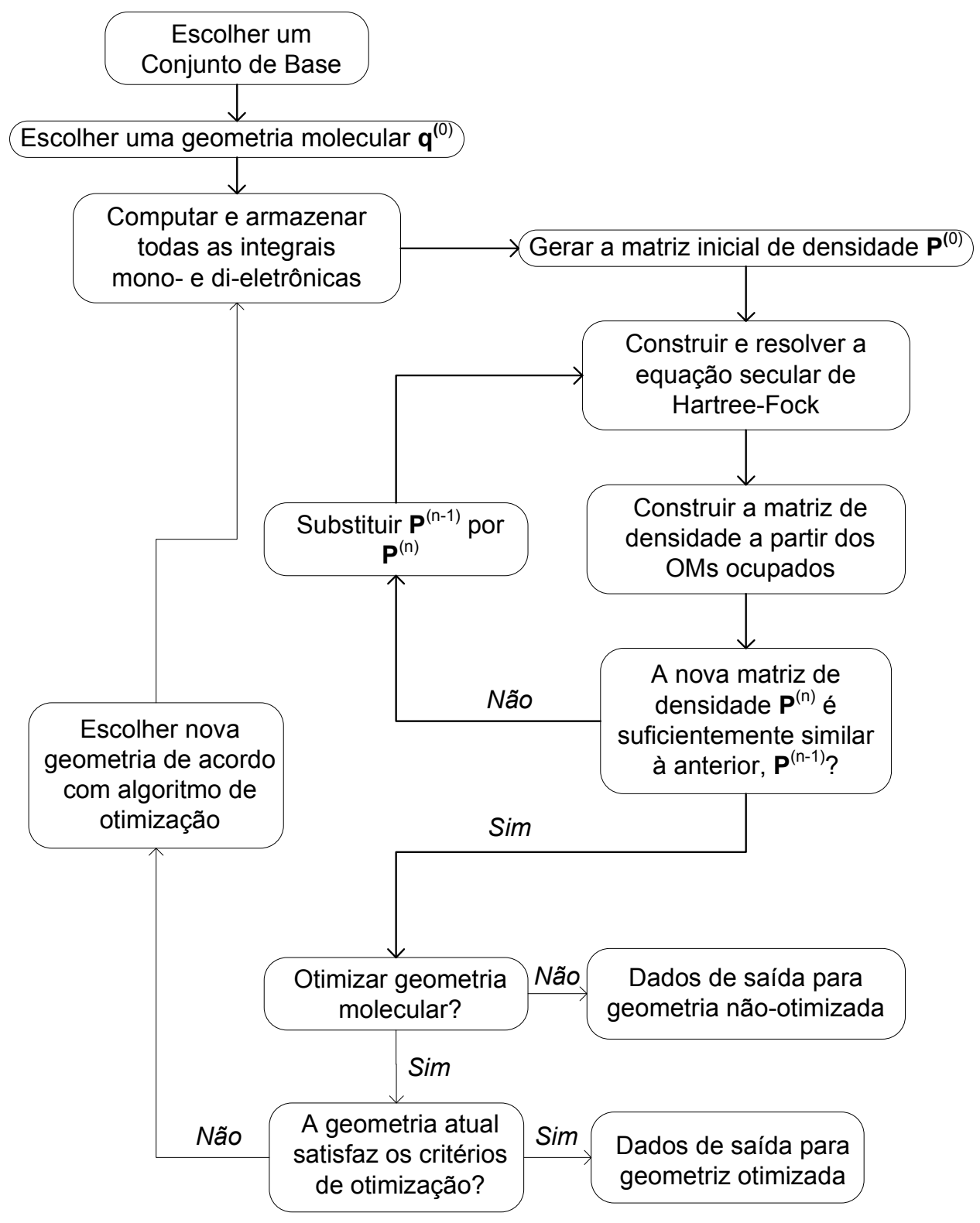

Figura II.4 - Diagrama de blocos ilustrando o procedimento seguido pelo algoritmo de minimização do modelo de Campo Auto-Consistente de Hartree-Fock (HF SCF).

\section{II-A2.12 CORRELAÇ̃̃o ELETRôNICA}

Como visto no subitem anterior, um determinante de Slater $\Phi_{S D}$, usado como uma aproximação à função de onda, absorve uma porção significativa da física de um sistema multieletrônico. Contudo, ele nunca corresponderá à função de onda exata. Portanto, devido ao princípio variacional, a energia retornada pelo procedimento de Hartree e Fock, $\mathrm{E}_{\mathrm{HF}}$, será 
necessariamente maior (i.e. menos negativa) do que a energia do estado fundamental exata, $\mathrm{E}_{0}$ (dentro da aproximação de Born-Oppenheimer e desconsiderando efeitos relativísticos). A diferença entre essas duas energias é, segundo Löwdin (1959), chamada de energia de correlação:

$$
E_{C}^{H F}=E_{0}-E_{H F}
$$

Existem duas contribuições principais para a correção eletrônica:

i) Correlação eletrônica dinâmica: Associada ao movimento dos elétrons, é um efeito de curto-alcance. Deve-se principalmente à repulsão instantânea dos elétrons, que não é contemplada pelo potencial de Hartree-Fock efetivo. Figurativamente, os elétrons podem ficar muito próximos no esquema de HF, porque a interação eletrostática é tratada como uma média. Como consequência, o termo de repulsão eletrônica é muito grande, resultando daí que $\mathrm{E}_{\mathrm{HF}}>\mathrm{E}_{0}$.

ii) Correlação eletrônica não-dinâmica (ou estática): Essa contribuição à correlação eletrônica está relacionada ao fato de que, em certas circunstâncias, o determinante de Slater do estado fundamental não constitui uma boa aproximação ao verdadeiro estado fundamental, por existirem outros determinantes de Slater com energias comparáveis.

A teoria de Hartree-Fock foi então (e é continuamente, uma vez que o estudo da correlação eletrônica é ainda um campo ativo de pesquisa na área de Físico-Química) aperfeiçoada com objetivo de incluir esses efeitos. Os métodos provenientes são incluídos em uma classe de métodos de química computacional conhecidos como pós-Hartree-Fock. Os principais métodos dessa categoria são: a Interação Configuracional (Configuration Interaction, $\mathrm{CI}$ ), a Teoria do Campo Auto-Consistente Multiconfiguracional (Multiconfiguration Self-Consistent Field, MCSCF), a Teoria da Perturbação (Perturbation Theory, cuja formalização proposta por Møller e Plesset (1934) é conhecida pelos acrônimos $M P(n)$, em que $n$ representa a ordem à qual a Teoria da Perturbação é truncada) e a Teoria do Cluster Acoplado (Coupled Cluster, CC). 


\section{Capítulo II-A3 \\ A TeOria do Funcional da Densidade}

"Everything should be made as simple as possible, but not simpler."

(Albert Einstein)

A abordagem convencional à Química Quântica usa a função de onda $\Psi$ como a variável central. A razão é que, uma vez que $\Psi$ (ou uma boa aproximação) seja conhecida, tem-se acesso à todas as informações que podem ser conhecidas sobre esse estado particular do sistema sob estudo. Existe, contudo, um grave problema. A função de onda é uma incógnita bastante complicada, que não pode ser medida experimentalmente e que depende de $4 \mathrm{~N}$ variáveis: três espaciais e uma de spin para cada um dos $\mathrm{N}$ elétrons do sistema. Os sistemas de interesse em química, biologia e ciência dos materiais contêm muitos átomos e ainda mais elétrons. Portanto, qualquer tratamento baseado nas funções de onda logo atingirá um tamanho intratável. Isso não apenas dificulta o tratamento computacional mas também reduz a possibilidade de um entendimento descritivo e torna a abordagem inacessível à intuição

química. Além do mais, o operador Hamiltoniano, $\hat{H}$, contém apenas operadores que atuam sobre uma ou no máximo duas partículas por vez, independente do tamanho do sistema.

Em face dessas observações, pode-se perdoar alguém que resolve sair do majestoso e complexo edifício da Teoria do Orbital Molecular e perguntar: Será que as coisas não podem ser mais simples? Muitos físicos dedicaram-se a encontrar alguma alternativa ao 'monstro de 4N cabeças' impersonado na função de onda. E assim nasceu a Teoria do Funcional da Densidade.

Por ser o método empregado neste trabalho, as acepções e implicações das teorias por trás deste modelo serão discutidas com mais detalhe, bem como seu desempenho na resolução dos principais problemas abordados por técnicas de Modelagem Molecular.

\section{II-A3.1 BUSCANDO A SIMPLICIDADE}

Em vez de trabalhar com uma função de onda, será que não se pode utilizar algum observável físico para determinar a energia (e possivelmente outras propriedades) de uma molécula? 
A análise da estrutura do operador Hamiltoniano permite chegar a uma grandeza física razoável para se lidar. O Hamiltoniano depende apenas das posições e dos números atômicos dos núcleos e do número total de elétrons. Esta última sugere imediatamente uma grandeza física observável útil: a densidade eletrônica $\rho$; uma vez que, integrada sobre todo o espaço, ela retorna o número total de elétrons, como mostrado pela Equação II-A3.1:

$$
N=\int \rho(\vec{r}) d \vec{r}
$$

Além disso, como os núcleos são cargas efetivamente pontuais, suas posições correspondem a máximos locais na densidade eletrônica. Para descrever o Hamiltoniano, então, resta apenas a determinação dos números atômicos dos núcleos. Essa informação também pode ser obtida a partir da densidade, uma vez que para cada núcleo A localizado a um máximo de densidade eletrônica $\vec{r}_{A}$

$$
\left.\frac{\partial \bar{\rho}\left(\vec{r}_{A}\right)}{\partial \vec{r}_{A}}\right|_{\vec{r}_{A}=0}=-2 Z_{A} \rho\left(\vec{r}_{A}\right)
$$

sendo $\mathrm{Z}$ o número atômico de $\mathrm{A}, \vec{r}_{A}$ a distância radial de $\mathrm{A}$, e $\bar{\rho}$ a densidade média esférica.

Os argumentos expostos acima não constituem um formalismo para encontrar a energia. Eles simplesmente indicam que, dado uma densidade conhecida, pode-se formar o Hamiltoniano, resolver a Equação de Schrödinger e determinar as funções de onda e os autovalores da energia. Sugerem, de alguma forma, que algumas simplificações podem ser possíveis.

As primeiras tentativas de usar a densidade eletrônica em vez da função de onda para obter informações acerca de sistemas atômicos e moleculares são quase tão antigas quanto a Mecânica Quântica em si, e datam dos primeiros trabalhos de Thomas (1927) e Fermi (1927). Eles usaram o conceito de uma substância fictícia, o jellium - um sistema composto de um número infinito de elétrons movendo-se em um volume infinito de um espaço caracterizado por uma carga positiva uniformemente distribuída. Essa distribuição eletrônica apresenta densidade constante não-nula. Fazendo uso de mecânica estatística, os autores chegaram à primeira expressão para a energia cinética de um sistema partindo unicamente da densidade eletrônica. A saber: 


$$
T_{T F}[\rho(\vec{r})]=\frac{3}{10}\left(3 \pi^{2}\right)^{2 / 3} \int \rho^{5 / 3}(\vec{r}) d \vec{r}
$$

Este modelo, conhecido como modelo de Thomas-Fermi, entretanto, tem valor meramente histórico, uma vez que suas assunções são suficientemente imprecisas para encontrarem aplicação na Química Quântica moderna (KOCH \& HOLTHAUSEN, 2001).

\section{II-A3.2 OS TEOREMAS DE HOHENBERG-KOHN}

A Teoria do Funcional da Densidade como empregada nos dias atuais tem sua origem em 1964, quando um artigo promissor dos físicos americanos Pierre Hohenberg e Walter Kohn foi publicado na Physical Review (HOHENBERG \& KOHN, 1964). Os teoremas provados naquele trabalho representam os principais pilares teóricos sobre os quais todas as DFTs modernas estão erigidas.

\section{II-A3.2.1 O primeiro teorema de HK: a Prova de Existência}

$O$ potencial externo, $V_{\text {ext }}(\vec{r})$, é (por uma constante) um functional

único de $\rho(\vec{r})$; já que, por sua vez, $V_{\text {ext }}(\vec{r})$ define $\hat{H}$, observamos que

o estado fundamental completo do sistema multiparticular é um

funcional único de $\rho(\vec{r})$.

A prova do primeiro teorema, aqui transcrito como no artigo original (à exceção da simbologia usada para as variáveis), segue pelo método reductio ad absurdum. Esse teorema declara que não existem dois potenciais externos diferentes associados a um mesmo valor de densidade eletrônica; que a densidade eletrônica do estado fundamental não degenerado determina o potencial externo e, portanto, o Hamiltoniano que, por sua vez, determina as funções de onda - tanto do estado fundamental quanto dos estados excitados. 


\section{II-A3.2.2 O segundo teorema de HK: o Princípio Variacional}

O primeiro teorema diz que a densidade do estado fundamental é, em princípio, suficiente para obter todas as propriedades de interesse. Mas como ter certeza que uma dada densidade é realmente a densidade do estado fundamental que se procura? Uma direção formal para se abordar esse problema é dada pelo segundo teorema provado por Hohenberg e Kohn. Em resumo, este teorema diz que - assim como $\psi$ da teoria do orbital molecular - a densidade eletrônica obedece a um princípio variacional. Isto é, quanto menor o valor da energia retornada pela densidade encontrada, mais próxima a densidade estará do valor real.

Até então, o que havia sido feito permitiu encontrar um caminho da densidade ao Hamiltoniano e à função de onda e, assim, à energia. Não se apresentou um caminho pelo qual a densidade possa ser usada como argumento para determinar a energia diretamente (algo na linha de raciocínio de Thomas-Fermi, da Equação II-A3.3), sem necessidade de recorrer à função de onda. A primeira abordagem neste sentido apareceu em 1965.

\section{II-A3.3 ABORDAGEM DE KOHN-SHAM}

A discussão anterior enfatizou que a densidade determina o potencial externo, que determina o Hamiltoniano, que determina a função de onda. E, obviamente, com o Hamiltoniano e a função de onda em mãos, a energia pode ser computada. Contudo, seguindo-se por esse caminho, não há nenhuma simplificação em relação à teoria do orbital molecular, já que o último passo ainda envolve a árdua resolução da Equação de Schrödinger.

Em um avanço crucial, Kohn e Sham (1965) - notando que grande parte dos problemas com funcionais diretos da densidade (como o método de Thomas-Fermi) está relacionada ao modo como a energia cinética é calculada - partiram de um sistema fictício de elétrons nãointeragentes que tem sua densidade no estado fundamental a mesma densidade de um sistema real onde os elétrons interagem. Em seguida, o funcional da energia é divido em componentes específicos:

$$
E[\rho(\vec{r})]=T_{n i}[\rho(\vec{r})]+V_{n e}[\rho(\vec{r})]+V_{e e}[\rho(\vec{r})]+\Delta T[\rho(\vec{r})]+\Delta V_{e e}[\rho(\vec{r})]
$$


Os termos no membro direito da equação referem-se, respectivamente, à energia cinética do sistema não-interagente, à interação núcleo-elétron, à repulsão elétron-elétron, à correção da energia cinética (derivada da natureza interagente dos elétrons), e todas as correções nãoclássicas da energia de repulsão elétron-elétron.

Notando que uma abordagem baseada em orbitais (como o método de Hartree-Fock) se sai melhor no quesito da energia cinética, Kohn e Sham usaram um conjunto de orbitais (i.e., funções monoeletrônicas) para a densidade, permitindo-se que se re-escreva a Equação IIA3.4 como

$$
\begin{aligned}
E[\rho(\vec{r})]= & \sum_{i}^{N}\left(\left\langle\chi_{i}\left|-\frac{1}{2} \nabla_{i}^{2}\right| \chi_{i}\right\rangle-\left\langle\chi_{i}\left|\sum_{k}^{\text {núcleos }} \frac{Z_{k}}{\left|\vec{r}_{i}-\vec{r}_{k}\right|} \nabla_{i}^{2}\right| \chi_{i}\right\rangle\right) \\
& +\sum_{i}^{N}\left\langle\chi_{i}\left|\frac{1}{2} \int \frac{\rho\left(\vec{r}^{\prime}\right)}{\left|\vec{r}_{i}-\vec{r}^{\prime}\right|} d \vec{r}^{\prime}\right| \chi_{i}\right\rangle+E_{X C}[\rho(\vec{r})]
\end{aligned}
$$

na qual os complicados termos $\Delta T$ e $\Delta V_{e e}$ foram agrupados em um termo um termo $E_{X C}$, tipicamente denominado energia de troca e correlação.

Ao tratar-se a Equação II-A3.5 da maneira usual para encontrar-se os orbitais $\chi$ que minimizam a energia $E$, encontra-se que os mesmos satisfazem as equações de autovalores (CRAMER, 2004):

$$
h_{i}^{K S} \chi_{i}=\varepsilon_{i} \chi_{i}
$$

às quais define-se o operador monoeletrônico de Kohn-Sham (KS) como:

$$
h_{i}^{K S}=-\frac{1}{2} \nabla_{i}^{2}-\sum_{k}^{\text {nicleos }} \frac{Z_{k}}{\left|\vec{r}_{i}-\vec{r}_{k}\right|}+\int \frac{\rho\left(\vec{r}^{\prime}\right)}{\left|\vec{r}_{i}-\vec{r}^{\prime}\right|} d \vec{r}^{\prime}+V_{X C}
$$

em que $V_{X C}$ pode ser entendido como o operador monoeletrônico para o qual o valor esperado ao se aplicar sobre o determinante de Slater de Kohn-Sham seja $\mathrm{E}_{\mathrm{XC}}$.

Para a determinação dos orbitais de Kohn-Sham, pode-se seguir a abordagem da Teoria do Orbital Molecular. Conforme explanado no capítulo anterior, os orbitais são expressos 
dentro de um conjunto de funções de base $\{\phi\}$ e seus coeficientes determinados pela solução de uma equação secular. De fato, ambas as teorias compartilham de bastantes similaridades (todo o ferramental matemático do princípio variacional, além da forma de alguns componentes da matriz secular). Entretanto, há uma diferença fundamental entre a teoria $\mathrm{HF}$ e a DFT: da forma apresentada, a DFT não contém aproximações. É exata. A teoria HF é uma teoria aproximada, cujo desenvolvimento foi, em parte, motivado pela capacidade de se resolverem as equações relevantes exatamente. Já a DFT é uma teoria exata, mas as equações relevantes só podem ser resolvidas aproximadamente, já que não se sabe a forma exata do funcional de troca e correlação (KOCH \& HOLTHAUSEN, 2001).

\section{II-A3.4 FunCionais de Troca e CorrelaÇão}

O funcional de troca e correlação conta não somente pela diferença entre a repulsão elétron-elétron clássica e a quântica, mas também inclui a diferença na energia cinética entre o sistema fictício não-interagente e o sistema real (CRAMER, 2004). A qualidade da abordagem do funcional da densidade depende unicamente da precisão da aproximação escolhida para $\mathrm{E}_{\mathrm{XC}}$. Portanto, a busca de funcionais cada vez melhores é um elemento fundamental na DFT. A seguir, serão apresentadas, de forma sucinta, as principais abordagens utilizadas para determinar a forma desse funcional.

\section{II-A3.4.1 Aproximação da Densidade Local (LDA)}

O termo aproximação da densidade local (local density approximation, LDA) foi empregado originalmente para indicar qualquer teoria do funcional da densidade cujo valor da densidade de energia em uma posição $\vec{r}$ qualquer pudesse ser computado exclusivamente a partir do valor de $\rho$ àquela posição, i.e., o valor "local" da densidade eletrônica.

Como peça central desse modelo está a ideia de um gás de elétrons uniforme (aquele mesmo conceito usado por Hohenberg e Kohn) hipotético. 
Segundo esse modelo, a dependência funcional que $\mathrm{E}_{\mathrm{XC}}$ exibe em relação à densidade eletrônica é expressa como uma interação entre a densidade eletrônica e uma "densidade de energia" $\varepsilon_{X C}$, que é por sua vez dependente da densidade eletrônica:

$$
E_{X C}^{L D A}[\rho(\vec{r})]=\int \rho(\vec{r}) \varepsilon_{X C}[\rho(\vec{r})] d \vec{r}
$$

A densidade de energia pode ainda ser separada em duas contribuições, a de troca e a de correlação:

$$
\varepsilon_{X C}[\rho(\vec{r})]=\varepsilon_{x}[\rho(\vec{r})]+\varepsilon_{C}[\rho(\vec{r})]
$$

A contribuição da troca, $\varepsilon_{X}$, que representa a energia de troca de um elétron no gás de elétrons uniforme, foi inicialmente derivada por Bloch e Dirac, no fim dos anos 1920, e é frequentemente denominada funcional de troca de Slater, abreviado como $S$ nos acrônimos usados para identificação dos métodos de cálculo (KOCH \& HOLTHAUSEN, 2001):

$$
\varepsilon_{x}^{S}[\rho(\vec{r})]=-\frac{3}{4} \sqrt[3]{\frac{3 \rho(\vec{r})}{\pi}}
$$

Em contrapartida, não há uma expressão explícita para a densidade de energia de correlação, nem mesmo para o sistema uniforme fictício; embora, para esse sistema, Ceperley e Alder (1980) tenham conseguido determinar a energia de correlação indiretamente, usando métodos de Monte Carlo. Posteriormente, Vosko, Wilk e Nussair (1980) desenvolveram funcionais que se adequassem aos resultados encontrados por Ceperley e Alder, como o mostrado a seguir:

$$
\begin{aligned}
\varepsilon_{C}^{i}\left[r_{s}\right] & =\frac{A}{2}\left\{\ln \frac{r_{s}}{r_{s}+b \sqrt{r_{s}}+c}+\frac{2 b}{\sqrt{4 c-b^{2}}} \tan ^{-1}\left(\frac{\sqrt{4 c-b^{2}}}{2 \sqrt{r_{s}}+b}\right)\right. \\
& \left.-\frac{b x_{0}}{x_{0}^{2}+b x_{0}+c}\left\{\ln \left[\frac{\left(\sqrt{r_{s}}-x_{0}\right)^{2}}{r_{s}+b \sqrt{r_{s}}+c}\right]+\frac{2\left(b+2 x_{0}\right)}{\sqrt{4 c-b^{2}}} \tan ^{-1}\left(\frac{\sqrt{4 c-b^{2}}}{2 \sqrt{r_{s}}+b}\right)\right\}\right\}
\end{aligned}
$$


em que $r_{s}$ representa um raio efetivo de forma tal que exatamente um elétron seria contido dentro da esfera definida por esse raio. Relaciona-se à densidade eletrônica por:

$$
r_{S}(\vec{r})=\left(\frac{3}{4 \pi \rho(\vec{r})}\right)^{1 / 3}
$$

No funcional representado pela Equação II-A3.10 são empregados diferentes conjuntos de constantes empíricas $A, x_{0}, b$ e $c$. Vosko, Wilk e Nussair propuseram vários esquemas de adequação a sistemas diversos, variando a forma de seus funcionais. As duas formas mais utilizadas são conhecidas pelos acrônimos VWN e VWN5. Cálculos que fazem uso de uma combinação do termo de troca de Slater e de correlação VWN são identificados como método SVWN (CRAMER, 2004).

Os funcionais podem também ser expressos em uma versão irrestrita, quando não a densidade eletrônica $\rho(\vec{r})$, mas as duas densidades de spin $\rho_{\alpha}(\vec{r})$ e $\rho_{\beta}(\vec{r})$ (sendo $\left.\rho_{\alpha}(\vec{r})+\rho_{\beta}(\vec{r})=\rho(\vec{r})\right)$ são utilizadas como quantidade central do cálculo. Apesar de que o funcional exato não deve - de um ponto de vista puramente teórico - depender das densidades de spin, a não ser que o sistema esteja sujeito a um campo magnético, usar essa aproximação garantirá flexibilidade adicional ao modelo por empregar duas variáveis em vez de apenas uma. Se a aproximação LDA for estendida ao caso irrestrito, chega-se à aproximação da densidade de spin local (local spin-density approximation, LSDA). Formalmente, as duas aproximações diferem unicamente pelo fato de, em vez da Equação II-A3.8, empregar-se a Equação II-A3.13 (KOCH \& HOLTHAUSEN, 2001):

$$
E_{X C}^{L S D A}\left[\rho_{\alpha}, \rho_{\beta}\right]=\int \rho(\vec{r}) \varepsilon_{X C}\left(\rho_{\alpha}(\vec{r}), \rho_{\beta}(\vec{r})\right) d \vec{r}
$$

Os sistemas caracterizados por $\rho_{\alpha}(\vec{r}) \neq \rho_{\beta}(\vec{r})$ são conhecidos como sistemas com polarização de spin. O grau de polarização de spin é comumente medido pelo parâmetro de polarização de spin (CRAMER, 2004):

$$
\zeta(\vec{r})=\frac{\rho_{\alpha}(\vec{r})-\rho_{\beta}(\vec{r})}{\rho(\vec{r})}
$$




\section{II-A3.4.2 Aproximação do Gradiente Generalizado}

Em um sistema molecular, a densidade eletrônica está longe de ser espacialmente uniforme, o que já é um bom motivo para se supor que existam limitações à aplicação da LDA ou da LSDA (CRAMER, 2004). De fato, devido à exatidão meramente moderada oferecida por essas aproximações a DFT teve pouquíssimo impacto na química computacional enquanto elas constituíam a única aproximação existente para $E_{X C}$. A situação viria a mudar nos anos 1980, quando as primeiras extensões da aproximação puramente local foram desenvolvidas (KOCH \& HOLTHAUSEN, 2001).

O primeiro passo dado foi a sugestão de usar não apenas a densidade $\rho(\vec{r})$ em um ponto $\vec{r}$ em particular, mas complementá-la com o gradiente da densidade, $\nabla \rho(\vec{r})$, para levar em consideração a não-homogeneidade da verdadeira densidade eletrônica (em compensação à uniformidade admitida no modelo teórico do gás uniforme de elétrons). Em outras palavras, interpreta-se a LDA como o primeiro termo de uma expansão de Taylor da densidade uniforme e espera-se obter aproximações melhores do funcional de troca e correlação ao expandir a série em mais ordens. Assim, chega-se a:

$$
\begin{aligned}
E_{X C}^{G E A}\left[\rho_{\alpha}(\vec{r}), \rho_{\beta}(\vec{r})\right] & =\int \rho(\vec{r}) \varepsilon_{X C}\left(\rho_{\alpha}(\vec{r}), \rho_{\beta}(\vec{r})\right) d \vec{r}+ \\
& +\sum_{\sigma, \sigma^{\prime}} \int C_{X C}^{\sigma, \sigma^{\prime}}\left(\rho_{\alpha}(\vec{r}), \rho_{\beta}(\vec{r})\right) \frac{\nabla \rho_{\sigma}(\vec{r})}{\rho_{\sigma}^{2 / 3}} \frac{\rho_{\sigma^{\prime}}(\vec{r})}{\rho_{\sigma^{\prime}}^{2 / 3}} d \vec{r}+\cdots
\end{aligned}
$$

Essa forma de funcional é denominada aproximação da expansão do gradiente (gradient expansion approximation, GEA). As quantidades $\sigma, \sigma^{\prime}$ referem-se aos spins $\alpha$ ou $\beta$. Infelizmente, se empregado para resolver problemas moleculares reais a GEA acaba sendo ainda pior que a L(S)DA (KOCH \& HOLTHAUSEN, 2001).

Um método que se mostrou mais útil do que a expansão do gradiente recebeu o nome de aproximação do gradiente generalizado (generalized gradient approximation, GGA). Esses funcionais podem ser genericamente escritos como:

$$
E_{X C}^{G G A}\left[\rho_{\alpha}(\vec{r}), \rho_{\beta}(\vec{r})\right]=\int f\left(\rho_{\alpha}(\vec{r}), \rho_{\beta}(\vec{r}), \nabla \rho_{\alpha}(\vec{r}), \nabla \rho_{\beta}(\vec{r})\right) d \vec{r}
$$


Existem diversas sugestões para a dependência explícita do integrante $f$ em relação às densidades e seus gradientes, incluindo funcionais semiempíricos - calibrados com parâmetros com valores de referência em vez de puramente derivados de primeiros princípios. Na prática, o funcional é normalmente separado nas contribuições de troca e de correlação:

$$
E_{X C}^{G G A}=E_{X}^{G G A}+E_{C}^{G G A}
$$

e aproximações para ambos os termos são objeto de pesquisa corrente na DFT. Os diferentes métodos variam na forma de expressão desses funcionais.

O funcional de troca pode ser escrito como:

$$
E_{X}^{G G A}=E_{X}^{L D A}-\sum_{\sigma} F\left(s_{\sigma}\right) \rho_{\sigma}^{4 / 3}(\vec{r}) d \vec{r}
$$

$\mathrm{O}$ argumento da função $\mathrm{F}$ é o gradiente da densidade reduzido para o spin $\sigma$ :

$$
s_{\sigma}(\vec{r})=\frac{\left|\nabla \rho_{\sigma}(\vec{r})\right|}{\rho_{\sigma}^{4 / 3}(\vec{r})}
$$

$s_{\sigma}$ deve ser entendido como um parâmetro de não-homogeneidade local. Ele assume valores altos não apenas para gradientes elevados, mas também em regiões de baixas densidades, como nas regiões distantes do núcleo. Da mesma forma, valores pequenos de $s_{\sigma}$ ocorrem para gradientes pequenos, típicos das regiões de ligações, mas também em regiões de grandes densidades (KOCH \& HOLTHAUSEN, 2001). Duas grandes abordagens foram tomadas com relação à função $F$ : a primeira delas baseada em um funcional de troca GGA desenvolvido por Becke, 1988. O funcional é abreviado simplesmente como B (ou B88):

$$
F^{B}=\frac{\beta s_{\sigma}^{2}}{1+6 \beta s_{\sigma} \operatorname{senh}^{-1} s_{\sigma}}
$$


$\beta$ é um parâmetro empírico, determinado como 0,0042 por uma análise de mínimos quadrados, de modo a adequar o modelo às energias de troca conhecidas com exatidão para os átomos dos gases nobres do He ao Rn.

A segunda classe de funcionais usa para o $\mathrm{F}$ uma função racional do gradiente de densidade reduzido. Como exemplo, segue o funcional de troca de Perdew (1986), que é livre de parâmetros semi-empíricos:

$$
F^{P 86}=\left(1+1,296\left(\frac{s_{\sigma}}{\left(24 \pi^{2}\right)^{1 / 3}}\right)^{2}+14\left(\frac{s_{\sigma}}{\left(24 \pi^{2}\right)^{1 / 3}}\right)^{4}+0,2\left(\frac{s_{\sigma}}{\left(24 \pi^{2}\right)^{1 / 3}}\right)^{6}\right)^{1 / 15}
$$

Os funcionais de correlação corrigidos pelo gradiente correspondentes têm formas analíticas ainda mais complexas, e não podem ser compreendidos em um raciocínio unicamente físico (KOCH \& HOLTHAUSEN, 2001). Um funcional bastante popular atualmente é o derivado por Lee, Yang e Parr, de acrônimo LYP.

Em princípio, cada funcional de troca poderia ser combinado com qualquer um dos funcionais de correlação, mas poucas combinações são usadas. A contribuição de troca é quase que exclusivamente calculada pelo funcional de Becke, que é normalmente combinado com o funcional de correlação de Perdew (1986) ou com o de Lee, Yang e Parr - níveis comumente abreviados como BP86 e BLYP, respectivamente.

\section{II-A3.5 A CONEXÃo AdIABÁTICA E OS FUNCIONAIS HíbRIDOS}

Dos componentes do funcional de troca e correlação, a contribuição da troca é, de longe, o principal componente (BECKE, 1993a). Portanto, uma expressão exata para o funcional de troca em particular é um pré-requisito para se obter bons resultados a partir da DFT.

O funcional de troca e correlação deve levar em consideração as contribuições devidas à diferença entre as energias cinéticas dos elétrons do sistema real e do sistema idealizado de elétrons não interagentes, além das contribuições não-clássicas à energia potencial da interação elétron-elétron. Assim sendo, pode-se escrevê-lo como: 


$$
E_{X C}[\rho(\vec{r})]=\Delta T[\rho(\vec{r})]+\Delta V_{e e}[\rho(\vec{r})]
$$

Pode-se estabelecer uma conexão entre o sistema ideal de elétrons não-interagentes e o sistema real, introduzindo um parâmetro de força de acoplamento $\lambda$, tomado como um contínuo de 0 (sistema não-interagente) a 1 (sistema real). Assim, tem-se:

$$
\hat{H}_{\lambda}=\hat{T}+V_{e x t}^{\lambda}+\lambda \sum_{i}^{N} \sum_{j>i}^{N} \frac{1}{r_{i j}}
$$

Para cada $\lambda$, o potencial externo efetivo $V_{e x t}^{\lambda}$ é adaptado de forma tal que a densidade sempre seja igual à densidade do sistema totalmente interagente. Assim, $\rho(\vec{r})$ é independente do valor de $\lambda$. Emprestando o termo da Termodinâmica, esse caminho que une os dois estados do sistema (não-interagente e totalmente interagente) é denominado conexão adiabática.

A energia de troca e correlação pode, fazendo uso dessa abordagem, ser expressa como (CRAMER, 2004):

$$
E_{X C}=\int_{0}^{1} \Delta V_{e e}^{\lambda} d \lambda
$$

Nota-se que, apesar de o integrante na Equação II-A3.23 conter apenas o termo da energia potencial, a parte cinética da energia de troca e correlação é gerada pela integração sobre $\lambda$ (CRAMER, 2004; KOCH \& HOLTHAUSEN, 2001).

Para calcular a integral da Equação II-A3.23 é necessário conhecer os valores assumidos por $\Delta V_{e e}^{\lambda}$ para os diferentes valores intermediários de $\lambda$ (para $\lambda=0$ é possível obter a expressão exata, uma vez conhecidos os orbitais de KS, e para $\lambda=1$, dispõe-se de boas aproximações (KOCH \& HOLTHAUSEN, 2001)). A aproximação mais simples seria $\operatorname{assumir} \Delta V_{e e}^{\lambda}$ como sendo linearmente dependente de $\lambda$, o que leva a:

$$
E_{X C}^{H H}=\frac{1}{2} E_{X C}^{\lambda=0}+\frac{1}{2} E_{X C}^{\lambda=1}
$$


que corresponde à situação representada na Figura II.5a. Usando o funcional de troca e correlação da LDA para $\Delta V_{e e}^{\lambda=1}$, a Equação II-A3.24 representa a combinação meio-a-meio (half-and-half, HH) do funcional de troca 'exato' e do de troca e correlação da DFT, como apresentado por Becke (BECKE, 1993b).

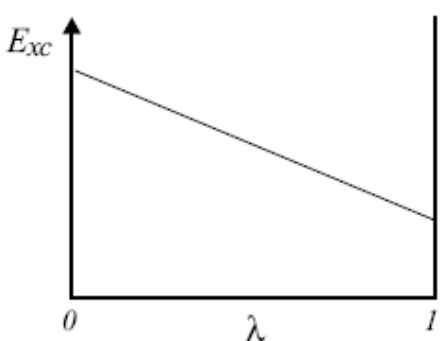

a)

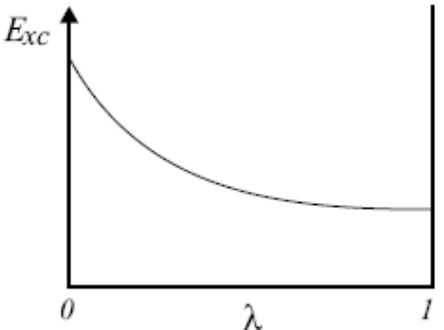

b)

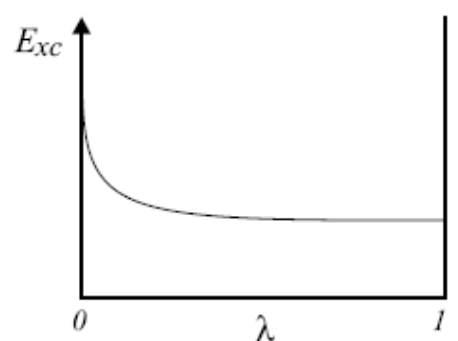

c)

Figura II.5 - Dependência de $\mathrm{E}_{\mathrm{XC}}$ em relação a $\lambda$.

O próximo passo tomado por Becke (BECKE, 1993b) foi introduzir coeficientes semiempíricos para ponderar os vários combonentes neste esquema, levando à seguinte extensão da Equação II-A3.24:

$$
E_{X C}^{B 3}=E_{X C}^{L S D A}+a\left(E_{X C}^{\lambda=0}-E_{X}^{L S D A}\right)+b E_{X}^{B}+c E_{C}^{P W 91}
$$

A equação apresenta 3 parâmetros (e, por isso, B 3 ). A quantidade do funcional de troca exato no funcional é determinado pelo parâmetro $a$, enquanto $b$ e $c$ controlam as contribuições das correções do gradiente de troca e correlação à LDA. Como indicado na equação, Becke utilizou seu funcional de troca de 1988 (BECKE, 1988), e o funcional de correlação de Perdew e Yang de 1991 (PERDEW, 1991). Os três parâmetros empíricos foram escolhidos de forma tal que as energias de atomização e ionização, assim como as afinidades protônicas incluídas no banco de dados G2 fossem otimamente reproduzidas. Isso levou a $a=0,20, b=$ 0,72 e $c=0,81$. Portanto, a quantidade do funcional de troca exato diminui em relação à abordagem meio-a-meio, resultando na forte inclinação de $E_{X C}^{\lambda}$ para $\lambda=0$ observada na Figura II.5b. Mais importante, esse modelo de três parâmetros reduziu o erro médio absoluto nas energias de atomização G2 de 6,5 kcal mol ${ }^{-1}$ (modelo $\mathrm{HH}$ ) para cerca de $2-3 \mathrm{kcal} \mathrm{mol}^{-1}$, bem perto do objetivo ( $2 \mathrm{kcal} / \mathrm{mol})$ (KOCH \& HOLTHAUSEN, 2001). Funcionais desse tipo, 
em que uma certa quantidade da troca exata é incorporada, são comumente chamados de funcionais híbridos $D F T / H F$, ou também funcionais $A C M$, acrônimo para método da conexão adiabática (adiabatic connection method).

Atualmente, o funcional híbrido mais popular (e empregado neste trabalho) é conhecido como B3LYP, e foi sugerido por Stephens et al., 1994. Apesar de ser estruturalmente bastante similar à forma proposta por Becke na Equação II-A3.25, no B3LYP o funcional de correlação PW91 é substituído pelo funcional de LYP. Os valores dos três parâmetros foram tomados da publicação original de Becke (i.e., têm os mesmos valores apresentados em BECKE, 1988). A expressão para este funcional é:

$$
E_{X C}^{B 3 L Y P}=(1-a) E_{X}^{L S D A}+a E_{X C}^{\lambda=0}+b E_{X}^{B}+c E_{C}^{L Y P}+(1-c) E_{C}^{L S D A}
$$

Para o funcional B3LYP, determinou-se um erro em relação ao banco de dados G2 levemente superior a $2 \mathrm{kcal} / \mathrm{mol}$.

Segundo Raghavachari (2000), desde seu surgimento, no começo dos anos 1990, os funcionais híbridos experimentaram um sucesso sem precedentes. Em particular o B3LYP, que logo tornou-se o funcional mais popular e mais extensivamente utilizado. Devido aos bons resultados que apresenta, o B3LYP foi o funcional escolhido para ser utilizado no presente trabalho.

\section{II-A3.6 DESEMPENHO DA DFT}

\section{II-A3.6.1 Energética}

A qualidade das teorias ab-initio e da DFT em relação à predição energética é julgada com base em seu desempenho para as energias de atomização. A Tabela II.2 agrupa uma coleção de erros absolutos médios e máximos nas energias de atomização, calculadas por vários funcionais, e para algumas outras metodologias computacionais em conjuntos de testes de diferentes complexidades. Os conjuntos G2 (1997) e G3 (1999), colunas D e E, incluem 
hidrocarbonetos substituídos, radicais, hidretos inorgânicos, anéis carbônicos insaturados, orgânicos polihalogenados e compostos inorgânicos.

Tabela II.2 - Valores absolutos de erro médio e máximo, quando disponíveis, em relação a energias de atomização para diferentes métodos em diferentes conjuntos de teste ( $\left.\mathrm{kcal} \mathrm{mol}^{-1}\right)$.

\begin{tabular}{|c|c|c|c|c|c|}
\hline \multirow{2}{*}{ Níveis de teoria } & \multicolumn{5}{|c|}{ Conjuntos de Teste ${ }^{\mathrm{a}}$} \\
\hline & A & $\mathrm{B}$ & $\mathrm{C}$ & $\mathrm{D}$ & $\mathrm{E}$ \\
\hline \multicolumn{6}{|c|}{ Métodos da Teoria do Orbital Molecular } \\
\hline AM1 & & & & $\begin{array}{c}7,8 \\
(58,2)\end{array}$ & \\
\hline PM3 & & & & $\begin{array}{c}7,0 \\
(32,2)\end{array}$ & \\
\hline $\mathrm{HF} / 6-31 \mathrm{G}(\mathrm{d})$ & 85,9 & $\begin{array}{c}80,5 \\
(184,3)\end{array}$ & 150,6 & & \\
\hline $\mathrm{HF} / 6-31 \mathrm{G}(\mathrm{d}, \mathrm{p})$ & & & 119,2 & & \\
\hline $\mathrm{HF} / 6-311 \mathrm{G}(2 \mathrm{df}, \mathrm{p})$ & 82,0 & & 146,2 & & \\
\hline MP2/6-31G(d) & 22,4 & $\begin{array}{c}16,0 \\
(40,3)\end{array}$ & 38,1 & & \\
\hline MP2/6-31G(d,p) & 23,7 & & 22,0 & & \\
\hline MP4/6-31G(2df,p) & & & 13,5 & & \\
\hline $\operatorname{CCSD}(\mathrm{T}) / 6-311 \mathrm{G}(2 \mathrm{df}, \mathrm{p})$ & 11,5 & & & & \\
\hline \multicolumn{6}{|l|}{ Funcionais LSDA } \\
\hline SVWN/6-31G(d) & 35,7 & $\begin{array}{c}36,4 \\
(84,0)\end{array}$ & & 83,8 & \\
\hline SVWN/6-31G(d,p) & & & 52,2 & & \\
\hline SVWN/6-311+G(2df,p) & 43,5 & & & $\begin{array}{c}83,7 \\
(207,7)\end{array}$ & $\begin{array}{c}121,9 \\
(347,5)\end{array}$ \\
\hline \multicolumn{6}{|l|}{ Funcionais GGA } \\
\hline BB98/numérico & & $\begin{array}{c}8,6 \\
(28,6)\end{array}$ & & & \\
\hline BVWN/6-31G(d) & 4,4 & & & & \\
\hline BLYP/6-31G(d) & 5,6 & $\begin{array}{c}5,3 \\
(18,8)\end{array}$ & & & \\
\hline BLYP/6-31G(d,p) & & & 7,0 & & \\
\hline $\mathrm{BLYP} / 6-31+\mathrm{G}(\mathrm{d})$ & & $\begin{array}{c}4,4 \\
(16,3)\end{array}$ & & & \\
\hline BP86/6-31G(d) & & $\begin{array}{c}7,2 \\
(24,0)\end{array}$ & & & \\
\hline BPW91/6-31G(d,p) & & & 7,4 & & \\
\hline
\end{tabular}


continuação

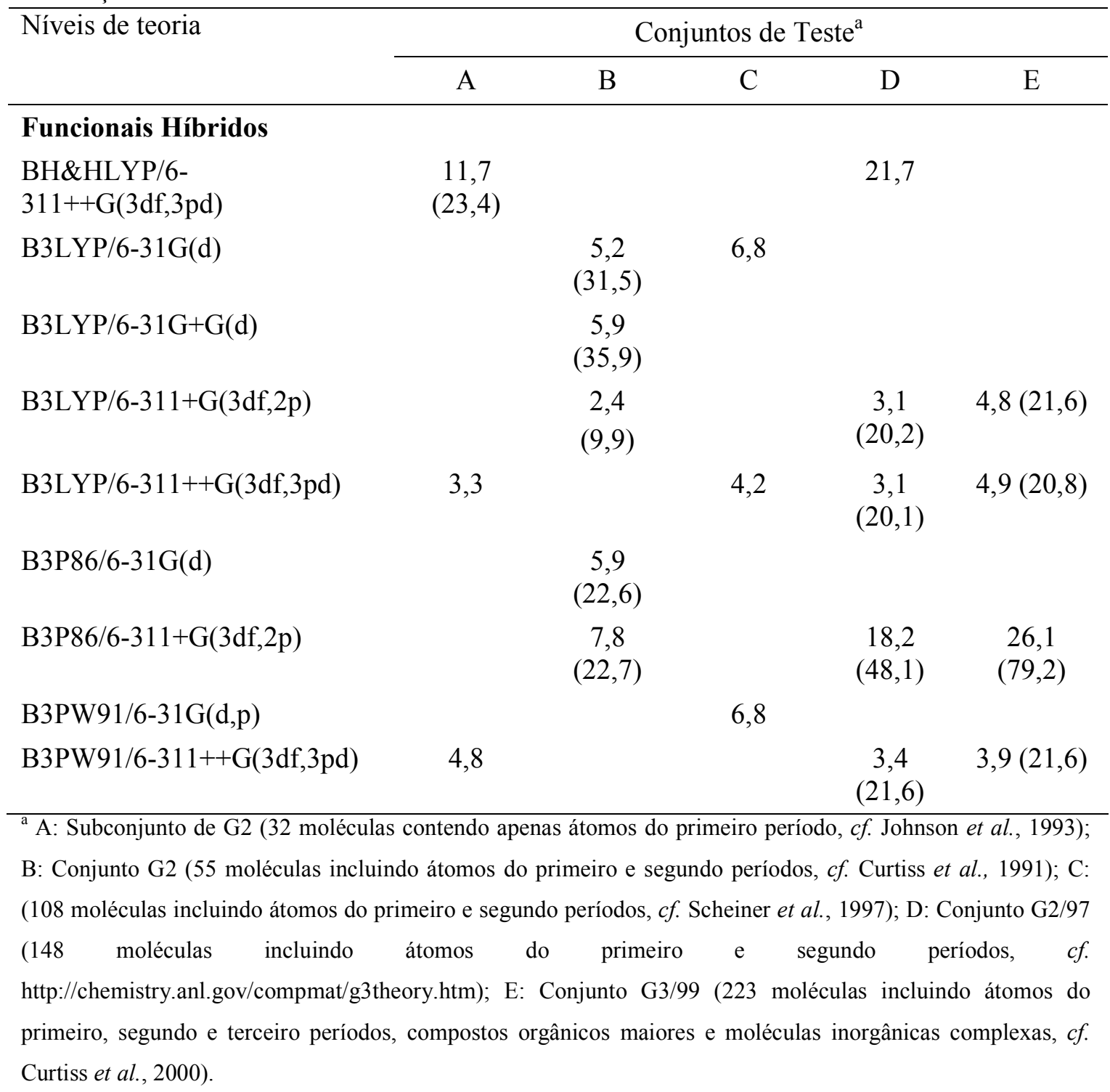

É importante notar pela análise da Tabela II.2 que, para um mesmo nível de exatidão, os métodos DFT híbridos são obviamente os mais eficientes, exibindo erros médios quase iguais em qualidade aos métodos correlacionados multiníveis bem mais exigentes computacionalmente. Contudo, os erros máximos absolutos são maiores, indicando uma generalidade ligeiramente menor. Pode-se notar, também, que os métodos híbridos oferecem mais exatidão do que os métodos DFT puros e que aumentar o tamanho do conjunto de base nem sempre significa aumentar a exatidão dos modelos DFT.

Com relação à energética de reações, Baker et al. (1995) compararam seis níveis de teoria para as entalpias de ativação e de reação para 12 reações orgânicas diretas: os rearranjos unimoleculares álcool vinílico $\longrightarrow$ acetaldeído, ciclobuteno $\longrightarrow s$-trans butadieno, $s$-cis 
butadieno $\longrightarrow s$-trans butadieno, e radical ciclopropila $\longrightarrow$ radical alila; as decomposições unimoleculares tetrazina $\longrightarrow 2 \mathrm{HCN}+\mathrm{N}_{2}$ e trifluormetanol $\longrightarrow$ difluoreto de carbonila + HF; as reações de condensação bimoleculares butadieno + etileno $\longrightarrow$ ciclohexeno (reação de Diels-Alder), radical metila + etileno $\longrightarrow$ radical propila, e radical metila + formaldeído $\longrightarrow$ radical etoxil; e as reações de troca bimoleculares $\mathrm{FO}+\mathrm{H}_{2} \longrightarrow$ $\mathrm{FOH}+\mathrm{H}, \mathrm{HO}+\mathrm{H}_{2} \longrightarrow \mathrm{H}_{2} \mathrm{O}+\mathrm{H}$, e $\mathrm{H}+$ acetileno $\longrightarrow \mathrm{H}_{2}+\mathrm{HC}_{2}$. Seus resultados estão mostrados na Tabela II.3

Tabela II.3 - Erros absolutos médios e máximos, quando disponíveis, nas entalpias de ativação e de reação direta para diferentes métodos $\left(\mathrm{kcal} \mathrm{mol}^{-1}\right)$.

\begin{tabular}{|c|c|c|c|c|}
\hline \multirow[t]{2}{*}{ Nível de teoria } & \multicolumn{2}{|c|}{ Ativação } & \multicolumn{2}{|c|}{ Reação } \\
\hline & Médio & Máximo & Médio & Máximo \\
\hline \multicolumn{5}{|l|}{ Conjunto $1^{a}$} \\
\hline AM1/6-31G(d) & 9,3 & 34,2 & 7,5 & 22,1 \\
\hline $\mathrm{HF} / 6-31 \mathrm{G}(\mathrm{d})$ & 13,6 & 30,6 & 10,5 & 24,8 \\
\hline $\mathrm{MP} 2 / 6-31 \mathrm{G}(\mathrm{d})$ & 9,9 & 28,8 & 6,3 & 26,0 \\
\hline BLYP/6-31G(d) & 5,9 & 21,9 & 5,9 & 13,0 \\
\hline B3LYP/6-31G(d) & & & 5,0 & 9,4 \\
\hline B3LYP/6-311G(2df,2pd) & & & 3,7 & 8,5 \\
\hline \multicolumn{5}{|l|}{ Conjunto $2^{b}$} \\
\hline $\mathrm{HF} / 6-31+\mathrm{G}(\mathrm{d}, \mathrm{p})$ & 12,4 & & 149,5 & \\
\hline $\mathrm{MP} 2 / 6-31+\mathrm{G}(\mathrm{d}, \mathrm{p})$ & 5,5 & & 24,4 & \\
\hline BLYP/6-31+G(d,p) & 8,3 & & 6,8 & \\
\hline B3LYP/6-31+G(d,p) & 5,0 & & 7,2 & \\
\hline \multicolumn{5}{|l|}{ Conjunto $3^{c}$} \\
\hline $\mathrm{HF} / 6-31 \mathrm{G}(\mathrm{d})$ & 18,7 & 26,7 & 3,8 & 6,5 \\
\hline CASSCF/6-31G(d) & 16,0 & 34,6 & 14,7 & 20,6 \\
\hline MP2/6-31G(d) & 4,6 & 7,6 & 6,0 & 9,6 \\
\hline B3LYP/6-31G(d) & 1,7 & 6,0 & 4,1 & 8,6 \\
\hline B3LYP/6-31+G(d,p) & 2,4 & 8,1 & 7,0 & 13,6 \\
\hline B3LYP/6-311+G(2d,p) & 2,9 & 10,1 & 8,2 & 15,9 \\
\hline
\end{tabular}

Os dados dispostos na Tabela II.3 mostram que o funcional B3LYP, a um mesmo nível de teoria, apresenta desempenho superior a um método eletrônico correlacionado, como o MP2. Entretanto (e notavelmente) observa-se que um aumento no conjunto de base para o método B3LYP leva a um pior desempenho. 
O desemprnho dos vários funcionais é normalmente bom, no que diz respeito também à predição das estruturas de menor energia. Um fato interessante de ser comentado é que os funcionais GGA tendem a superestimar sistematicamente os comprimentos de ligação, ao passo que o nível HF tende a subestimá-los. Assim, os funcionais híbridos como o B3LYP acabam exibindo resultados mais precisos, por um cancelamento de erros (Cramer, 2004). A Tabela II.4 mostra erros médios absolutos nos comprimentos de ligação para diferentes conjuntos de teste.

Tabela II.4 - Erros absolutos médios nos comprimentos de ligação para diferentes métodos

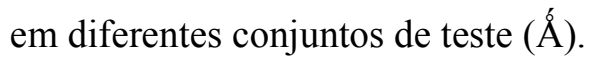

\begin{tabular}{|c|c|c|c|}
\hline \multirow{2}{*}{ Nível de teoria } & \multicolumn{3}{|c|}{ Conjuntos de teste } \\
\hline & $\mathrm{A}$ & B & $\mathrm{C}$ \\
\hline \multicolumn{4}{|c|}{ Métodos da Teoria do Orbital Molecular } \\
\hline $\mathrm{HF}$ & 0,022 & 0,021 & \\
\hline MP2/6-31G(d,p) & 0,014 & 0,014 & 0,022 \\
\hline $\operatorname{CCSD}(\mathrm{T}) / 6-31 \mathrm{G}(\mathrm{d}, \mathrm{p})$ & 0,005 & & \\
\hline \multicolumn{4}{|l|}{ Funcional LSDA } \\
\hline SVWN & 0,017 & $\begin{array}{l}0,016 \\
0,013^{\mathrm{a}}\end{array}$ & \\
\hline \multicolumn{4}{|l|}{ Funcional GGA } \\
\hline BLYP & 0,014 & $\begin{array}{l}0,021 \\
0,019^{\mathrm{b}} \\
0,022^{\mathrm{a}}\end{array}$ & 0,048 \\
\hline $\begin{array}{l}\text { Funcional híbrido } \\
\text { B3LYP }\end{array}$ & 0,004 & $\begin{array}{l}0,008^{\mathrm{b}} \\
0,010^{\mathrm{a}}\end{array}$ & 0,030 \\
\hline
\end{tabular}

A: Subconjunto de G2 (32 moléculas contendo apenas átomos do primeiro período, cf. Johnson et al., 1993), conjunto de base 6-311G(d,p), exceto quando explicitado outro; B: (108 moléculas incluindo átomos do primeiro e segundo períodos, $c f$. Scheiner et al., 1997), conjunto de base 6-31G(d,p); C: (40 moléculas contendo átomos do terceiro período $\mathrm{Ga}-\mathrm{Kr}$, cf. Redfern et al., 1997). ${ }^{a}$ Conjunto de 96 moléculas, usando o conjunto de base 6-311++G(3df,3pd). ${ }^{\text {b }}$ Subconjunto de 40 moléculas, usando conjunto de base zeta-triplo polarizado.

De acordo com a Tabela II.4 observa-se também que os funcionais tendem a ser menos exatos para o cálculo da geometria de moléculas contendo átomos de elementos do terceiro período, em comparação com aquelas contendo apenas átomos dos dois primeiros períodos.

Wiest et al. (1997) estudaram um grande número de estruturas de estados de transição para reações orgânicas eletrocíclicas e, com base em comparações com experimentos e com altos níveis da teoria da estrutura eletrônica, concluíram que o funcional B3LYP é particularmente robusto para predizer geometrias nessa área. 
Como pretendeu-se ressaltar, os funcionais oferecem um bom desempenho nos cálculos típicos de modelagem molecular. Em comparação com os métodos pós-HF, permitem obter resultados comparáveis aos correlacionados, como $\mathrm{MP} n$, a um custo computacional menor. Entretanto, é importante ressaltar que metodologias baseadas na teoria do orbital molecular mais avançadas e com altos níveis de teoria, como os métodos MC-QCISD (multi-coefficient quadratic interaction with single and double excitations) e de cluster acoplado, apresentam desempenho melhor que os funcionais DFT usuais, mas demandam um custo computacional mais elevado.

Em resumo, a DFT representa um método alternativo bastante atraente para os estudos eletrônicos de moléculas. Mesmo a aproximação mais simples da DFT (LDA) gera estruturas moleculares comparáveis àquelas obtidas por métodos ab-initio correlacionados convencionais. Os métodos DFT GGA resultam em energias que estão de acordo com resultados ab-initio correlacionados, a poucos $\mathrm{kcal} / \mathrm{mol}$ de diferença. A efíciência computacional e os menores exigências computacionais fazem da DFT uma ferramenta útil para estudar sistemas moleculares que são muito grandes para serem tratados por métodos pós-HF convencionais. 
Título II

FUNDAMENTAÇÃo TEÓRICA

PaRTe B: FundamentaÇ̃̃o dos Mecanismos Propostos 


\section{Capítulo II-B1 \\ OS RADICAIS DE OXIGÊNIO}

\section{II-B1.1 INTRODUÇÃo}

Um radical livre (ou simplesmente radical) pode ser definido como uma espécie que contém um ou mais elétrons desemparelhados. Eles são formados a partir de moléculas estáveis pela quebra de uma ligação, de forma que cada fragmento contenha um elétron do par (cisão homolítica). A energia necessária para que a ligação se quebre é suprida de duas maneiras diferentes (MARCH \& SMITH, 2007).

1. Clivagem térmica. A sujeição de qualquer molécula orgânica a uma temperatura suficientemente alta em fase gasosa resulta na formação de radicais livres. Quando a molécula contém ligações com energias entre $20-40 \mathrm{kcal} \mathrm{mol}^{-1}\left(80-170 \mathrm{~kJ} \mathrm{~mol}^{-1}\right)$, a clivagem pode ocorrer em fase aquosa, como no caso da reação sofrida por diacil peróxidos:

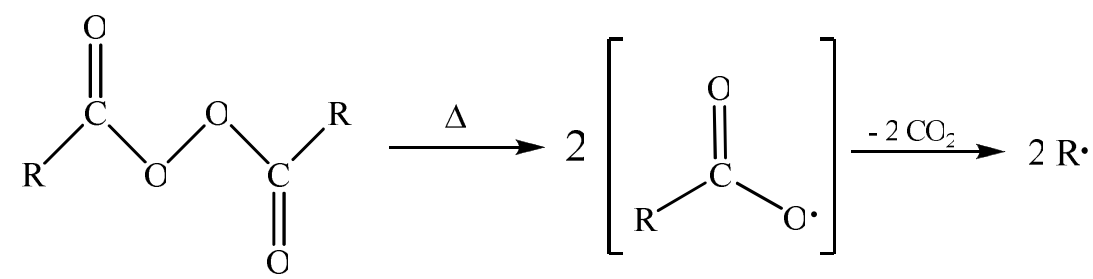

2. Clivagem fotoquímica. A energia da radiação de $600-300 \mathrm{~nm}$ é $48-96 \mathrm{kcal} \mathrm{mol}^{-1}$ $\left(200-400 \mathrm{~kJ} \mathrm{~mol}^{-1}\right)$, que corresponde à ordem de magnitude das energias das ligações covalentes. Um exemplo típico é a clivagem de cetonas:

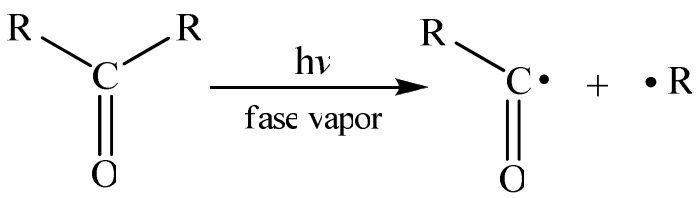


Os radicais também podem ser formados a partir da reação entre outros radicais, por uma reação entre um radical e uma molécula (o que deve obrigatoriamente resultar em um radical, já que o número total de elétrons será ímpar), ou pela clivagem de um radical, resultando em outro radical (CLAYDEN et al., 2001). As etapas formadoras dos primeiros radicais são conhecidas como reações de iniciação.

As reações dos radicais podem resultar ou em produtos estáveis (etapas de terminação), ou levar a outros radicais, que por sua vez devem dar sequência a uma série de reações (etapas de propagação). Existem quatro tipos principais de reações de propagação, dos quais os dois primeiros são os mais comuns:

1. Abstração de outro átomo ou grupo, normalmente átomo de hidrogênio:

$$
\mathrm{R}^{\cdot}+\mathrm{R}^{\prime} \longrightarrow \mathrm{H} \longrightarrow \mathrm{R}-\mathrm{H}+\mathrm{R}^{\prime} \cdot
$$

2. Adição a uma ligação dupla ou tripla:

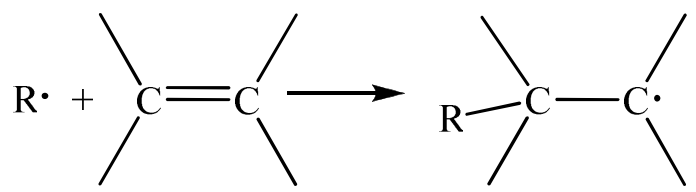

3. Decomposição:

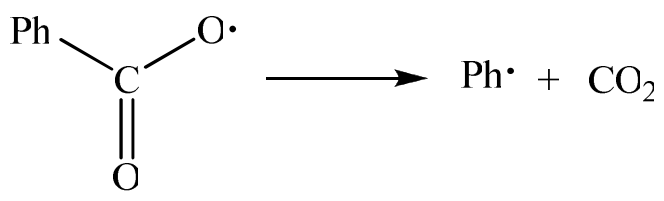

4. Rearranjo:<smiles>[R]C([R])C([R])([2H])[2H]</smiles> 
Nos Processos Oxidativos Avançados, conforme mencionado no Capítulo I-2, as principais espécies oxidativas envolvidas na degradação do poluente orgânico são o oxigênio e as espécies reativas de oxigênio $\left(\mathrm{O}_{\mathrm{x}}, \mathrm{HO}_{\mathrm{x}}, \mathrm{x}=1,2,3,4\right)$ (OPPENLÄNDER, 2003). A Figura II.6 mostra as estruturas de Lewis das principais espécies de oxigênio envolvidas nos POAs:

\begin{tabular}{|c|c|c|c|}
\hline \multicolumn{2}{|c|}{ Espécie } & \multicolumn{2}{|c|}{ Estrutura de Lewis } \\
\hline${ }^{3} \mathrm{O}_{2}$ & ${ }^{1} \mathrm{O}_{2}$ & $\uparrow \cdot \overline{\mathrm{O}} \equiv \overline{\mathrm{O}} \cdot \uparrow$ & $\overline{\mathrm{O}}=\overline{\mathrm{O}}$ \\
\hline $\mathrm{O}_{2}^{2-}$ & $\mathrm{O}_{2}^{--}$ & $\Theta_{\mid \bar{O}}-\overline{\mathrm{O}} \mid{ }^{\Theta}$ & $\Theta_{\mathrm{I} \overline{\mathrm{C}}}$ \\
\hline $\mathrm{HO}^{-}$ & $\mathrm{HO} \cdot$ & $\mathrm{H}-\overline{\mathrm{O}} \mathrm{I}^{\ominus}$ & $\mathrm{H}-\overline{\mathrm{O}}$. \\
\hline $\mathrm{HO}_{2}^{-}$ & $\mathrm{HO}_{2}^{\circ}$ & & \\
\hline
\end{tabular}

Figura II.6 - Estruturas de Lewis das principais espécies de oxigênio envolvidas nas reações de degradação de poluentes orgânicos por Processos Oxidativos Avançados (baseado em (OPPENLÄNDER, 2003))

\section{II-B1.2 RADICAIS HIDROXILA (•OH)}

Os radicais hidroxila são a principal espécie oxidativa gerada nos POAs (OPPENLÄNDER, 2003). São espécies transientes extremamente reativas, de vida curta e não seletivas. A alta reatividade e a curta meia-vida leva a uma baixíssima concentração de radicais hidroxila de estado-estacionário em águas contendo matéria orgânica natural dissolvida, determinada em torno de $1,0 \times 10^{-12} \mathrm{~mol} \mathrm{~L}^{-1}$, de acordo com Hoigné (1998) durante um processo de ozonação.

Estes radicais podem oxidar substratos inorgânicos por diferentes tipos de reação, conforme apontado por Legrini et al. (1993): 
1. Abstração de hidrogênio:

$$
\mathrm{HO}^{\bullet}+\mathrm{RH} \longrightarrow \mathrm{R}^{\bullet}+\mathrm{H}_{2} \mathrm{O}
$$

2. Adição eletrofílica:

$$
\mathrm{HO}^{\bullet}+\mathrm{PhX} \longrightarrow \mathrm{HOPhX}^{\bullet}
$$

3. Transferência de elétrons:

$$
\mathrm{HO}^{\bullet}+\mathrm{RX} \longrightarrow \mathrm{RX}^{\bullet+}+\mathrm{HO}^{-}
$$

Há um consenso de que os radicais hidroxila representam o ponto de partida da degradação do poluente por meio de POAs (OPPENLÄNDER, 2003; LEGRINI et al., 1993; SONNTAG \& SCHUCHMANN, 1997; HOIGNÉ, 1998). A Figura I-2.3 ilustra as principais reações sofridas por um poluente $M$ na presença de radicais hidroxila e em meio saturado de oxigênio. Como pode ser observado por aquela figura, e pelos demais diagramas das reações dos principais POAs apresentados ao longo do Capítulo I-2, ocorre a geração de outras espécies de oxigênio reativas no meio, como o ânion radical superóxido $\cdot \mathrm{O}_{2}{ }^{-} \mathrm{e}$ de peróxidos, $\mathrm{HO}_{2} \bullet, \mathrm{RO}_{2} \bullet$ Estes compostos participam ativamente no mecanismo de degradação dos poluentes.

$\mathrm{Na}$ ausência de poluentes e demais espécies sequestradoras de radicais, o radical hidroxila e sua base conjugada, o radical $\bullet^{-} \mathrm{O}^{-}$, podem sofrer dimerização a taxas quase que controladas por difusão, como ilustrado na Figura II.7:

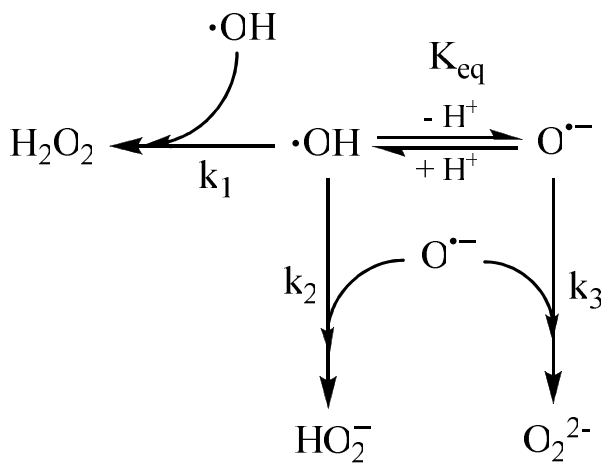

Figura II.7 - Reatividade dos radicais hidroxila na ausência de espécies sequestradoras (baseado em Bielski \& Cabelli (1995)). $\mathrm{k}_{1}=5,0 \times 10^{9} \mathrm{M}^{-1} \mathrm{~s}^{-1} ; \mathrm{k}_{2}=2,5 \times 10^{10} \mathrm{M}^{-1} \mathrm{~s}^{-1} ; 8,4 \times 10^{9} \mathrm{M}^{-1} \mathrm{~s}^{-1}<\mathrm{k}_{3}<9 \times 10^{8} \mathrm{M}^{-1} \mathrm{~s}^{-1} ; \mathrm{K}_{\text {eq }}=1,26 \mathrm{x}$ $10^{-12}$ (id.). 
Os radicais hidroxila são gerados principalmente por métodos físicos (radiação ionizante, sonólise e fotólise, discutida no Capítulo I-2) e por métodos químicos (e.g. reações de Fenton e do tipo Fenton; e reações do peroxinitrito de potássio).

\section{II-B1.3 RADICAIS PEROXILA $\left(\mathrm{RO}_{2}{ }^{\bullet}\right)$}

A formação dos radicais peroxila orgânicos resulta da reação de um radical orgânico, como o formado pela abstração de hidrogênio ou pela adição eletrofílica ilustradas nas Reações II-C.7 e II-C.8, com oxigênio molecular presente no meio reacional:

$$
\mathrm{R}^{\bullet}+\mathrm{O}_{2} \underset{\text { reversa }}{\stackrel{\text { direta }}{\rightleftarrows}} \mathrm{RO}_{2}^{\bullet}
$$

Segundo Sonntag e Schuchmann (1997), essa reação é reversível, quando a ligação entre $\mathrm{C}$ e O-O é fraca. A presença de oxigênio em condições saturadas contribui para a manutenção do equilíbrio no sentido da reação direta, de acordo com o Princípio de Le Chatelier.

Os radicais peroxila podem sofrer uma série de processos unimoleculares, sendo os mais frequentes as eliminações de $\mathrm{HO}_{2} \bullet$ e $\bullet \mathrm{O}_{2}{ }^{-}$(Reações II-C.11 e II-C.12, respectivamente), embora já se tenha demonstrado a ocorrência de adição intramolecular à dupla ligações ou abstrações de hidrogênio.<smiles></smiles>

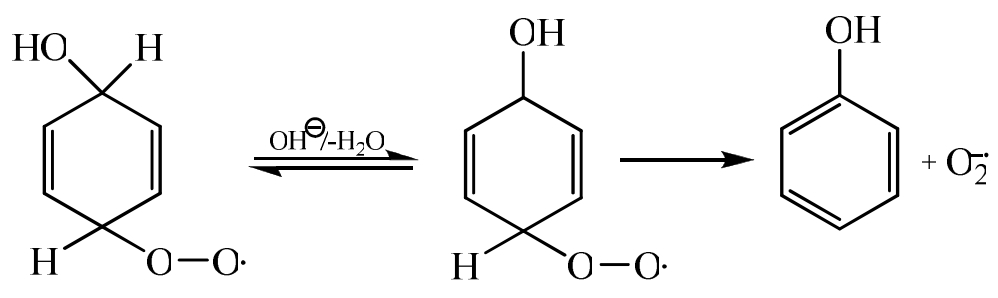




\section{II-B1.4 ÂNION RADICAL SUPERÓXIDO $\left(\cdot \mathrm{O}_{2}^{-}\right)$E HIDROPEROXILA $\left(\mathrm{HO}_{2}{ }^{\cdot}\right)$}

$\mathrm{O}$ equilíbrio ácido-base entre $\mathrm{HO}_{2} \bullet$ e $\cdot \mathrm{O}_{2}{ }^{-}$é bem estabelecido em fase aquosa, como mostrado na Figura II.8. Estes radicais são gerados tanto pela decomposição dos radicais peroxila em condições saturadas de oxigênio, como mostrado acima, quanto pela reação dos radicais hidroxila com peróxido de hidrogênio em solução, sistema de geração prevalente em processos anaeróbios (Reações II-C.13 e II-C.14).

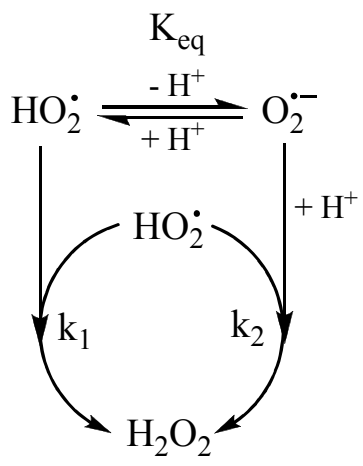

Figura II.8 - Reatividade do radical hidroperoxila e superóxido na ausência de espécies sequestradoras de radicais (Baseado em Czapski \& Bielski (1992)). $\mathrm{k}_{1}=8,3 \times 10^{5} \mathrm{M}^{-1} \mathrm{~s}^{-1} ; \mathrm{k}_{2}=9,7 \times 10^{7} \mathrm{M}^{-1} \mathrm{~s}^{-1} ; \mathrm{K}_{\mathrm{eq}}=1,6 \times 10^{-5} \mathrm{M}^{-}$ 1 (BIELSKI \& CABELLI, 1995).

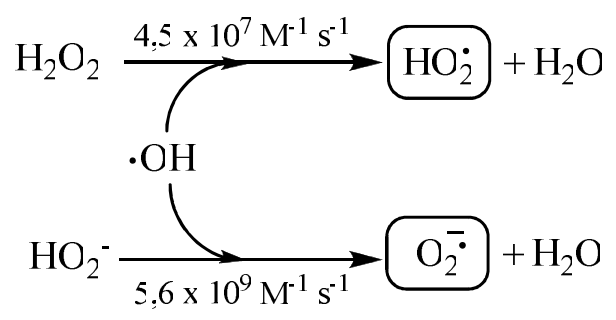

Adicionamente, esses radicais podem ser gerados por radiólise (BUXTON et al., 1988), fotólise VUV da água (OPPENLÄNDER, 2003) e por sonólise (LIPPITT et al., 1982), como ilustrado na Figura II.9. Em particular, esses métodos são mais efetivos na presença do ânion formato $\left(\mathrm{HCO}_{2}{ }^{-}\right)$, que reage com radicais hidroxila formados (BIELSKI \& CABELLI, 1995). O produto desta reação, o ânion radical formila $\left(\mathrm{CO}_{2}^{-} \bullet\right)$, transfere elétrons para o oxigênio molecular, gerando o ânion radical superóxido, segundo os mecanismos expostos na Figura II.10. 


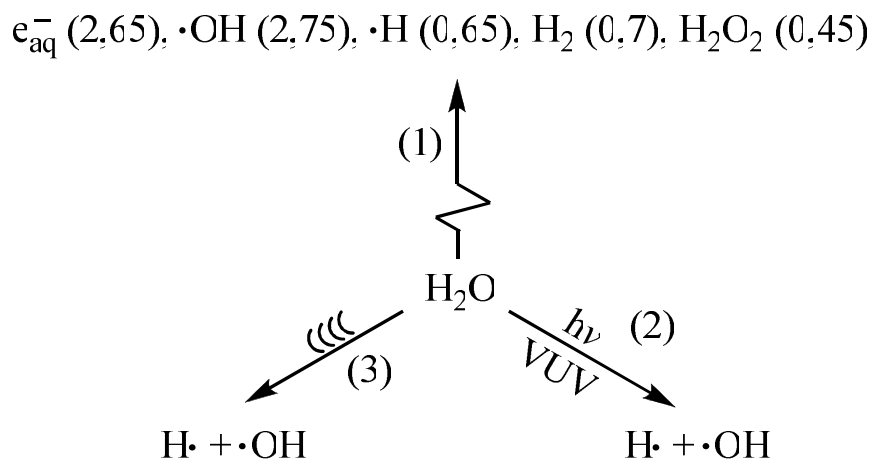

Figura II.9 - Resumo dos principais métodos físicos usados para a geração das espécies precursoras dos radicais superóxido e hidroperoxila. (1) Método radiolítico com radiação $\gamma$ ou feixe de elétrons. Os números em parênteses são os valores $G$ (ICHINO \& FESSENDEN, 2007), i.e., o número de espécies geradas por $100 \mathrm{eV}$ de energia dissipada em água. (2) Método fotolítico VUV. (3) Método sonolítico.

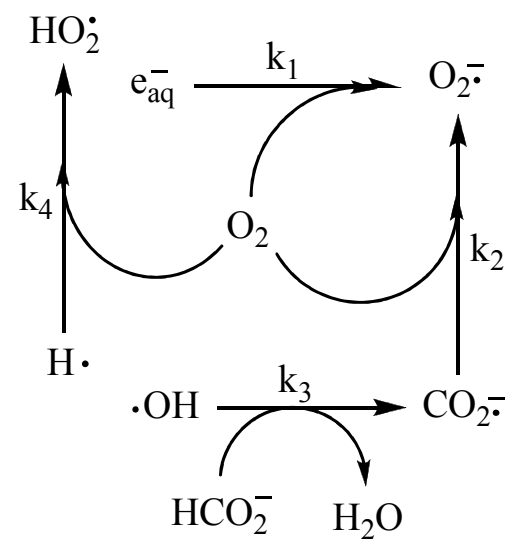

Figura II.10 - Reações sofridas pelas espécies precursoras geradas pelos métodos físicos ilustrados na Figura IIC.4. Destaca-se a necessidade de oxigênio no meio reacional. $\mathrm{k}_{1}=1,9 \times 10^{10} ; \mathrm{k}_{2}=3,0 \times 10^{9} \mathrm{M}^{-1} \mathrm{~s}^{-1} ; \mathrm{k}_{3}=3,2 \mathrm{x}$ $10^{9} ; \mathrm{k}_{4}=1,2 \times 10^{10}$ (BUXTON et al., 1988) (Baseado em Cabelli (1997)).

Além dos métodos físicos, os radicais superóxido e hidroperóxido podem ser gerados por métodos químicos, fazendo uso de $\mathrm{KO}_{2}$ ou através de catálise enzimática com uso do sistema xantina/xantina oxidase (BIELSKI \& CABELLI, 1995).

As espécies discutidas neste capítulo são encontradas com frequência nos mecanismos estudados ao longo deste trabalho, e são as principais responsáveis pela degradação de poluentes através dos Processos Oxidativos Avançados. 
Título II

FUNDAMENTAÇÃO TEÓRICA

PARTe C: A Modelagem dos Efeitos de SolvataÇão 


\section{Capítulo II-C1 \\ SOLVATAÇÃO}

"Corpora non agunt nisi fluida"

(Aristóteles, 350 a.C.)

Seja no laboratório ou na indústria, a maioria das reações é conduzida na fase líquida. Reações na ausência de solventes são raras (mas incluem importantes exemplos, como a polimerização bulk do estireno ou do metacrilato de metila). Dada a importância do solvente, é óbvia a necessidade de um estudo mais aprofundado sobre seu papel ao longo do curso de uma reação, e de como essas espécies afetam os solutos.

Há uma interação energética entre soluto e solvente. Por isso, as propriedades do soluto que dependem da energia - como geometria, frequências vibracionais, energia total e espectro eletrônico - dependem do solvente. A presença de um solvente (sendo ele polar, particularmente) pode também estabilizar uma separação de cargas dentro da molécula de soluto. Isso não apenas afeta a energia, mas também resulta em uma alteração na densidade eletrônica e nas propriedades associadas.

A energia de solvatação pode ser separada em termos que são função do bulk de solvente, e termos que estão especificamente associados à primeira esfera de solvatação. A contribuição do bulk deve-se principalmente ao shielding dielétrico de interações eletrostáticas de cargas (YOUNG, 2001). Essa alteração das interações de cargas é responsável pelas mudanças na densidade eletrônica, conforme possibilitado pel polarizabilidade da molécula.

Há vários efeitos presentes na região onde a molécula encontra a camada de solvatação. Há a energia de cavitação, a energia necessária para afastar as moléculas de solvente e, assim, abrir uma cavidade que comporte a molécula de soluto. Há também a força que atrai a molécula de soluto ao solvente; as interações de van der Waals, de dispersão e as ligações de Hidrogênio. Por fim, as moléculas de solvente na primera esfera de solvatação podem se reorganizar para maximizar as interações com o soluto. A modelagem dessa região é o que representa a maior dificuldade na construção de um modelo de solvatação. Neste sentido, há dois tipo de abordagem aos modelos de solvatação: aqueles que consideram as moléculas de solvente implicitamente (i.e. através de parâmetros que são inseridos nos potenciais do soluto), e aqueles em que as moléculas de solvente são incluídas no modelo do soluto, formando uma supermolécula ou um cluster molecular. 
O efeito da solvatação aquosa em reações químicas é ilustrado no ciclo termodinâmico da Figura II.11:

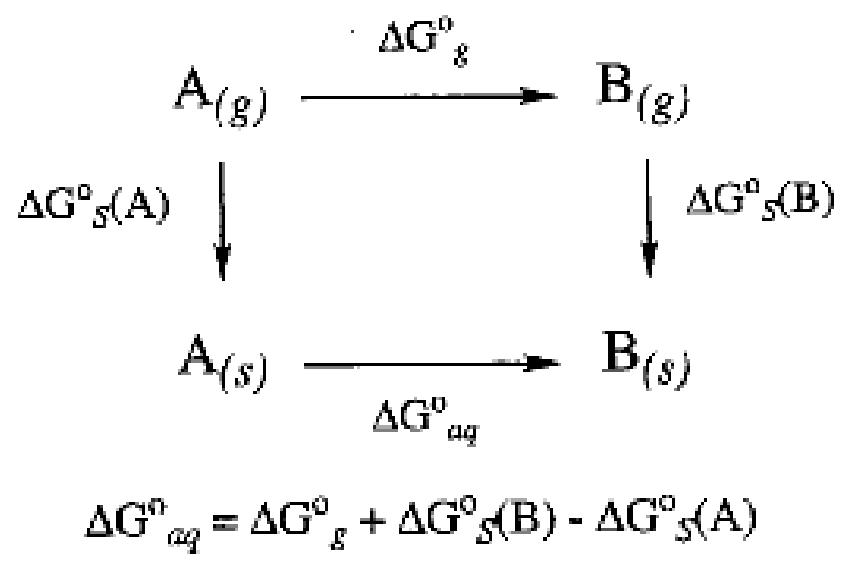

Figura II.11 - Ciclo termodinâmico representando o relacionamento entre as energias livres em fase gasosa e solvente com as energias livres de solvatação. (g) e (s) indicam, respectivamente, meio gasoso e meio solvatado.

A Figura II.12 ilustra o efeito da solvatação aquosa na reação do cloreto com clorometano (CRAMER \& TRUHLAR, 1995):

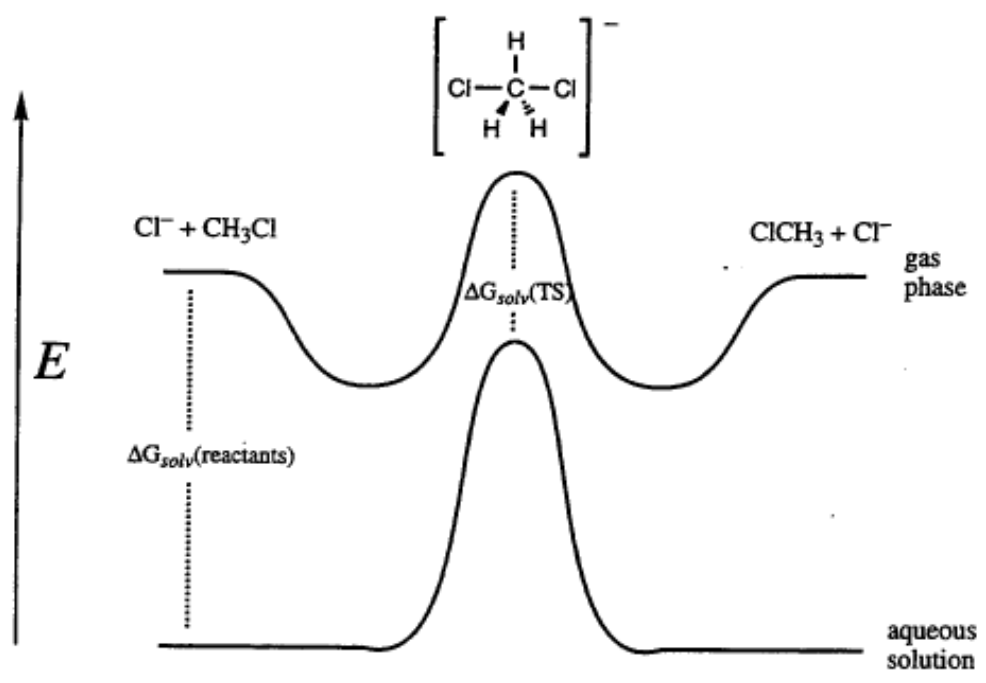

Figura II.12 - Efeito da solvatação aquosa na reação de cloreto com clorometano.

A observação das Figuras II.12 e 13 ilustra o efeito de abaixamento de energia observado nos sistemas solvatados, em relação aos sistemas em fase gasosa. Isso é uma consequência natural do papel "estabilizador" do solvente, i.e. da distribuição de cargas do soluto que contribuiriam para um maior conteúdo energético do sistema. A Figura II.12 também ilustra o efeito drástico que um solvente pode desempenhar em uma reação química. A solvatação 
mais favorável dos reagentes e produtos em relação ao estado de transição é o suficiente para mudar completamente o perfil energético da reação, aumentando a barreira energética consideravelmente. 


\section{Capítulo II-C2}

\section{MODElos de SolvataÇão IMPlíCita}

A interação eletrostática de um soluto com o solvente depende sensivelmente da distribuição de cargas e da polarizabilidade do soluto. Esse ultimo é importante porque o soluto e o solvente relaxam-se auto-consistentemente à presença um do outro. $\mathrm{O}$ conceito físico chave para tratar a polarização do soluto em um solvente é o campo de reação. $\mathrm{O}$ campo de reação é o campo elétrico exercido sobre o soluto pelo solvente que aquele polarizou. A inclusão desse efeito no Hamiltoniano do soluto prediz uma nova estrutura eletrônica, que então altera novamente a polarização do solvente. Iteragir esse sistema até a auto-consistência é o procedimento realizado pelo método do campo de reação autoconsistente (self-consistent reaction field, SCRF), e foi inicialmente proposto por Onsager (1936).

A maioria dos modelos de solvatação implícitos disponíveis calculam o componente eletrostático da energia livre de solvatação pela solução da equação de Poisson-Boltzmann (YOUNG, 2001):

$$
\nabla^{2} \phi=-\frac{4 \pi \rho(r)}{\varepsilon}
$$

que descreve a interação eletrostática entre uma densidade de carga arbitrária $\rho(r)$ e um contínuo dielétrico. Ela diz que o potencial eletrostático $\phi$ está relacionado à densidade de carga e à permissividade dielétrica $\varepsilon$ segundo o modelo expresso acima.

Um dos métodos atuais mais utilizados é o modelo do continuum polarizado (polarized continuum model, PCM). Este modelo faz uso de métodos de elemento de fronteira (boundary element) (para descrição e equacionamento do método, ver Miertus et al., 1981). Existem três abordagens para cálculos PCM. O método original (o PCM dielétrico (D-PCM)), um modelo alternativo em que o meio de solvatação é modelado como um condutor, ao invés de um dielétrico (C-PCM), e uma implementação em que as equações PCM são expressas em um formalismo de equações integrais (IEF-PCM) (CRAMER \& TRUHLAR, 1999).

O modelo PCM é usado neste trabalho conforme implementado no Gaussian 03, em conjunto com cálculos DFT. 


\section{II-C2.1 Modelos De SolvataÇÃo Universais}

Um dos modelos de solvatação utilizado foi o SM5.42R, desenvolvido pelo Supercomputer Institute da Universidade do Minnesota. Os pesquisadores criaram uma série de modelos de solvatação universais, parametrizados para uma variedade de métodos de estrutura eletrônica e conjuntos de base. Essa série de modelos é conhecida por SM5.

Os modelos SM5 fazem uso de parametrização das tensões superficiais atômicas em termos não apenas das propriedades dos átomos do soluto, mas também em termos das propriedades do solvente (CRAMER \& TRUHLAR, 1999). Para a parametrização, foram utilizados conjuntos amplos de grupos funcionais de solutos e solventes.

O modelo empregado neste trabalho, SM5.42R, é um modelo SM5 rígido, baseado em cargas obtidas pelo Modelo de Cargas 2 (CM2). Todos os modelos SM5 são parametrizados para solutos contendo $\mathrm{H}, \mathrm{C}, \mathrm{N}, \mathrm{O}, \mathrm{F}, \mathrm{S}, \mathrm{Cl}, \mathrm{Br}$ e I. O conjunto de testes final contém 2135 energias livres de solvatação para 275 solutos neutros em 91 solventes, e 43 energias livres de solvatação para íons em meio aquoso. O erro médio varia de 0,38 a $0,48 \mathrm{kcal} \mathrm{mol}^{-1}$ (incerteza experimental: $\pm 0,2 \mathrm{kcal} \mathrm{mol}^{-1}$ ) (HAWKINS et al., 1998). 


\section{Capítulo II-C3 \\ Modelos DE SolvataÇÃo EXPlícita}

Em princípio, os efeitos da primeira camada de solvatação podem ser modelados pela inclusão da primeira camada de solvente no soluto, explicitamente. Efeitos importantes, como as ligações de Hidrogênio, são muitas vezes melhor simulados com um modelo de solvatação que inclua as moléculas de solvente explicitamente. Pequenos clusteres que incluem ligações de hidrogênio podem servir de modelos para sistemas maiores, enquanto permitem investigações teóricas e experimentais precisas.

Para o fenol, diversos modelos já foram testados e caracterizados experimentalmente (Lüchow et al., 2001; Plugatyr et al., 2006; Helm \& Neusser, 1998; Watanabe et al., 1996). O modelo encontrado com melhor descrição dos efeitos de solvatação é o que conta com um cluster de quatro moléculas de água ligadas ao fenol:

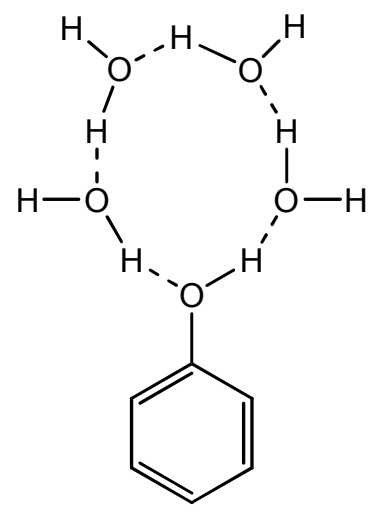

Figura II.13 - Cluster Fenol- $\left(\mathrm{H}_{2} \mathrm{O}\right)_{4}$ (representação genérica 2D).

Lüchow et al. (2001), comentam que o fenol pode ser pensado como "uma molécula de água um hidrogênio substituído por um anel benzênico". Neste sentido, espera-se que o fenol tenha três pontos de ligação com a molécula de água (cf. Figura II.14): o hidrogênio hidroxílico (isômero doador), o oxigênio hidroxílico (isômero aceptor), e o anel $\pi$, que leva a um complexo fenol-água similar aos já identificados de benzeno-água. Para uma descrição adequada, é importante montar modelos que incluam os três tipos de interações. 

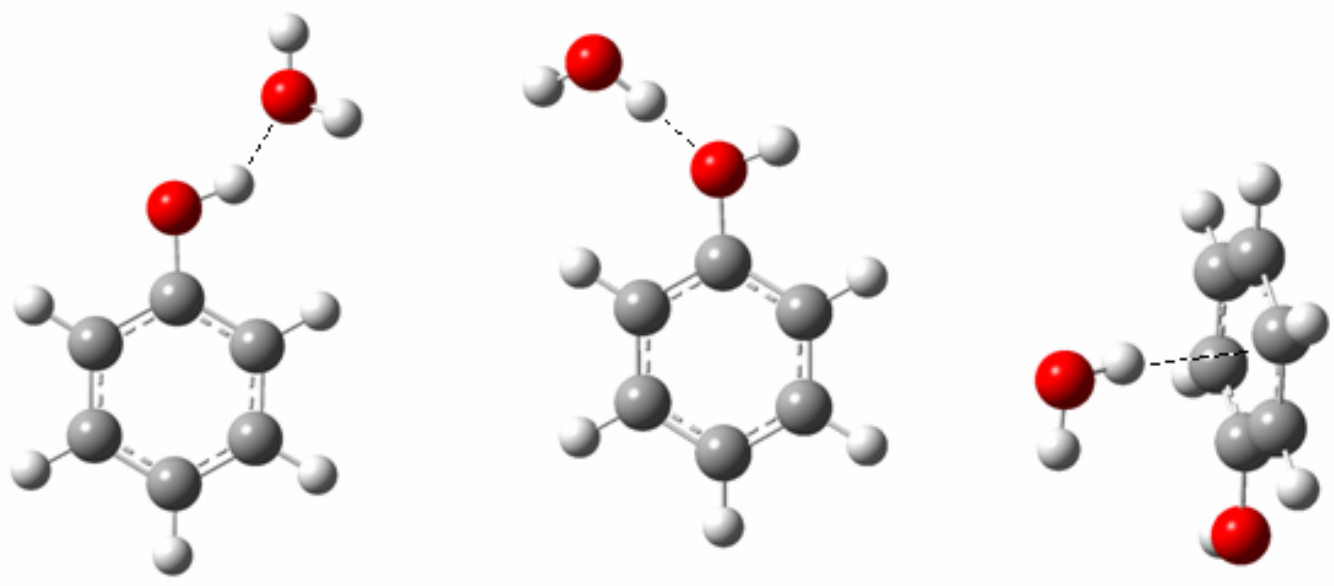

Figura II.14 - Isômeros dos dímeros fenol + água: isômero doador, isômero aceptor e isômero $\pi$ (respectivamente).

As estruturas desenhadas para modelagem são expostas no Capítulo III-2.6. 
Título III

APRESEntaÇÃo E Discussão da Metodologia 


\section{Capítulo III-1}

\section{EQUIPAMENTOS E SOFTWARES}

Para execução do trabalho, dispôs-se das máquinas e dos softwares apresentados na Tabela III.1.

Tabela III.1 - Equipamentos e softwares utilizados no desenvolvimento do trabalho.

\begin{tabular}{|c|c|c|c|c|}
\hline & \multicolumn{4}{|c|}{ Máquinas } \\
\hline & Cluster Alcatéia & Edmara & Edward & Workstation \\
\hline Localização & $\begin{array}{l}\text { Laboratório de } \\
\text { Computação } \\
\text { Científica } \\
\text { Avançada } \\
\text { (LCCA/CCEUSP) }\end{array}$ & $\begin{array}{l}\text { Laboratório de } \\
\text { Simulação e } \\
\text { Controle de } \\
\text { Processos } \\
\text { (CESQ/DEQ- } \\
\text { EPUSP) }\end{array}$ & $\begin{array}{l}\text { Laboratório de } \\
\text { Simulação e } \\
\text { Controle de } \\
\text { Processos } \\
\text { (CESQ/DEQ- } \\
\text { ESPUSP) }\end{array}$ & $\begin{array}{l}\text { Laboratório de } \\
\text { Simulação e } \\
\text { Controle de } \\
\text { Processos } \\
\text { (CESQ/DEQ- } \\
\text { EPUSP) }\end{array}$ \\
\hline \multirow{2}{*}{$\begin{array}{l}\text { Softwares } \\
\text { disponíveis }\end{array}$} & Gaussian 03 & Gaussian 98 & Gaussian 03 & Gauss View 3 \\
\hline & GAMESS & GaussView 2 & $\begin{array}{l}\text { GaussView } 2 \\
\text { AMSOL } \\
\text { MOLDEN }\end{array}$ & WinMOPAC \\
\hline $\begin{array}{l}\text { Configuração } \\
\text { de hardware }\end{array}$ & $\begin{array}{l}\text { Intel Dual Xeon } \\
2400 \mathrm{MHz}\end{array}$ & $\begin{array}{l}\text { Alpha Digital } \\
\text { V4.0 } 1229 \mathrm{MHz}\end{array}$ & $\begin{array}{l}\text { Intel PentiumIII } \\
1004 \mathrm{MHz}\end{array}$ & $\begin{array}{l}\text { Intel PentiumIV } \\
1800 \mathrm{MHz}\end{array}$ \\
\hline Uso & $\begin{array}{l}\text { Remoto, acesso } \\
\text { por SSH com } \\
\text { login e senha do } \\
\text { projeto }\end{array}$ & $\begin{array}{l}\text { Remoto, acesso } \\
\text { por TELNET } \\
\text { com login e } \\
\text { senha de } \\
\text { usuário. }\end{array}$ & $\begin{array}{l}\text { Remoto, acesso } \\
\text { por SSH com } \\
\text { login e senha de } \\
\text { usuário. }\end{array}$ & $\begin{array}{l}\text { Terminal de } \\
\text { trabalho. }\end{array}$ \\
\hline Memória & $2.5 \mathrm{~GB}$ & $1 \mathrm{~GB}$ & $532 \mathrm{MB}$ & $532 \mathrm{MB}$ \\
\hline $\begin{array}{l}\text { Sistema } \\
\text { Operacional }\end{array}$ & GNU/Linux i686 & UNIX & Open SuSE & $\begin{array}{l}\text { Windows } \\
\text { SP2 }\end{array}$ \\
\hline
\end{tabular}

As principais etapas de modelagem molecular executados ao longo do trabalho são:

a) Desenho das estruturas moleculares e construção da matriz em coordenadas internas;

b) Otimização da geometria molecular de moléculas estáveis;

c) Otimização da geometria molecular de estados de transição; 
d) Cálculo de frequência de moléculas estáveis;

e) Cálculo de frequência de estados de transição;

f) Cálculos de energia, fazendo uso de modelos de solvatação;

g) Cálculos da coordenada intrínseca de reação (IRC);

h) Avaliação de parâmetros termodinâmicos usando métodos semi-empíricos.

As diferentes etapas são executadas nos softwares, de acordo com a Tabela III.2.

Tabela III.2 - Discriminação do uso dos softwares disponíveis por etapa de modelagem.

\begin{tabular}{lcccccccc}
\hline & \multicolumn{7}{c}{ Softwares } \\
& GV 2 & GV 3 & G98 & G03 & GAMESS & WinMOPAC & AMSOL & MOLDEN \\
\cline { 2 - 7 } & $\times$ & $\times$ & & & & & \\
\hline a) & $\times$ & & $\times$ & $\times$ & $\times$ & $\times$ & \\
b) & & & $\times$ & $\times$ & & & \\
c) & & & $\times$ & $\times$ & $\times$ & & \\
d) & & & $\times$ & $\times$ & & & \\
e) & & & & $\times$ & & & \\
f) & & & $\times$ & $\times$ & & & \\
g) & & & & & & \\
h) & & & & & & \\
\hline
\end{tabular}




\section{Capítulo III-2}

\section{ETAPAS DAS MODELAGENS}

O primeiro passo da modelagem é a seleção das estruturas e das reações a serem modeladas. O mecanismo escolhido para o projeto foi o proposto em 1984 por Devlin e Harris (Devlin \& Harris, 1984). O mecanismo é ilustrado na Figura III.1. As reações modeladas são marcadas na figura em negrito.

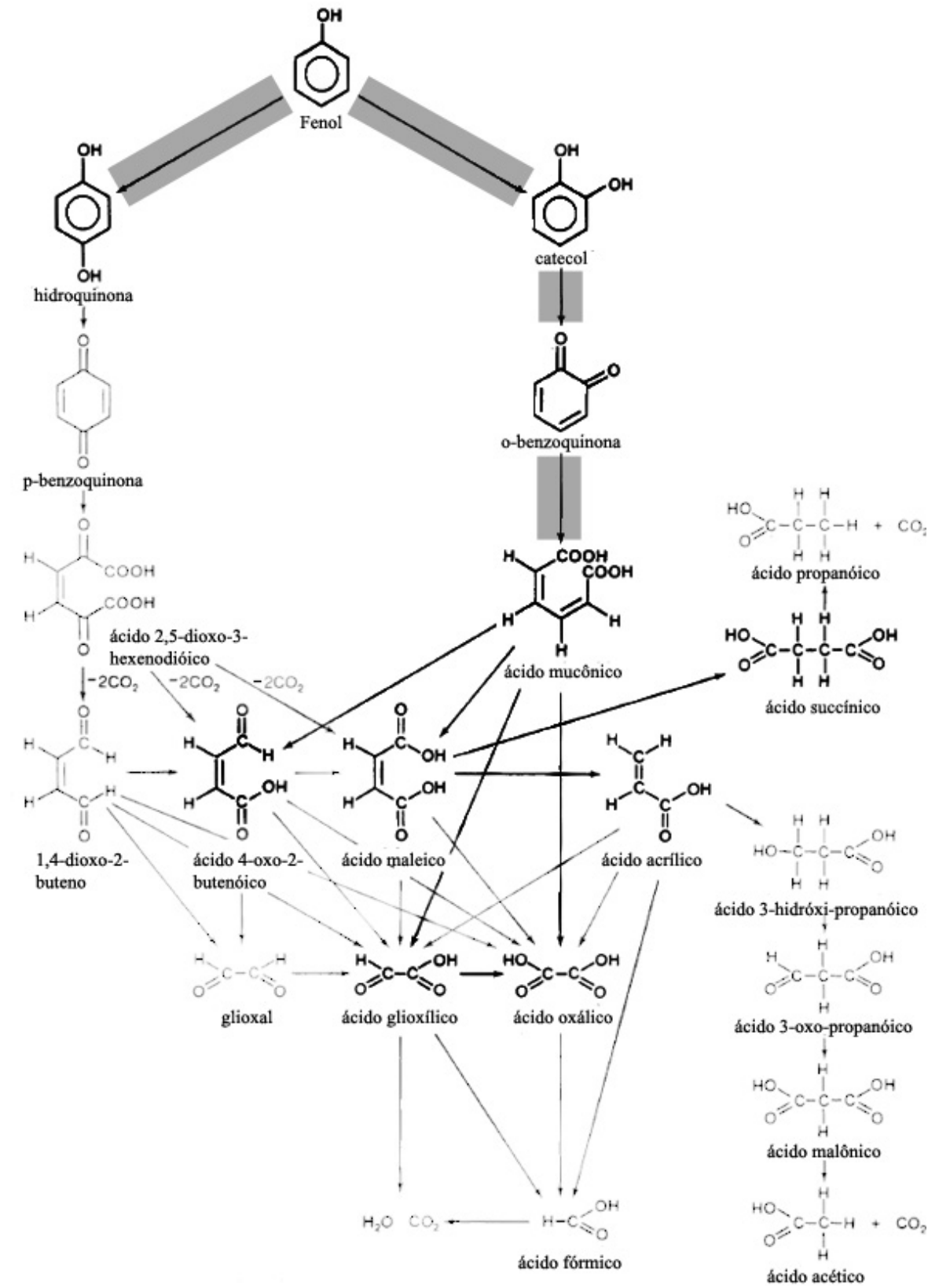

Figura III.1 Mecanismo de oxidação do fenol proposto por Devlin e Harris (1984). As reações grifadas em cinza representam as etapas detalhadas e modeladas. 
As etapas das modelagens são esquematizadas na Figura III.2, para o exemplo de uma reação unimolecular simples:

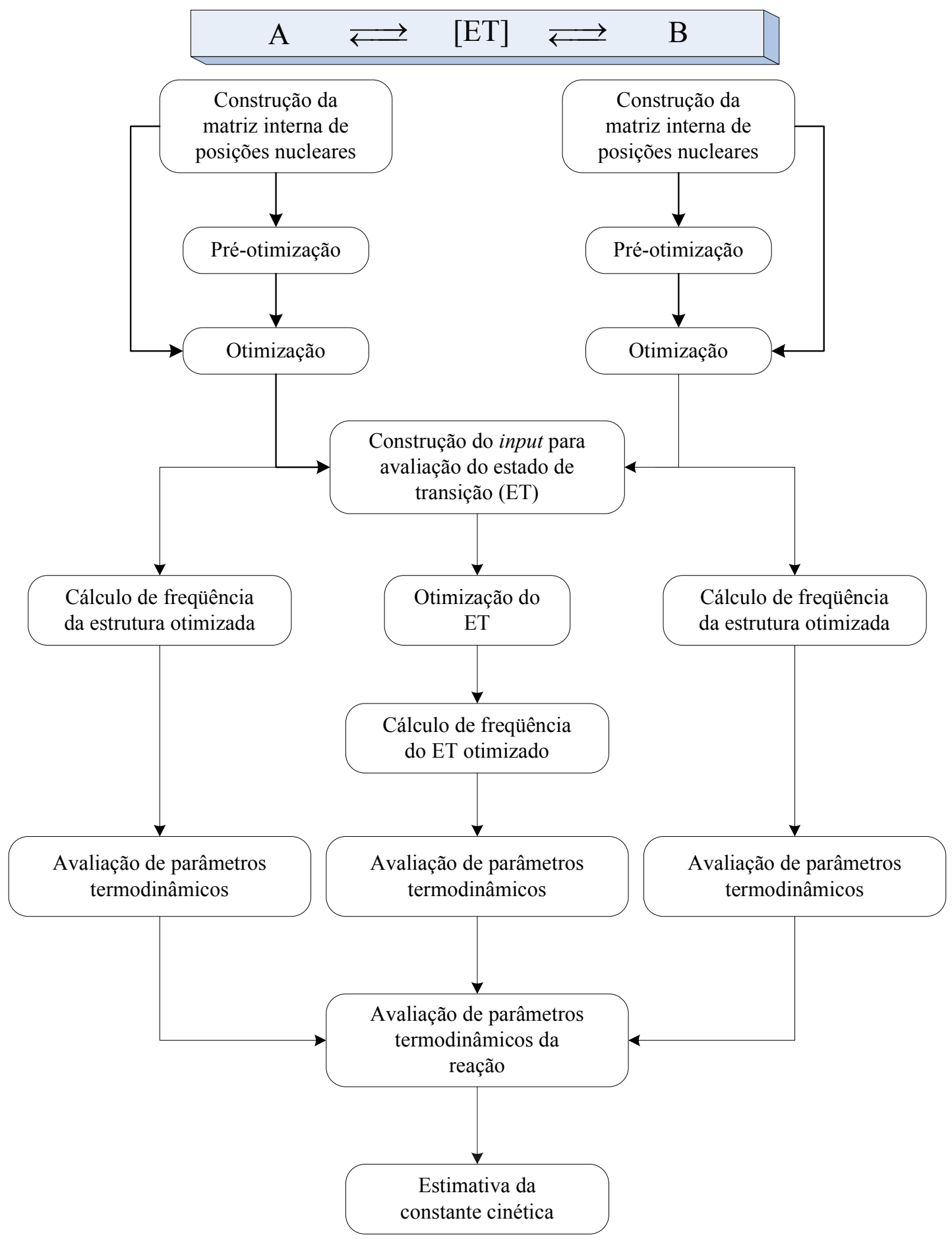

Figura III.2 - Fluxograma das etapas das modelagens de reações químicas. 
A reação pode ser mais bem visualizada através de uma superfície de energia potencial (PES), como a mostrada na Figura III.3:

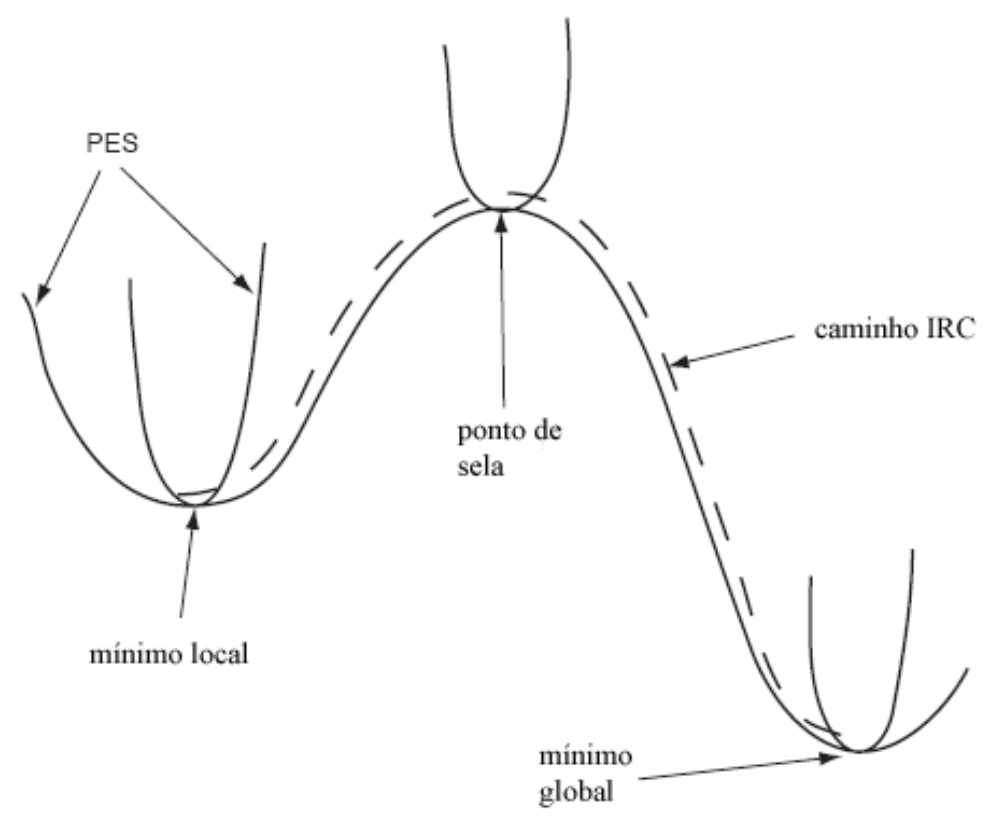

Figura III.3 - Principais pontos de uma superfície de energia potencial. Os mínimos correspondem às estruturas de reagentes ou produtos, e no ponto de sela encontra-se o estado de transição, que - por definição - deve ser um máximo com relação à coordenada da reação, e um mínimo nas demais direções.

\section{III-2.1 CONSTRUÇÃO DAS MATRIZES INTERNAS}

Para realizar a otimização das estruturas, o Gaussian demanda um input que deve incluir posições iniciais dos núcleos dos átomos que compõem aquela estrutura molecular. A estrutura pode ser escrita em coordenadas cartesianas ou em matrizes internas. Neste trabalho, optou-se por descrever as estruturas em matrizes internas, devido à maior facilidade de manipular as estruturas. A Tabela III.3 mostra um exemplo de matriz interna para o fenol.

Tabela III.3 - Matriz interna para otimização da geometria do fenol.

\begin{tabular}{lllllll}
\hline C & & & & & & \\
C & 1 & B1 & & & & \\
C & 1 & B2 & 2 & A1 & & D1 \\
C & 3 & B3 & 1 & A2 & 2 & D2 \\
C & 4 & B4 & 3 & A3 & 1 & D3 \\
C & B & B5 & 4 & A4 & 3 & \\
\hline
\end{tabular}




\begin{tabular}{|c|c|c|c|c|c|c|}
\hline 0 & 3 & B6 & 1 & A5 & 2 & D4 \\
\hline $\mathrm{H}$ & 1 & B7 & 2 & A 6 & 6 & D5 \\
\hline $\mathrm{H}$ & 2 & B8 & 1 & A7 & 3 & D 6 \\
\hline $\mathrm{H}$ & 4 & B9 & 3 & A8 & 1 & D7 \\
\hline $\mathrm{H}$ & 5 & B10 & 4 & A9 & 3 & D8 \\
\hline $\mathrm{H}$ & 6 & B11 & 5 & A10 & 4 & D9 \\
\hline $\mathrm{H}$ & 7 & B12 & 3 & A11 & 1 & D10 \\
\hline
\end{tabular}

A primeira coluna da Tabela III.3 discrimina o elemento químico do átomo, a segunda e a terceira especificam uma das ligações químicas feitas por este átomo (a segunda indica o átomo ao qual ele se liga, de acordo com a ordem de citação na matriz; e a terceira descreve o comprimento da ligação, em Ångstrons); a quarta e a quinta descrevem o ângulo da ligação; e as duas últimas colunas especificam um ângulo diedro associado àquele átomo.

Após a matriz, segue a relação com os valores iniciais de B, A e D, que serão otimizados utilizando um algoritmo escolhido, como será detalhado a seguir.

\section{III-2.2 OTIMIZAÇÃO E PRÉ-OTIMIZAÇÃO}

A otimização da estrutura de interesse tem por objetivo localizar o mínimo de energia na superfície de potencial (ponto M da Figura III.4). Para uma energia potencial U e coordenadas $\vec{q}$, as coordenadas otimizadas devem satisfazer a Equação III-2.1:

$$
\frac{\partial U}{\partial \vec{q}}=0
$$

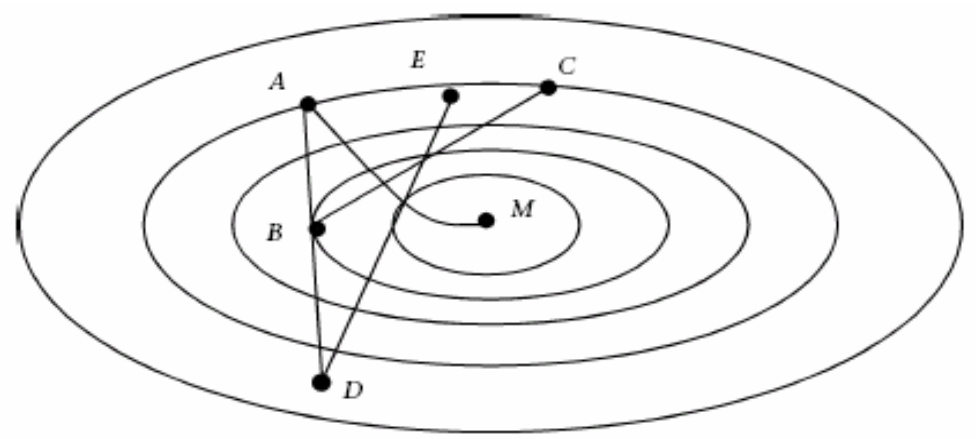

Figura III.4 - Diagrama ilustrando o processo de otimização pelo algoritmo steepest descent. Seja uma superficie de energia potencial com um mínimo em M. Se a minimização se inicia no ponto A e procede a passos infinitesimalmente pequenos, a estrutura segue o caminho A-M. Se o passo inicial é mais largo, ela pode seguir pelo caminho A-B, e então prosseguiria no sentido B-C. Um passo inicial ainda maior poderia levar o sistema à posição D, do qual ela seguiria para o ponto E, divergindo assim do mínimo M (HOWARD et al., 2002). 
Esse processo é executado para um destes fins:

- Caracterizar um mínimo de energia potencial;

- Obter uma nova estrutura estável como ponto de partida para o cálculo do single point mecânico-quântico, que provê uma série de propriedades estruturais e eletrônicas;

- Preparar a estrutura para uma simulação de dinâmica molecular.

O processo de otimização de estruturas baseia-se essencialmente na minimização de uma função arbitrária (energia) de várias variáveis (distâncias interatômicas $r$, ângulos de ligação $\alpha$ e ângulos diedros $\theta$ - os graus geométricos de liberdade). Uma ilustração de um dos algoritmos típicos do processo iterativo de otimização é mostrado na Figura III.5. Parte-se de um conjunto de coordenadas pré-definido e busca-se encontrar um novo conjunto de coordenadas com um mínimo de energia potencial. Ao se mudarem as coordenadas, se a energia encontrada para a nova estrutura for menor que a da estrutura inicial, continuam-se modificando os parâmetros nessa direção, até tornar as variações energéticas mínimas (valor definido pelo usuário do software como limite (threshold)) (Cramer, 2004).

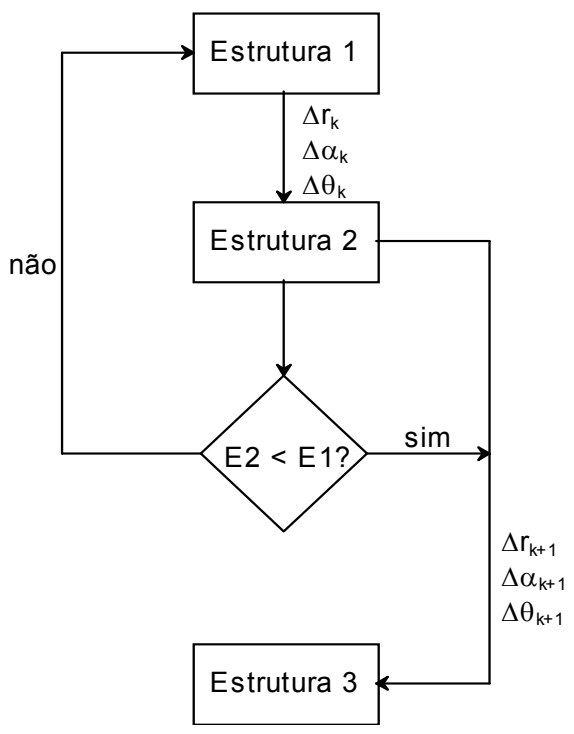

Figura III.5 - Fluxograma de um processo de otimização de estruturas.

A pré-otimização é realizada em casos em que a otimização no nível de base escolhido não é possível, e deve-se fazer uma pré-otimização em um nível de base menor, e este resultado é então utilizado como input para a otimização no nível escolhido. 


\section{III-2.2.1 Eigenvector Following (EF)}

O algoritmo empregado neste trabalho para a otimização é conhecido como Eigenvector Following (encalço do autovetor), algoritmo padrão para otimização de estruturas do Gaussian 03.

Trata-se de um método robusto, similar ao de Newton-Raphson. Neste último, são calculadas as derivadas segundas da energia potencial em função das coordenadas (a matriz Hessiana) (CRAMER, 2004). Seja a energia potencial de uma molécula diatômica AB expressa pela Figura III.6.

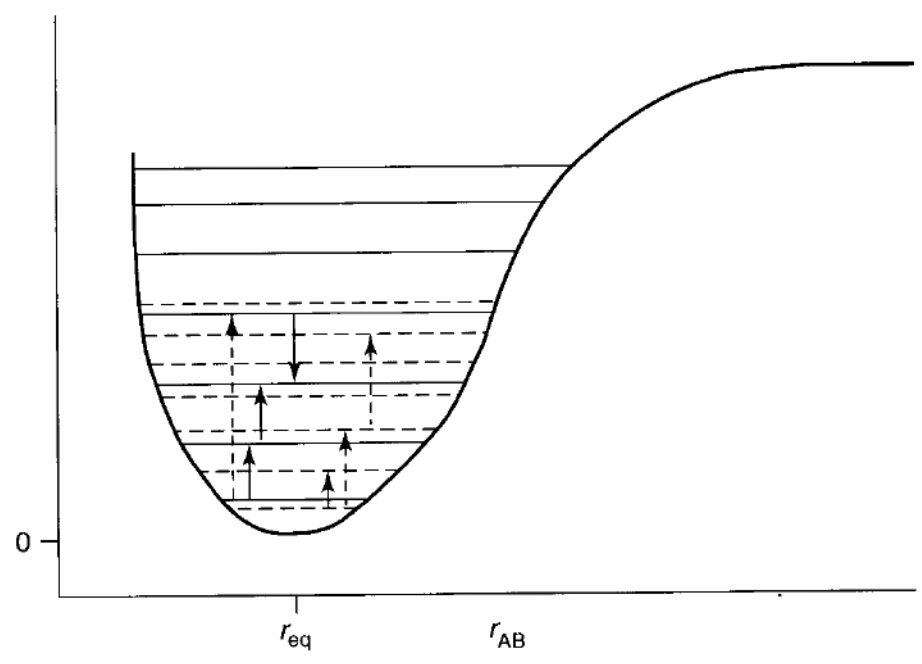

Figura III.6 - Superfície de energia potencial.

Definindo o valor mínimo de energia potencial como zero, e considerando o comprimento dessa ligação nesse patamar como $r_{\text {eq }}$, pode-se determinar o valor da energia potencial $\mathrm{U}$ num ponto arbitrário $\mathrm{r}$ por uma expansão de Taylor em $\mathrm{r}_{e q}$ :

$$
U(r)=U\left(r_{e q}\right)+\left.\frac{d U}{d r}\right|_{r=r_{e q}}\left(r-r_{e q}\right)+\left.\frac{1}{2 !} \frac{d^{2} U}{d r^{2}}\right|_{r=r_{e q}}\left(r-r_{e q}\right)^{2}+\cdots+\left.\frac{1}{n !} \frac{d^{n} U}{d r^{n}}\right|_{r=r_{e q}}\left(r-r_{e q}\right)^{n}
$$

Fazendo a expansão multidimensional: 


$$
\begin{aligned}
U(\vec{q}) & =U\left(\vec{q}_{e q}\right)+\left.\sum_{i=1}^{3 N-6}\left(q_{i}-q_{i, e q}\right) \frac{\partial U}{\partial q_{i}}\right|_{\vec{q}=\vec{q}_{e q}}+\left.\frac{1}{2 !} \sum_{i=1}^{3 N-6} \sum_{j=1}^{N-6}\left(q_{i}-q_{i, e q}\right)\left(q_{j}-q_{j, e q}\right) \frac{\partial^{2} U}{\partial q_{i} \partial q_{j}}\right|_{\vec{q}=\vec{q}_{e q}}+ \\
& +\left.\frac{1}{3 !} \sum_{i=1}^{3 N-6} \sum_{j=1}^{N-6} \sum_{k=1}^{N-6}\left(q_{i}-q_{i, e q}\right)\left(q_{j}-q_{j, e q}\right)\left(q_{k}-q_{k, e q}\right) \frac{\partial^{3} U}{\partial q_{i} \partial q_{j} \partial q_{k}}\right|_{\vec{q}=\vec{q}_{e q}}+\cdots
\end{aligned}
$$

Escrevendo essa expressão em notação matricial e truncando-a no segundo termo, para um estado de referência $\mathrm{q}^{(\mathrm{k})}$, chega-se à Equação III-2.4:

$$
U\left(\vec{q}^{(k+1)}\right)=U\left(\vec{q}^{(k)}\right)+\left(\vec{q}^{(k+1)}-\vec{q}^{(k)}\right) g^{(k)}+\frac{1}{2}\left(\vec{q}^{(k+1)}-\vec{q}^{(k)}\right)^{\mathrm{T}} \mathbf{H}^{(k)}\left(\vec{q}^{(k+1)}-\vec{q}^{(k)}\right)
$$

em que $\mathbf{H}^{(k)}$ representa a matriz Hessiana do ponto de referência. Diferenciando a expressão acima com relação à i-ésima coordenada de $\mathrm{q}^{(\mathrm{k}+1)}$, obtém-se:

$$
\begin{aligned}
\frac{\partial U\left(\vec{q}^{(k+1)}\right)}{\partial \vec{q}_{i}^{k+1}} & =\frac{\partial \vec{q}^{(k+1)}}{\partial \vec{q}_{i}^{k+1}} \vec{g}^{(k)}+\frac{1}{2} \frac{\partial \vec{q}^{(k+1) \dagger}}{\vec{q}_{i}^{k+1}} \mathbf{H}^{(k)}\left(\vec{q}^{(k+1)}-\vec{q}^{(k)}\right)+ \\
& +\frac{1}{2}\left(\vec{q}^{(k+1)}-\vec{q}^{(k)}\right)^{\mathrm{T}} \mathbf{H}^{(k)} \frac{\partial \vec{q}^{(k+1)}}{\partial \vec{q}_{i}^{k+1}}
\end{aligned}
$$

O membro esquerdo da Equação III-2.5 é o i-ésimo elemento do vetor $\mathrm{g}^{(\mathrm{k}+1)}$. No membro direito, como a derivada parcial de $q$ com relação a sua i-ésima coordenada define o próprio vetor unitário na direção da i-ésima coordenada, as várias multiplicações matriciais simplesmente produzem o i-ésimo elemento dos vetores multiplicados. Como os valores das derivadas parciais mistas são independentes da ordem de diferenciação (a matriz Hessiana é Hermitiniana), a Equação III-2.5 pode ser simplificada como:

$$
g_{i}^{(k+1)}=g_{i}^{(k)}+\left[\mathbf{H}^{(k)}\left(\vec{q}^{(k+1)}-\vec{q}^{(k)}\right)\right]_{i}
$$


A condição para se encontrar um ponto estacionário demanda que a Equação III-2.6 seja nula para todas as coordenadas:

$$
0=\vec{g}_{i}^{(k)}+\mathbf{H}^{(k)}\left(\vec{q}^{(k+1)}-\vec{q}^{(k)}\right)
$$

que pode ser rearranjado para:

$$
\vec{q}^{(k+1)}=\vec{q}^{(k)}-\mathbf{H}^{(k)} \vec{g}_{i}^{(k)}
$$

Essa equação provê uma prescrição para a localização de pontos estacionários. Em princípio, partindo-se de uma estrutura com coordenadas $q^{(\mathrm{k})}$, pode-se computar seu vetor

gradiente $g$ e sua matriz Hessiana $\mathbf{H}$ e, então, selecionar uma nova geometria $q^{(k+1)}$ de acordo com a Equação III-2.8. O processo é repetido iterativamente até que se chegue a um ponto em que o gradiente se torna tão pequeno que as estruturas $k+n$ e $k+n+1$ diferem por uma quantidade quimicamente insignificante, e diz-se que a geometria da estrutura convergiu.

O método Eigenvector Following em vez de calcular explicitamente as derivadas segundas da matriz Hessiana, faz uso de uma matriz Hessiana diagonal para obter implicitamente as derivadas segundas da energia potencial com relação aos deslocamentos atômicos. A estimativa inicial é computada empiricamente a partir de um banco de dados do software.

\section{III-2.2.2 Otimização do Estado de Transição (ET)}

As estruturas dos estados de transição para cada reação individual são calculadas no Gaussian, que faz uso do método STQN (Synchronous Transit Quasi-Newton) (PENG \& SCHLEGEL, 1993). Existem dois métodos de trânsito sincrônico, o trânsito sincrônico linear (LST) e o trânsito sincrônico quadrático (QST). O método LST forma a geometria do ET através da procura do máximo ao longo de um caminho linear entre reagentes e produtos, ao 
passo que o QST faz uma aproximação quadrática da região do ET (LEACH, 2001). A Figura III.7 ilustra uma comparação entre os dois métodos.

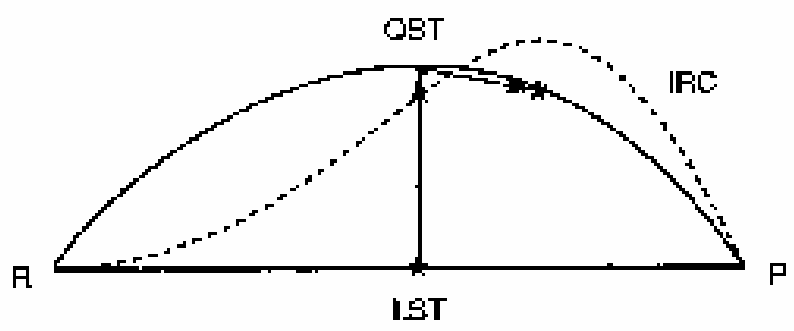

Figura III.7 - Ilustração dos métodos QST e LST, comparados com a coordenada da reação (IRC).

Após se aproximar da região do estado de transição pelo método QST, o software utiliza o algoritmo EF para a otimização da estrutura do ET com relação às demais coordenadas.

\section{III-2.3 CÁLCULOS DE FREQUÊNCIA}

Os cálculos de frequência têm dois objetivos neste de trabalho: computar a vibração do ponto zero e outras quantidades termodinâmicas para a estrutura otimizada e indicar a natureza do estado de transição encontrado. Os cálculos de energia e as otimizações de geometria ignoram as vibrações dos sistemas moleculares e, por isso, esses cálculos fazem uso de uma visão idealizada das posições nucleares uma vez que, na realidade, os núcleos atômicos das moléculas estão em constante movimento. Nos estados de equilíbrio, entretanto, essas vibrações são regulares e previsíveis. De fato, as moléculas podem ser identificadas pelo seu espectro de vibração (FORESMAN \& FRISCH, 1996).

As frequências moleculares dependem da derivada segunda da energia com relação às posições nucleares (a matriz Hessiana). Após uma transformada de coordenadas, a matriz é diagonalizada, gerando um conjunto de autovalores cujas raízes quadradas correspondem às frequências fundamentais de vibração da estrutura. Após isso, é gerado um sistema de coordenadas com base nos principais eixos de inércia. A matriz desse sistema de coordenadas internas é então utilizada para uma nova transformada de coordenadas da matriz Hessiana, com objetivo de eliminar as componentes de rotação e translação e, assim, obter frequências 
de vibração "puras”. A estrutura do algoritmo, como aplicado pelo software Gaussian, é apresentada na Figura III.8 (OCHTERSKi, 1999).

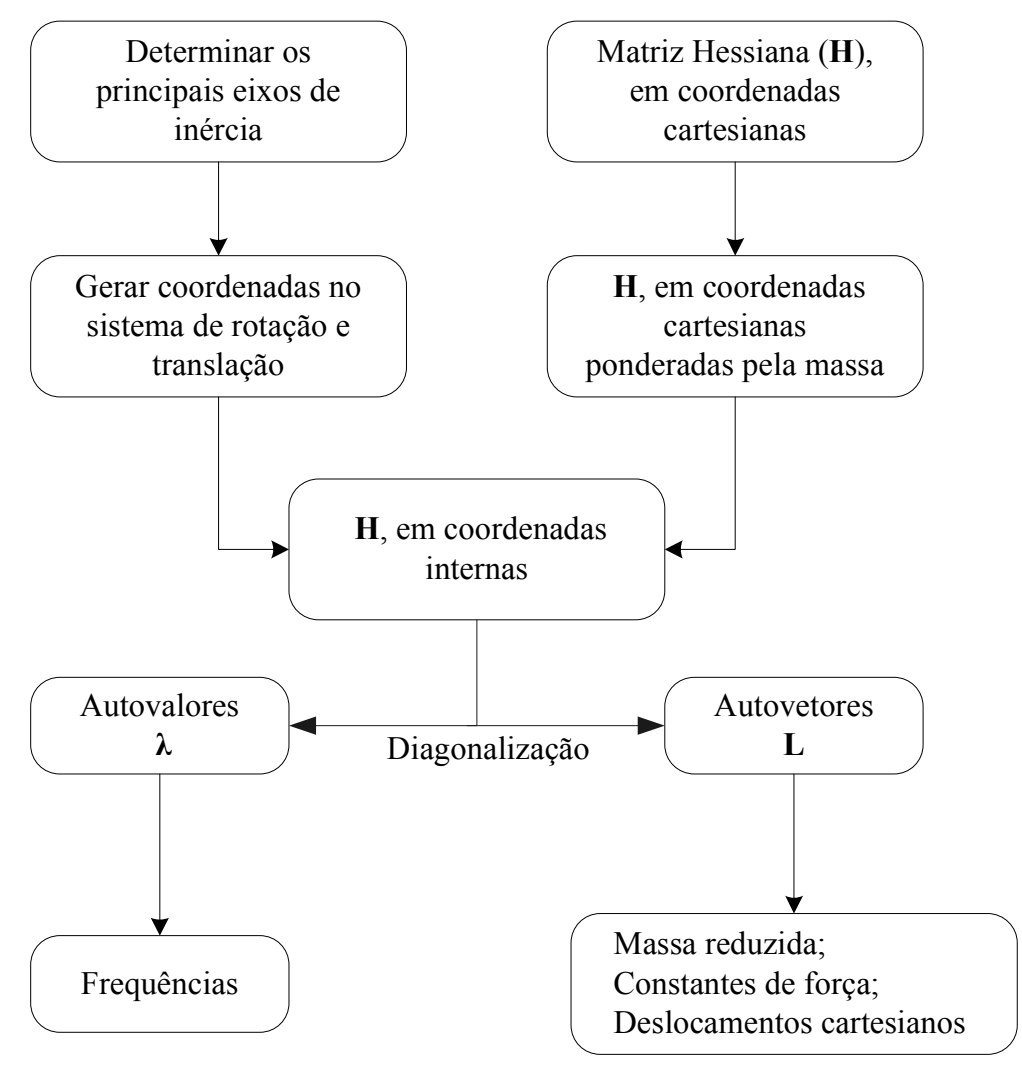

Figura III.8 - Ilustração do algoritmo utilizado pelo software Gaussian para o cálculo das frequências e das propriedades relacionadas.

\section{III-2.4 CÁLCULOS TERMODINÂMICOS}

A ligação entre as propriedades microscópicas e macroscópicas da matéria é feita através da termodinâmica estatística (ATKINS \& DE PAULA, 2002). Para lidar com conjuntos de moléculas, deve-se fixar algumas condições macroscópicas. A enumeração dessas condições define um 'ensemble'. Quando as propriedades mantidas constantes são o número total de partículas $N$, o volume $V$ e a temperatura $T$, o ensemble recebe o nome de ensemble canônico. 
Assim como existe uma função fundamental que caracteriza o sistema microscópico na mecânica quântica (função de onda) e na DFT (densidade eletrônica), há uma função de status equivalente na mecânica estatística: a função de partição. Para o ensemble canônico ela é escrita como mostrado na Equação III-2.9:

$$
Q(N, V, T)=\sum_{i} e^{-E_{i}(N, V) / k_{B} T}
$$

em que o somatório é feito sobre todos os $i$ estados energéticos possíveis de um sistema que contenha a energia $E_{i}$. No ensemble canônico, e usando as definições termodinâmicas estabelecidas, podem-se se construir as seguintes relações (CRAMER, 2004):

$$
\begin{aligned}
& E=k_{B} T^{2}\left(\frac{\partial \ln Q}{\partial T}\right)_{N, V} \\
& H=E+P V \\
& S=k_{B} \ln Q+k_{B} T\left(\frac{\partial \ln Q}{\partial T}\right)_{N, V} \\
& G=H-T S
\end{aligned}
$$

Infelizmente, não é simples obter uma expressão analítica para $Q$ que permita as diferenciações parciais das Equações III-2.10 e 12. Para um ensemble verdadeiro, $Q$ deve ser uma função multiparticular fantasticamente complexa, envolvendo um número enorme de níveis energéticos. Para progredir nos cálculos, são feitas algumas premissas. A primeira é tomar o ensemble como um gás ideal. Com isso, chega-se a uma expressão para $Q$ em função de uma quantidade denominada função de partição molecular, q, (Equação III-2.14), reduzindo o problema ao cálculo da função de partição de uma única molécula e, a partir dela, calcular a função de partição do sistema:

$$
Q(N, V, T)=\frac{[q(V, T)]^{N}}{N !}
$$

em que a função de partição molecular $q$ é dada por:

$$
q(V, T)=\sum_{k}^{\text {niveis }} g_{k} e^{-\varepsilon_{k}(V) / k_{B} T}
$$

sendo $\varepsilon$ a energia total da molécula no estado $k$. 
Considerando a energia total $\varepsilon$ como combinação linear das energias eletrônica, translacional, rotacional e vibracional, a Equação III-2.15 pode ser reescrita como

$$
q(V, T)=q_{\text {elet }}(T) q_{\text {trans }}(V, T) q_{\text {rot }}(T) q_{v i b}(T)
$$

Para o cálculo das propriedades termodinâmicas, o Gaussian calcula as componentes individuais das funções de partição e, a partir delas, avalia as contribuições de cada um dos movimentos para as propriedades termodinâmicas (derivadas das Equações III-2.10 - 13, usando as Equações III-2.14 e III-2.16), como ilustra a Figura III.9 (OCHTERSKI, 2000).

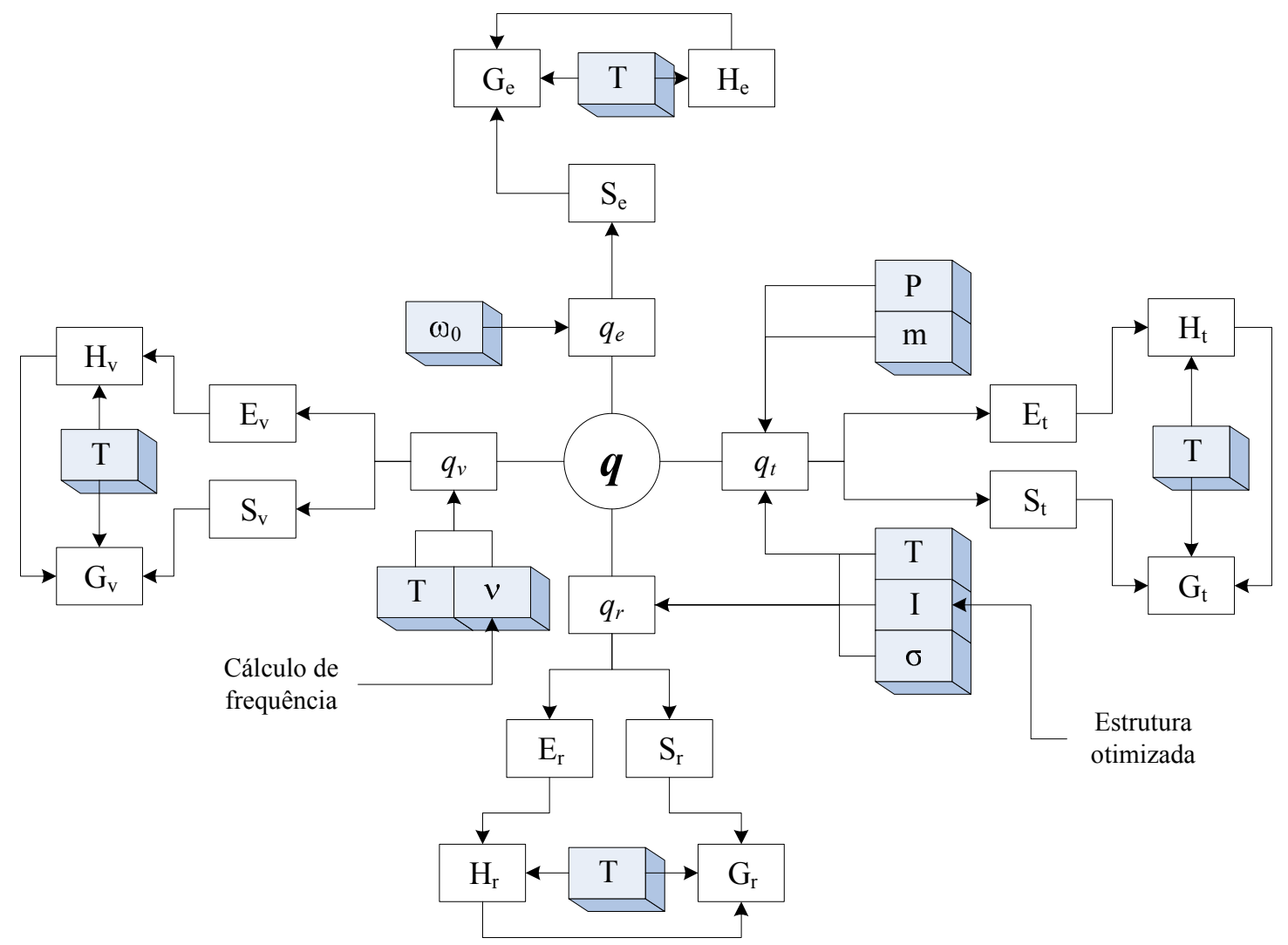

Figura III.9 - Ilustração do algoritmo utilizado pelo software Gaussian para o cálculo das propriedades termodinâmicas. Os blocos sombreados denotam os dados de entrada utilizados pelo software. $\omega_{0}$ corresponde à multiplicidade de spin eletrônico da molécula, $\sigma$ denota o número de simetria rotacional, $I$ o momento de inércia e $v$ as frequências da molécula. $P$ é a pressão, $m$ a massa e $T$ a temperatura do sistema. Nota-se a dependência da temperatura nas diversas etapas do cálculo. Todas as quantidades mostradas na figura são calculadas e retornadas pelo software (exceto T e P, especificadas pelo usuário). 


\section{III-2.5 CÁLCULO CINÉTICO}

Os cálculos cinéticos realizados no trabalho baseiam-se na Teoria do Estado de Transição (TST). De acordo com esta teoria, a constante cinética para uma reação é dada por:

$$
k=\kappa(T) \frac{k_{B} T}{h} \frac{Q^{\ddagger}}{Q_{R}} \frac{Q_{R}^{0}}{Q^{\ddagger}} \exp \left[-\frac{\Delta V^{\ddagger}}{k_{B} T}\right]
$$

em que $k_{B}$ é a constante de Boltzmann, $Q_{R}$ representa a função de partição total do reagente (ou o produto das funções de partição totais dos reagentes), $Q^{\ddagger}$ a função de partição total do estado de transição, os termos de $Q^{0}$ têm valor unitário e contêm as unidades de volume do estado padrão. $\Delta V^{*}$ representa a diferença nas energias potenciais (incluindo o ponto zero) entre a estrutura do estado de transição e os reagentes (CRAMER, 2004). As funções de partição podem ser absorvidas no termo exponencial, resultando na Equação III-2.18:

$$
k=\kappa(T) \frac{k_{B} T}{h} \exp \left[-\frac{\Delta G^{0,}}{k_{B} T}\right]
$$

$\kappa(T)$ corresponde ao coeficiente de transmissão (relacionado aos efeitos de tunelamento e de reflexão não-clássica), cuja boa aproximação é dada por Skodje e Truhlar (1981):

$$
\kappa(T)=\frac{\beta \pi / \alpha}{\operatorname{sen}(\beta \pi / \alpha)}-\frac{\beta}{\alpha-\beta} \exp \left[(\beta-\alpha)\left(\Delta V^{\ddagger}-V\right)\right],
$$

se $\beta \leq \alpha$, ou

$$
\kappa(T)=\frac{\beta}{\beta-\alpha}\left\{\exp \left[(\beta-\alpha)\left(\Delta V^{\ddagger}-V\right)\right]-1\right\},
$$

se $\alpha \leq \beta$. $V$ é 0 para reações exoérgicas e, para reações endoérgicas, equivale à diferença (positiva) de energia potencial entre reagentes e produtos. Os parâmetros $\alpha$ e $\beta$ são calculados segundo as Equações III-2.21 e 22: 


$$
\begin{gathered}
\alpha=\frac{2 \pi}{h \operatorname{Im}\left(v^{\ddagger}\right)} \\
\beta=\frac{1}{k_{B} T}
\end{gathered}
$$

em que Im refere-se à frequência imaginária da vibração característica do estado de transição.

\section{III-2.6 MODELOS DE SOLVATAÇÃo}

Neste trabalho, foram testados dois tipos de métodos de solvatação para a primeira reação elementar do mecanismo que leva à formação do catecol a partir do fenol: os métodos de solvatação implícita (SCI-PCM e SM5.42R) e os métodos de solvatação explícita. Os cálculos de solvatação SCI-PCM foram executados no Gaussian 03, utilizando a DFT, e os calculos SM5.42R foram conduzidos no AMSOL, usando o modelo semiempírico AM1.

Para a construção do modelo de solvatação explícita, foram construídas estruturas de acordo com estudos encontrados na literatura (LÜCHOW et al., 2001; WATANABE et al., 1996; PLUGATYR et al., 2006; WOLFE et al., 1995; 1998). As estruturas modeladas são mostradas abaixo:

Tabela III.4 - Modelos de solvatação explicíta.

\section{Código} Estrutura 2D

Estrutura 3D
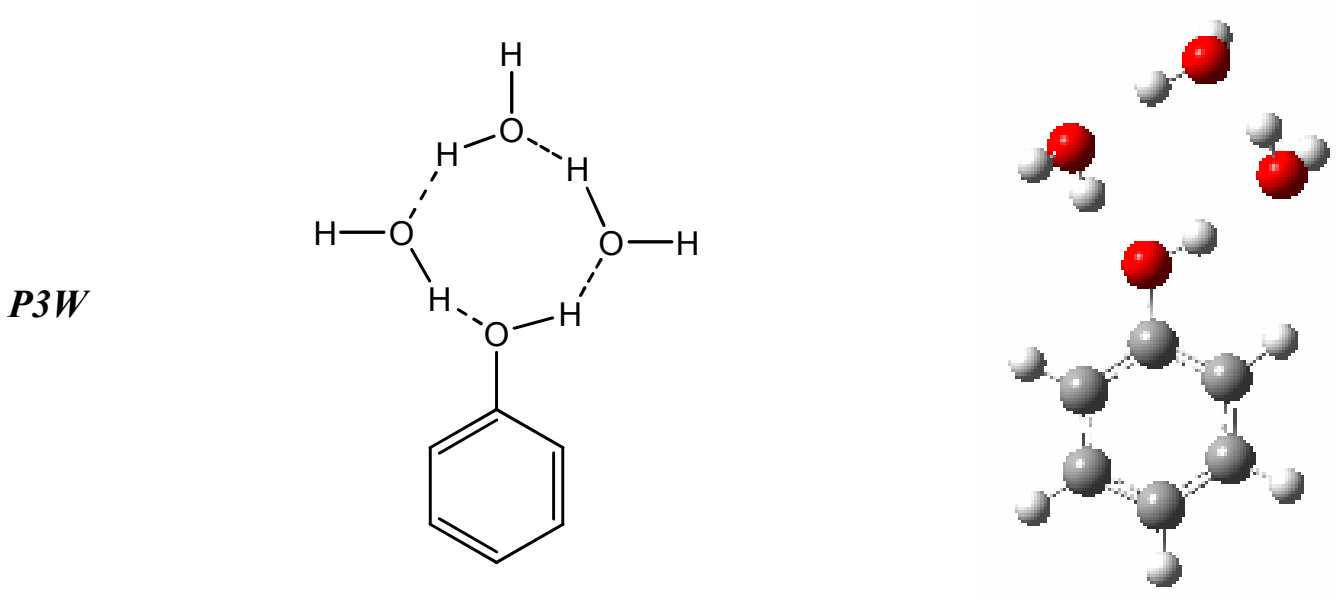


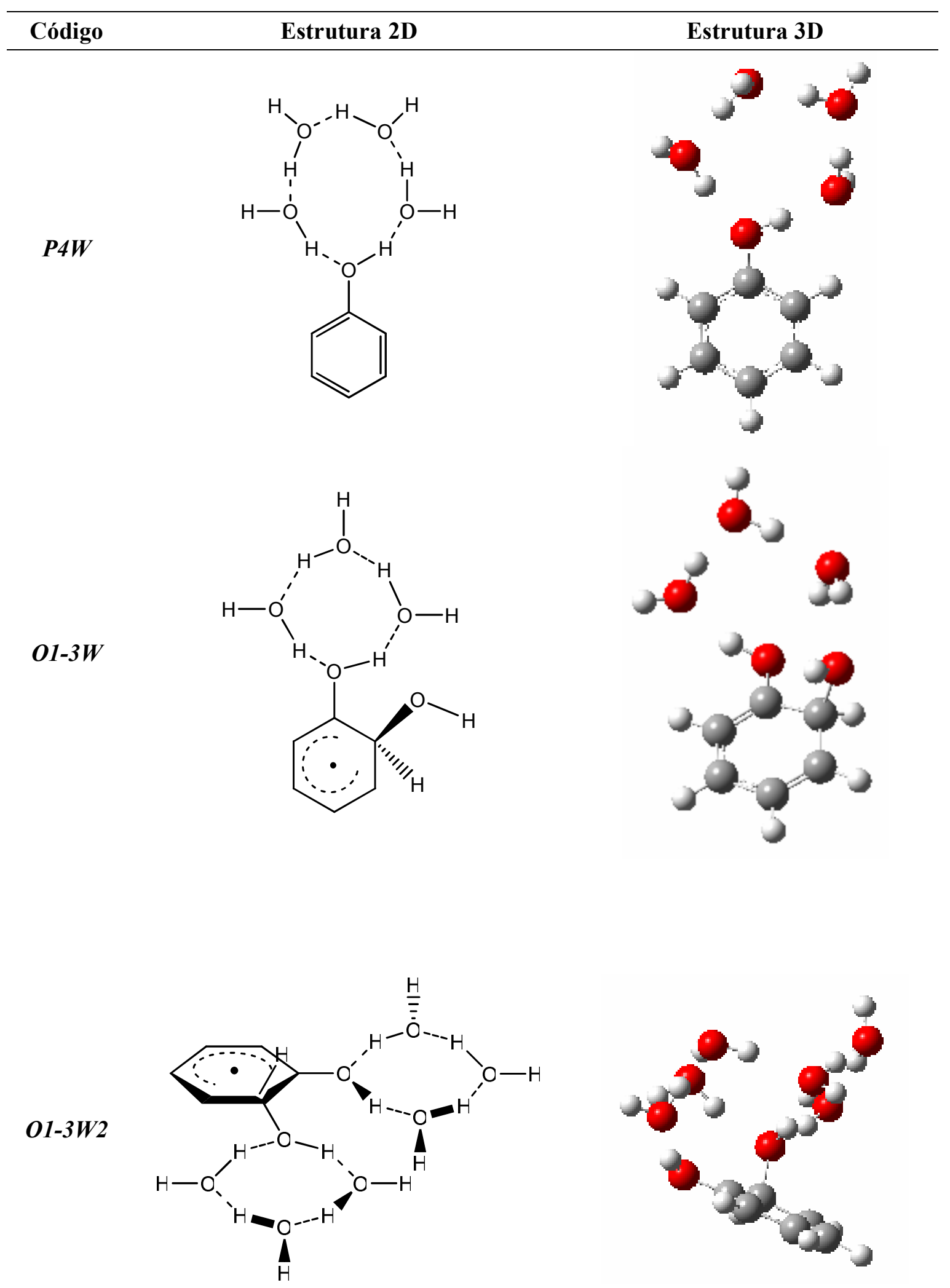




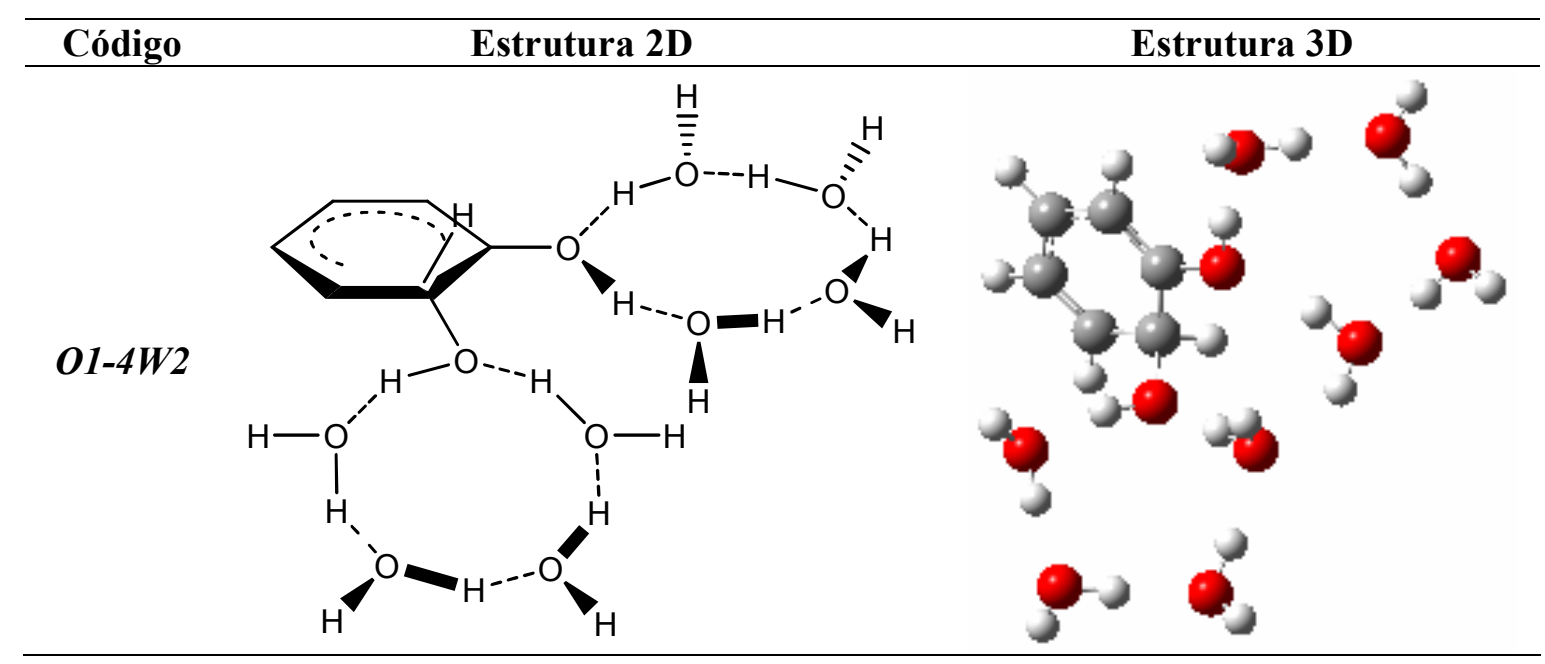

As supermoléculas foram otimizadas com o funcional B3LYP, utilizando o conjunto de base $6-31++\mathrm{G}(\mathrm{d}, \mathrm{p})$ (mesmo nível de teoria utilizado para os cálculos em fase gasosa); seguindo-se um cálculo de frequência para avaliação das propriedades termodinâmicas quando possível. As estruturas otimizadas foram submetidas ao cálculo de solvatação usando o método semi-empírico AM1 e o modelo de solvatação SM5.42R com objetivo de avaliar a representatividade do modelo desenhado.

Para os cálculos de solvatação implícita foram utilizadas as estruturas otimizadas em fase gasosa pela DFT. Essas estruturas foram submetidas ao AMSOL para cálculo de solvatação usando o modelo SM5.42. 
Título IV

Resultados E Discussão 


\section{Capítulo IV-1}

\section{ESTUDO DE INTERMEDIÁRIOS}

O mecanismo proposto (Figura III.1) foi subvidido em etapas, com objetivo de propor etapas elementares. Foram estudadas quatro etapas, cujos resultados serão expostos e discutidos a seguir:

\section{IV-1.1 ADIÇÃo ORTO AO ANEL AROMÁTICO}

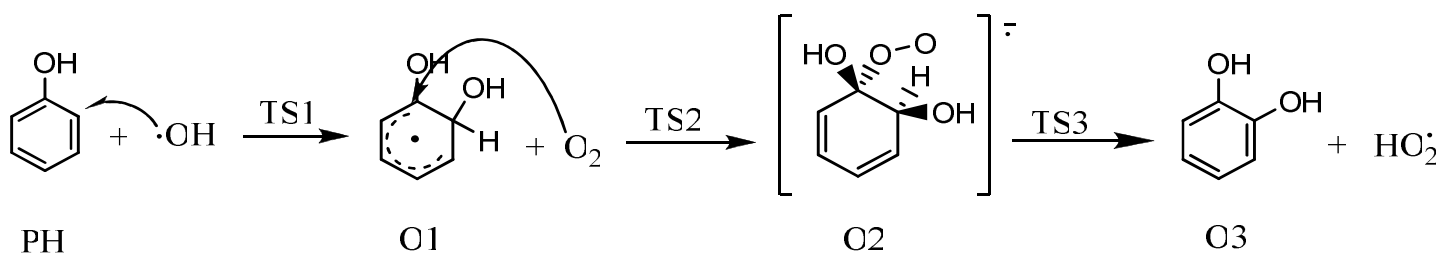

A primeira etapa do mecanismo envolve a conversão do fenol a catecol ou hidroquinona, dependendo da posição do ataque do radical hidroxila ao anel aromático. Kiliç et al. (2007) demonstraram que a influência da reação por abstração de hidrogênio do anel fenólico pelo radical hidroxila e a adição na posição meta têm cinética desprezível, justificando os dados experimentais encontrados na literatura corrente e, portanto, tais vias não são estudadas neste trabalho.

A Figura IV.1 exibe as energias calculadas para os intermediários em fase gasosa e aquosa $^{7}$, bem como as entalpias avaliadas pelo método semi-empírico PM3.

\footnotetext{
${ }^{7}$ A menos que o texto indique o contrário, considerar cálculo realizado por meio da Teoria do Funcional da Densidade com o funcional de Becke-Lee-Yang-Parr, B3LYP, utilizando o conjunto de base 6-31++G(d,p). A simulação do solvente é feita utilizando o modelo SCI-PCM com os mesmos método e nível de teoria.
} 


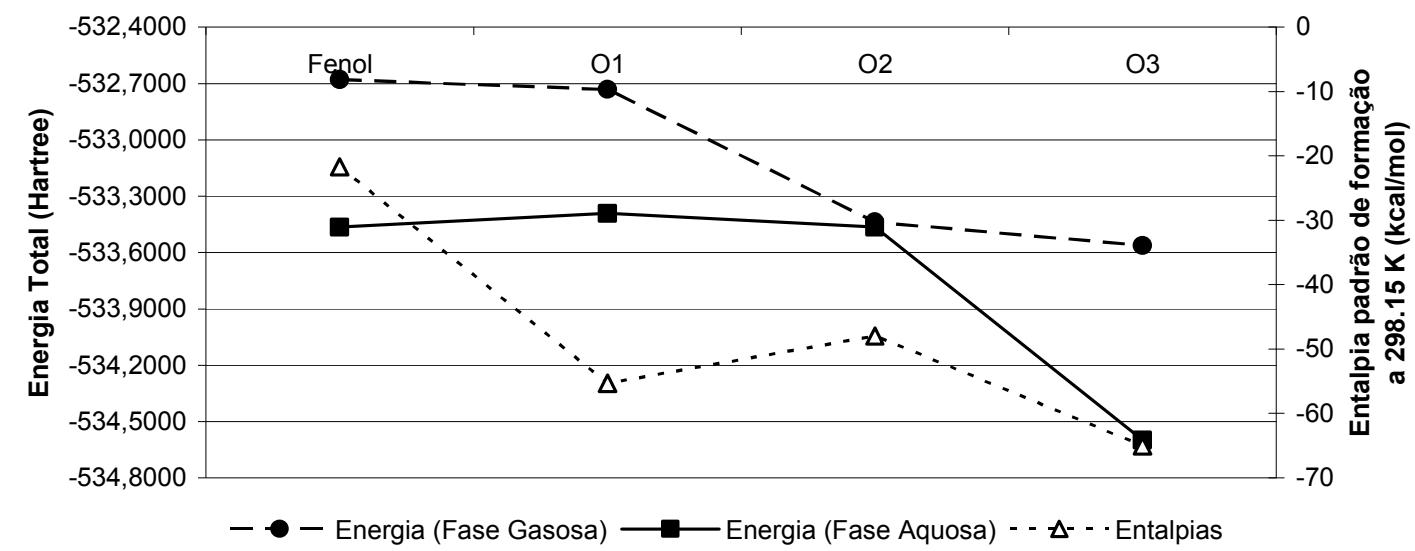

Figura IV.1 - Energias totais em fase gasosa e aquosa e entalpias calculadas para os intermediários estáveis propostos para a primeira etapa do mecanismo.

Para o primeiro passo de R1, a estrutura de transição foi otimizada, de acordo com a metodologia descrita no Capítulo III. A Tabela IV.1 resume as principais características da reação:

Tabela IV.1 - Resultados energéticos obtidos para a primeira reação da primeira etapa, usando método DFT e PM3. Todos valores são dados em kJ mol ${ }^{-1}$.

\begin{tabular}{lcccccccccc}
\hline \multirow{2}{*}{ Estrutura } & \multicolumn{4}{c}{ DFT/(U)B3LYP 6-31++G(d,p) } & \multicolumn{5}{c}{ (U)PM3 } \\
\cline { 2 - 11 } & $\mathrm{U}$ & $\Delta \mathrm{U}^{\ddagger}$ & $\Delta \mathrm{G}^{\ddagger}$ & $\Delta_{\mathrm{R}} \mathrm{H}$ & $\Delta_{\mathrm{R}} \mathrm{G}$ & $\mathrm{U}$ & $\Delta \mathrm{U}^{\ddagger}$ & $\Delta \mathrm{G}^{\ddagger}$ & $\Delta_{\mathrm{R}} \mathrm{H}$ & $\Delta_{\mathrm{R}} \mathrm{G}$ \\
\hline $\mathrm{PH}+\cdot \mathrm{OH}$ & -1006160 & & & & & $-79,25$ & & & & \\
$\mathrm{TS} 1$ & -1006108 & 51,79 & 12,96 & -123 & $-39,55$ & $-57,04$ & 22,21 & 64,27 & $-87,71$ & $-62,27$ \\
$\mathrm{O} 1$ & -1006252 & & & & & $-200,76$ & & & & \\
\hline
\end{tabular}

$\mathrm{U}$ é a energia total, $\Delta \mathrm{U}^{\ddagger}$ a energia de ativação, $\Delta \mathrm{G}^{\ddagger}$ a energia livre de ativação, $\Delta_{\mathrm{R}} \mathrm{H}$ a entalpia de reação, e $\Delta_{\mathrm{R}} \mathrm{G}$ a energia livre de reação. A sigla (U) ao lado do modelo de cálculo indica o uso de um formalismo de cálculo irrestrito.

Kiliç et al. (2007) estudaram essa reação, utilizando o mesmo funcional DFT, mas com conjunto de base menor $(6-31 \mathrm{G}(\mathrm{d}))$ e o modelo semi-empírico PM3, obtendo os resultados mostrados na Tabela IV.2. 
Tabela IV.2 - Resultados energéticos obtidos por Kiliç et al. (2007). Todos valores são dados em kJ mol ${ }^{-1}$. Os parâmetros seguem a mesma simbologia da Tabela VI.1.

\begin{tabular}{rccccccc}
\hline \multicolumn{3}{c}{ DFT/(U)B3LYP 6-31G(d) } & \multicolumn{4}{c}{ (U)PM3 } \\
\hline$\Delta \mathrm{U}^{\ddagger}$ & $\Delta \mathrm{G}^{\ddagger}$ & $\Delta_{\mathrm{R}} \mathrm{H}$ & $\Delta_{\mathrm{R}} \mathrm{G}$ & $\Delta \mathrm{U}^{\ddagger}$ & $\Delta \mathrm{G}^{\ddagger}$ & $\Delta_{\mathrm{R}} \mathrm{H}$ & $\Delta_{\mathrm{R}} \mathrm{G}$ \\
\hline \multirow{2}{*}{10,96} & - & $-81,88$ & - & 18,702 & - & $-156,48$ & - \\
\hline
\end{tabular}

Essa reação foi estudada experimentalmente, como mostra o trabalho publicado por Bonin et al. (2007). Os autores estudaram-na usando radiólise de pulso eletrônico e espectroscopia de absorção transiente em uma extensa faixa de temperaturas. Observou-se o comportamento da constante cinética, com relação à temperatura, como mostrado na Figura IV.2:

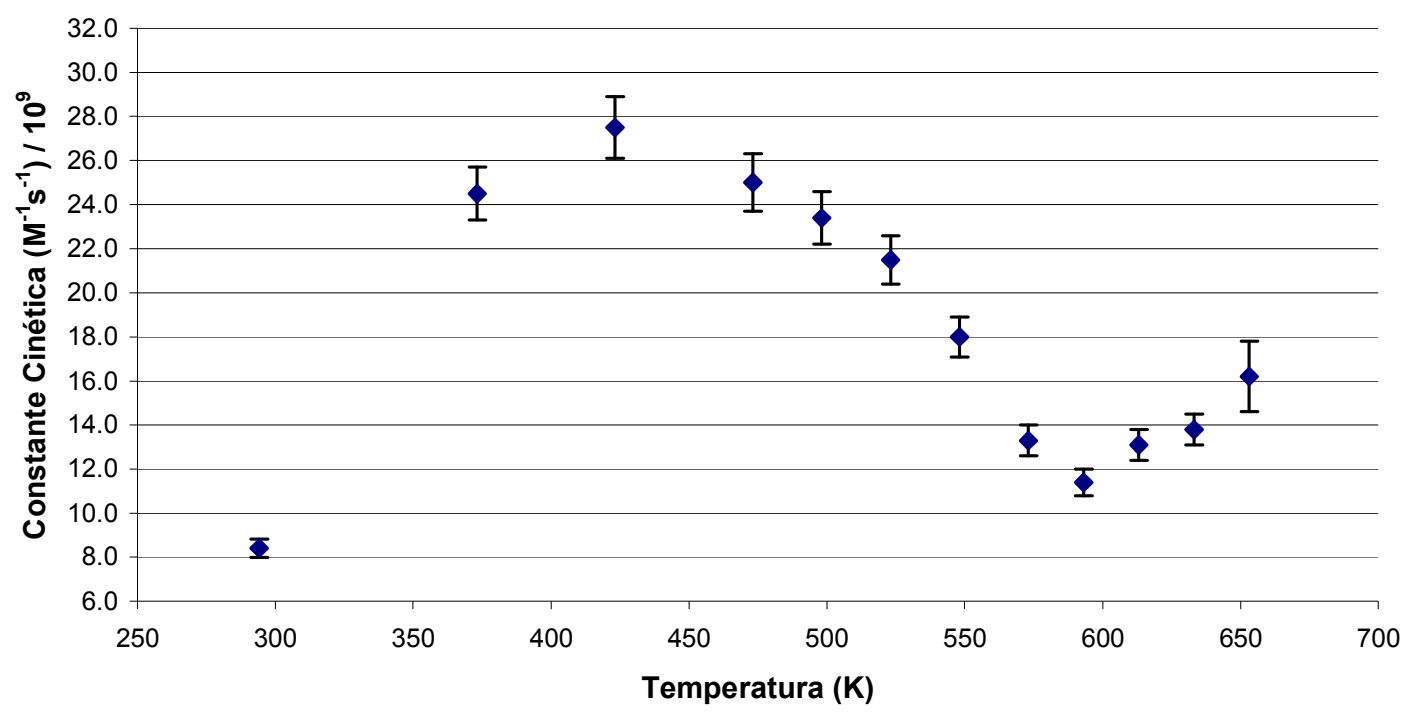

Figura IV.2 - Comportamento da constante cinética para a reação de adição do radical hidroxila ao anel fenólico. Dados experimentais de Bonin et al. (2007).

Nota-se que há uma temperatura em que a constante cinética tem um valor máximo, a partir da qual ele passa a decrescer com incrementos de temperatura, até um mínimo local em, aproximadamente, $600 \mathrm{~K}$. Fixando-se a faixa de estudo nos três primeiros pontos (cujas temperaturas são, a saber, $21{ }^{\circ} \mathrm{C}, 100{ }^{\circ} \mathrm{C}, 150^{\circ} \mathrm{C}$ ), pode-se traçar o gráfico de Eyring, como mostrado na Figura IV.3. 


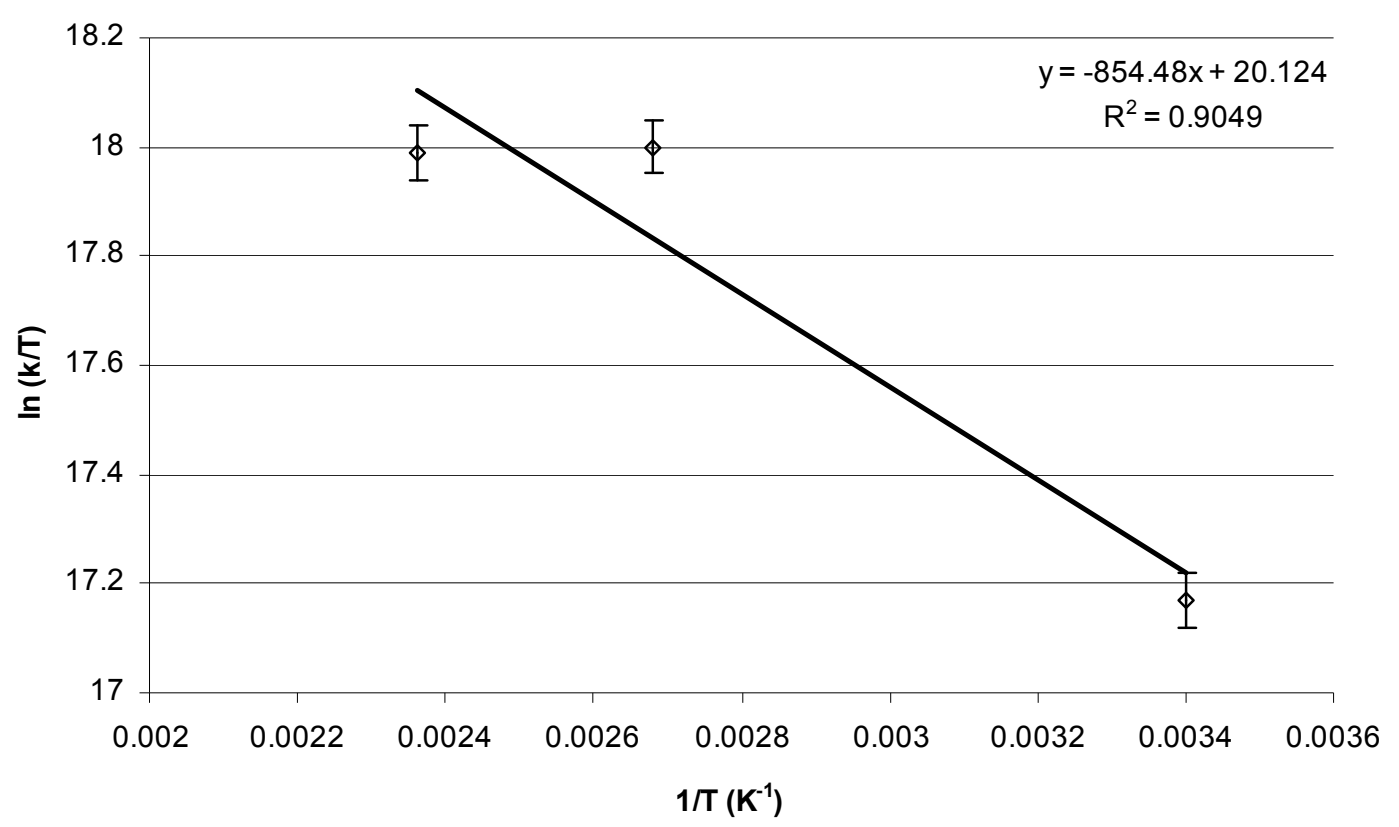

Figura IV.3 - Curva de Eyring para os dados experimentais levantados por Bonin et al. (2007).

A expressão empírica para a curva de Eyring é dada pela Equação IV-1.1 abaixo:

$$
\ln \left(\frac{k}{T}\right)=-\frac{\Delta H^{\ddagger}}{R T}+\frac{\Delta S^{\ddagger}}{R}+\ln \left(\frac{k_{B}}{h}\right)
$$

em que o superscrito $\ddagger$ remete às diferenças entre as quantidades termodinâmicas do estado de transição e dos reagentes.

Com essa expressão e os dados experimentais, pode-se avaliar a energia livre de ativação, $\Delta \mathrm{G}^{\ddagger}$, dada pela Equação III-2.13, tomando entalpia e entropia de ativação, calculadas com auxílio da Equação IV-1.1:

$$
\Delta G^{\ddagger}=\Delta H^{\star}-T \Delta S^{\star}
$$

Assim, chega-se às estimativas experimentais dispostas na Tabela IV.3: 
Tabela IV.3 - Parâmetros termodinâmicos estimados a partir de dados experimentais, conforme a Equação IV-1.1.

\begin{tabular}{ccc}
\hline \multicolumn{3}{c}{ Parâmetros termodinâmicos experimentais } \\
\hline$\Delta H^{\ddagger}\left(\mathrm{kJ} \mathrm{mol}^{-1}\right)$ & $\Delta S^{\ddagger}\left(\mathrm{J} \mathrm{mol}^{-1} \mathrm{~K}^{-1}\right)$ & $\Delta G^{\ddagger}\left(\mathrm{kJ} \mathrm{mol}^{-1}\right)$ \\
\hline $7,13 \pm 0,77$ & $-30,33 \pm 2,18$ & $16,17 \pm 1,42$ \\
\hline
\end{tabular}

A Figura IV.4 mostra os resultados das energias livres, como avaliados por três diferentes cálculos.

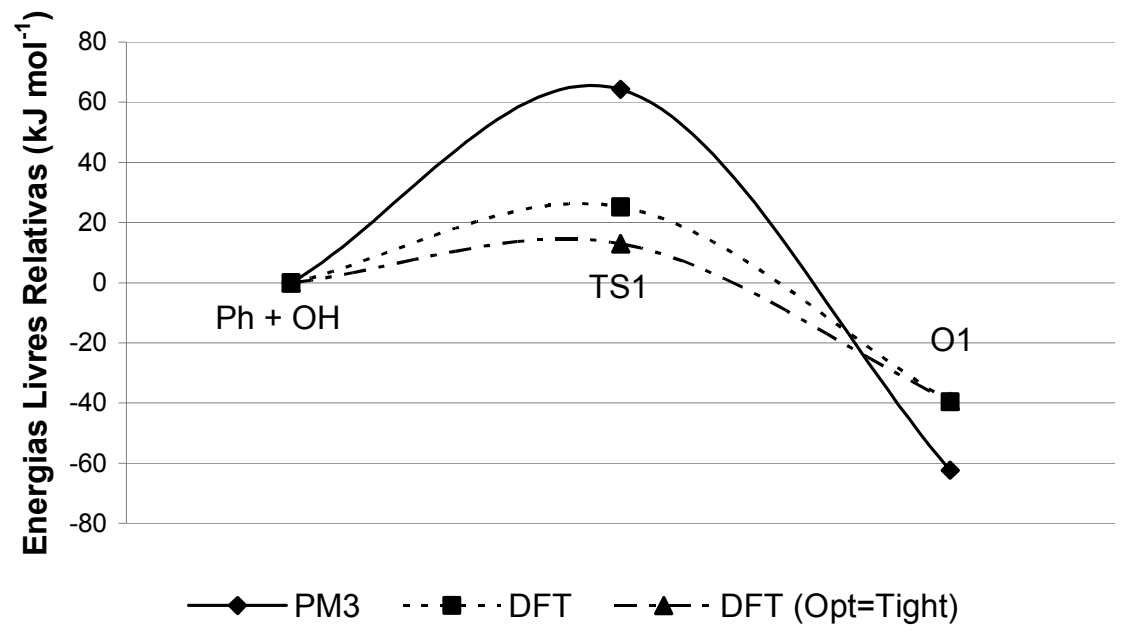

Figura IV.4 - Avaliação da energia livre por três métodos de cálculo distintos.

A observação dos resultados mostrados na Figura IV.4 e na Tabela IV.1 leva à escolha da DFT como método de cálculo, visto que os resultados estão mais próximos às estimativas experimentais.

De acordo com Legrini et al. (1993), o radical orgânico formado pela adição eletrofílica do radical hidroxila pode reagir com oxigênio dissolvido no meio reacional de um POA. A posição do ataque é determinada após uma análise energética das estruturas possíveis. A molécula de oxigênio pode adicionar-se em posição ipso em relação à hidroxila fenólica, ou nas posições meta $m 1$ e $m 2$, como mostrado na Figura IV.5. 


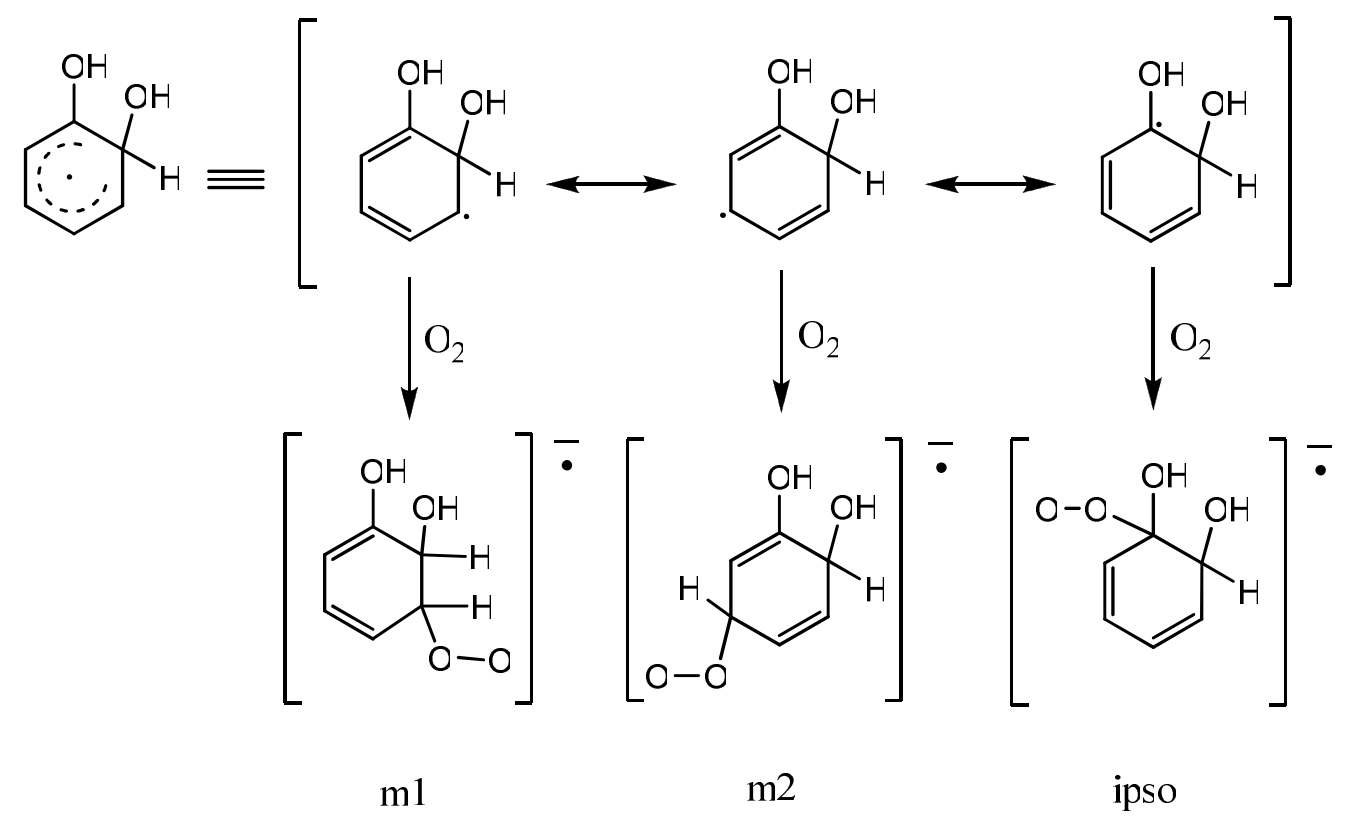

Figura IV.5 - Posições possíveis para a adição do oxigênio molecular ao radical orgânico formado após a etapa de adição eletrofílica do radical hidroxila.

As energias das estruturas acima, conforme avaliadas em fase gasosa com a Teoria do Funcional da Densidade, são ilustradas na Figura IV.6.

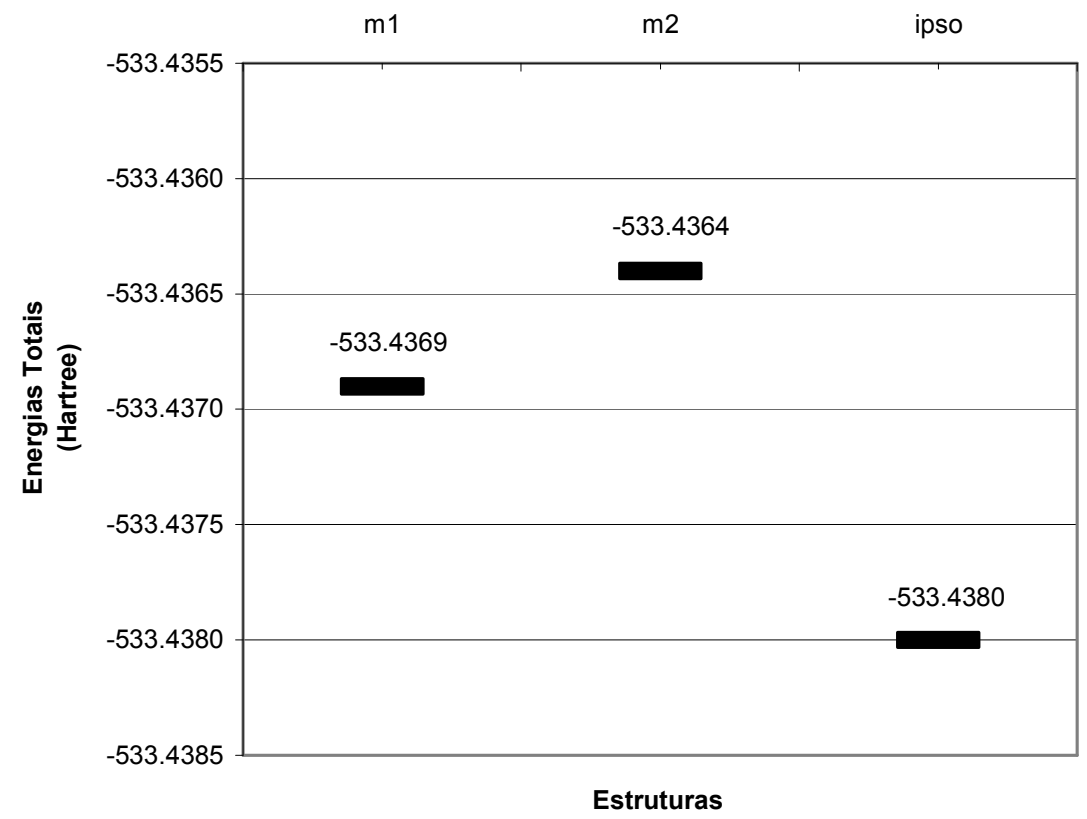

Figura IV.6 - Energias totais das três estruturas possíveis após a adição do oxigênio molecular, como indicado na Figura IV.5. 1 Hartree partícula ${ }^{-1}\left(627,509 \mathrm{kcal} \mathrm{mol}^{-1}\right)$ é uma unidade de energia atômica definida como sendo o valor absoluto da energia potencial elétrica do átomo de hidrogênio em seu estado fundamental. 
A comparação das energias permite comentar acerca da estabilidade relativa dessas estruturas. Pode-se dizer, então, que a estrutura formada com o oxigênio ligado à posição ipso apresenta a menor energia dentre as estruturas possíveis e, por isso, é mais estável. Devido aos requerimentos estéricos da reação de eliminação do radical hidroperoxila (passo subsequente à adição do oxigênio), a adição na posição $m 2$ é desprezada. Para verificar qual a posição preferencial para adição do oxigênio, é necessário - além da comparação energética um estudo do Estado de Transição para os dois casos concorrentes (ataque $m 1$ versus ataque ipso). Os resultados são mostrados na Figura IV.7.

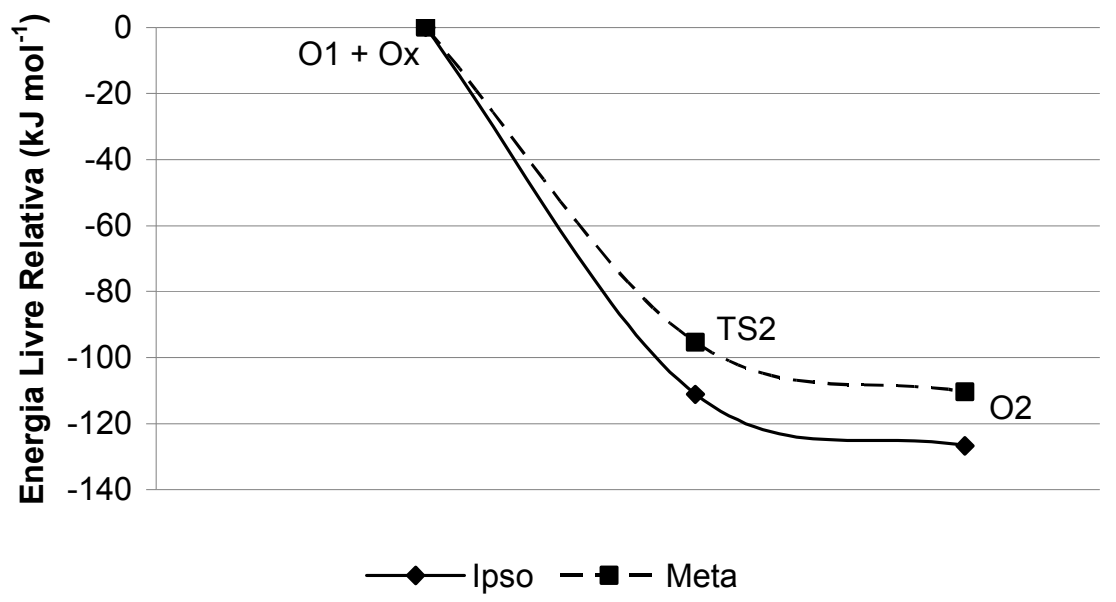

Figura IV.7 - Variação da energia livre durante a adição do oxigênio molecular na posição ipso e na posição meta, em relação ao grupo funcional; conforme avaliadas pela DFT.

Observa-se que ambos os estados de transição apresentam energias intermediárias entre reagentes e produtos, sendo a adição ipso privilegiada em relação à meta. Isto sugere que a reação seja, como comentado por Legrini et al. (1993) instantânea e, portanto, controlada unicamente pela difusão dos reagentes. É então interessante que o processo seja conduzido sob condições saturadas de oxigênio para assegurar sua pronta disponibilidade.

A eliminação de radicais hidroperoxila é proposta por Sonntag et Schuchmann (1997) e March \& Smith (2007). Segundo os autores, essa reação obedece a um mecanismo concertado, que envolve um intermediário pentacíclico, como mostrado na Figura IV.8. 


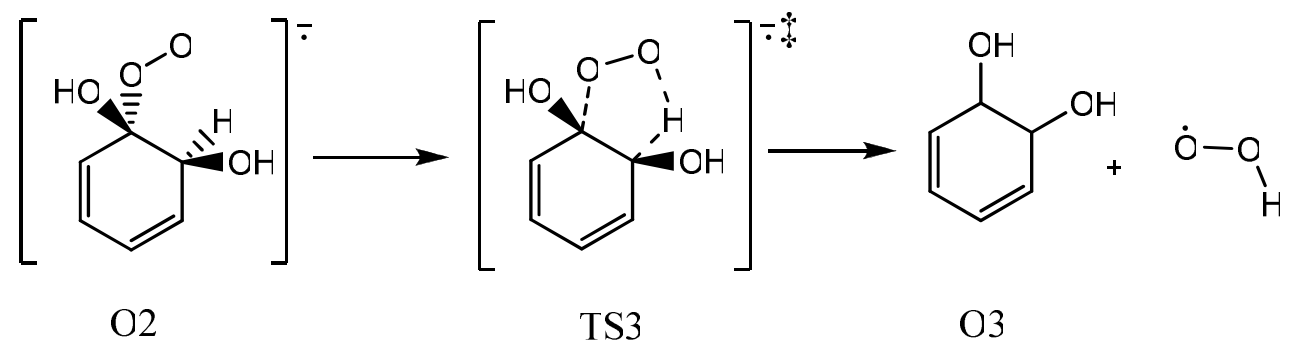

Figura IV.8 - Mecanismo proposto para a etapa final da conversão de fenol a catecol.

Para essa reação, foi obtido um perfil de variação de energia livre como mostrado na Figura IV.9. Determinou-se a energia livre de ativação $\Delta \mathrm{G}^{\ddagger}=14,27 \mathrm{~kJ} \mathrm{~mol}^{-1}$.

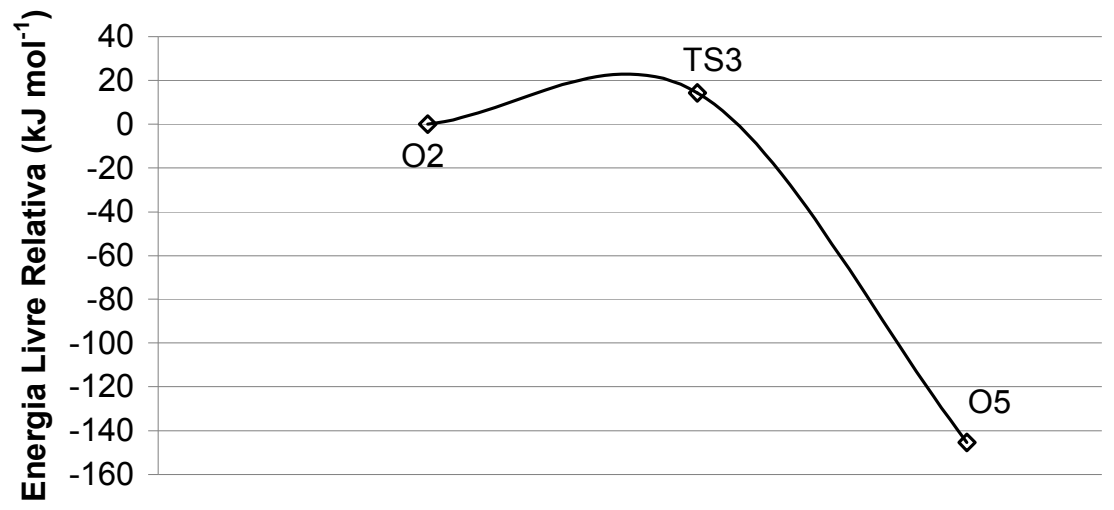

Figura IV.9 - Variação de energia livre para a reação proposta na Figura IV.8, conforme avaliada pela DFT.

Por fim, o perfil energético da primeira etapa do mecanismo pode ser visualizado na Figura IV.10.

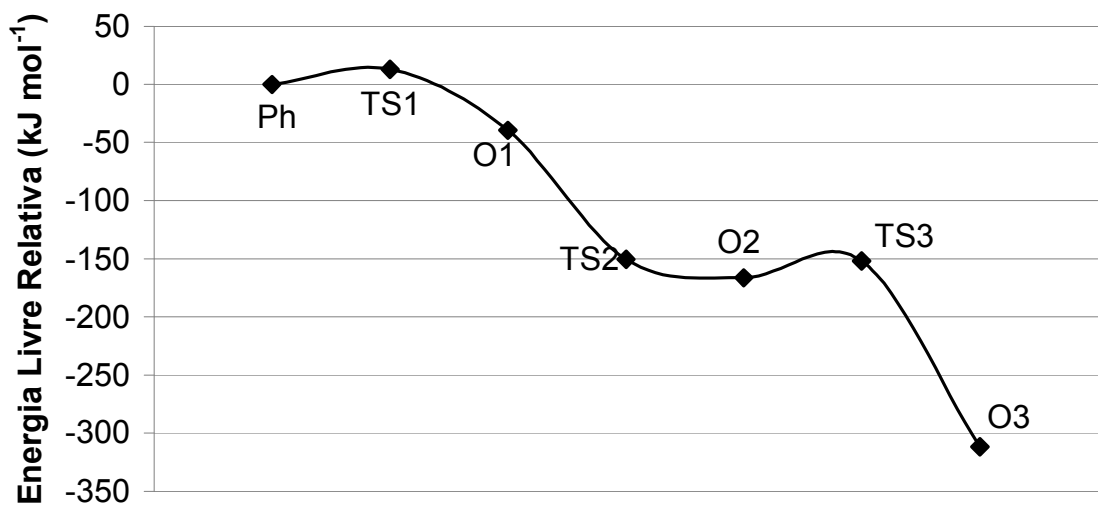

Figura IV.10 - Perfil energético da primeira etapa do mecanismo de degradação do fenol. 
Os resultados permitem concluir que para a primeira reação estudada a etapa termodinamicamente limitante é a etapa de eliminação do radical hidroperoxila, por apresentar a maior barreira energética (energia livre de ativação), como mostrado na Tabela IV.4:

Tabela IV.4 - Energias livres de ativação calculadas para as etapas elementares da Reação

R1.

\begin{tabular}{ccc}
\hline$\Delta G^{\ddagger}{ }_{(\mathrm{TS} 1)}\left(\mathrm{kJ} \mathrm{mol}^{-1}\right)$ & $\Delta G^{\ddagger}{ }_{(\mathrm{TS} 2)}\left(\mathrm{kJ} \mathrm{mol}^{-1}\right)$ & $\Delta G^{\ddagger}(\mathrm{TS} 3)\left(\mathrm{kJ} \mathrm{mol}^{-1}\right)$ \\
\hline 22,377 & $\mathrm{~N} / \mathrm{A}^{8}$ & 12,403 \\
\hline
\end{tabular}

\section{IV-1.2 AdIÇÃo PARA AO ANEL AROMÁTICO.}

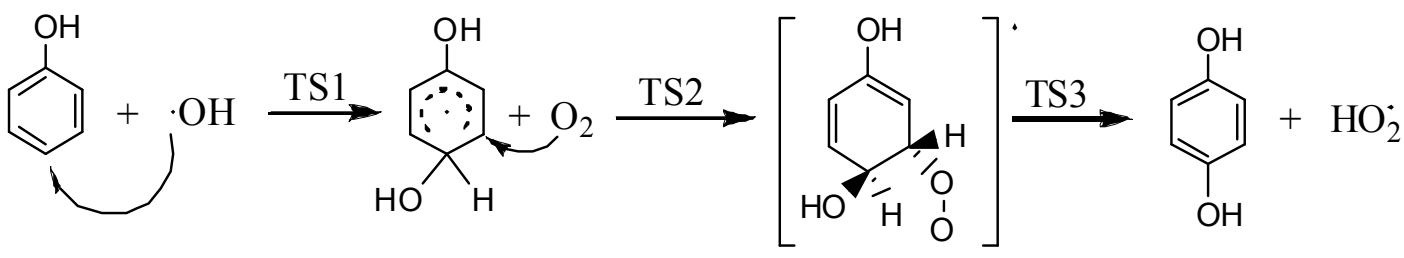

$\mathrm{PH}$

P1

$\mathrm{P} 2$

P3

Mecanisticamente, as etapas dessa reação são bastante similares às apresentadas em R1. A Figura IV.11 mostra o perfil energético desta reação. Como pode ser observado, o comportamento é bastante similar ao apresentado na Figura IV.10. A Tabela IV.4 resume os resultados para as energias de ativação calculadas para as etapas dessa reação.

\footnotetext{
${ }^{8}$ Não aplicável
} 


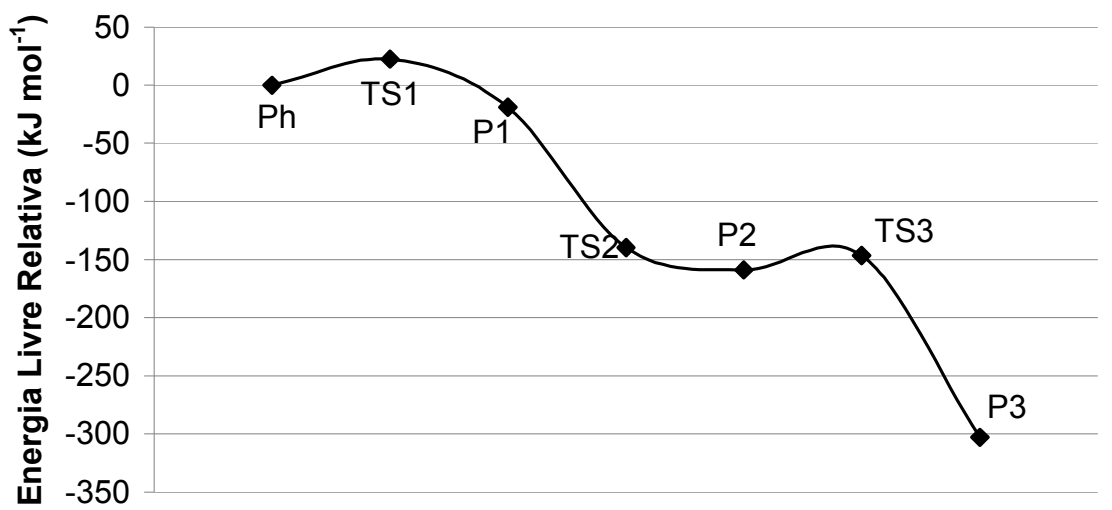

Figura IV.11 - Perfil energético para a etapa de adição para ao anel aromático.

Tabela IV.4 - Resultados termodinâmicos obtidos para a adição para ao anel aromático.

\begin{tabular}{ccc}
\hline$\Delta G_{(\mathrm{TS} 1)}^{\ddagger}\left(\mathrm{kJ} \mathrm{mol}^{-1}\right)$ & $\Delta G^{\ddagger}{ }_{(\mathrm{TS} 2)}\left(\mathrm{kJ} \mathrm{mol}^{-1}\right)$ & $\Delta G^{\ddagger}(\mathrm{TS} 3)\left(\mathrm{kJ} \mathrm{mol}^{-1}\right)$ \\
\hline 22,377 & $\mathrm{~N} / \mathrm{A}^{9}$ & 12,403
\end{tabular}

Diferentemente do observado para a adição orto, esta reação tem como etapa termodinamicamente limitante a adição do radical hidroxila, em vez da eliminação do radical hidroperoxila; e pela alta energia livre de ativação daquela, associada à maior estabilidade atingida pelo produto final de R1 (catecol), espera-se que a formação desse seja privilegiada em relação ao produto final de R2 (hidroquinona).

\section{IV-1.3 OXIDAÇÃO DO CATECOL A O-BENZOQUINONA}

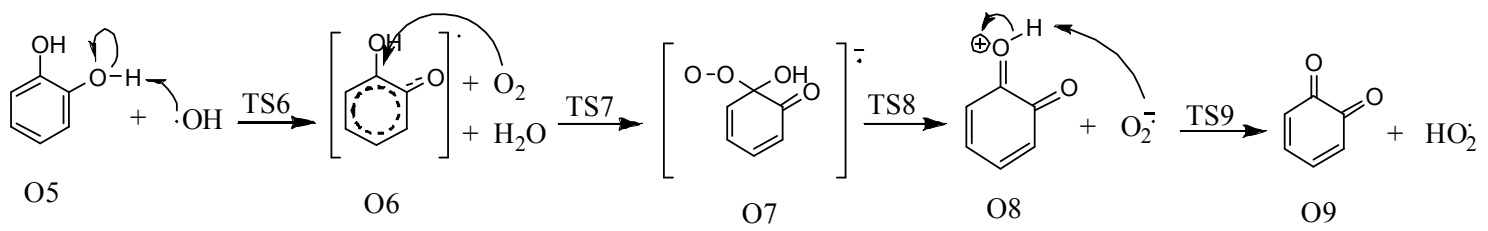

Essa reação exibe um perfil de variação de energia livre como mostrado na Figura IV.12. Nota-se naquela figura a alta energia do intermediário O8. March \& Smith (2007) comentam sobre a alta energia envolvida em reações que geram separação de cargas. Os resultados indicam que, devido a essa elevada instabilidade, a reação provavelmente não ocorre em fase

\footnotetext{
${ }^{9}$ Não aplicável
} 
gasosa, sugerindo então a necessidade de um mecanismo alternativo para essa conversão. Uma hipótese é a conversão direta do intermediário $\mathrm{O} 6$ ao $\mathrm{O} 9$ através da reação com $\mathrm{O}_{2}$, como mostrado na Reação R4:
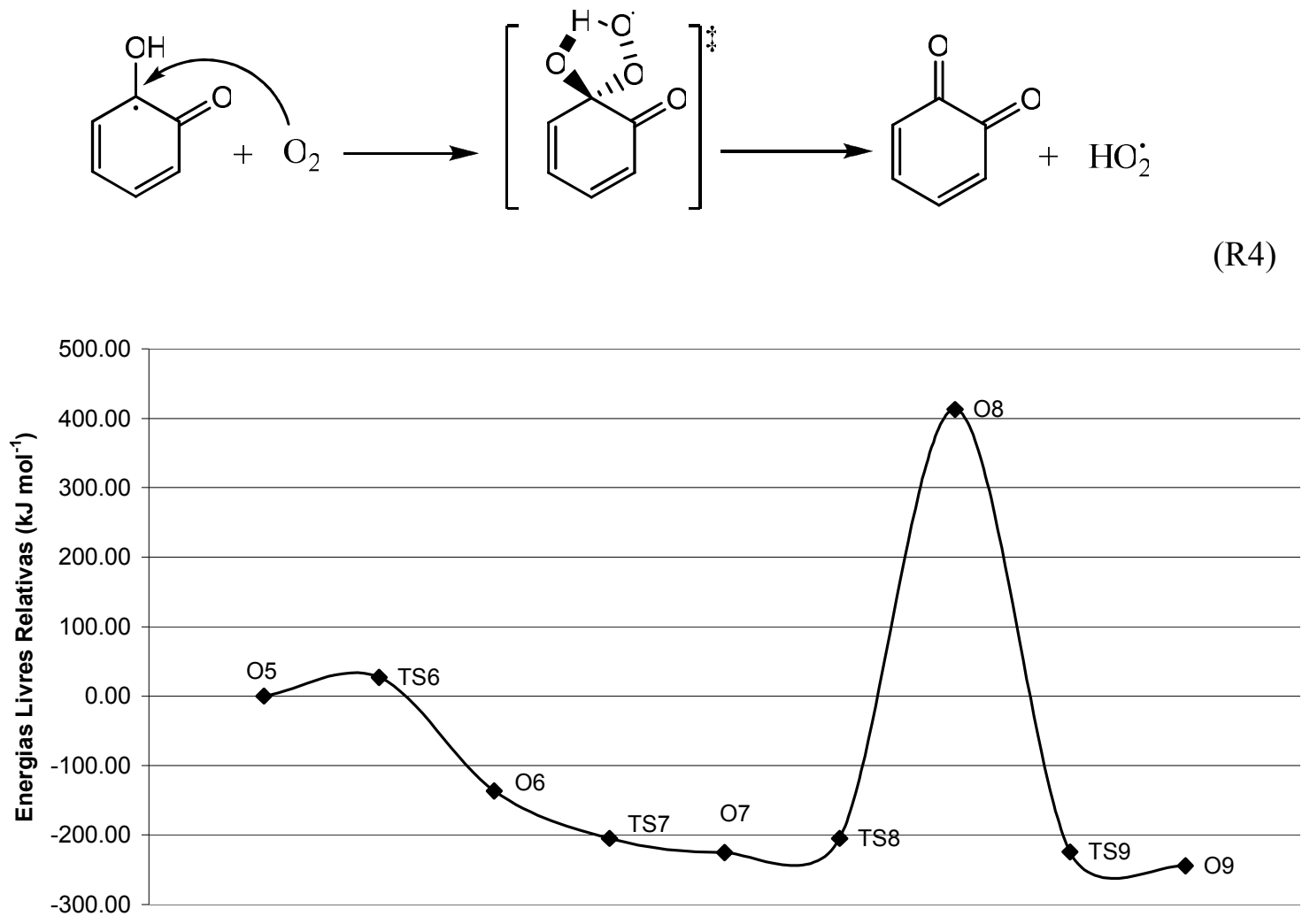

Figura IV.12 - Variação de energia livre ao longo da Reação R3.

Para a Reação R4, foram calculadas as energias livres de ativação dadas na Tabela IV.5. Para a etapa de adição do oxigênio, assim como observado nas Reações R1 e R2, a energia livre de ativação é negativa, indicando que a reação ocorre sem barreira energética. O mesmo ocorre com a conversão O8 a O9. Devido a alta energia do intermediário O8, a energia de ativação encontrada para a conversão $\mathrm{O} 7 \rightarrow \mathrm{O} 8$ não pode ser considerada como tal, e sim como um ponto intermediário na superfície de potencial que leva do reagente $\mathrm{O} 7$ aos produtos O8.

Tabela IV.5 - Energias livres de ativação para os processos moleculares da Reação 4.

\begin{tabular}{cccc}
\hline$\Delta G^{\ddagger}$ (TS6) $\left(\mathrm{kJ} \mathrm{mol}^{-1}\right)$ & $\Delta G^{\ddagger}{ }_{(\mathrm{TS} 7)}\left(\mathrm{kJ} \mathrm{mol}^{-1}\right)$ & $\Delta G^{\ddagger}{ }_{(\mathrm{TS} 8)}\left(\mathrm{kJ} \mathrm{mol}^{-1}\right)$ & $\Delta G^{\ddagger}$ (TS9) $\left(\mathrm{kJ} \mathrm{mol}^{-1}\right)$ \\
\hline 27,20 & N/A & 20,670 & N/A \\
\hline
\end{tabular}




\section{IV-1.4 OXIDAÇÃO DA O-BENZOQUINONA: ABERTURA DO ANEL}

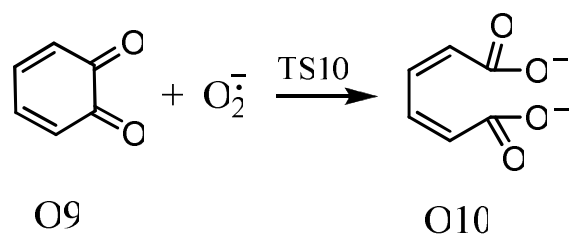

A última reação modelada é a abertura do anel, promovida pelo ânion radical superóxido, segundo Moro-oka \& Foote (1976) e March \& Smith (2007). A reação envolve a adição do superóxido em conjunto com o rompimento das ligações $\mathrm{C}-\mathrm{C}$ e $\mathrm{O}-\mathrm{O}$. $\mathrm{O}$ caminho energético da reação é mostrado na Figura IV.13:

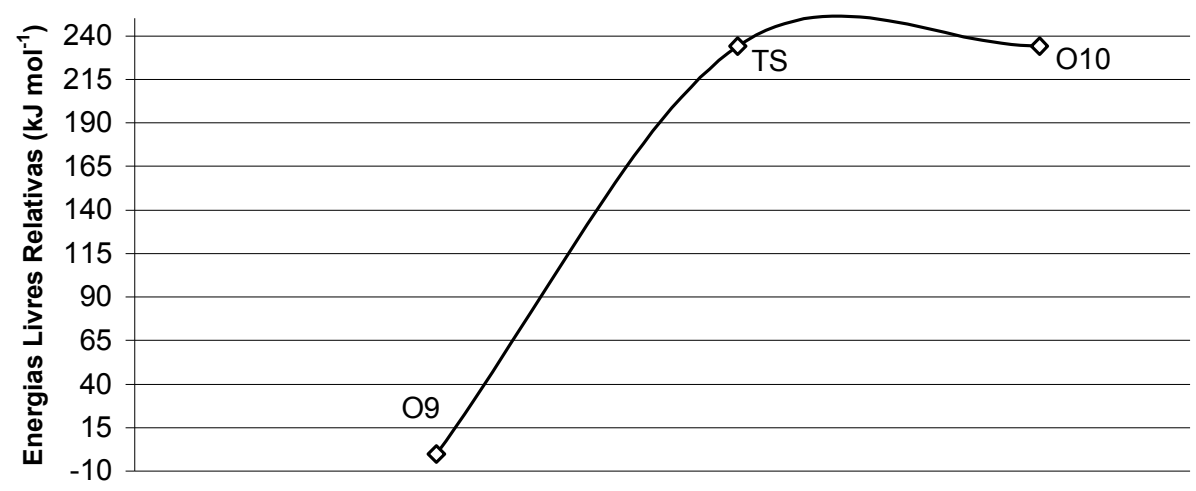

Figura IV.13 - Caminho energético da Reação R5.

Nota-se por este gráfico que a barreira energética é extremamente proibitiva. A energia livre de ativação calculada para essa reação é de $234,07 \mathrm{~kJ} \mathrm{~mol}^{-1}$. Devido a isso, essa reação provavelmente não ocorre em fase gasosa. Em fase aquosa, o intermediário O10 poderia abstrair prótons do meio aquoso e formar então o ácido mucônico, de estabilidade bem maior que o intermediário O10. Ademais, em meio aquoso a formação de intermediários carregados (como o O10) é mais energeticamente permissível, uma vez que a solvatação desempenha um papel chave na estabilização de um sistema com cargas. Portanto, embora seja um mecanismo plausível para a reação em fase aquosa, talvez o intermediário O9 siga por outra via de degradação em fase gasosa. 


\section{Capítulo IV-2}

\section{ESTUDO CINÉTICO}

As constantes cinéticas foram avaliadas usando a Equação III-2.18. A Tabela IV.6 resume as constantes cinéticas calculadas e experimentais (quando disponíveis) para as reações modeladas.

Tabela IV.6 - Constantes cinéticas calculadas neste trabalho $\left(\mathrm{k}_{\text {calc }}\right)$ e valores experimentais ( $\mathrm{k}_{\mathrm{exp}}$, quando disponíveis).

\begin{tabular}{|c|c|c|}
\hline Reação & $\mathrm{k}_{\text {calc }}\left(\mathrm{M}^{-1} \mathrm{~s}^{-1}\right)$ & $k_{\exp }\left(M^{-1} s^{-1}\right)$ \\
\hline $\mathrm{PH}+\cdot \mathrm{OH} \rightarrow \mathrm{O} 1$ & $3,33 \times 10^{10}$ & $\begin{array}{l}9,0 \times 10^{8 \mathrm{~B}} \\
8,4 \times 10^{9 \mathrm{C}} \\
2,0 \times 10^{10 \mathrm{D}}\end{array}$ \\
\hline $\mathrm{O} 1+\mathrm{O}_{2} \rightarrow \mathrm{O} 2$ & $1,79 \times 10^{36 \mathrm{~A}}$ & $\mathrm{~N} / \mathrm{D}^{10}$ \\
\hline $\mathrm{O} 2 \rightarrow \mathrm{O} 3+\cdot \mathrm{OH}_{2}$ & $1,97 \times 10^{10}$ & N/D \\
\hline $\mathrm{O} 5+\cdot \mathrm{OH} \rightarrow \mathrm{O} 6+\mathrm{H}_{2} \mathrm{O}$ & $1,07 \times 10^{8}$ & $\mathrm{~N} / \mathrm{D}$ \\
\hline $\mathrm{O} 6+\mathrm{O}_{2} \rightarrow \mathrm{O} 7$ & $5,34 \times 10^{28 A}$ & N/D \\
\hline $\mathrm{O} 7 \rightarrow \mathrm{O} 8$ & $1,65 \times 10^{8}$ & $\mathrm{~N} / \mathrm{D}$ \\
\hline $\mathrm{O} 8 \rightarrow \mathrm{O} 9$ & $\mathrm{~N} / \mathrm{A}^{\mathrm{A}}$ & N/D \\
\hline $\mathrm{O} 9 \rightarrow \mathrm{O} 10$ & $9,88 \times 10^{-30}$ & N/D \\
\hline Fenol $+\cdot \mathrm{OH} \rightarrow \mathrm{P} 1$ & $7,47 \times 10^{8}$ & $\begin{array}{l}2,0 \times 10^{8 \mathrm{~B}} \\
8,4 \times 10^{9 \mathrm{C}} \\
6,0 \times 10^{9} \mathrm{D}\end{array}$ \\
\hline $\mathrm{P} 1+\mathrm{O}_{2} \rightarrow \mathrm{P} 2$ & $8,56 \times 10^{36 \mathrm{~A}}$ & $\mathrm{~N} / \mathrm{D}$ \\
\hline $\mathrm{P} 2 \rightarrow \mathrm{P} 3+\cdot \mathrm{OH}_{2}$ & $4,17 \times 10^{10}$ & $\mathrm{~N} / \mathrm{D}$ \\
\hline
\end{tabular}

Como mostram os valores dispostos na Tabela VI.6, os valores experimentais estão de acordo com as predições teóricas, dentro dos erros associados aos experimentos e aos cálculos, como já esperado. Fan \& Zhang (2008) e McFerrin et al. (2008) comentam sobre o bom desempenho da DFT no estudo termodinâmico de radicais fenoxílicos e suas reações. Estudos teóricos anteriores foram feitos para avaliar os métodos químico-quânticos aplicáveis às reações de oxidação de aromáticos (DA SILVA et al., 2007). O último trabalho mostrou que, para a reação do tolueno com radical hidroxila, $\cdot \mathrm{OH}$, a DFT previa energias de ligação e de ativação em boa concordância com valores experimentais, em comparação com cálculos

\footnotetext{
${ }^{10}$ Não disponível.
} 
ab-initio multiconfiguracionais (CASSCF) para otimizações e MP2 e CCSD(T) para cálculos energéticos single point.

Como ilustração de aplicação e comparação com dados experimentais, foi feita a simulação cinética das Reações R1 e R2 utilizando as constantes cinéticas calculadas dispostas na Tabela IV.6, usando concentrações típicas de radicais hidroxila encontradas em processos oxidativos em fase gasosa (a saber, $\left.[\cdot \mathrm{OH}]=4,5 \times 10^{-15} \mathrm{~mol} \mathrm{~L}^{-1}\right)(\mathrm{HENRY}$ et al., 2008). A Figura IV.14 mostra a curva teórica para essas reações, e a Figura IV.15 mostra dados experimentais obtidos pelo grupo.

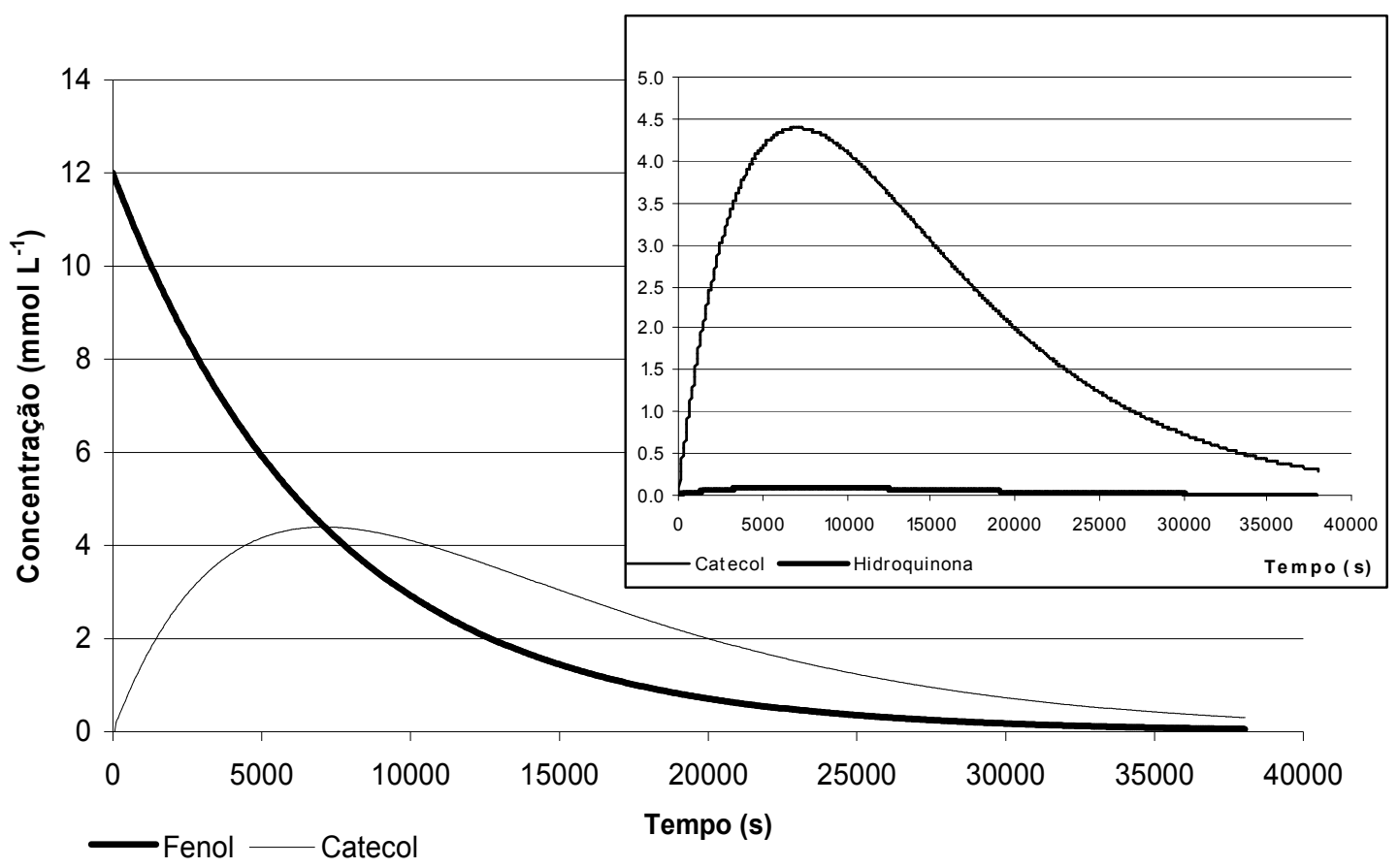

Figura IV.14 - Simulação para a reação de degradação do fenol em fase gasosa com a subsequente formação do catecol e hidroquinona (em destaque), utilizando as constantes cinéticas calculadas. 


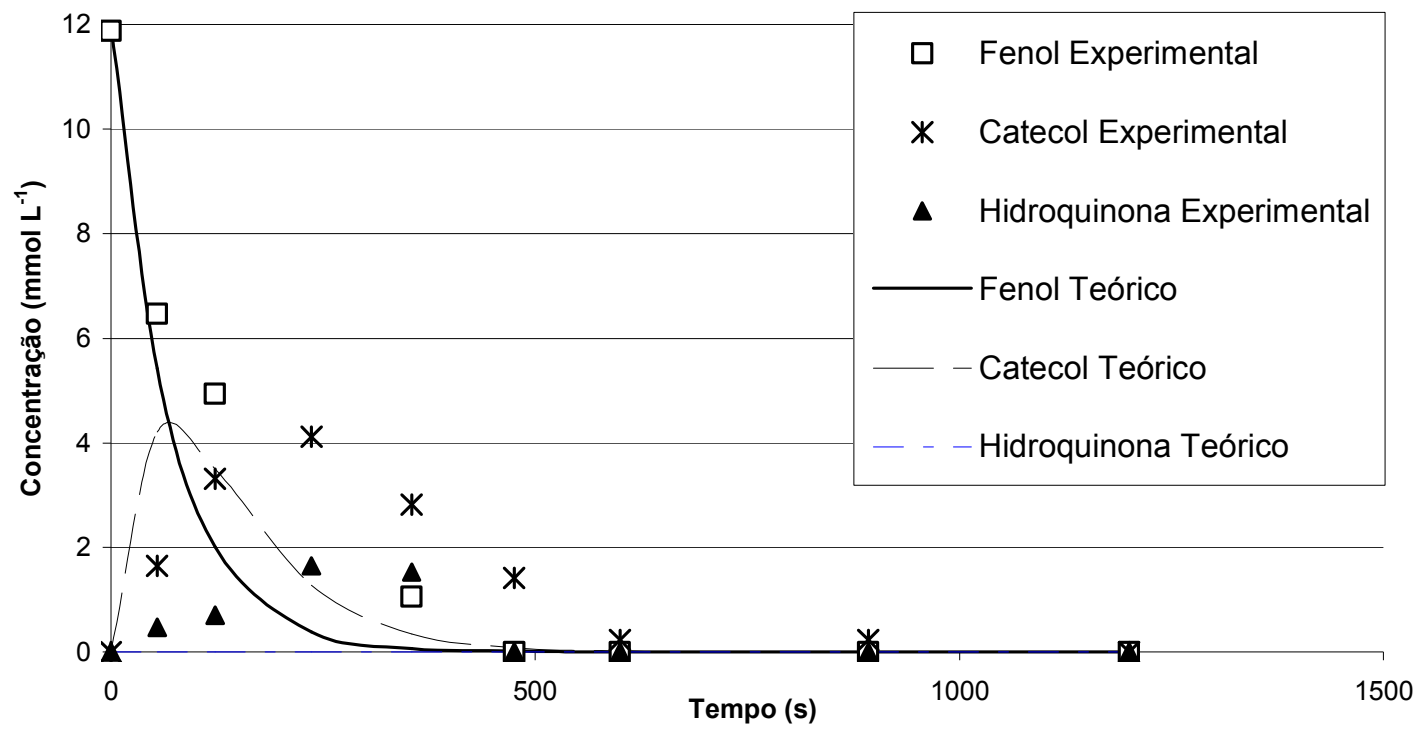

Figura IV.15 - Dados experimentais obtidos para a degradação do fenol pelo processo foto-Fenton, em meio aquoso $\left([\cdot \mathrm{OH}] \approx 10^{-13} \mathrm{~mol} \mathrm{~L}^{-1}\right)$. Dados de Friedrich et al. (2007). As curvas representam as predições teóricas utilizando as constantes calculadas neste trabalho.

Os dados obtidos pelo grupo foram modelados segundo o mecanismo mostrado na Tabela IV.7.

Tabela IV.7 - Modelo cinético para a oxidação do fenol pelo processo foto-Fenton.

\begin{tabular}{lll}
\hline \multicolumn{1}{c}{ Reação } & \multicolumn{1}{c}{$\begin{array}{c}\text { Constante Cinética } \\
\left(\mathrm{s}^{-1} \text { ou M }^{-1} \mathrm{~s}^{-1}\right)\end{array}$} \\
\hline 1 & $\mathrm{Fe}^{+2}+\mathrm{H}_{2} \mathrm{O}_{2} \rightarrow \mathrm{Fe}^{+3}+\mathrm{HO} \cdot+\mathrm{HO}^{-}$ & 70 \\
2 & $\mathrm{Fe}^{+3}+\mathrm{H}_{2} \mathrm{O}_{2} \rightarrow \mathrm{Fe}^{+2}+\mathrm{HO}_{2} \cdot+\mathrm{H}^{+}$ & 0,01 \\
3 & fenol $+\mathrm{HO} \cdot \rightarrow o$-DHCR $\cdot$ & $2,0 \times 10^{10}$ \\
4 & fenol $+\mathrm{HO} \cdot \rightarrow p$-DHCR $\cdot$ & $6,0 \times 10^{9}$ \\
5 & $o-\mathrm{DHCR} \cdot+\mathrm{Fe}^{+3} \rightarrow$ catecol $+\mathrm{Fe}^{+2}$ & 7000 \\
6 & $p$-DHCR $+\mathrm{Fe}^{+3} \rightarrow$ hidroquinona $+\mathrm{Fe}^{+2}$ & 7000 \\
7 & catecol $+\mathrm{HO} \cdot \rightarrow \mathrm{THCD} \cdot$ & $1,4 \times 10^{10}$ \\
8 & hidroquinona $+\mathrm{HO} \cdot \rightarrow \mathrm{THCD} \cdot$ & $4,0 \times 10^{9}$ \\
9 & THCD $+\mathrm{Fe}^{+3} \rightarrow \mathrm{Fe}^{+2}+\mathrm{THB}$ & 7000 \\
\hline
\end{tabular}

DHCR : radicais di-hidroxi-ciclohexadienila. THCD $:$ radical tri-hidroxi-ciclohexadienila. THB: tri-hidroxibenzeno. Dados de Friedrich et al. (2007).

A observação das Figuras IV.14 e IV.15 mostra similaridade dos perfis das curvas teórica e experimental, como pode ser observado, por exemplo, pela concentração máxima de catecol obtida nos experimentos e a calculada. Há de se pontuarem as diferenças nos tempos de degradação entre as duas figuras, algo já esperado haja vista a baixa concentração de 
radicais hidroxila encontrada em fase gasosa, (ca. $10^{5}$ vezes menor do que em fase aquosa). A curva simulada na Figura IV.15 faz uso do mesmo valor de concentração de radicais hidroxila encontrado para os experimentos e as constantes cinéticas calculadas neste trabalho, e mostra tempos de degradação que concordam razoavelmente com os encontrados experimentalmente. Outra diferença notável ocorre em relação às concentrações de hidroquinona, o produto final da Reação R2. O quadro em destaque na Figura IV.14 mostra que o pico máximo de concentração deste produto encontra-se na ordem de $0,10 \mathrm{mmol} \mathrm{L}^{-1}$, ao passo em que os experimentos mostram um máximo de ca. $1,8 \mathrm{mmol} \mathrm{L}^{-1}$. Esta diferença deve-se principalmente à lenta cinética calculada para esse processo em fase gasosa, que se inicia com a formação do intermediário P1 com uma cinética da ordem de $10^{8}$, aproximadamente 10 vezes menor que a encontrada por Friedrich et al. (2007) (vide Tabela IV.6). Kiliç et al. (2007) encontraram proporção similar à deste trabalho entre os intermediários formados. A Figura IV.16 mostra os resultados obtidos de uma simulação com os diferentes valores de constantes cinética disponíveis para as reações de formação de $\mathrm{O} 1$ e P1, utilizando a mesma concentração de radicais hidroxila $\left([\cdot \mathrm{OH}]=4,0 \times 10^{-15} \mathrm{~mol} \mathrm{~L}^{-1}\right)$, sob a hipótese de que esses intermediários fossem espécies estáveis.

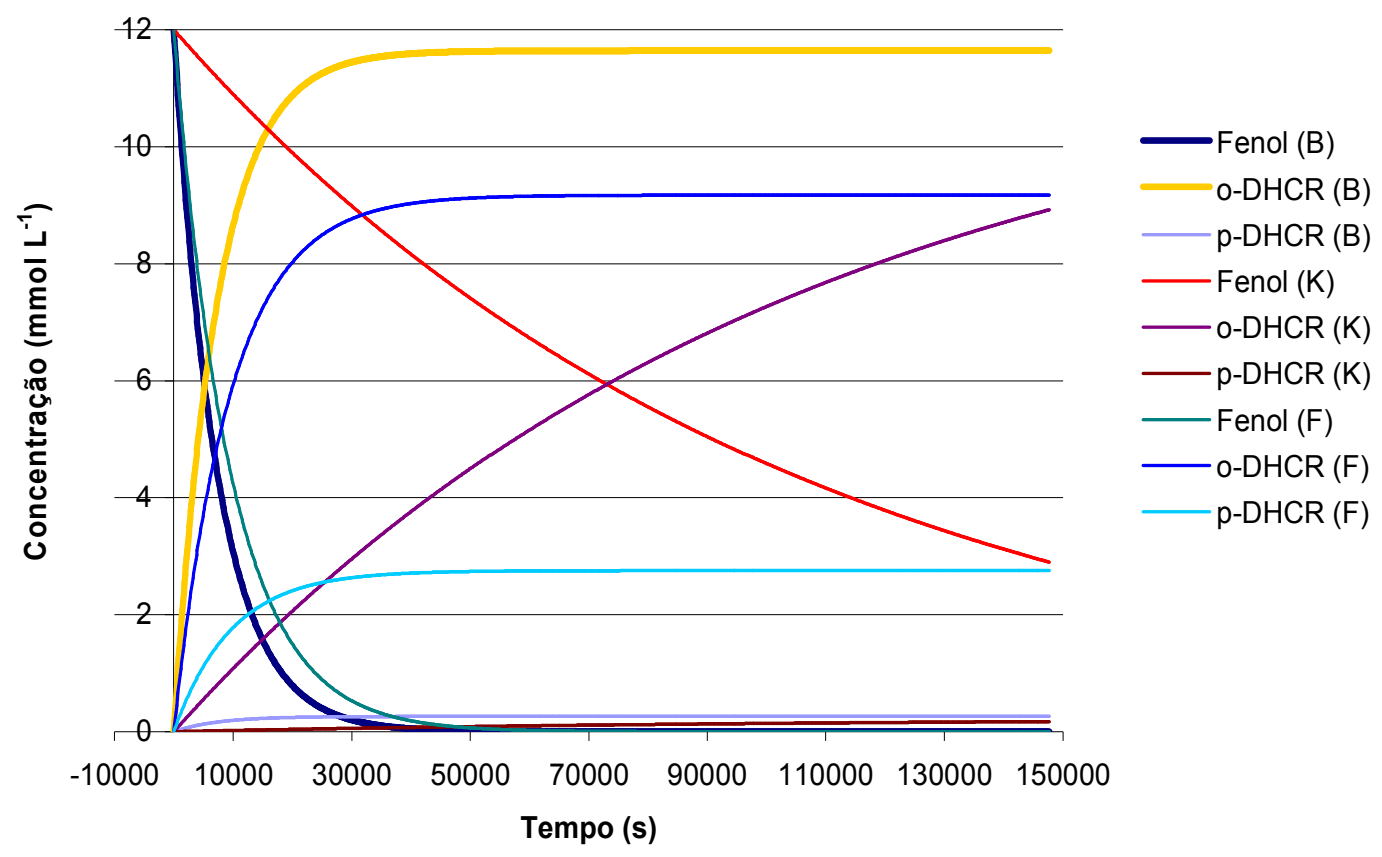

Figura IV.16 - Perfis de concentração do fenol, $o$ - e $p$-DCHR (radical di-hidróxi-hexadienila) (O1 e P1 respectivamente), simulados com diferentes constantes cinéticas. (B) refere-se aos perfis simulados fazendo uso da constante cinética da respectiva reação calculada neste trabalho, $(\mathrm{K})$ refere-se às estimadas por Kiliç et. al. (2007) e (F) às modeladas experimentalmente por Friedrich et al. (2007). 
Ao analisar a Figura IV.16, dois resultados chamam a atenção: primeiro, as constantes cinéticas calculadas por Kiliç et al. (2007), cerca de uma ordem de grandeza menores que as calculadas neste trabalho e as reportadas por Friedrich et al. (2007), resultam em um perfil de velocidades bastante distinto dos outros dois, fazendo com que a estimativa do tempo de degradação do fenol seja por sua vez uma ordem de grandeza maior. Portanto, enquanto os tempos para a eliminação ${ }^{11}$ do fenol ficam em torno de $20 \mathrm{~h}$ para as constantes $(\mathrm{B})$ e $(\mathrm{F})$, as constantes (K) resultam em um tempo de 271 h (!). Essa exemplificação ressalta a importância do uso de uma estimativa correta das constantes cinéticas no projeto de reações químicas. A título de ilustração, se essas constantes fossem empregadas no projeto de um reator contínuo de fluxo pistonado (PFR) para o tratamento de uma corrente gasosa inicialmente contaminada com $12 \mathrm{mmol} \mathrm{L}^{-1}$ de fenol (ca. $1128 \mathrm{ppm}(\mathrm{m} / \mathrm{V})$ ) a uma vazão de $3,6 \mathrm{~m}^{3} \mathrm{~h}^{-1}$, com objetivo de atingir uma conversão de $99,9 \%$ utilizando uma concentração de radicais hidroxila em estado estacionário de $4,0 \times 10^{-15} \mathrm{~mol} \mathrm{~L}^{-1}$, os volumes calculados dos reatores seriam, de acordo com a Equação IV-2.1, aqueles mostrados na Tabela IV.8. Observa-se que o volume necessário para o reator segundo a cinética de Kiliç et al. (2007) seria cerca de 14 vezes maior do que aquele necessário segundo os dados experimentais e a estimativa teórica deste trabalho.

$$
\mathrm{V}=-\dot{\mathrm{Q}} \int_{[\mathrm{Ph}]_{0}}^{[\mathrm{Ph}]_{\mathrm{f}}} \frac{\mathrm{d}[\mathrm{Ph}]}{\left(\mathrm{k}_{\mathrm{o}}+\mathrm{k}_{\mathrm{p}}\right)[\mathrm{Ph}][\cdot \mathrm{OH}]}
$$

sendo $\dot{\mathrm{Q}}$ a vazão volumétrica do reator $\left(\mathrm{L} \mathrm{s}^{-1}\right)$, $[\mathrm{Ph}]$ refere-se à concentração de fenol e, analogamente, $[\cdot \mathrm{OH}]$ à de radicais hidroxila $\left(\mathrm{mol} \mathrm{L}^{-1}\right), \mathrm{k}_{\mathrm{o}}$ e $\mathrm{k}_{\mathrm{p}}$ denotam, respectivamente, as constantes cinéticas das reações de adição orto e para do radical hidroxila ao anel fenólico (L $\mathrm{s}^{-1} \mathrm{~mol}^{-1}$ ); e V corresponde ao volume do reator (L). Considera-se a densidade do sistema constante ao longo do volume do reator.

Tabela IV.8 - Dados de projeto de um reator PFR para degradação de corrente gasosa com contaminação por fenol.

\begin{tabular}{lcccc}
\hline & $\mathrm{k}_{\mathrm{o}}\left(\mathrm{L} \mathrm{s}^{-1} \mathrm{~mol}^{-1}\right)$ & $\mathrm{k}_{\mathrm{p}}\left(\mathrm{L} \mathrm{s}^{-1} \mathrm{~mol}^{-1}\right)$ & $\mathrm{V}\left(\mathrm{m}^{3}\right)$ & $\tau(\mathrm{h})$ \\
\hline $\mathrm{K}$ & $2,36 \times 10^{9}$ & $4,61 \times 10^{7}$ & 717,74 & 199,37 \\
$\mathrm{~F}$ & $2,00 \times 10^{10}$ & $6,00 \times 10^{9}$ & 66,42 & 18,45 \\
Calculada & $3,33 \times 10^{10}$ & $7,47 \times 10^{8}$ & 50,77 & 14,10 \\
\hline
\end{tabular}

$\mathrm{V}$ : volume do reator tubular; $\tau$ : tempo de residência no reator.

\footnotetext{
${ }^{11}$ Considerando a uma redução da ordem de $10^{3}$ na carga inicial de fenol.
} 
Outro resultado que chama a atenção na observação da simulação na Figura IV.16 é, novamente, a diferença nos perfis de distribuição do intermediário orto vs. intermediário para. Ambas as predições teóricas indicam diferença mais acentuada entre as cinéticas de formação dos dois intermediários, como pode ser ressaltado na Tabela IV.7. Enquanto o trabalho experimental exibe uma diferença na constante cinética de pouco menos de uma ordem de grandeza, o trabalho de Kiliç et al. (2007) exibe uma diferença similar à encontrada neste trabalho, de aproximadamente duas ordens de grandeza. A discrepância encontrada com os dados experimentais deve-se possivelmente ao fato de as constantes cinéticas teóricas serem avaliadas em fase gasosa, ao passo que os experimentos foram realizados em meio aquoso.

Um ponto que deve ser ressaltado nesta discussão é a validade da comparação dos resultados obtidos (para reações em fase gasosa) com os resultados experimentais (avaliados em fase aquosa). Kiliç et al. (2007) fizeram avaliações energéticas e cinéticas também em fase aquosa dessa primeira reação. Os resultados obtidos por esses autores revelam que as constantes cinéticas calculadas em fase aquosa são quase iguais $(0,51-0,65 \%$ de diferença) às obtidas em fase gasosa. 


\section{Capítulo IV-3}

\section{ESTUdO DO MODElo de SolvataÇão}

\section{IV-3.1 DEFINIÇÃO DO OBJETO DE ESTUDO}

Para o teste dos modelos de solvatação foram selecionados os reagentes, estado de transição e produto da primeira etapa da Reação R1. A saber:

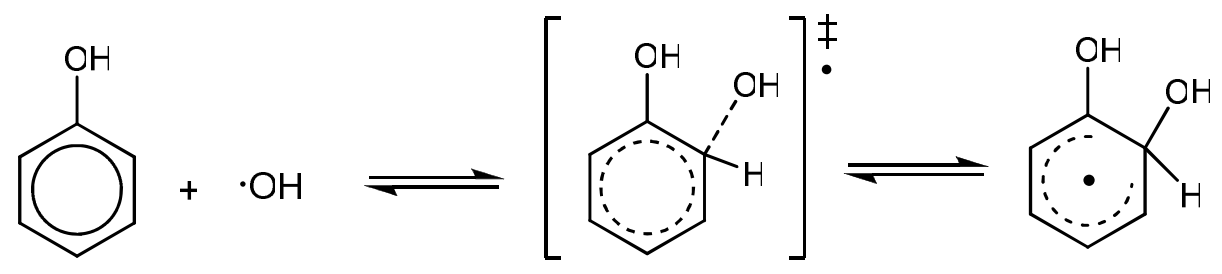

Existem dados experimentais acerca das energias de solvatação do fenol e do radical hidroxila em meio aquoso (LI et al., 1999; DO COUTO et al., 2003), assim como dados espectroscópicos de clusteres de fenol- $\left(\mathrm{H}_{2} \mathrm{O}\right)_{n}$ (HELM \& NEUSSER, 1998; WATANABe et al., 1996; PLUGATYR et al., 2006); importantes para a avaliação dos métodos de solvatação e do quanto eles representam a fenomenologia do sistema.

\section{IV-3.2 MODElos de SOLVATAÇÃo IMPLÍCITA}

A Tabela IV.9 resume os principais resultados obtidos utilizando o modelo SM5.42R, para geometrias otimizadas em fase gasosa.

Tabela IV.9 - Principais resultados energéticos obtidos pelo modelo SM5.42R para as espécies envolvidas na reação estudada.

\begin{tabular}{ccccccc}
\hline \multirow{2}{*}{ Estrutura } & \multicolumn{5}{c}{ Energias $\left(\mathrm{kcal} \mathrm{mol}^{-1}\right)$} \\
& $\Delta G_{\text {solv }}^{0}$ & $G_{S}^{0}$ & $U_{E N}(\mathrm{gas})$ & $U_{E N}(\mathrm{sol})$ & $G_{P}(\mathrm{sol})$ & $\Delta G_{\text {solv }}^{0}(\mathrm{exp})$. \\
\hline Fenol & $-6,760$ & $-28,406$ & $-21,646$ & $-20,310$ & $-7,186$ & $-6,62$ \\
OH & $-9,173$ & $-7,767$ & 1,405 & 2,112 & $-5,700$ & - \\
TS1 & $-9,894$ & $-12,238$ & $-2,344$ & 2,688 & $-11,639$ & - \\
O1 & $-10,887$ & $-56,928$ & $-46,041$ & $-44,606$ & $-8,870$ & - \\
\hline
\end{tabular}


$\Delta G_{\text {solv }}^{0}=$ variação de energia livre de solvatação; $G_{S}^{0}=$ energia livre do sistema solvatado; $U_{E N}($ gas $)=$ energia eletrônica e nuclear do soluto em fase gasosa; $U_{E N}(\mathrm{sol})$ = energia eletrônica e nuclear do soluto na solução; $G_{P}(\mathrm{sol})$ = contribuição da polarização à energia livre de solvatação.

Com os dados da Tabela IV.9, pode-se traçar uma curva ilustrando a coordenada de raação em fase gasosa, assim como calcular as energias livres de reação $\left(\Delta G_{R}\right)$ e de ativação $\left(\Delta^{\ddagger} G\right)$, como mostrado na Figura IV.17:

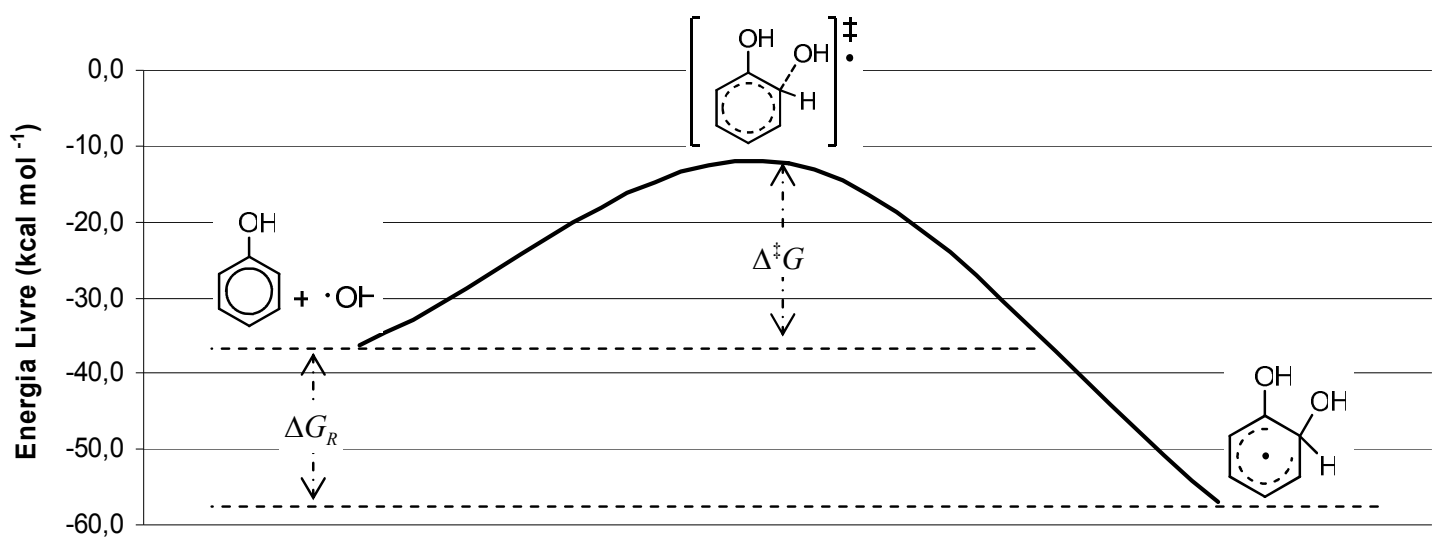

Figura IV.17 - Coordenada da reação, usando o modelo de solvatação SM5.42R.

Assim, foram obtidos os dados da Tabela IV.10

Tabela IV.10 - Energias livres de ativação e de reação em fase aquosa para a reação estudada, usando o modelo de solvatação SM5.42R.

\begin{tabular}{cr}
\hline$\Delta G_{R}(\mathrm{aq})\left(\mathrm{kcal} \mathrm{mol}^{-1}\right)$ & $-20,755$ \\
$\Delta^{\star} G(\mathrm{aq})\left(\mathrm{kcal} \mathrm{mol}^{-1}\right)$ & 23,935 \\
\hline
\end{tabular}

Estes resultados podem ser comparados para os calculados em fase gasosa $\left(\Delta G_{R}(\mathrm{~g})=-\right.$ 9,44 kcal mol$\left.{ }^{-1} ; \Delta^{\ddagger} G(\mathrm{~g})=5,43 \mathrm{kcal} \mathrm{mol}^{-1}\right)$. A comparação mostra que a energia livre de ativação calculada para a fase aquosa foi ca. 4 vezes maior do que a em fase gasosa. Já a energia livre de reação calculada para a fase aquosa foi aproximadamente o dobro da encontrada em fase gasosa. O resultado de energia livre de reação indica que a formação do produto é mais favorável em fase aquosa do que em fase aquosa, devido ao maior 
abaixamento no conteúdo energético livre do sistema. Em contrapartida, a elevada energia de ativação indica uma barreira energética maior; ou seja, indica que a reação se processaria com maior facilidade (i.e. demandando menos energia) em fase gasosa do que em fase aquosa. Contudo, é necessário levar em consideração duas observações importantes acerca do último resultado: i) o modelo empregado não foi padronizado para estados de transição e radicais, e ii) o cálculo de solvatação foi feito de forma rígida, i.e. não foram executadas otimizações geométricas no meio solvatado. Considerando que ambos reagentes (e, conseguentemente, o estado de transição) são espécies fortemente polares com hidrogênios hidroxílicos, é de se esperar que haja uma relaxação nas geometrias em presença de um solvente como a água. Este efeito pode ser ainda mais forte no estado de transição.

A Tabela IV.11 resume os principais resultados obtidos usando o modelo B3LYP/6$31++\mathrm{G}(\mathrm{d}, \mathrm{p}) / / \mathrm{PCM}$, para as mesmas geometrias otimizadas em fase gasosa submetidas aos cálculos AM1//SM5.42R. Segundo esse modelo, a energia livre de solvatação é calculada pelas contribuições devido às interações eletrostáticas $\left(\mathrm{G}_{\mathrm{es}}\right)$ e à repulsão $\left(\mathrm{G}_{\text {rep }}\right)$ e dispersão $\left(\mathrm{G}_{\mathrm{disp}}\right)$, e a energia de cavitação $\left(\mathrm{G}_{\mathrm{cav}}\right)$ :

$$
\Delta G_{\text {solv }}=G_{e s}+G_{\text {rep }}+G_{\text {disp }}+G_{\text {cav }}
$$

Tabela IV.11 - Resultados obtidos pelo modelo PCM.

\begin{tabular}{lccccc}
\hline & Fenol $(1)$ & Fenol $(2)$ & OH & TS1 & O1 \\
\hline $\mathrm{G}_{\text {es }}(\mathrm{kcal} / \mathrm{mol})$ & $-9,95$ & $-8,07$ & $-7,18$ & $-9,37$ & $-12,02$ \\
$\mathrm{G}_{\text {cav }}(\mathrm{kcal} / \mathrm{mol})$ & 15,59 & 13,87 & 4,08 & 15,98 & 15,33 \\
$\mathrm{G}_{\text {disp }}(\mathrm{kcal} / \mathrm{mol})$ & $-12,41$ & -16 & $-4,31$ & $-17,48$ & $-18,63$ \\
$\mathrm{G}_{\text {rep }}(\mathrm{kcal} / \mathrm{mol})$ & 1,16 & 3,35 & 1,48 & 3,64 & 5,04 \\
$\Delta \mathrm{G}_{\text {solv }}(\mathrm{kcal} / \mathrm{mol})$ & $-5,61$ & $-6,85$ & $-5,94$ & $-7,24$ & $-10,28$ \\
\hline
\end{tabular}

Fenol (1) = a cavidade foi construída utilizando o modelo topológico UA0 (simple united atom topological model). Fenol (2) = para a construção da cavidade, foi usado o modelo UAHF (United Atom for Hartree-Fock)

Foram testados dois modelos topológicos para a construção da cavidade em que seria inserido o soluto para o cálculo PCM. Os resultados obtidos indicaram que o modelo UAHF representaria melhor o sistema, como pode ser observado pelos resultados da energia de solvatação calculados para o fenol e o valor experimental, na Tabela IV.10. Com base nesta comparação, selecionou-se o modelo UAHF para o cálculo das demais espécies. 
Comparando-se os valores para energia de solvatação dos dois modelos, nota-se que o desvio encontrado para fenol utilizando-se o AM1//SM5.42R foi menor do que o encontrado com o B3LYP/6-31++G(d,p)//PCM. Os valores calculados para o $\mathrm{O} 1$ pelos dois modelos foram próximos. Contudo, há uma diferença notável entre as energias de solvatação do radical hidroxila e do estado de transição da reação. Isso provavelmente deve-se à dificuldade em modelar a fenomenologia dos radicais. Autrey et al. (2004) calcularam uma energia livre de solvatação de $-3,9 \pm 0,3 \mathrm{kcal} \mathrm{mol}^{-1}$ para o radical hidroxila, valor consideravelmente abaixo do encontrado nos cálculos realizados neste trabalho. Nota-se, pela observação da Tabela IV.11, que as contribuições de cavitação e dispersão são bem menores para o radical hidroxila, reflexo do pequeno tamanho da espécie em comparação com as demais: é de se esperar que sua presença perturbe menos o solvente. A Tabela IV.12 abaixo mostra algumas propriedades de solvatação calculadas:

Tabela IV.12 - Propriedades de solvatação em função dos oxigênios e hidrogênios hidroxílicos.

\begin{tabular}{lccccc}
\hline Propriedade & Fenol & $\mathbf{- O H}$ & TS1 & O1 & $\mathbf{H}_{\mathbf{2}} \mathbf{O}$ \\
\hline CM2 (O) & $-0,49$ & - & $-0,45$ & $-0,45$ & $-0,790$ \\
CM2 (O') & - & $-0,41$ & $-0,79$ & $-0,55$ & - \\
CM2 (H) & 0,41 & - & 0,42 & 0,41 & 0,400 \\
CM2 (H') & - & 0,41 & 0,32 & 0,38 & - \\
G-P (O) & $-1,46$ & - & $-1,73$ & $-0,59$ & $-1,610$ \\
G-P (O') & - & $-0,52$ & $-10,53$ & $-3,73$ & - \\
G-P (H) & $-2,94$ & - & 1,02 & $-3,78$ & $-2,92$ \\
G-P (H') & - & $-5,18$ & 3,22 & 0,13 & - \\
A (O) & 13,75 & - & 13,88 & 13,56 & 17,83 \\
A (O') & - & 23,44 & 15,25 & 13,9 & - \\
A (H) & 8,64 & - & 6,99 & 8,7 & 9,25 \\
A (H') & - & 9,39 & 9,25 & 8,73 & - \\
S-k (O) & $-107,98$ & - & $-76,96$ & $-91,72$ & $-148,98$ \\
S-k (O') & - & $-148,98$ & $-140,42$ & $-147,23$ & - \\
S-k (H) & $-74,12$ & - & $-73,49$ & -74 & 197,88 \\
S-k (H') & - & $-73,18$ & $-73,65$ & $-73,93$ & - \\
\hline
\end{tabular}

CM2: Carga obtida pelo Modelo de Cargas II $\left(\mathrm{kcal} \mathrm{mol}^{-1}\right)$; G-P: Energia livre de polarização $\left(\mathrm{kcal} \mathrm{mol}^{-1}\right)$; A = Área acessível ao solvente $\left(\AA^{2}\right)$; S-k = Coeficiente de tensão superficial $\left(\mathrm{cal} \AA^{-2}\right)$. O índice $(\mathrm{O})$ refere-se ao oxigênio fenólico, assim como o $(\mathrm{H})$ ao hidrogênio ligado a ele (exceção aos dados referentes à água); $\left(\mathrm{O}^{\prime}\right)$ indica o oxigênio do radical hidroxila que se adiciona ao anel aromático e (H') ao hidrogênio ligado a ele.

A Tabela IV.12 permite que se façam algumas observações interessantes: i) observa-se uma energia livre de polarização bastante elevada no O' do TS1, em comparação com os demais oxigênios dos reagentes e produtos. Como este oxigênio é a espécie que promove efetivamente o ataque nucleofílico ao carbono do anel fenólico, espera-se que sua nuvem 
eletrônica esteja mais distorcida e, portanto, a polarização promovida pelo solvente desempenharia um papel chave; ii) nota-se também a elevada área de acesso ao solvente do oxigênio do radical hidroxila, a maior de todos os oxigênios das espécies calculadas. Isso provavelmente deve-se tanto à ausência de um segundo ligante (mais "espaço" para interação com o solvente) quanto ao seu maior raio atômico (uma vez que sua nuvem eletrônica é maior do que nos demais casos).

\section{IV-3.3 Modelos de Solvatação ExPlícita}

Conforme apontado por Lüchow et al. (2001), existem três principais pontos de interação da molécula de fenol com as moléculas de água. Esses complexos foram desenhados, e os resultados são apresentados na Tabela IV.13. Os estudos foram feitos a nível semi-empírico (modelo AM1), usando o software AMSOL, simulando os clusteres solvatados implicitamente com o modelo SM5.42R.

Tabela IV.13 - Resultados energéticos para os três pontos de interação da molécula de fenol com as moléculas de água.

\begin{tabular}{lllllll}
\hline & Estruturas & E-EN(g) & E-EN(s) & G-S & DE-EN & DG-S \\
\hline P-H-O & $-85,371$ & $-83,775$ & $-94,273$ & 1,596 & $-8,902$ \\
P-O-H & & & & & & \\
& & & & & & \\
& & & & & & \\
\end{tabular}




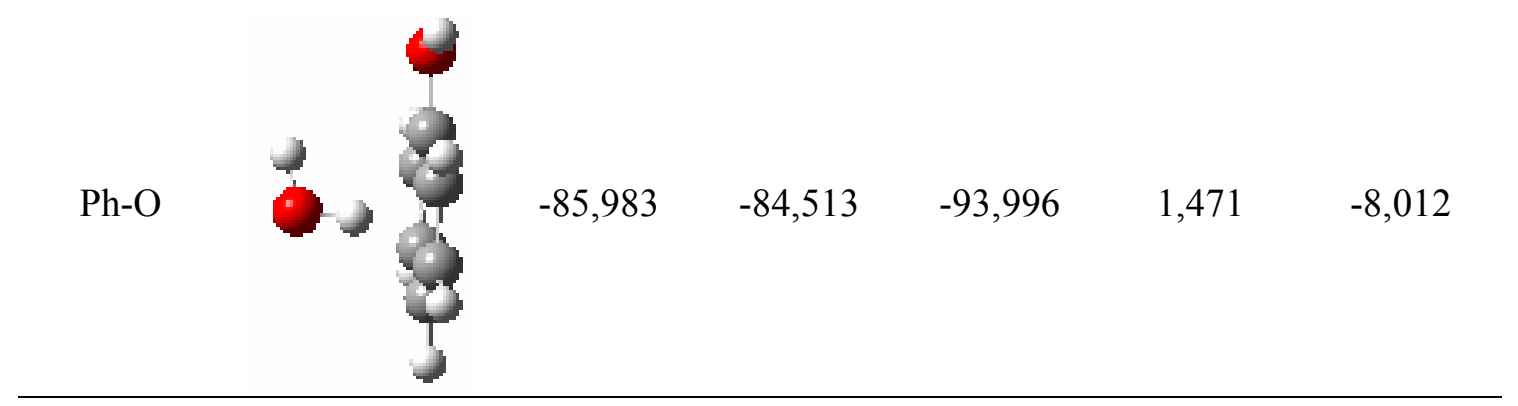

E-EN: Energia eletrônica-nuclear (g) em fase gasosa e (s) em meio solvatado; G-S: Energia livre do sistema solvatado; DE-EN = E-EN(s) - E-EN(g): energia eletrônica-nuclear de reorganização do soluto; DG-S: Energia livre de solvatação.

Os dados da Tabela IV.13 apontam que, dentre os três isômeros possíveis, o que apresenta maior estabilidade em fase gasosa (ou seja, sem o modelo de solvatação implícita) é o que envolve a interação anel aromático - água através da atração do hidrogênio da água com o orbital $\pi$ do fenol. Em fase aquosa, entretanto, essa estabilidade é contrabalanceada pela baixa estabilização desta espécie promovida pelos efeitos de polarização, cavitação e dispersão do solvente, em comparação com os outros dois isômeros. Desta forma, em fase aquosa o isômero de maior estabilidade é aquele em que a molécula de solvente estabelece uma ligação de hidrogênio com o oxigênio do fenol, fazendo com que este aja como uma base de Lewis (um doador de elétrons). É a estrutura que apresenta menor penalidade energética devido à reorganização do soluto e a maior (mais negativa) energia livre de solvatação. Entretanto, é conveniente ressaltar que os resultados foram obtidos para geometrias otimizadas com modelo semi-empírico (AM1), e as contribuições de polarização das nuvens eletrônicas e de correlação eletrônica - melhor avaliadas nos métodos da DFT - podem exercer uma importância considerável na geometria das estruturas. Portanto, um estudo mais detalhado, usando um nível de teoria maior, é necessário para confirmar as observações apontadas.

Quanto aos modelos das espécies participantes das reações, a Tabela IV.14 exibe os valores calculados de energia livre de solvatação 
Tabela IV.14 - Energias livres de solvatação para as diferentes supermoléculas construídas (cf. Tabela III.4 para as estruturas representadas a seguir)

\begin{tabular}{lc|lc}
\hline & DG-S & \multicolumn{1}{c}{ DG-S } \\
\hline \multirow{2}{*}{ Fenol } & \multirow{2}{*}{ P3W } & O1 & $-10,887$ \\
\multirow{2}{*}{ P4W } & $-6,551$ & $O 1-3 W$ & $-8,246$ \\
& \multirow{2}{*}{1,583} & $O 1-3 W 2$ & 1,377 \\
& & $O 1-4 W$ & $-2,494$ \\
& & 9,397 \\
\hline
\end{tabular}

Observando a Tabela IV.14 para o fenol, nota-se que há uma progressiva diminuição na energia livre de solvatação. Recordando que essa é a variação de energia livre entre o sistema em fase gasosa e o mesmo sistema em meio a um continuum de solvente, é lógico esperar que quanto melhor o modelo explícito represente o sistema a que se propõe, mais próximo de zero seja esse valor. Com isto em mente, pode-se inferir a partir dos dados da tabela que, para o fenol, o modelo que melhor representa a solvatação desta espécie é aquele em que se explicitam quatro moléculas de água formando um ciclo com a hidroxila do fenol através de ligações de hidrogênio:<smiles>FC1PC(F)PC(F)C(F)PC(F)PC(c2ccccc2)P1</smiles>

(P4W)

A Figura IV.18 resume as principais propriedades dos modelos do fenol:

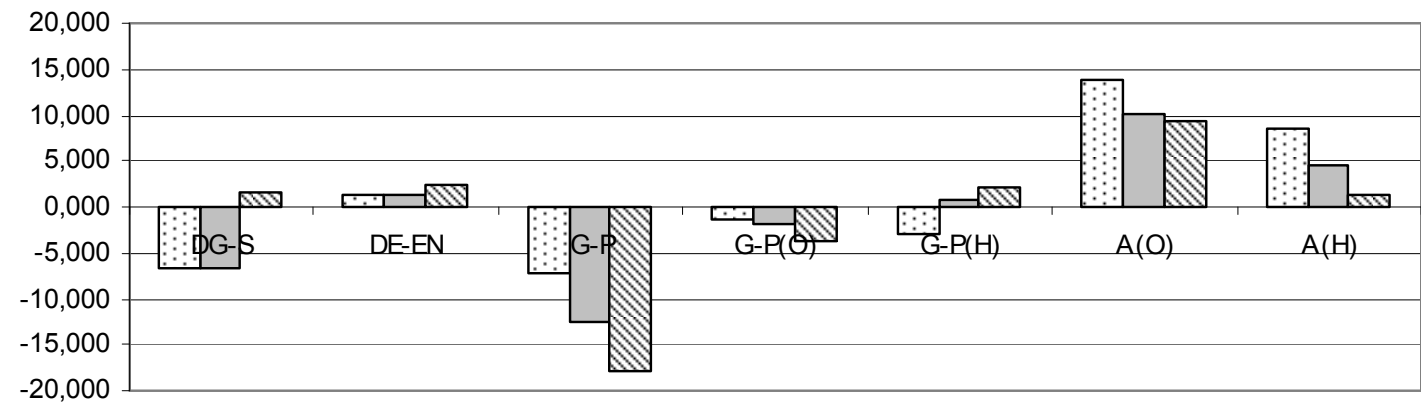

๑ Fenol $\square$ P3W $₫ \mathrm{P} 4 \mathrm{~W}$

Figura IV.18 - Principais propriedades calculadas para os diferentes modelos do fenol. Vide Tabelas IV.12 e IV.13 para descrição das propriedades representadas. 
A Figura IV.18 permite uma comparação mais nitida das propriedades particulares de cada modelo de solvatação. Nota-se que houve pouca diferença nas energias de solvatação (DG-S) e de reorganização do soluto (DE-EN) quando se tenta explicitar o efeito do solvente com três moléculas de água formando um ciclo com a hidroxila do fenol (P3W); ao passo em que ocorre um aumento na estabilização devido à polarização, provavelmente decorrente da maior polarização da nuvem eletrônica do fenol devido à ocorrência de interações de hidrogênio estabelecidas com as moléculas de água. Observa-se também uma diminuição na área acessível ao solvente do oxigênio e do hidrogênio da hidroxila do fenol, decorrente como se espera - da presença de moléculas de água ao redor destes, diminuindo assim os pontos de interação com o solvente e diminuindo a densidade eletrônica sobre estes átomos (devido ao compartilhamento de elétrons) e a consequente diminuição do raio atômico. Comparando-os com o modelo $\mathrm{P} 4 \mathrm{~W}$, nota-se que este apresenta uma energia de reorganização do soluto ligeiramente maior, bem como uma energia de polarização ainda mais negativa. Nota-se também que há uma diminuição mais sutil da área de contato do oxigênio, em comparação com a diminuição da área de contato do hidrogênio. Observa-se também uma maior contribuição à estabilidade devido à polarização do oxigênio, ao passo em que a polarização do hidrogênio contribui para desestabilizar o sistema. Espera-se então que a presença da quarta molécula de água no ciclo contribua para que todos os efeitos de primeira camada de solvatação sejam satisfeitos sem a necessidade de um modelo de solvatação implícita.

Com relação ao intermediário O1, a Tabela IV.14 sugere que para a descrição adequada do sistema, um modelo explicito deve envolver a presença de uma camada de solvatação sobre as duas hidroxilas da espécie. Conforme os dados apresentados, o modelo mais adequado para representar o intermediário $\mathrm{O} 1 \mathrm{em}$ meio solvatado seria aquele em que três moléculas de água são explicitadas em um anel sobre cada hidroxila ligada ao anel aromático:

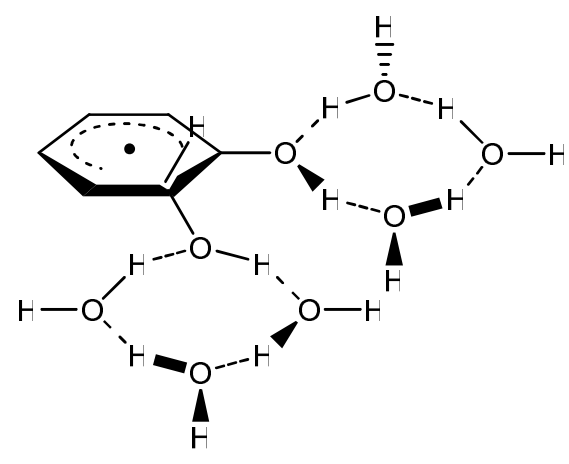

$(01-3 W 2)$ 
A Figura IV.19 resume as principais propriedades dos modelos do intermediário O1:

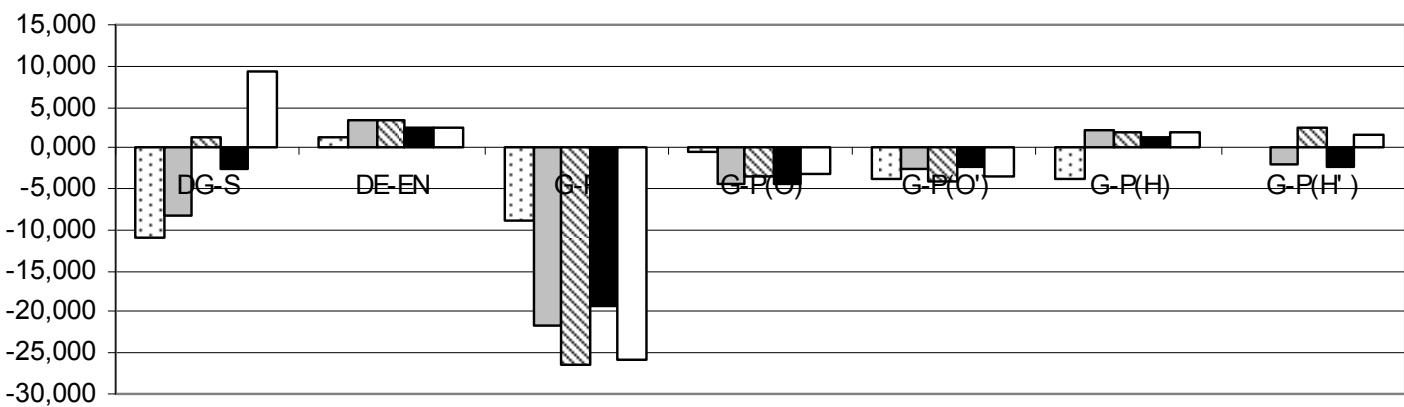

$\square 01 \square 01-3 W \square 01-3 W 2 \square 01-4 W \square 01-4 W 2$

Figura IV.19 - Principais propriedades calculadas para os modelos do intermediário O1. cf. Tabelas IV.12 e IV.13.

A Figura IV.19 exibe algumas características diferentes das esperadas, se fosse seguido o mesmo padrão do fenol. Comparando, por exemplo, O1, O1-3W e O1-4W observa-se que houve uma diminuição em DE-EN ao se passar de O1-3W para O1-4W, comportamento contrário ao observado para $\mathrm{P} 3 \mathrm{~W}$ e $\mathrm{P} 4 \mathrm{~W}$. A mesma inversão é notada nos resultados de G-P. Por quê? Essas diferenças energéticas parecem derivar das interações entre os ciclos de água sobre a hidroxila fenólica e a hidroxila do carbono vizinho. A Figura IV.20 mostra a projeção da estrutura O1-3W evidenciando a formação das interações de hidrogênio:

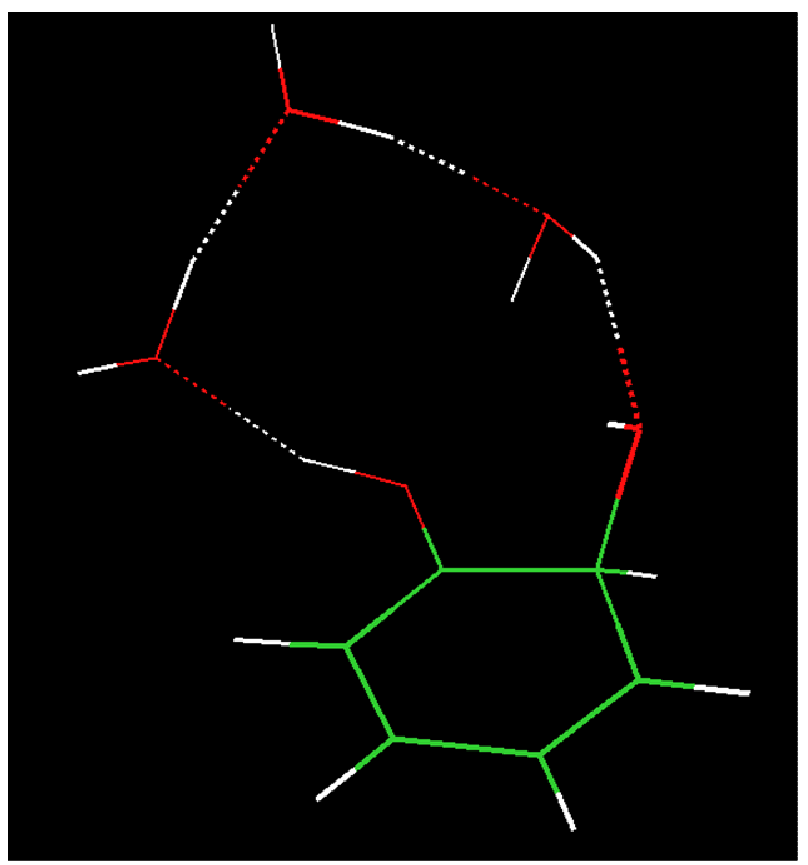

Figura IV.20 - Estrutura otimizada para o intermediário $\mathrm{O} 1$ com modelo de três moléculas de solvente explícitas (O1-3W) 
O modelo mais estável (estrutura otimizada) para o intermediário $\mathrm{O} 1$ é representado na Figura IV.21:

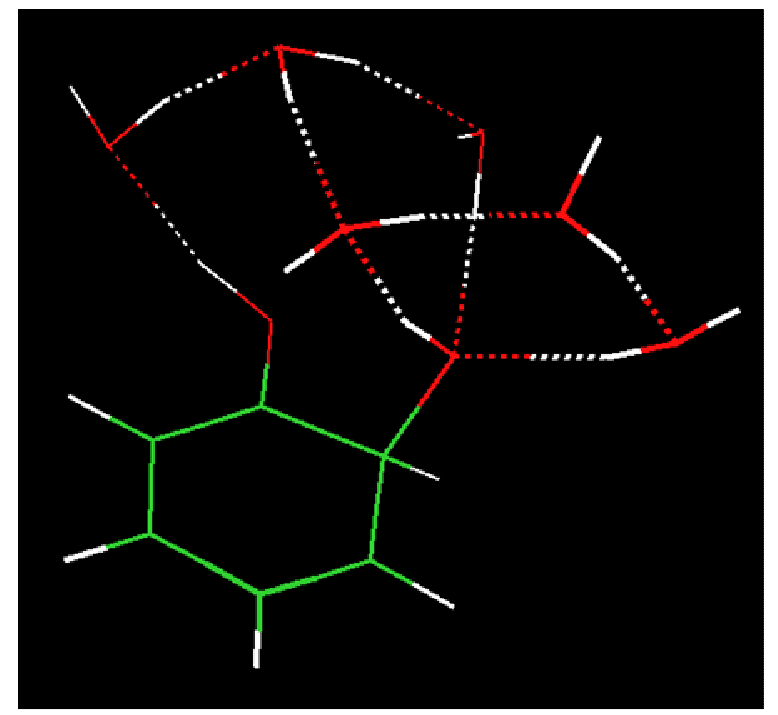

Figura IV.21 - Estrutura otimizada para o modelo mais estável do intermediário $\mathrm{O} 1$ (O1-3W2)

Como pode ser observado, há uma interação bastante intensa entre os dois aneis de água que solvatam as hidroxilas do intermediário O1. Ademais, observa-se na estrutura que todos os tipos de solvatação discutidos nos pontos de interação do fenol com a água são representados, incluindo uma ligeira atração com a densidade eletrônica que resta no anel. 
Título V

Conclusões 
Os resultados mostram que o método escolhido para a avaliação dos parâmetros termodinâmicos e das constantes cinéticas permite a obtenção de predições adequadas, dentro da variação observada nos trabalhos experimentais. As energias livres de ativação calculadas concordam com observações experimentais, bem como as cinéticas das primeiras reações, dentro do erro experimental.

Energeticamente, pode-se concluir por hora que as reações de adição de oxigênio aos radicais orgânicos modelados são reações sem barreira energértica e, portanto, dependem unicamente do encontro dos dois reagentes no meio reacional, o que trás à tona um importante fator de processo: a manutenção de condições saturadas e homogêneas de oxigênio no meio. Ademais, conclui-se que as barreiras energéticas para a adição orto do radical hidroxila ao anel fenólico fazem dessa via a rota preferencial de degradação. O perfil das adições orto e para são bastante similares, mas apresentam uma diferença quanto à etapa determinante. $\mathrm{Na}$ adição orto, a etapa lenta é a última (eliminação de radical hidroperoxila), ao passo em que na adição para a própria adição do radical é a etapa que limita a cinética do processo.

Devido à concordância com os dados experimentais, pode-se concluir que a Teoria do Funcional da Densidade aplicada com funcional híbrido B3LYP e conjunto de base 6$31++\mathrm{G}(\mathrm{d}, \mathrm{p})$ constitui um método teórico adequado para o estudo dessa classe de reações orgânicas e, portanto, pode ser utilizado para predições, ainda que qualitativas, dos perfis de concentração dos intermediários da degradação do fenol.

No que diz respeito à modelagem do meio solvatado, pôde-se observar que o modelo implícito empregado (SM5.42R), associado às geometrias previstas pela DFT, constitui uma aproximação interessante para o estudo das reações em meio aquoso. Dentre os modelos explícitos construídos, foi observado que uma supermolécula com quatro moléculas de água é o modelo mais adequado para representar os efeitos de solvatação na molécula de fenol, enquanto para o intermediário $\mathrm{O} 1$ o modelo mais adequado envolve dois ciclos de três moléculas de água cada ao redor das duas hidroxilas da espécie.

O detalhamento de um processo químico é um trabalho bastante árduo, no sentido de demandar um vasto conhecimento acerca da reatividade das espécies e das condições em que o processo é conduzido. A principal dificuldade em se detalhar um mecanismo reside 
justamente na necessidade de um embasamento teórico adequado, e a modelagem molecular permite que se faça um estudo mais detalhado de cada etapa elementar das reações químicas, como pretendeu-se mostrar também neste trabalho. O mecanismo só foi detalhado nas reações elementares mostradas depois de uma quantidade considerável de cálculos de mecanismos tentativos, e da procura por dados experimentais.

Predizer o valor de uma constante cinética também é um procedimento complicado. Teoricamente, as únicas fontes de variação de uma constante cinética são a temperatura e a energia de ativação (cf. Equação III-2.18). Entretanto, encontra-se uma discrepância muito grande entre os dados experimentais (como pode ser observado pela Tabela IV.6). Por quê? Quanto mais complexo um sistema químico, mais difícil detectar a constante cinética de uma reação elementar em particular. As diferenças encontradas nas constantes experimentais reportadas possivelmente devem-se à ocorrência de uma série de reações paralelas cujas taxas cinéticas acabam por ser erroneamente detectadas e tratadas como sendo devidas à apenas uma reação. Isso ocorre particularmente quando se lida com um meio complexo, como o meio de um Processo Oxidativo Avançado, e mais ainda por se tratar de um meio contínuo.

Quanto mais complexo um sistema, mais efeitos devem ser incorporados ao modelo para que este represente uma descrição adequada da realidade. As reações modeladas neste trabalho envolvem espécies radicalares; ou seja, envolvem orbitais com elétrons não emparelhados e, possivelmente, a ocupação de orbitais não-ligantes. Tratar isso do ponto de vista teórico requer modelos mais "caros", que levem em consideração efeitos que - para sistemas bem comportados - podem ser desconsiderados em certa extensão, como é o caso da correlação eletrônica. Métodos que consideram a correlação eletrônica explicitamente, como os métodos do cluster acoplado, de interação de configurações e etc. demandam um tempo computacional que torna o estudo de sistemas grandes senão impraticável, bastante oneroso. O método teórico escolhido neste trabalho, a Teoria do Funcional da Densidade e - em particular - o funcional B3LYP, levam esses efeitos em consideração, ainda que implicitamente, e fornecem bons resultados para o sistema estudado - provavelmente por uma compensação de erros.

A título de continuidade do trabalho, poder-se-iam ser testados outros funcionais, de desempenho bem conhecido, como por exemplo o B3PW91; além de outros conjuntos de base mais amplos. O uso de métodos correlacionados não traria um benefício tal que justificasse seu alto custo. $\mathrm{O}$ modelo de solvatação escolhido corresponde bem à realidade de sistemas 
como o fenol, mas não contém em sua parametrização espécies radicalares. A falta de informações experimentais sobre a energia livre de solvatação das espécies radicalares estudadas difículta uma avaliação mais detalhada acerca da aplicabilidade deste modelo para o sistema estudado. A continuidade do trabalho poderia envolver, também, uma parametrização do modelo para espécies radicalares, como as frequentemente encontradas nos mecanismos modelados. A modelagem mais completa do sistema estudado deveria incluir algumas das reações paralelas que, por conveniência, foram desconsideradas neste trabalho, como a dimerização do intermediário $\mathrm{O} 1$, a formação de um radical por abstração de um hidrogênio do fenol pelo radical hidroxila e a formação de um intermediário meta desta mesma reação, conforme estudado por Kiliç et al. (2007). A avaliação das constantes cinéticas e dos parâmetros termodinâmicos de todas as principais reações sofridas pelo fenol neste sistema poderia, por exemplo, ajudar a elucidar o mecanismo inicial da degradação, a distribuição inicial dos primeiros produtos e fornecer mais informações acerca das espécies químicas que podem ser formadas naquele meio, bem como uma previsão das condições em que elas podem ser formadas e eventualmente recuperadas. É claro que quanto mais se avança no curso da degradação do fenol, mais espécies estão presentes no meio e mais reações cruzadas podem acontecer, gerando uma miríade de produtos. Um estudo detalhado de um sistema desses é, portanto, quase impossível. Entretanto, é interessante que se estudem as principais reações do processo, especialmente aquelas em que há a formação de co-produtos persistentes, como é o caso das reações do ácido maleico e do ácido acrílico (cf. Figura III.1), que podem fornecer um insight das condições de processo que devem ser preconizadas para que se minimize a formação destes co-produtos.

De forma geral, como pretendeu ser mostrado neste trabalho, a Modelagem Molecular é uma ferramenta que permite a avaliação de diversas propriedades de um meio reacional, possibilitando predições quantitativas e insights qualitativos a respeito do comportamento de um sistema - informações que podem ser utilizadas como parâmetros no projeto e na otimização de um processo químico. Como comentado por Charpentier (2007), o conhecimento mais detalhado dos processos moleculares é crucial para o avanço da Engenharia Química, uma vez que possibilitam o estudo de uma gama de novos produtos de interesse econômico e de processos que sejam cada vez mais rentáveis e limpos. Embora ainda seja uma ferramenta com consideraveis limitações computacionais, a Modelagem Molecular já adquiriu um nivel de confiabilidade que possibilita sua aplicação em estudos de 
interesse industrial e tecnológico e é interessante que seja explorada com mais afinco na Engenharia Química. 


\section{REFERÊNCIAS BIBLIOGRÁFICAS}

AGRICOLA, G. De Re Metallica. Traduzido (Inglês) por H.C. Hoover e L.H. Hoover. Salisbury House: Londres, 1912.

AICHE. American Institute of Chemical Engineers. AIChE - as amended to January 17, 2003. Disponível em: http://www.aiche.org/. Acesso em 06 de março de 2008.

AMUNDSON, N. R. (ed). Frontiers of Chemical Engineering: Research needs and opportunities. National Academy of Sciences: Washington, 1988.

ATKINS, P.; DE PAULA, J. Physical Chemistry. 7 ed. W. H. Freeman \& Co., 2002.

AUTREY, T.; BROWN, A. K.; CAMAIONI, D. M.; DUPUIS, M.; FOSTER, N. S.; GETTY, A. Hydroxyl radical at the water/air interface. Journal of the American Chemical Society, v. 126, pp. 3680-3681, 2004.

AYLING, G. W.; CASTRANTAS, H. M. Waste treatment with hydrogen peroxide. Chemical Engineering, v. 88, n. 24, p. 79, 1981.

BAKER, J., MUIR, M., AND ANDZELM, J. A study of some organic reactions using density functional theory, Journal of Chemical Physics, v. 102, p. 2063, 1995.

BBC; GLOBESCAN; PIPA. Man causing climate change - poll. BBC News. 25 de setembro de 2007. Disponível em: http://news.bbc.co.uk/2/hi/in_depth/7010522.stm. Acesso em 10 de novembro de 2007.

BECKE, A. D. Density-Functional Exchange-Energy Approximation With Correct Asymptotic Behavior, Physical Reviews A, v. 38, p. 3098, 1988.

BECKE, A. D. Density-Functional Thermochemistry. III. The Role of Exact Exchange, Journal of Chemical Physics, v. 98, p. 5648, 1993a,

BECKE, A. D. A New Mixing of Hartree-Fock and Local Density-Functional Theories, Journal of Chemical Physics, v. 98, p. 1372, 1993b 
BIELSKI, B. H.; CABELLI, D. E. Superoxide and hydroxyl radical chemistry in aqueous solution. In: Foote, C. S.; Valentine, J. S.; Greenberg, A.; Liebman, J. F. (eds) Active oxygen in chemistry. SEARCH Series, v. 2. Blackie Academic \& Professional: New York, 1995.

BIRD, R. B. Department of Chemical and Biological Engineering - R. Byron Bird. College of Engineering - University of Wisconsin-Madison: Wisconsin, Estados Unidos. Página Institucional disponível em: http://www.engr.wisc.edu/che/faculty/bird byron.html. Acesso em 26 de novembro de 2007.

BIRD, R. B.; STEWART, W. E.; LIGHTFOOT, E. L. Fenômenos de Transporte. 2 ed traduzida. LTC: Rio de Janeiro, 2002.

BONIN, J.; JANIK, D.; BATELS, D. M. Reaction of hydroxyl radical with phenol in water up to supercritical conditions. Journal of Physical Chemistry, v. 111, p. 1869-1878, 2007.

BRASIL. Diretrizes Curriculares Nacionais dos Cursos de Engenharia. Parecer CNE/CES 1362/2001. Publicado no D.O.U. de 25 de fevereiro de 2002, Seção 1, p. 17.

BUXTON, G. V.; GREENSTOCK, C. L.; HELMAN, W. P.; ROSS, A. B. Journal of Physical and Chemical Reference Data, v. 17, p. 513, 1988.

CABELLI, D. E. The reactions of $\mathrm{HO}_{2} / \mathrm{O}_{2}{ }^{-}$radicals in aqueous solution. In: Alfassi, Z. (ed) Peroxyl radicals. John Wiley \& Sons, Inc.: New York, 1997.

CEPERLEY, D. M.; ALDER, B. J. Ground State of the Electron Gas by a Stochastic Method Physical Review Letters, v. 45, p. 566, 1980.

CHAKRABORTY, A. Molecular Modelling in Chemical Engineering. Advances in Chemical Engineering, v. 28, p. xii-xiv, 2001.

CHARPENTIER, J. C. The triplet "molecular processes - product - process" engineering: the future of chemical engineering? Chemical Engineering Science, v. 57, p. 4667-4690, 2002.

CHARPENTIER, J. C. In the frame of globalization and sustainability, process intensification, a path to the future of chemical and process engineering (molecules into money). Chemical Engineering Journal, v. 134, p. 84-92, 2007. 
CHEN, R.; PIGNATELLO, J. J. Role of quinine intermediates as electron shuttles in Fenton and photoassisted Fenton oxidations of aromatic compounds. Environmental Science Technology, v. 31, p. 2399-2406, 1997.

CLAYDEN, J.; WARRE, S.; GREEVES, N.; WOTHERS, P. Organic Chemistry. Oxford University Press: Oxford, 2001.

COBB, C.; GOLDWHITE, H. Creations of Fire: Chemistry lively History from Alchemy to the Atomic Age. Plenum Press: New York, 1995.

COBB, J. T., PATTERSON, G. K., WICKRAMASINGHE, S. R. The future of Chemical Engineering - An educational perspective. Chemical Engineering Progress, v. 103, n. 1, p30$35,2001$.

CONSELHO FEDERAL DE ENGENHARIA E ARQUITETURA. Resolução Nº 068: Fixa as atribuições do engenheiro químico. Publicada no D.O.U. de 20 de abril de 1948.

CONSELHO FEDERAL DE QUÍMICA. Resolução Normativa $N^{\circ}$ 36: Dá atribuições aos profissionais da Química e estabelece critérios para concessão das mesmas [em substituição à RN 26]. Publicada no D.O.U. de 13 de maio de 1974.

CONSELHO FEDERAL DE QUÍMICA. Resolução Ordinária No 1511: Complementa a Resolução Normativa $n^{\circ} 36$, para efeitos dos artigos $4^{\circ}, 5^{\circ}, 6^{\circ}$ e $7^{\circ}$. Publicada no D.O.U. de 10 de fevereiro de 1976.

COSTA, R., MOGGRIDGE, G. D., SARAIVA, P. M. Chemical product engineering: an emerging paradigm within Chemical Engineering. American Institute of Chemical Engineers Journal, v. 52, n. 6, p. 1976-1986, 2006

CRAMER, C. J.; TRUHLAR, D. G. Continuum solvation models: classical and quantum mechanical implementations. In: Lipkowitz, K. B.; Boyd, D. B. (Eds.) Reviews in Computational Chemistry. v. 6, VCH Publishers, New York, 1995.

CRAMER, C. J.; TRUHLAR, D. G. Structure and reactivity in aqueous solution: an overview. In: Cramer, C. J.; Truhlar, D. G. Structure and reactivity in solution: characterization of chemical and biological systems. ACS Symposium Series, v. 568. American Chemical Society: Washington, DC, 1994, p. 1-9.

CRAMER, C. J. Essentials of Computational Chemistry. 2 ed. John Wiley \& Sons Ldt: New York, 2004. 
CREMASCO, M.A. A responsabilidade social na formação de engenheiros. Universidade Estadual de Campinas. Artigo submetido à premiação pelo Instituto Ethos. Divulgação em mídia virtual. 2004.

CURTISS, L. A.; RAGHAVACHARI, K.; REDFERN, P. C.; POPLE, J. A. Assessment of Gaussian-3 and density functional theories for a larger experimental test set. Journal of Chemical Physics, v. 112, p. 7374, 2000.

CURTISS, L. A., RAGHAVACHARI, K., TRUCKS, G. W., AND POPLE, J. A. Gaussian-2 theory for molecular energies of first- and second-row compounds. Journal of Chemical Physics, v. 94, p. 7221, 1991.

CZAPSKI, G.; BIELSKI, B. H. J. Absorption spectra of the $\cdot \mathrm{OH}$ and ${ }^{\circ} \mathrm{O}^{-}$radicals in aqueous solution. Radiation Physical Chemistry, v. 41, p. 503, 1992.

DA SILVA, G.; CHEN, C.-C.; BOZZELLI, J. W. Toluene combustion: reaction paths, thermochemical properties, and kinetic analysis for the methylphenyl radical $+\mathrm{O}_{2}$ reaction. Journal of Physical Chemistry A, v. 111, p. 8663, 2007.

DANCKWERTS, P. V. Science in Chemical Engineering. Nature, v. 210, p. 571, 1966.

DEPARTMENT OF CHEMICAL ENGINEERING. The History of Chemical Engineering at MIT. Massachusets Institute of Technology: Cambridge, MA. Disponível na página oficial do departamento em: http://web.mit.edu/cheme/che/history.html. Acesso em 25 de novembro de 2007.

DEVLIN, H. R., HARRIS, I. J. Mechanism of the oxidation of aqueous phenol with dissolved oxygen. Industrial \& Engineering Chemistry Fundamentals, v. 23, p. 387, 1984.

DIXON, D. A.; FELLER, D. Computational chemistry and process design. Chemical Engineering Science, v. 54, p. 1929, 1999.

DRAPERI, L. Modelisation moleculaire. Rapport de stage. Escola Politécnica da Universidade de São Paulo: São Paulo, 2007.

ESPLUGAS, S. Comparison of different advanced oxidation processes for phenol degradation. Water Research, v. 36, p. 1034, 2002.

FAN, J.; ZHANG, R. Density Functional Theory study on OH-initiated atmospheric oxidation of $m$-xylene. Journal of Physical Chemistry A, v. 112, p. 4314, 2008. 
FAVRE, E., MARCHAL-HEUSLER, L., KIND, M. Chemical product engineering: research and educational challenges. Institution of Chemical Engineers, v. 80, p. 65, 2002.

FERMI, E. Un Metodo Statistice per la Determinazionedi Alcune Proprieta dell' Atomo, Rendiconti Accademia dei Lincei, v. 6, p. 602, 1927.

FORESMAN, J. B.; FRISCH, A. Exploring Chemistry with Electronic Structure methods. 2ed. Gaussian, Inc.: Pittsburgh, 1996.

FRIEDRICH, L. C.; MENDES, M. A.; VAUTIER-GIONGO, C.; QUINA, F. H. Modelagem cinética da oxidação do fenol pela reação de Fenton. Importância das reações envolvendo o ciclo redox do ferro. In: 30 a Reunião Anual da Sociedade Brasileira de Química. 2007.

GILBERT, E. Influence of ozone on the photocatalytic oxidation of organic compounds. Ozone Science Engineering, v. 24, p. 75, 2002.

GIROTO, J. A. Estudo da degradação fotoquímica de soluções aquosas de polietilenoglicol, poliacrilamida e polivinilpirrolidona. Tese de Doutoramento em Engenharia. Escola Politécnica da Universidade de São Paulo: São Paulo, 2007.

GOGATE, P. R.; PANDIT, A. B. A review of the imperative technologies for wastewater treatment I: oxidation technologies at ambient conditions. Advances in Environmental Research, v. 8, p. 501, 2004.

GORE JR, A. A. An inconvenient Truth: The planetary emergency of Global Warming and what we can do about it. Rodale Books: New York, 2006a.

GORE JR, A. A. Earth in the balance: Ecology and the Human Spirit. Rodale Books: New York, 2006b.

GUNER, V.; KHUONG, K. S.; LEACH, A. G.; LEE, P. S.; BARTBERGER, M. D.; HOUK, K. N. A Standard Set of Pericyclic Reactions of Hydrocarbons for the Benchmarking of Computational Methods: The Performance of ab Initio, Density Functional, CASSCF, CASPT2, and CBS-QB3 Methods for the Prediction of Activation Barriers, Reaction Energetics, and Transition State Geometries. Journal of Physical Chemistry A, v. 107, p. 11445, 2003.

HAGER, D. G. -. Innovative Hazardous Waste Treatment Technologies Services, v. 2, p. 143, 1990. 
HAWKINS, G. D.; ZHU, T; LI, J.; CHAMBERS, C. C.; GIESEN, D. J.; LIOTARD, D. A.; CRAMER, C. J.; TRUHLAR, D. G. Universal Solvation Models. In: Gao, J.; Thompson, M. A. (Eds.) Combined Quantum Mechanical and Molecular Mechanical Models. ACS Symposium Series, v. 712. American Chemical Society: Washington, DC, p. 201, 1998

HENRY, F.; COEUR-TORNEUR, C.; LEDOUX, F.; TOMAS, A.; MENU. D. Secondary organic aerosol formation from the gas phase reaction of hydroxyl radicals with $m-, o$ - and $p$ cresol. Atmospheric Environment, v. 42, p. 3035, 2008.

HOHENBERG, P.; KOHN, W. Inhomogeneous electron gas. Physical Reviews, v. 136 (3B), B864, 1964.

HOIGNÉ, J. Chemistry of aqueous ozone and transformatioin of pollutants by ozonation and Advanced Oxidation Processes. In: Hutzinger, O. (ed.) The handbook of Environmental Chemistry. v. 5, pt C, 83-141. Springer-Verlag: Berlin, 1998.

HOUGEN, O.A. Seven decades of Chemical Engineering. Chemical Engineering Progress, v. 73 , p. 89, 1977.

HOWARD, A.; MCIVER, J.; COLLINS, J. HyperChem ${ }^{\circledR}$ Release 7 for Windows ${ }^{\circledR}$. Publication HC70-00-O1-00. Software user manual. Hypercube, Inc., 2002.

ICHINO, T.; FESSENDEN, R. W. Reactions of hydrated electron with various radicals: spin factor in diffusion-controlled reactions. Journal of Physical Chemistry A, v. 111, p. 2527, 2007.

INCE, N. H. Light-enhanced chemical oxidation for tertiary treatment of municipal landfill leachate. Water Environmental Research, v. 70, p. 1161, 1998.

IPCC - INTERGOVERNMENTAL Panel on Climate Change. Climate Change 2007: Synthesis Report (AR4). IPCC: Valência, 2007.

JENSEN, F. Introduction to Computational Chemistry. 2ed. John Wiley \& Sons: Chichester, 2007.

JOHNSON, B. G.; GILL, P. M. W.; POPLE, J. A. The performance of a family of density functional methods. Journal of Chemical Physics, v. 98, p. 5612, 1993 
KAVITHA, V.; PALANIVELU, K. Degradation of nitrophenols by Fenton and photo-Fenton processes. Journal of Photochemistry \& Photobiology A, v. 170, p. 83, 2005.

KILIC, M.; KOCTURK, G.; SAN, N.; CINAR, Z. A model for prediction of product distributions for the reactions of phenol derivatives with hydroxyl radicals. Chemosphere, v. 69, p. 1396, 2007.

KOCH, W.; HOLTHAUSEN, M. C. A chemist's guide to Density Functional Theory. 2 ed. Wiley-VCH Verlag: Londres, 2001.

KOHN, W.; SHAM, L. J. Self-Consistent Equations Including Exchange and Correlation Effects. Physical Reviews, v. 140, p. A1133, 1965.

KUHN, T. S. The Structure of Scientific Revolutions. 3 ed. The University of Chicago Press: Chicago, 1996.

KURNIAWAN, T. A.; LO, W.-H.; CHAN, G. Y. S. Radicals-catalyzed oxidation reactions for degradation of recalcitrant compounds from landfill leachate. Chemical Engineering Journal, v. 125, p. 35, 2006.

LAUDARES, J.B.; RIBEIRO, S. Trabalho e formação do engenheiro. Revista Brasileira de Estudos Pedagógicos, v. 81, p. 491, 2000.

LEACH, A. R. Molecular Modelling: principles and applications. 2 ed. Prentice Hall: Essex, 2001.

LEGRINI, O.; OLIVEROS, E.; BRAUN, A. M. Photochemical processes for water treatment. Chemical Reviews, v. 93, p. 671, 1993.

LI, J.; ZHU, T.; HAWKINS, G. D.; WINGET, P.; LIOTARD, D. A.; CRAMER, C. J.; TRUHLAR, D. G. Extension of the platform of applicability of the SM5.42R universal solvation model. Theoretical Chemistry Accounts, v. 103, p. 9, 2003.

LIPPITT, B.; MCCORD, J. M.; FRIDOVICH, I. The Sonochemical Reduction of Cytochrome c and Its Inhibition by Superoxide Dismutase. Journal of Biological Chemistry, v. 247, p. 4688, 1972.

LÜCHOW, A.; SPANGENBERG, D.; JANZEN, C.; JANSEN, A.; GERHARDS, M.; KLEINERMANNS, K. Structure and energetic of phenol $\left(\mathrm{H}_{2} \mathrm{O}\right)_{\mathrm{n}}, \mathrm{n}<7$ : Quantum Monte 
Carlo calculations and double resonance experiments. Physical Chemistry Chemical Physics, v. 3, p. 2771, 2001.

LYNCH, B. J.; TRUHLAR, D. G. Robust and Affordable Multicoefficient Methods for Thermochemistry and Thermochemical Kinetics: The MCCM/3 Suite and SAC/3. Journal of Physical Chemistry A, v. 107, p. 3898, 2003.

MARCH, J.; SMITH, M. B. March's advanced organic chemistry. 6 ed. John Wiley \& Sons, Inc.: New York, 2007.

MARCINOWSKI, S. How research contributes to the success of BASF group. News Release. Presentation on August 3 in London, 1998.

MAROUDAS, D. Modeling of radical-surface interactions in the plama-enhanced chemical vapor deposition of silicon thin films. In: Chakraborty, A (Ed.) Molecular Modeling in Chemical Engineering. Advances in Chemical Engineering, v. 28, p. 251, 2001.

MASTEN, S. J.; DAVIES, S. H. R. The use of ozonation to degrade organic contaminants in wastewater. Environmental Science Technology, v. 28, p. 180A, 1994.

MATSUOKA, M.; KITANO, M.; TAKEUCHI, M.; TSUJIMARU, K.; ANPO, M.; THOMAS, J. M. Photocatalysis for new energy production - recent advances in photocatalytic water splitting reactions for hydrogen production. Catalysis Today, v. 122, p. 51, 2007.

MATTHEWS, R. W. Photo-oxidation of organic material in aqueous suspensions of titanium dioxide. Water Research, v. 20, p. 569, 1986.

MCFERRIN, C. A.; HALL, R. W.; DELLINGER, B. Ab initio study of the formation and degradation reactions of semiquinone and phenoxyl radicals. THEOCHEM, v. 848, p. 16, 2008 .

MENDES, L. M. Z.; GUARDANI, R.; TEIXEIRA, A. C. S. C.; TAKAHASHI, S. N.; NASCIMENTO, C. A. O. Aplicação de técnicas de modelagem molecular a processos fotoquímicos. $11^{\circ}$ Simpósio Internacional de Iniciação Científica. USP: São Paulo, 2003.

MESQUITA, S. A. M. História da Filosofia Contemporânea: Thomas Kuhn. Texto apresentado à Universidade Estadual de Campinas como parte dos requisitos para obtenção do título de licenciado em Filosofia. 2007. 
MIERTUS, S.; SCROCCO, E.; TOMASI, J. Electrostatic interacation of a solute with a continuum. A direct utilization of ab initio molecular potentials for the prevision of solvent effects. Chemical Physics, v. 55, p. 117, 1981.

MORAES, J. C. T. B. (org). 500 Anos de Engenharia no Brasil. Editora da Universidade de São Paulo: São Paulo, 2005.

MORO-OKA, Y.; FOOTE, C. S. Chemistry of the superoxide ion. I. Oxidation of 3,5-Di-tertbutylcatechol with $\mathrm{KO}_{2}$. Journal of the American Chemical Society, v. 98, p. 1510, 1976.

MUKHERJEE, K. K. R. Fundamentals of Photochemistry. Rev. Ed. New Age International: Calcutá, 1986.

OCHTERSKI, J. W. Thermochemistry in Gaussian. Gaussian, Inc., 2000.

OCHTERSKI, J. W. Vibrational Analysis in Gaussian. Gaussian, Inc., 1999.

ONSAGER, L. Electric Moments of Molecules in Liquids. Journal of the American Chemical Society, v. 58, p. 1486, 1936.

OPPENLÄNDER, T. Photochemical purification of water and air - Advanced Oxidation Processes (AOPs): principles, reaction mechanisms, reactor concepts. Wiley-VCH: Weinheim, 2003.

PENG, C.; SCHLEGEL, H. B. Combining synchronous transit and quasi-Newton methods to find transition states. Israel Journal of Chemistry, v. 33, p. 449, 1993.

PERDEW, J. P. Density-Functional Approximation for the Correlation Energy of the Inhomogeneous Electron Gas, Physical Reviews B, v. 33, p. 8822, 1986.

PERDEW, J. P. Unified Theory of Exchange and Correlation Beyond the Local Density Approximation. In: Ziesche, P.; Eschrig, H. (Eds.) Electronic Structure of Solids, Akademie Verlag, Berlin, 1991.

PEYTON, G. R. Oxidative treatment methods for removal of organic compounds from drinking water supplies. In: Ram, N. (Ed.) Significance and treatment of VOCs in water supplies. CRC, London, 1990. 
PINTO, R. P. D.; TEIXEIRA, A. C. S. C.; NASCIMENTO, C. A. O. Aplicação de técnicas de modelagem molecular ao estudo da reação de hidrólise do anidrido acético. In: VII Congresso Brasileiro de Engenharia Química em Iniciação Científica. DEQ/UFSCar: São Carlos, Brasil, 2007.

PIZA, A. F. R. T. Mecânica Quântica: uma nova imagem do mundo. Ciência Hoje, v. 36, p. 40, 2005.

PLUGATYR, A.; NAHTIGAL, I.; SVISHCHEV, I. M. Spatial hydration sctructures and dynamics of phenol in sub- and supercritical water. Journal of Chemical Physics, v. 124, 2006 .

QUEIROGA, H. L. Aplicação de métodos de modelagem molecular à predição de constantes cinéticas de reações de interesse ambiental. Dissertação de Mestrado em Engenharia. Escola Politécnica da Universidade de São Paulo: São Paulo, 2007.

RAGHAVACHARI, K. Perspective on 'Density Functional Thermochemistry. III. The Role of Exact Exchange. Theoretical Chemistry Accounts, v. 103, p. 361, 2000.

REDFERN, P. C.; BLAUDEAU, J. -P.; CURTISS, L. A. Assessment of Modified Gaussian-2 (G2) and Density Functional Theories for Molecules Containing Third-Row Atoms Ga-Kr. Journal of Physical Chemistry A, v. 101, p. 8701, 1997.

RITTER, S. K. The changing face of Chemical Engineering. CENEAR, v. 79, p. 63, 2001.

SALINARO, A.; EMELINE, A.V.; ZHAO, J.; HIDAKA, H.; RYABCHUK, V. K.; SERPONE, N. Relative photonic efficiencies and quantum yields in heterogeneous photocatalysis. Part II: Experimental determination of quantum yields (Technical Report). Pure \& Applied Chemistry, v. 71, p. 321, 1999.

SANDLER, S. I.; SUM, A. K.; LIN, S. -T. Some chemical engineering applications of quantum chemical calculations. In: Chakraborty, A. (Ed). Molecular Modeling in Chemical Engineering. Advances in Chemical Engineering, v. 28, p. 313, 2001.

SCHEINER, A. C., BAKER, J., AND ANDZELM, J. W. Molecular energies and properties from density functional theory: Exploring basis set dependence of Kohn - Sham equation using several density functionals. Journal of Computational Chemistry, v. 18, p. 775, 1997. 
SEGRÈ, E. From X-Rays to Quarks: modern physicists and their discoveries, San Francisco, W.H. Freeman and Co. 1980.

SKODJE, R. T.; TRUHLAR, D. G.; GARRETT, B. C. A general small curvature approximation for transition-state theory transmission coefficients. Journal of Physical Chemistry, v. 85, p. 3019, 1981.

SONNTAG, C. V-; SCHUCHMANN, H. -P. Peroxyl radicals in aqueous solutions. In: Alfassi, Z. (ed) Peroxyl radicals. John Wiley \& Sons, Inc.: New York, 1997.

STEPHENS, P. J., DEVLIN, J. F., CHABALOWSKI, C. F., FRISCH, M. J. Ab Initio Calculations of Vibrational Absorption and Circular Dichroism Spectra Using SCF, MP2, and Density Functional Theory Force Fields. Journal of Physical Chemistry, v. 98, p. 11623, 1994.

TEIXEIRA, A. C. S. C. Fotodegradação de poluentes orgânicos industriais: estudo experimental e aplicação do método de Monte Carlo à modelagem matemática de mecanismos reacionais. Relatorio científico de atividades de pós-doutoramento - processo FAPESP 1999/10580-5, 2005.

THOMAS, L. H. The Calculation of Atomic Fields. Proceedings of the Cambridge Philosophical Society, v. 23, p. 542, 1927.

THORPE, F. H.; LEWIN, W. K. Outlines of Industrial Chemistry. 3 ed. MacMillan \& CO: Londres, 1916.

TIME Magazine. TIME Polls: Global Warming. 26 de agosto de 2006. Disponível em: http://www.time.com/time/magazine/article/0,9171,1176975,00.html.

VOSKO, S.J.; WILK, L.; NUSSAIR, M. -. Canadian Journal of Physics, v. --, p. 1200, 1980.

WATANABE, T.; EBATA, T.; TANABE, S.; MIKAMI, N. Size-selected vibrational spectra of phenol- $\left(\mathrm{H}_{2} \mathrm{O}\right)_{n}(\mathrm{n}=1-4)$ clusters observed by IR-UV double resonance and stimulated Raman-UV double resonance spectroscopies. Journal of Chemical Physics, v. 106, p. 408, 1996.

WEI, J. Molecular structure and property: product engineering. Industrial \& Engineering Chemical Research, v. 41, p. 1917, 2002. 
WIEST, O.; MONTIEL, D. C.; HOUK, K. N. Quantum mechanical methods and the interpretation and prediction of pericyclic reaction mechanisms. Journal of Physical Chemistry A, v. 101, p. 8378, 1997.

WINTERMANTEL, K. Process and product engineering - achievements, present and future challenges. Chemical Engineering Science, v. 54, p. 1601, 1999.

WOLFE, S.; KIM, C. -K.; YANG, K.; WEINBERG, N.; SHI, Z. Hydration of the carbonyl group. A theoretical study of the cooperative mechanism. Journal of the American Chemical Society, v. 117, p. 4240, 1995.

WOLFE, S.; SHI, Z.; YANG, K.; RO, S.; WEINBERG, N.; KIM, C. -K. Hydration of the carbonyl group. Further evidence for a cooperative mechanism from experimental and theoretical studies of the hydrations of formaldehyde, acetaldehyde, acetone, and cyclohexanone. Canadian Journal of Chemistry, v. 76, p. 114, 1998.

YOUNG, D. C. Computational Chemistry: a practical guide for applying techniques to realworld problems. John Wiley \& Sons: New York, 2001.

ZAZO, J. A.; CASAS, J. A.; MOHEDANO, A. F.; GILLARANZ, M. A.; RODRIGUEZ, J. J. Chemical pathway and kinetics of phenol oxidation by Fenton's reagent. Environmental Science Technology, v. 39, p. 9295, 2005.

ZAZO, J. A.; CASAS, J. A.; MOLINA, C.-B.; QUINTANILLA, A.; RODRIGUEZ, J. J. Evolution of ecotoxicity upon Fenton's oxidation of phenol in water. Environmental Science Technology, v. 41, p. 7164, 2007. 